\title{
The empirics of contracts : theoretical and empirical observations on contract design
}

Citation for published version (APA):

Hesen, G. G. (2009). The empirics of contracts : theoretical and empirical observations on contract design. [Doctoral Thesis, Maastricht University]. Datawyse / Universitaire Pers Maastricht. https://doi.org/10.26481/dis.20090515gh

Document status and date:

Published: 01/01/2009

DOI:

10.26481/dis.20090515gh

Document Version:

Publisher's PDF, also known as Version of record

\section{Please check the document version of this publication:}

- A submitted manuscript is the version of the article upon submission and before peer-review. There can be important differences between the submitted version and the official published version of record.

People interested in the research are advised to contact the author for the final version of the publication, or visit the DOI to the publisher's website.

- The final author version and the galley proof are versions of the publication after peer review.

- The final published version features the final layout of the paper including the volume, issue and page numbers.

Link to publication

\footnotetext{
General rights rights.

- You may freely distribute the URL identifying the publication in the public portal. please follow below link for the End User Agreement:

www.umlib.nl/taverne-license

Take down policy

If you believe that this document breaches copyright please contact us at:

repository@maastrichtuniversity.nl

providing details and we will investigate your claim.
}

Copyright and moral rights for the publications made accessible in the public portal are retained by the authors and/or other copyright owners and it is a condition of accessing publications that users recognise and abide by the legal requirements associated with these

- Users may download and print one copy of any publication from the public portal for the purpose of private study or research.

- You may not further distribute the material or use it for any profit-making activity or commercial gain

If the publication is distributed under the terms of Article $25 \mathrm{fa}$ of the Dutch Copyright Act, indicated by the "Taverne" license above, 
THE EMPIRICS OF CONTRACTS

Theoretical and empirical observations on contract design 
(c) Geerte Hesen, Amsterdam 2009

ISBN 9789052788272

Universitaire Pers Maastrich

Layout and printing: Datawyse bv 
THE EMPIRICS OF CONTRACTS

Theoretical and empirical observations on contract design

\section{PROEFSCHRIFT}

ter verkijging van de graad van doctor aan de Universiteit Maastricht, op gezag van de Rector Magnificus, Prof. mr. G.P.M.F. Mols,

volgens het besluit van het College van Decanen,

in het openbaar te verdedigen

op vrijdag 15 mei 2009 om 14.00 uur

door

Geerte Gudule Hesen

$\mathrm{U}_{\mathrm{M}}$

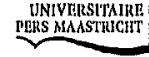




\section{Promotores}

Prof. dr. J. Hagedoorn

Prof. mr. J.M. Smits (Universiteit van Tilburg)

\section{Beoordelingscommissie}

Prof. mr. M.G. Faure (voorzitter)

Prof. mr. G.E. van Maanen

Prof. dr. F. Moers 


\section{ACKNOWLEDGEMENTS}

So often we dwell on the things that seem impossible rather than on the things that are possible. So often we are depressed by what remains to be done and forget to be thankful for all that has been done.

\section{Marian Wright Edelman}

Founder of the Children's Defense Fund

I would like to thank everyone who has contributed to making the writing of this PhDthesis possible.

John and Jan as 'promotores',

Michael Faure, Gerrit van Maanen and Frank Moers as 'beoordelingscommissie',

Henrike and Loes as 'paranimfen',

Maastricht Faculty of Law, SCANCOR (Stanford University), Berkeley School of Law

(Boalt Hall) and Columbia Law School,

family, friends, colleagues and students.

Thank you. 
To make progress in understanding all this, we probably need to begin with simplified (oversimplified?) models and ignore the critics' tirade that the real world is more complex.

The real world is always more complex, which

has the advantage that we shan't run out of work.

John Ball

Radio astronomer 
TABLE OF CONTENTS

CHAPTER 1 INTRODUCTION

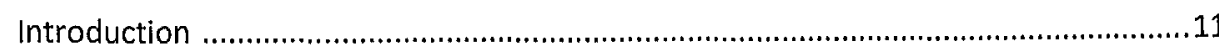

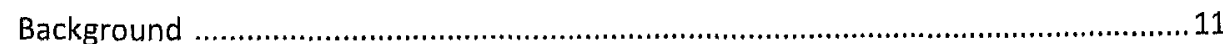

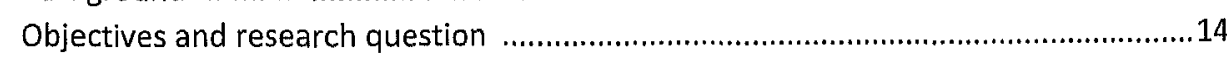

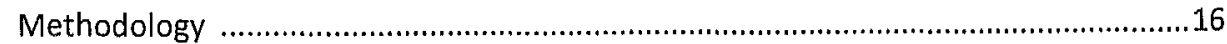

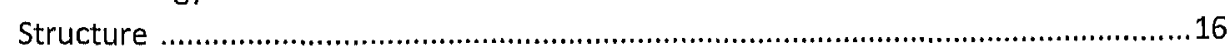

CHAPTER 2 CONTRACT LAW AND THE GOVERNANCE OF INTER-FIRM TECHNOLOGY PARTNERSHIPS - AN ANALYSIS OF DIFFERENT MODES OF PARTNERING AND THEIR CONTRACTUAL IMPLICATIONS

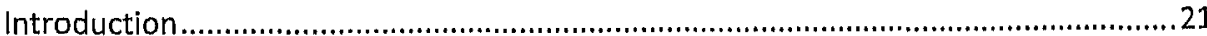

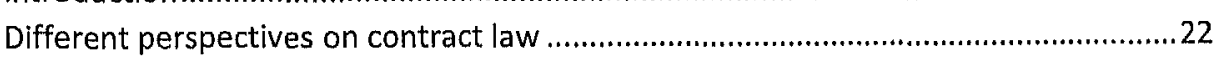

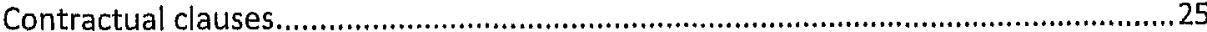

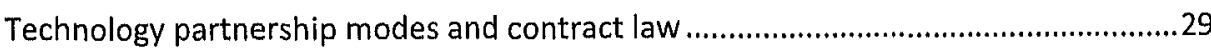

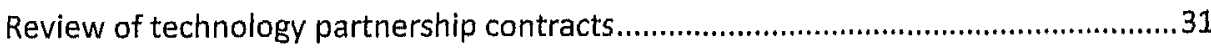

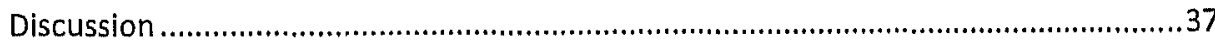

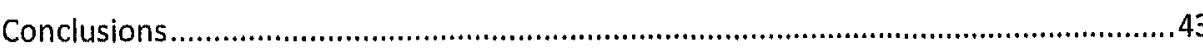

CHAPTER 3 AN INSTITUTIONAL AND INTERNATIONAL COMPARISON OF THE COMPLEXITY OF CONTRACTS: A THEORETICAL FRAMEWORK

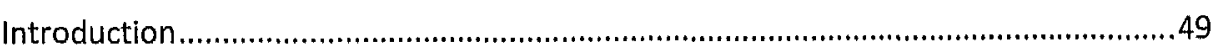

Completeness and incompleteness, complexity and simplicity of contracts .................52

Factors that give rise to the complexity and simplicity of contracts .............................70

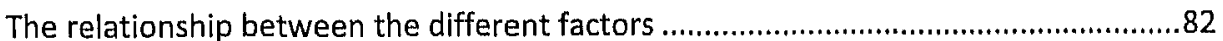

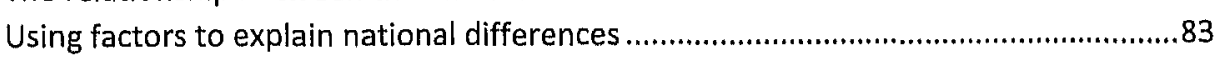

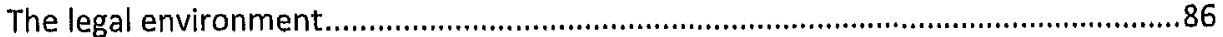

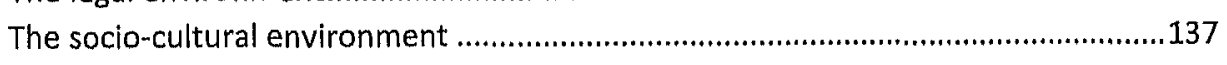

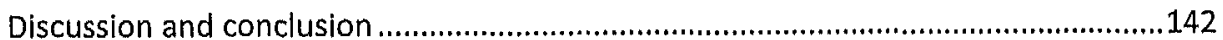


CHAPTER 4 CONTRACTUAL COMPLEXITY AND THE COGNITIVE LOAD OF R\&D ALLIANCE CONTRACTS

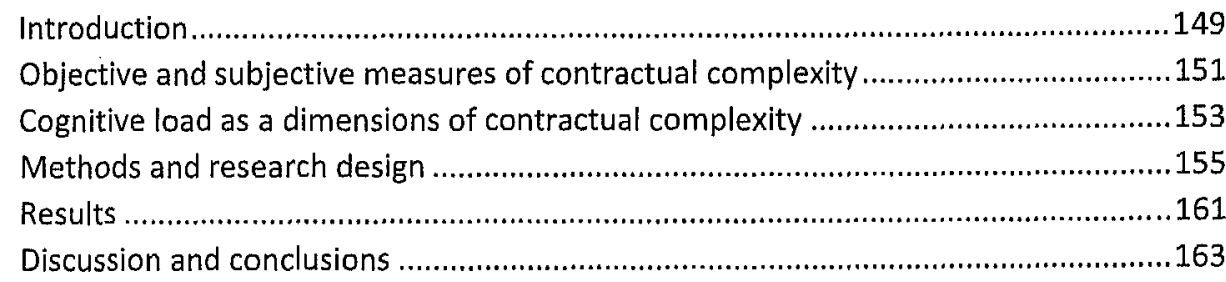

CHAPTER 5 THE CONTRACTUAL COMPLEXITY OF R\&D ALLIANCE CONTRACTS

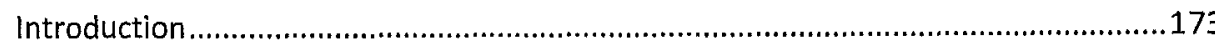

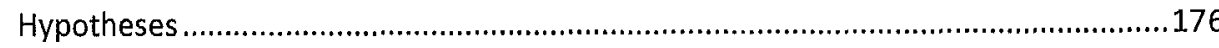

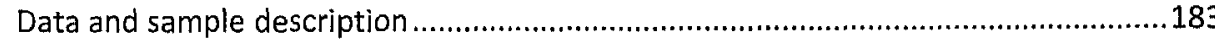

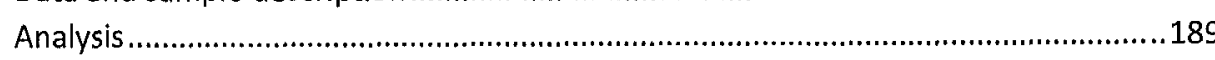

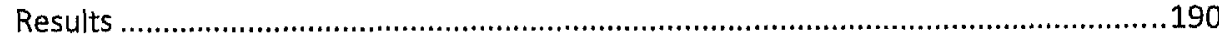

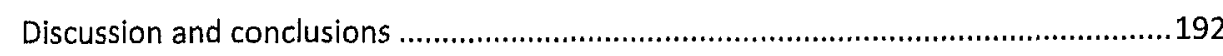

\section{CHAPTER 6 CONCLUSION}

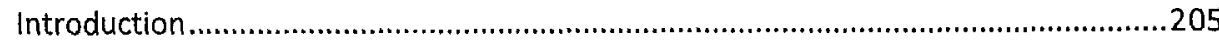

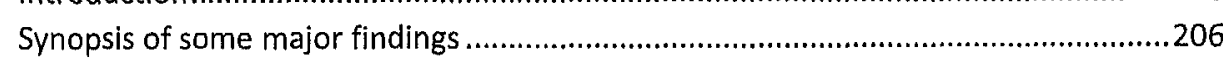

Limitations and suggestions for further research..................................................223

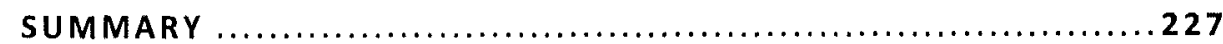

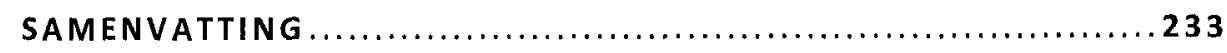

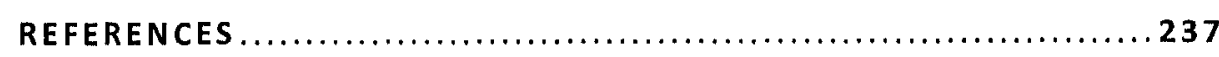

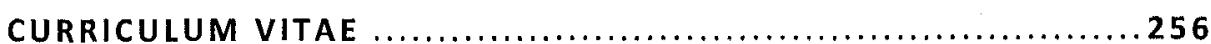




\section{CHAPTER 1}

INTRODUCTION 


\section{INTRODUCTION}

Almost everyone enters into contracts every day. Contracting aims to create a bigger transactional pie in a world where parties' incentives are misaligned. The writing of contracts enables parties to hedge against market risks, and to coordinate the production of information, rights, duties and procedures. The notion of contract and contract law are indispensably linked to legal studies. Within the legal context a contract can generally be defined as a meeting of minds which creates effects in law. ${ }^{1}$ The law of contracts is grounded in the moral principle that a person should fulfill promises and abide by agreements. An economist's view of a contract is less strict and refers to any agreement under which two or more parties engage in mutual commitments concerning their behavior. ${ }^{2}$

Rules of contract law and theories of contract enable us to predict ultimate contract design. Only the study of contracts themselves, however, will allow us to actually conceptualize and comprehend the world of structures that in fact shape economic activity. With an eye to empirics and contracting practices, the aim of this research is to offer the reader a better insight in and understanding of actual contract design.

\section{BACKGROUND}

Let's avert our attention from the body of substantive contract law and specific con tract law rules as it has developed, is enforced and has been studied extensively in different jurisdictions, to focus instead on contract as a concept. In doing so, we may establish that theories of contract have developed not only in law, but in a number of other disciplines such as management, economics and sociology. Despite the simplicity of contract as a concept, its success lies in its analytical power. The idea of contract permits us to analyze coordination mechanisms within a simple but meticulous framework. ${ }^{3}$ Not only does this shed light on the properties of contracts, but also on 'other harmonization instruments such as markets, organizations and institutions' which 'reveal mechanisms comparable to those of typical contracts'. ${ }^{4}$ While contracts epitomize economic exchange, the diverse theories often mirror the social and economic developments of their time.

Law as a discipline has of course long paid the most attention to the notion of contract. Legal scholars in common law jurisdictions for example, have written extensively on diverse depictions of contract (law). ${ }^{5}$ In general, legal scholars have distin-

\footnotetext{
${ }^{1}$ I acknowledge that a universal definition of 'contract', which is recognized in all bodies of substantive law, is not feasible.

${ }^{2}$ See also Brousseau and Glachant 2002.

${ }^{3}$ Ibid., p. 5.

${ }^{4}$ Ibid.

${ }^{5}$ While I focus on contract as a concept, I cannot dismiss the fact that in legal studies the concept of contrac is influenced by substantive rules of contract law.
} 
guished between classical, neoclassical and more recently modern or relational contract theory. ${ }^{6}$ The precise relevance and content of these doctrines is subject to debate $^{7}$, and we can generally distinguish between two polar types of contract doctrine: classical and relational contract doctrine.

Classical contract theory supports the discrete market transaction. The manifestation of parties' intention or will is leading, and contracts function primarily as a risk allocation mechanism, are short-lived and expected to be complete and binding. The paradigm of classical contract law can be traced to classical economic theory of the $19^{\text {th }}$ century where the 'economic man' with self-interested exogenous preferences engages in complete and costless contracting in a market dictated by laissez faire policy and maximum individual freedom. With the sophistication of commerce, the complexity of the exchange relationship increased. The idea of the discrete transaction which lay at the hart of classical contract theory was replaced by the notion that contracts are a social institution, a result of mutual planning over a longer period of time. ${ }^{8}$ Relational contract theory is based on the knowledge that contracts are incomplete and governed by relational norms, with a central role for flexibility, interdependency and trust. ${ }^{9}$

From the 1970s onward, the concept of contract also became a central theme in the economics literature. Contract economics developed primarily due to dissatisfaction with Walrasian (neoclassical) economic thought, which was based on the costless operation and coordination of the market. Inspired by Coase's seminal 1937 article $^{10}$, new analytical tools were sought to explain the market mechanism and the existence of different contractual and organizational forms. Leaving aside applicable rules of contract law, theories of contract such as transaction cost theory, property rights theory and agency theory attempt to examine and predict the optimal design of contracts. This economics of contracts literature is produced mainly by economists and published predominantly in economics journals. ${ }^{11}$

Both property rights and transaction cost theory derive from the idea that writing and enforcing contracts is not costless. Transactions costs give rise to incomplete contracts. Williamson indicates that transaction costs vary with each transaction depending on the presence of relation specific investments, the frequency of the transaction and the uncertainty involved. Different types of transactions are therefore aligned with governance structures in a transaction cost economizing manner. Williamson considers three types of governance structures - market, hybrid and hierarchy - and links them to

\footnotetext{
${ }^{6}$ Atiyah 1989, Eisenberg 2000b, Friedman 1973, Horwitz 1977. See also Macneil's three way discussion of contracts in Macneil 1978.

${ }^{7}$ Eisenberg 2000a, Feinman 2000, Gordley 1991, Macneil 2000

${ }^{8}$ Williamson 1979, Nassar 1995, Macneil 1978.

${ }^{9}$ Schwartz 1992, Eisenberg 2001.

${ }^{10}$ Coase 1937.

${ }^{11}$ Eggleston et al. 2000.
} 
(classical, neoclassical and relational) contract law doctrine. ${ }^{12}$ Property rights theory is based on the premise that the type of governance structure hinges on the allocation of property rights. ${ }^{13}$ Property rights entail both ownership and control over non-human assets. In a world dictated by transaction costs, it is costly to specify all rights to an asset. The right to decide in case of non-specification resides with the owner of the asset. These 'residual rights of control' are important in that they affect ex post bargaining power and the division of wealth. Within the framework of contract, principalagent theory appreciates the roles of different economic actors and recognizes that conflicts of interest may arise between them, for example between owners of resources and managers. In order to maximize welfare, the owner (i.e. principal) must establish appropriate incentives for the manager (i.e. agent) in order to align objectives. With regard for observability problems and information asymmetry, agency theory examines the nature of optimal incentive schemes. ${ }^{14}$ The foregoing theories have given rise and relate to a more general economic 'theory of incomplete contracts' which applies the mathematical modeling methods associated with agency theory to problems addressed by transaction cost theory. The main idea is to specify optimal contracts in presence of specific investments which are non-verifiable.

The economics of contracts literature can be distinguished from another literature on contracting which developed in the 1970s. The law and economics literature concerns the economic analysis of law. ${ }^{15}$ Law and economics developed from the insight that economic concepts can be applied as a normative standard for evaluating law and more specifically to predict the effect of policies on efficiency and welfare distribution. This literature appears mostly in law-related journals and is produced primarily by law professors and some economists who teach at law schools. ${ }^{16}$ The distinction between the economics of contracts and law and economics literature might seem somewhat artificial. ${ }^{17}$ Both literatures attempt to describe the conditions under which the value of contractual exchange is maximized. As economists become more familiar with legal theory and legal scholars with economic concepts, the literatures coalesce. ${ }^{18}$

Both the legal and economic theories of contract have been criticized. Scholars write that the 'law review literature on contracts is almost completely devoid of the positive analysis of contracts ${ }^{19}$ and that the law and economics approach 'does not explain the current system of contract law' nor provide a 'solid basis for criticizing and

\footnotetext{
${ }^{12}$ Williamson 1985, 1991 and 1996

${ }^{13}$ Grossman and Hart 1986.

${ }^{14}$ Alchian and Demsetz 1972, Stiglitz 1974, Grossman and Hart 1983, Milgrom and Roberts 1992.

${ }^{15}$ Eggleston et al. 2000, Posner 2003.

${ }^{16}$ Eggleston et al. 2000

${ }^{17}$ lbid.

${ }^{18}$ Both literatures for example maintain a theory of incomplete contracts. The definition of what constitutes an incomplete contract and its implications, however, varies. Only recently have scholars accepted a more general definition (see the most recent American Law and Economics Association conference (2008), which includes papers from both literatures).

${ }^{19}$ Eggleston et al. 2000, p. 93.
} 
reforming contract law. ${ }^{20}$ 'What good is contract law? Who uses it? When and how $?^{21}$ Legal scholarship in general is criticized for its lack of empirical and experimental work. The empirical work that exists is often descriptive rather than analytical. The economics literature on the other hand, is characterized by complicated theoretical analyses, while the validation of theory seems to lag behind. This gap in the legal and social science literature leaves scholars, lawyers, and policymakers without a basic knowledge of contract design. Scholars in both economics and law have made a plea for the study of actual contracts in order to develop a deeper understanding of how contracts actually operate in practice. ${ }^{22}$ Only recently have scholars attempted to study actual contracts on a greater scale. These studies have generally been based on transaction cost and property rights theory, which has led to the examination of control rights and/or transaction cost implications.

\section{OBJECTIVES AND RESEARCH QUESTION}

Sophisticated contractual relationships have become an increasingly important feature of the business landscape. Contractual terms vary depending on parties' characteristics and goals, their shared understandings, transaction costs, the characteristics of the transaction, and the background legal regime. What distinguishes contract design? Why are some contracts relatively complex or simple? Understanding the functions and implications of contractual terms is important for the design (legislature/policymakers), drafting (practitioners) and enforcement (courts) of contract law. A greater understanding substantiates the debate on the proper content and role of contract law. Contract law being largely non-mandatory, the freedom of contract is often used to develop new rules. To what extent do parties opt out of default law rules? Should there be an argument for more or less law? And what rules of contract law best serve the interest of parties? These questions are not only relevant on a national level, but also have implications for the European debate on the harmonization of contract law. Especially since the study of contracts provides us with an insight into the effects of internationalization and cross pollination of contract styles and allows us to compare legal rules within their symbolic and functional context; how do cultural aspects such as trust and negotiation styles affect contract design? The analysis of contracting practices also provides useful information on the level of enforcement: should the variety in contract design give rise to a differentiated enforcement of contracts? The study of contracts will allow courts to develop a deeper understanding of contracting practices and processes.

But information regarding contract design is also food for thought for practitioners i.e. lawyers. Commercial contracts evolve over time in response to a complex and

\footnotetext{
${ }^{20}$ Posner 2003, p. 830

${ }^{21}$ Macaulay 1963.

${ }^{22}$ Coase 1992, Suchman 2003, Bercowitz et al. 2003.
} 
shifting set of influences. ${ }^{23}$ Clauses may be added, modified or dropped, and some clauses may loose their significance in changing context. Adding clauses may come at a cost and we must ask ourselves whether more detail is always good. ${ }^{24}$

My research question can therefore be stated as follows:

'How do we define contract design and what differences do we find within a particular industry and between countries?'

As reviewed above, numerous theories of contract exist in the legal and economics literatures which attempt to prescribe the manner in which contracts should be drafted under certain conditions. In an attempt to integrate the legal and economic perspectives on contract, Williamson aligns different governance structures with contract law doctrines. But theory has not been able to provide us with a unifying structure for the specificity and testing of contract design hypotheses. ${ }^{25}$ This may in part be due to the fact that the diversity of possible contractual designs is virtually unlimited. Contractual structure may vary with objectives, underlying relations, nature and size of informational and strategic impediments to contract formation, legal rules and enforcement. My main research question is split into three sub-questions:

- to what degree are commercial contracts governed by either a classical or more relational contracting perspective,

- how can we measure contract design, and

- what factors influence contract design?

In order to answer these questions in full would require an investigation of almost every type of transaction between individuals and organizations. This is not feasible, while the main difficulty regarding the study of actual contracts is the acquisition of data. ${ }^{26}$ Most insights are therefore gained from studying a particular type of contract and/or industry. In choosing a certain industry the researcher has to make a trade-off between precision and generality. In addition, the question arises whether contract research should focus on the study of the actual contracts or a firm's interpretation of the contract. The actual contract contains apparent objectivity but excludes any unwritten terms that parties involved in drafting the contract may accept as standard or customary. Conducting a survey on the manner in which the contract is interpreted on the other hand, is subject to a subjectivity bias. Researchers also have to deal with issues of confidentiality, the construction of a database and the description and coding of the contents of contracts. Keeping the aforementioned reservations in mind, I am ready to confront contract theory with evidence.

${ }^{23}$ Buchheit (unpublished note).

${ }^{21}$ Eggleston et al. 2000.

${ }^{25}$ Masten and Saussier 2002.

${ }^{26}$ Brousseau and Glachant 2002, Masten and Saussier 2002, Lyons 1996, Furlotti 2007. 


\section{METHODOLOGY}

For my empirical research, I set up a contracts database, which contains over 400 actual contracts. The dataset is restricted to commercial agreements concluded in the biotechnological and pharmaceutical sector. The agreements are all inter-firm collaborative agreements. ${ }^{27}$ This choice is driven by the fact that since the 1980 s inter-firm collaborations have increased in relative importance. ${ }^{28}$ Globalization has driven the interdependence of technologies and industries, thereby creating a higher demand for solutions involving different types of competences. The biotechnological and pharmaceutical sectors reflect this growth in various types of contractual collaborations. ${ }^{29}$ These contracts therefore make an interesting study case.

A detailed conceptual analysis of the number, types and length of the contractual provisions of the contracts in the dataset was made possible with the use of content analysis software. This software enables me to accurately distinguish between different types of (for example) termination and dispute resolution terms, in addition to mapping their co-occurrence within a particular contract. The dataset of contracts is supplemented by extensive information on the contracting parties and their contracting environment, such as the size of the undertakings, total revenue and asset turnover, and contracting experience. Additional data was also collected by means of case studies and through numerous interviews with experts in the field.

\section{STRUCTURE}

My dissertation consists of four main chapters. Each of the chapters originally comprised a separate paper. Together, these papers provide the reader with a broad perspective on contract design.

In the next chapter (chapter 2), I study some major legal implications of inter-firm technology partnering through equity joint ventures, non-equity partnerships ${ }^{30}$, and licensing contracts. These different partnerships are placed within classical and relational contracting perspectives, while also considering intellectual property rights is sues. Samples of contracts in bioscience, fine chemicals, biotechnology and biopharmaceuticals are analyzed in detail, with reference to distribution of property rights, major contractual clauses, and measures of conflict resolution.

Chapter 3 presents a new perspective on contract theory and comparative contract law. Complex contracts are defined to mean those contracts that contain many

${ }^{27}$ 'Inter-firm collaborative agreements' is a term used in the business literature, What is meant is a commercial contract entalling the cooperation of two or more firms on a project.

${ }^{28}$ Narula and Hagedoorn 1998.

${ }^{29}$ Powell et al. 1996, Hagedoorn and Kranenburg 2003, Hagedoorn 2002.

${ }^{30}$ The term 'partnership' is used in the business sense and does not refer to the legal definition of 'partnership'. 
clauses with a relatively large number of interdependencies that also impose a significant cognitive load upon parties. Starting from differences in comparative contract law, the concept of complex contracts allows us to better study the intricacy of contract design. Integrating both legal and business insights on the study of contracts, 1 develop a theoretical and multidimensional framework of contractual complexity. The framework is used to illustrate that factors generally invoked to explain contract design, such as limits of cognition, asymmetric information, asset specificity and strategic importance, uncertainty of the environment, and trust and reputation, are ultimately driven by their embeddedness in the particular legal and socio-cultural environment.

In chapter 4, 1 further develop the concept of contractual complexity as expounded in chapter 3 . In this chapter in particular, I seek rapprochement with the business economics literature where several constructs of complexity have been advanced and tested empirically. These studies on contractual complexity employ objective measures such as the number of contractual provisions, pages or the amount of kilobytes of the contract file to measure complexity. Following some suggestions in the literature, I argue that the degree to which a contract imposes a cognitive load, i.e. an information processing effort, upon contracting parties should be taken as another important dimension of contractual complexity. I define and empirically test the conceptual model of the complexity of contracts using a multidimensional perspective where both objective and subjective dimensions are taken into account. The empirical analysis is based on a sample of nearly 400 research and development (R\&D) alliance contracts in the biopharmaceutical industry.

In chapter 51 apply the multi-dimensional construct of contractual complexity as developed in chapter 4 . Continuing along the lines of business economic theory, 1 am interested to learn under which conditions firms are inclined to increase contractual complexity. Most empirical studies that try to explain diversity in contractual design are heavily influenced by transaction cost economics (TCE) and property rights theory. Based in part on this prior research, but also on other approaches found in empirical industrial organization, finance, strategic management, law and economics, and legal theory, I focus on three levels of conditions that impact contractual complexity: company characteristics, transaction characteristics, and the organizational routines of firms. Using a dataset of over 300 R\&D alliance contracts and extensive company information, I model the effects of size, R\&D capability and information asymmetry (company characteristics), strategic importance and asset specificity (transactional characteristics), and general and partner-specific contracting experience (organizational routines) on the complexity of $R \& D$ alliance contracts.

In a final overview (chapter 6) I gather my conclusions and discuss the limitations and implications for further research.

Chapter 6 of this dissertation was concluded in September 2008. Some of the chapters were, however, concluded at an earlier date and have (in a modified version) either been accepted or submitted for publication. 
CHAPTER 2

CONTRACT LAW AND THE GOVERNANCE OF INTER-FIRM TECHNOLOGY PARTNERSHIPS - AN ANALYSIS OF DIFFERENT MODES OF PARTNERING AND THEIR CONTRACTUAL IMPLICATIONS

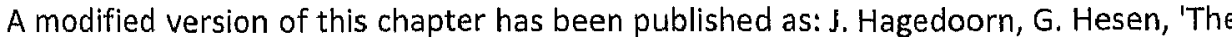
governance of inter-firm technology partnerships and contract law - an analysis of different modes of partnering and their contractual implications', Journal of Management Studies, 44, 2007, p. 342-365. 


\section{INTRODUCTION}

Over a decade ago, when Ronald Coase delivered his 1991 Nobel Prize lecture in Stockholm, he noticed, amongst other things, a strong need for economists ${ }^{1}$ to develop a much more detailed understanding of the actual process of contracting between companies in a 'real-world setting'. ${ }^{2}$ More than seventy years ago, Coase already paid attention to the important role of contracts and inter-firm relationships in his seminal paper on 'The nature of the firm'. ${ }^{3}$ This chapter follows Coase's suggestion and as such it is part of the growing body of literature that studies, in detail, the legal and organizational ramifications of inter-firm contracting. In that context, I study three major forms of inter-firm partnering, i.e. equity joint ventures, non-equity partnerships, and licensing contracts. I will concentrate on a specific group of inter-firm partnerships for which technology development or technology sharing is a crucial element in the agreement. Not only have these technology agreements become a major category of inter-firm partnering ${ }^{4}$, the specific nature of the development, sharing, or transfer of technology through these agreements also creates some interesting intellectual property rights issues for inter-firm contractual arrangements.

Earlier work by Ring and Van de Ven (1992) and Williamson (1985, 1991 and 1996) already discussed some general perspectives on contract law in the context of the types of transactions between companies and their specific mode of governance and organization. ${ }^{5}$ Hierarchies appear to follow relational contractual governance, market transactions coincide primarily with classical contract law, and a broad group of interfirm arrangements (hybrids) are expected to be regulated by relational governance. ${ }^{6}$ Other contributions that consider the general association between types of transaction and mode of governance indicate that equity joint ventures are to be seen as quasihierarchical organizational structures, non-equity inter-firm partnerships are contractual hybrids, while licensing contracts largely reflect market transactions.?

I will take the next step and analyze in greater detail the different perspectives on contract law, describe various incentive schemes, and discuss specific transactional characteristics that play a role in equity joint ventures, non-equity partnerships and licensing contracts. Compared to some recent studies ${ }^{8}$, which are still somewhat more

${ }^{1}$ I assume that this need is not only relevant for economists but for all social scientists interested in the implications of inter-firm contracting.

${ }^{2}$ Coase 1992.

${ }^{3}$ Coase 1937

${ }^{4}$ Hagedoorn 2002

${ }^{5} \mathrm{~A}$ broader social perspective on the social factors affecting contracting is offered by Bonn (1972). His contribution discusses the effects of social institutions, formal organizations and inter-organizational linkages on the use of contracts and contract law.

${ }^{6}$ Williamson 1991 and 1996.

"Contractor and Lorange 2002, Narula 2001

${ }^{8}$ Kalnins and Mayer 2004, Mayer and Argyres 2004, Parkhe 1993, Poppo and Zenger 2002, Reuer and Ariño 2002, Sampson 2004 
general in nature, my analysis aims at presenting an in-depth and detailed, qualitative analysis of the interaction of contract law and different modes of technology partnering. As such, this chapter follows some recent contributions that study the interaction between organizational and legal implications of inter-firm relationships. ${ }^{9}$

My contribution will clarify the degree to which different modes of inter-firm technology partnering are governed by either a classical or a more relational contracting perspective. From a theoretical perspective, I argue that inter-firm technology partnerships organized through equity joint ventures and non-equity partnerships will largely follow a relational contracting perspective. This relational perspective is expected to play little or no role in licensing contracts which are primarily governed by a classical contracting perspective. As these different perspectives can be linked to the actual legal interpretation and the use of a variety of contractual clauses, I will also be able to interpret how these clauses are applied in different contractual settings and whether the content and scope of these different clauses and provisions demonstrate subtle differences according to the actual mode of technology partnerships for which they are incorporated in concrete contracts. As such, this will enable me to present a fine-grained analysis of different modes of technology partnering, based on a theoretical understanding of different contractual perspectives and the actual legal implications of these perspectives on the contractual clauses in different inter-firm technology partnerships.

In the following section, I will first briefly discuss some of the major differences between the classical and the relational contracting perspective. This is followed by a section in which these perspectives are projected on relevant contractual provisions for various partnerships. In the next section, the role of different perspectives on contract law will be examined further for three major categories of inter-firm technology partnering: equity joint ventures, non-equity partnerships, and licensing contracts. This is followed by a detailed analysis of a small set of actual contracts for equity joint ventures, non-equity partnerships, and licensing. I continue with a discussion of my findings in the context of the distribution of property rights and the relevant contractual provisions such as adaptation clauses, damage measures, warranties, and dispute resolution. The final section presents the conclusions with some directions for further research.

\section{DIFFERENT PERSPECTIVES ON CONTRACT LAW}

Legal scholars, predominantly in common law jurisdictions, have extensively written about the diverse depictions of contract law ${ }^{10}$, which have been applied by business scholars to explore the content and scope of different governance structures and con-

\footnotetext{
${ }^{9}$ Harrison 2004, Wright and Lockett 2003.

${ }^{10}$ Atiyah 1989, Friedman 1973, Gordley 1991, Horwitz 1977, Nassar 1995, Wightman 1996
} 
tracting practices. ${ }^{11}$ In general, legal scholars in both the US and UK have distinguished between classical contract law, dominant in the first three quarters of the 19th century, and neoclassical contract law and more recently relational contract theory, which have slowly replaced classical contract law from the late 19th century onwards. ${ }^{12}$ The exact content and relevance of these doctrines is, however, subject to debate..$^{13}$ Given these unclear demarcations, I will concentrate on two broad, apparently polar, contracting perspectives, namely a 'classical contracting perspective' and a 'relational contract perspective. ${ }^{14}{ }^{14}$ This classification into perspectives enables me to extract the relevant characterizing principles from each depiction of contract law, classical and relational. As such, I am able to abstract from the particular jurisdiction, in this case common law, in which classical and relational contract law have originally developed. The current classification then, makes it possible to apply these 'perspectives' to different types of technology partnerships and contracts, regardless of the applicable legal regime, namely common or civil law. ${ }^{15}$

The classical contracting perspective supports the discrete market form of organization. ${ }^{16,17}$ In that context, the identity of parties is irrelevant and transactions occur entirely separate from all other past, present and future transactions..$^{18}$ Freedom of contract constitutes the basis of market exchange and is enforced by a laissez-faire policy envisioning the sanctity of contracts. ${ }^{19}$ The freedom of contract emphasizes the fact that the mere consent or will of the parties is sufficient to create content obligatitons and justify enforceability. ${ }^{20}$ Contracts are regarded as risk allocation mechanisms, which incorporate all relevant contingencies and obligations, i.e. a contract is considered to be a clear-cut and 'complete' agreement. ${ }^{21}$ The adaptation of a contract to accommodate archange of circumstances is considered to impede the sanctity of contracts. ${ }^{22}$ The classical contracting perspective can also be characterized by the follow-

${ }^{11}$ Ring and Van de Ven 1992, Williamson 1985, 1996.

${ }^{12}$ Atiyah 1989, Eisenberg 2001, Friedman 1.973, Horwitz 1977.

${ }_{13}^{13}$ Eisenberg 2000, Feinman 1983 and 1990, Gordley 1991, Macneil 2000, Wightman 1996.

${ }^{14}$ Eisenberg 2000, Macneil 1979. I discuss these different approaches as perspectives because, given the primarily, private ordering nature of relational contracting, there is no relational contract law in the strict sense. Harrison (2004) discusses an interesting case where both the UK High Court and the Court of Appeal refused to legally enforce a relational contract between two companies, based on implied obligations and refused to legally enforce a relation
promises without a formal contract.

${ }^{15}$ Economic theory and some of its spill-over to the management literature, rely on other approaches than either a classical or a relational contracting perspective. In that context one has to think of the contributions related to incomplete contracting (Hart and Moore 1999, Posner 1986), and work on the property rights theory of the firm (Hart and Moore 1990).

${ }^{16}$ Discrete must be understood as 'asuif-discrete' (Macneil 2000), as almost every exchange is embedded in a minimal social context and truly discrete transactions are rare.

minimal social context and truly
${ }^{17}$ Williamson 1991, Macneil 1978.

${ }^{17}$ Williamson 1991, Macneil 1978.
${ }^{18}$ Foss et al. 2000, Williamson 1991, 1996

${ }^{19}$ Nassar 1995, Friedman 1973

${ }^{20}$ Wightman 1996, Atiyah 1979, Nassar 1995.

${ }^{21}$ Ring and Van de Ven 1992, Triantis 2000.

${ }^{22}$ Nassar 1995. 
ing legal recommendations: account for as much of the subject matter of the contract as possible, avoid open-ended agreements, restrict the sources used to define the content of the agreement i.e. formal documents are preferred over informal communication, limit the amount of contractual remedies available to parties, court enforcement is the preferred method of dispute resolution. ${ }^{23}$

The relational contracting perspective is modeled upon the assumption that contracts are incomplete. ${ }^{24}$ Models of incomplete contracting assume that in a complex world, characterized by asset specificity, measurement difficulties and uncertainty, transaction costs impede the writing of elaborate contracts. ${ }^{25}$ More specifically, bounded rationality and verification and information constraints increase transaction costs and thus make it impossible to efficiently allocate parties' obligations across all future contingencies contractually. ${ }^{26}$ Such incompleteness raises the risk of contractual hazards and thus reinforces the need for (in)formal contractual safeguards that aim to realign the incentives and interests of parties. With the recognition that contracts are to some degree incomplete, flexibility plays an important role for the governance of contractual relationships. ${ }^{27}$

The relational contracting perspective supports these incomplete contracts as it replaces discreteness and presentiation by relational norms. ${ }^{28}$ Such norms may be explicitly expressed in the contract through the incorporation of vague terms such as 'best efforts' and 'reasonableness', or through mechanisms which facilitate continuity and promote efficient adaptation, such as revision clauses, the doctrine of excuse, internal dispute resolution agreements and arbitration. ${ }^{29}$ Furthermore, various scholars use the term relational governance to refer to norms such as reputation and trust that act to enhance cooperation between parties. ${ }^{30}$ It is important to note that under the relational contracting perspective the contract is regarded as a risk sharing mechanism, as opposed to a risk allocation mechanism under the classical approach. ${ }^{31}$

${ }^{23}$ Macneil 1978

${ }^{24}$ Scott 2003.

${ }^{25}$ Brousseau and Glachant 2002, Harrison 2004, Poppo and Zenger 2002, Ring and Van de Ven 1992, Williamson 1985, 1991

${ }^{26}$ Ayres and Gertner 1992, Masten 1996, Williamson 1996, 1991. Legal scholars and economic and management scholars seem to define the incompleteness of contracts differently. However, the definition as articulated in this chapter is increasingly accepted, i.e. a contract is considered incomplete if the contract does not specify all future contingencies and/or the contract does not exploit all gains from trade.

${ }^{27}$ This differentiation into complete and incomplete contracting, that stresses the role of flexibility and adaptability to conflict, is somewhat similar to Peter Ring's distinction between 'state of contract' and 'state of union' (Ring 1997).

${ }^{28}$ Bonn 1972, Eisenberg 2000, Williamson 1985.

${ }^{29}$ Eisenberg 2000, Scott 2003, Speidel 2000.

${ }^{30}$ The effect of these latter norms on partnerships has been subject to extensive research and does not pertain to the scope of this paper (Gulati 1995, Macaulay 1963, Parkhe 1993, Poppo and Zenger 2002, Reuer and Ariño 2002, Ring 2002, Ring and Van de Ven 1992).

${ }^{31}$ Speidel (2000) gives an example of a contract in which a pricing mechanism designed to track the market rate for the transportation of ore allows parties to share the risk of a price change instead of allocating such a risk ex ante. 


\section{CONTRACTUAL CLAUSES}

It is generally acknowledged that the environment within which technology partnerships are negotiated is complex. The partnerships generally involve asset specific investments and they are characterized by uncertainty, raising the risk of contractual exchange. ${ }^{32}$ As indicated in the introduction, previous studies have predominantly investigated the way in which (intellectual) property and control rights, payment schemes and contract duration are able to mitigate exchange hazards and induce efficient contract structures. Whilst the foregoing constructs have been held to effectuate cooperative behavior in the long run, scholars have recently acknowledged that as the risk of opportunistic behavior augments there is a greater need for contractual safeguards. Such provisions, specifying the consequences of breach and termination, as well as dispute resolution processes have become increasingly important. ${ }^{33}$ Building upon these prior literatures, that discuss the relevance of particular clauses for understanding contracts in the context of technology partnering, I will analyze revision clauses, hardship and force majeure clauses, damage measures, warranties and dispute resolution mechanisms in the light of classical and relational contracting perspectives.

\section{Revision clauses}

In complex environments, revision clauses can mitigate the effect of unforeseen contingencies, as they impose a general duty on the revision of a contract. ${ }^{34}$ Under a revision clause, parties are expected to initiate and pursue good faith negotiations and the advantaged party generally has a duty to accept an equitable adjustment. ${ }^{35} \mathrm{~A}$ revision clause, for example, may pertain to force majeure and hardship clauses, and will stipulate that parties are obliged to review the situation and attempt to accommodate the unforeseen change of circumstances before deciding upon termination. The incorporation of revision clauses clearly falls within the domain of the relational contracting perspective. Under the classical contracting perspective, a closed contract is sanctioned and final and a revision clause would set aside the discreteness inherent to the classical approach. The fact that revision clauses do not impose well-defined obligations on the parties to the contract will suffice to render them invalid and unenforceable. $^{36}$

\footnotetext{
${ }^{32}$ Gulati 1995. It also possible to consider inter-firm partnerships, in particular those outside the most research intensive high-tech sectors, in the context of non-specific public good aspects of technological knowledge that leads to property rights problems and associated transaction failures. ${ }^{33}$ Dyer 1997, Poppo and Zenger 2002, Reuer and Ariño 2002.

${ }^{34}$ Perillo 1998.

${ }^{35}$ Eisenberg 2000.

${ }^{36}$ Nassar 1995.
} 
Hardship and force majeure clauses ${ }^{37}$

The implementation of hardship or force majeure clauses indicates that parties are willing to accommodate the relationship to an unforeseen change of circumstances in order to intercept the harmful effects of such unforeseen contingencies. ${ }^{38}$ Under the classical approach, the principle of pacta sunt servanda plays a primary role; the final goal is performance of the contract even if this has become burdensome to one of the parties. Although parties will attempt to ex ante identify and efficiently allocate all future risks, bounded rationality, verification and information constraints impede complete ex ante allocation. In the case of a disruptive event, not accounted for in the contract, parties intend to let the loss lie where it falls, and in general, the classical contracting perspective will thus not provide for adjustment. A relationship involving specific investments, however, increases the costs related with premature termination. Nassar (1995) argues that in that context, adjustment will be preferred even under the classical contracting perspective. The situations in which performance is excused will be limited to truly disruptive external events, which are both unforeseeable, unavoidable and render performance absolutely impossible, e.g. wars, revolution (force majeure). ${ }^{39}$ The legal consequence of force majeure is either termination or suspension of the relationship. In case of termination each party must carry its own risk, which often means that the debtor bears the consequences of termination. In some cases, the parties might be compensated for the performance already rendered (restitution interest), dependent on the duration of the event.

The relational contracting approach is focused on the continued relation between parties and clauses calling for termination of the relationship in the light of unforeseen circumstances are essentially discrete in nature. Relational elements may be added to such clauses by stipulating parties to use 'best efforts' in remedying the cause, initiate negotiations and attempt to accommodate the changes instead of direct termination, pursue equitable remedies. Under the relational contracting perspective performance does not have to be completely impossible, but may be excused as soon as performance becomes onerous ${ }^{40}$, e.g. economic, financial, legal or technological factors that cause serious adverse consequences to a contracting party. ${ }^{41}$ The legal consequences of hardship may range from excusing performance to renegotiating and adjusting contractual rights and obligations in order to accommodate for the change. ${ }^{42}$ In case of termination, parties may be compensated for costs already incurred (reliance interest) and / or performance already rendered (restitution interest).

${ }^{37}$ I realize that 'hardship' and 'force majeure' are general legal terms, which are subject to different interpretations in each national jurisdiction. I have, however, chosen this terminology in accordance with the international legal practice.

${ }^{38}$ Perillo 1998.

${ }^{39}$ Doudko 2001, Perillo 1998

${ }^{40}$ Perillo 1998.

${ }^{42}$ Doudko 2001. 


\section{Damage measures}

Termination rights and the associated damages act to reinforce cooperative behavior. In case of breach of contract ${ }^{43}$, the main question that arises - after it has been decided which party should bear the risk of the debtor's inability to perform - is to what extent damages should be awarded. According to the classical perspective, parties voluntarily assume liability through a promise or an agreement, losses lie where they fall. ${ }^{44}$ Furthermore, the dominant principle of pacta sunt servanda requires performance - actual or hypothetical - to take place and damages are assigned accordingly. ${ }^{45}$ The classical contracting perspective thus complies well with the doctrine of expectation damages, which places the 'injured' party in the same position as it would have been in, had the contract been fulfilled. ${ }^{46}$ The classical approach will in principle fail to recognize consequential damages - damages incurred to other protected interests of the party - as it will only allow for compensation of losses that follow immediately and directly from non-performance.

Apart from the scope of damages to be awarded, the question arises how the precise amount of expectation damages is to be determined. The fact that parties under the classical approach attempt to specify all rights and obligations ex ante, complies well with the doctrine of liquidated damages, which refers to contractual ex ante damage specification. Liquidated damages are static and their application depends entirely on the circumstances existing at the time of contract formation, whilst later events are deemed irrelevant. ${ }^{47}$

In contrast to classical theory, the relational contracting perspective is based upon the premise of risk-sharing instead of ex ante risk allocation; damages must be both reasonable and fair. ${ }^{48}$ In the case of asset specific investments, parties must be compensated for the sunk costs thereof if the investments have not been covered by income from performance. ${ }^{49}$ Accordingly, parties are compensated for performance already rendered (restitution interest) and / or costs incurred prior to the breach (reliance interest). Reliance damages and restitution will place a party in the position it would have been in, had there been no contract in the first place. In the light of the foregoing it becomes evident that the relational contracting perspective does not comply well with the doctrine of expectation damages.

\footnotetext{
${ }^{43}$ 'Breach of contract' extends to include every case where performance rendered falls short of a promise in contract. I will not extensively discuss the difference between the case where the debtor is 'innocent' and at

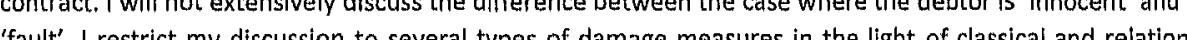
'fault'. I restrict my discusslon to several types of damage meas in theory; a more extensive legal discussion of this subject, including various other remedies for breach of contract, is beyond the scope of this chapter.

${ }^{44}$ Feinman 1990.

${ }^{45}$ Macneil 1978.

${ }^{46}$ Feinman 1990.

${ }^{17}$ Eisenberg 2001.

${ }^{48}$ Nassar 1995.

${ }^{49}$ ibid.
} 


\section{Warranties $^{50}$}

A warranty in a contract between companies may be characterized as an information mechanism that mitigates the hazards associated with problems of asymmetric information regarding the characteristics of parties or their product quality. ${ }^{51}$ The implementation of warranties incites parties to correctly display all relevant rights and obligations. The enforcement of warranties through the legal system reduces warranty commitments to credible signals; the firm presenting a warranty has to be aware of the resulting costs if the warranty is based on misrepresentation. ${ }^{52}$ Warranties are often enforced by indemnifications. An indemnity is a promise by one party to take responsibility for the loss the other party will suffer as a result of the first party's breach of its warranties.

In general, warranties comply with the classical contracting perspective, i.e. warranties act as an ex ante risk allocation mechanism. A warranty indicates that a party is willing to guarantee a certain state of affairs and consequently carry the risk of misrepresentation. On the other hand, warranties concerning the characteristics of a party may be employed under the relational contracting perspective while the exact identity of parties is of substantial importance in such long-term partnerships.

\section{Dispute resolution mechanisms}

Two main categories of dispute resolution may be distinguished: internal dispute resolution and third party dispute resolution such as arbitration, mediation and litigation. In the context of internal dispute resolution an attempt is made to resolve the dispute without reference to a third-party, goodwill and cooperation thus play a significant role. A common type of third-party dispute resolution is arbitration, under which a dispute is submitted to an arbitrator who will make a binding decision. ${ }^{53}$ Arbitration procedures can be tailored to the parties' needs and parties often feel that arbitration is faster, less expensive and more efficient than litigation. ${ }^{54}$ Both internal dispute resolution and arbitration comply well with the relational contracting perspective as these mechanisms take into account the general context of the partnership, the identity of parties and their relationship, and pursue fair and equitable solutions. ${ }^{55}$

Under the classical contracting perspective, the relationship is of secondary importance and parties prefer an effective resolution with an assignment of damages over a 'fair' resolution of the conflict. Litigation complies with this classical approach as courts strictly apply applicable law, they might pay less attention to the context of the relationship and they will often take the written terms of the contract as an approximation

${ }^{50}$ This section refers to warranties in the sense of guarantees, not be confused with the qualification of a warranty in Anglo-Saxon law as a non-essential term of the contract.

${ }^{51}$ Courville and Hausman 1979.

${ }^{52}$ Wehrt 2000.

${ }^{53}$ Bonn 1972

${ }^{51}$ Ibid., Williamson 1985, 1996

${ }^{55}$ Speidel 2000, Bonn 1972. 
of parties' intentions. ${ }^{56}$ Macaulay (1963) and others have observed that even in a classical setting, contract execution by companies is often less formal and not necessarily frequently relied upon. However, l expect that litigation is both relevant and crucial in the context of inter-firm partnerships where intellectual property rights protection and control over resources are of vital interest to companies. ${ }^{57}$

\section{TECHNOLOGY PARTNERSHIP MODES AND CONTRACT LAW}

Equity joint ventures

Equity joint ventures are quasi-hierarchical in nature as the new venture embodies the creation of a hierarchy structure, namely common governance of the joint venture by the parent companies, which remain legally and economically independent of each other. ${ }^{58}$ The legal form of governance which supplants these common ownership structures is the contractual agreement embodying the creation of the joint venture.

The (reciprocal) contribution of specific assets and consequently the share participation of each parent company in an equity joint venture, will serve as credible commitments. ${ }^{59}$ More specifically, property rights are able to ex ante allocate risks inherent to e.g. R\&D projects undertaken within the equity joint venture. ${ }^{60}$ If all partners contribute assets that are of significant importance to the relationship, it is expected that shareholding should occur on an equal basis in order to induce optimal investment decisions. Equity participation may mitigate contractual hazards, but it also creates additional monitoring rights and administrative controls, inducing potential principal-agent conflicts as joint venture ownership accrues to different parent companies, whilst the management resides with the equity joint venture. This means that incentives have to be aligned, not only between the owners themselves, but also between management and owners.

Due to the investments in specific assets and the uncertainty concerning the outcome of R\&D projects or other innovative efforts, I contemplate that equity joint ventures will be governed by a relational contracting perspective that complements the 'safeguards' that are provided for by the distribution of property rights. Relational contracting can create the flexibility necessary to mitigate the negative effects of unforeseen contingencies and ensure long-run collaboration and mutual forbearance. ${ }^{61}$ More in particular, I argue that equity joint ventures refer to internal dispute resolu-

\footnotetext{
${ }^{56} 1$ am aware of the fact that there is a difference in contract interpretation between common and civil law courts; compared with civil law Jurisdictions, common law jurisdictions attach more importance to the precise language / words of the written contract.

${ }^{57}$ See also Rothaermel and Deeds 2004.

${ }^{58}$ Gulati 1995.

${ }^{59}$ Klein 1996, Klein et al. 1978, Teece 1992

${ }^{60}$ Killing 1988.

${ }^{61}$ Williamson 1.985, 1991 and 1996
} 
tion mechanisms and include adaptation clauses construed in the light of a relational contracting perspective.

\section{Non-equity partnerships}

Non-equity partnerships are 'pure hybrid forms ${ }^{\prime 62}$ which do not include the creation of a new venture. ${ }^{63}$ Property rights and profit allocation schemes do not ensue from shareholdings and residual rights of control are thus not automatically accounted for. ${ }^{64}$ The division of property rights derives solely from the formal contract, which must specifically allocate these rights. I stipulate that the lack of a de facto common ownership structure in a complex environment incites parties to resort to a substantial range of other contractual safeguards.

The norms eminent to the classical contracting perspective do not seem to provide for the flexibility needed to create and prolong mutual forbearance in these long-term partnerships. Relational contracting, on the other hand, attributes considerable attention not only to the initial agreement, but also to the relationship as it evolves between parties. Non-equity partnerships are thus expected to be governed by a relational contracting perspective. In this context, these partnerships will stipulate that property rights and research outcomes are shared on an equal basis, and damage measures must be reasonable and fair. In addition, revision clauses and force majeure, extending to include hardship, will need to be incorporated into the contract. Moreover, disputes will be resolved internally, with arbitration acting as a last resort.

\section{Licensing contracts}

Licensing contracts involve the transfer of intellectual property protected by law, usually in the form of a patent. ${ }^{65}$ Unlike equity joint ventures and non-equity partnerships, licensing contracts are unilateral in nature. They entail the one-way flow of technical information from the licensor to the licensee in return for some compensation. In principle, a licensing contract complies with a market transaction, the identity of parties is of secondary importance, the transaction does not involve reciprocal investments, and information exchange is minimal (except at the initial stage). Licensing contracts do not entail long-term research cooperation, but are based on the static relationship between parties, as each party independently attempts to pursue profit maximization. Because cooperation is less important, contracts will be based on risk allocation instead of risk sharing, which corresponds with the classical contracting perspective. More specifically, licensing contracts are expected to: contain no general revision clauses, excuse performance only when this has become absolutely impossible, stipulate liquidated damages which cover only the expectation interest, use war-

\footnotetext{
${ }^{62}$ Williamson 1991 and 1986, Gulati 1995.

${ }^{63}$ Hagedoorn 1990, Killing 1988, Wolf 1995.

${ }^{54}$ Root 1988.

${ }^{65}$ Bessy and Brousseau 1998, Fox 1992, Hagedoorn 1990.
} 
ranties to ex ante allocate certain risks, and refer disputes to court. Therefore, the classical contracting perspective will in general apply to licensing contracts. ${ }^{66}$

Concerning ex ante property rights allocation, the licensor holds all property rights and thereby residual rights of control with respect to the transferred knowledge. Unless explicitly specified in the contract, the licensee usually owns all property rights to the product or process that may result from the use of the patent. ${ }^{67}$ Whilst property rights are clearly defined and they guarantee the licensor a certain return on investment, contracts remain characterized by considerable information and verification constraints. The licensor faces a relatively low degree of ex ante uncertainty due to intellectual property protection, whilst the licensee is confronted with an informational disadvantage regarding the true value of the asset. Moreover, the fact that a licensing contract involves both the transfer of codified knowledge (the patent) and tacit knowledge (the instructions), gives rise to double moral hazard. Upon receipt of the patent fee, the licensor can forego to foreclose all necessary instructions, whilst the licensee may fail to complete payment upon receipt of the full instructions. ${ }^{68}$

\section{REVIEW OF TECHNOLOGY PARTNERSHIP CONTRACTS}

\section{Methods}

In order to exemplify our understanding of different modes of inter-firm technology partnering and their contractual setting, I present a detailed, qualitative analysis of concrete contracts for different technology partnerships, i.e. equity joint ventures, non-equity partnerships, and licensing. I will review two samples of contracts for each mode of inter-firm technology partnering. In the following I will summarize the content of these contracts, concentrating on property rights, major contractual clauses, and measures for conflict resolution, as discussed in the above, but I will also provide a large number of direct quotes from these contracts that illustrate how companies write such contracts.

Based on information from the MERIT-CATI database on technology partnerships ${ }^{69}$ and the sources of these contracts (see below) these six sample contracts can be understood as exemplary for the partnerships established in the high-tech industries mentioned below. Moreover, some extensive and detailed discussions with corporate

\footnotetext{
${ }^{65}$ In this context, it is irrelevant whether companies are jointly engaged in licensing, joint ventures or othe agreements. The co-existence of numerous agreements between partners will not affect the drafting style of greements. The co-existence of numerous agreements between partners will not affect the drafting style of the contract, while such contracts relate to different areas of research and are usually drafted by different departments within companies. I note that the foregoing does not apply to e.g. all licensing and option agreements which are sometimes specifically attached as appendix to a collaborative agreement and the constitute an integral part of that collaborative agreement.

The question as to who owns know-how related to licenses may depend on the law of a particular jurisdic tion.

${ }^{68}$ Arora 1995, Arora and Fosfuri 2002

${ }^{69}$ Hagedoorn 2002
} 
lawyers and legal counsel involved in these contracts revealed that these contracts are to be seen as representative for contracts made in the high-tech industrial context that surrounds the three modes of technology partnering discussed in this chapter. ${ }^{70}$ This in-depth review complements prior literature through its detailed analysis of the content of contractual provisions (adaptation clauses, such as revision and force majeure/hardship clauses, damage measures, warranties, dispute resolution) and relevant property rights issues.

In order to get this in-depth understanding of these contractual provisions and relevant property rights issues, I not only studied the actual contracts but I also interviewed corporate lawyers and legal counsel involved in the drafting of each of these technology partnerships. Each of these interviews took several hours, in that context I discussed both general legal issues such as the preferred jurisdiction in case of litigation, the level of detail that is needed in each of these contracts, intellectual property rights issues, and specific provisions in these contracts. ${ }^{71}$ In addition to corporate lawyers and legal counsel involved in drafting these technology partnership contracts, 1 also interviewed corporate lawyers and legal counsel in four other high-tech companies, mainly in advanced electronics, and an international legal firm that specializes in technology partnering in biotechnology and pharmaceuticals. ${ }^{72}$

All six partnerships and their contracts refer to companies in bioscience, fine chemicals, biotechnology and biopharmaceuticals. These industries are characterized by rapid technological developments and a high degree of intellectual property rights protection. In these specific high-tech industries, relational contract theory will provide parties with the flexibility needed to adapt their contract to the constantly changing environment. Some of these partnerships fall under a common law regime; others are subject to a civil law regime. The two cases of non-equity partnerships entail the collaboration between Orchid Biocomputer Inc. and Affymetrix Inc., both from the USA, and the partnership between ImClone Systems Inc. from the USA and Boehringer Ingelheim Pharma KG (BI Pharma KG) from Germany. Orchid Biocomputer is a provider of services and products for profiling genetic uniqueness, whereas Affymmetrix develops technologies for analyzing and managing complex genetic information for use in biomedical research. ImClone Systems is a biopharmaceutical company engaged in the development of biologic medicines and BI Pharma KG produces pharmaceuticals, chemicals and biopharmaceuticals. The two cases of licensing contracts and the two

${ }^{70}$ It should be noted that additional research is necessary to study the exact effects of contingencies such as repeated ties, general partnering experience, partner specific experience, expertise with regard to different legal systems on the particular content of contract provisions.

legal systems on the particular content of contract provisions.
${ }_{11}$ Although I will make an attempt to be as specific as possible when it comes to citing specific clauses in contracts, I am limited by the non-disclosure agreements that I was asked to sign by some of the companies involved.

${ }^{12}$ In total, I interviewed ten experts. Nine of them are in-company legal counsel, general legal counsel, senior legal counsel, or head of the department of intellectual property and standards of their respective companies, one expert is an associate of an international law firm and an expert on intellectual property and technology, responsible for negotiating and drafting technology agreements. 
cases of contracts for the equity joint ventures were provided by DSM, a Dutch chemical company. The contracts for the non-equity partnerships were extracted from the FindLaw.com internet database on inter-firm partnership contracts. The FindLaw.com internet database is freely accessible and powered by Thomson; it contains information on more than 7000 deals, including over 1000 inter-firm partnerships.

\section{The equity joint ventures}

The contracts for the equity joint ventures indicate a common ownership structure (shareholdings) and income, profits and losses are allocated accordingly. The joint ventures are controlled by a board of directors, but day-to-day operations are run by general managers, one appointed by each party. Shareholdings correspond to voting rights and structural decisions, e.g. decisions relating to an increase or reduction in the venture's share capital, the dissolution of the venture, and the issuance of new shares, require approval not only of the parties, but are subject to complex majority voting procedures. As typically stated in such contracts, such decisions may '(...) require the approval by the parties before being presented to the general meeting and when presented to the general meeting require affirmative votes of shareholders and their proxies representing not less than three-fourth (3/4) of all votes which all shareholders are entitled to cast thereat and at a subsequent general meeting of shareholders affirmative votes of not less than three-fourth $(3 / 4)$ of all votes which all shareholders are entitles to cast thereat.'

Parties must use their 'best efforts' to cooperate and to prevent any conflict of interest arising. Clauses that are found to be invalid, illegal or unenforceable are open to negotiations. In that case, the contract may stipulate that the '(...) parties shall promptly meet and negotiate substitute provisions of equivalent economic impact for those rendered invalid, illegal or unenforceable (...)'. Also, the equity joint ventures are established for an indefinite period, unless dissolved or terminated sooner. Each partner has the right to withdraw from the equity joint venture, but will need prior consent of the other party(s) if it decides to do so before the xth anniversary of each venture. Upon the xth anniversary of each equity joint venture, parties may sell their shares under the condition that the other party is offered a 'right of first refusal'.

The contracts state several grounds for termination: the unanimous consent of parties to dissolve the joint venture, the decision of parties not to fulfill the capital requirements for the joint venture, the sale or disposition of all the assets of the venture, the occurrence of an event of default, or a force majeure exceeding three hundred and sixty five consecutive calendar days. An event of default is, for example, ' $(. .$. considered to have occurred if either party: (...) fails to perform or violates any of the material terms or conditions of (the) agreement or of the associated agreement, and continues such failure or violation for sixty $(60)$ calendar days after it has been given notice by the non-defaulting party (...)' The force majeure condition refers to a delay in performance or non-performance in whole or in part caused by the circumstances reasonably beyond the control of the affected party. In one of the sample contracts it 
is typically stated that this includes, '(...) but is not limited to: acts of God, fire, flood, war, accident, explosion, breakdowns, or labour trouble; embargoes or other import or export restrictions; shortage of or inability to obtain energy, equipment, transportation, (the inputs for making the product), or good faith compliance with any regulation, direction or request (whether valid or invalid) made by any governmental authority or person (...)'.

When a joint venture's affairs are wound up, due to the occurrence of an event of termination, the assets and equity of the venture are divided in proportion to each party's equity ownership. As stated in these contracts, in '(...) event of default, the non-defaulting party may choose to purchase (...) the equity ownership of the defaulting party $(\ldots)$ and continue the business of the venture (...) or dissolve the venture (...) without prejudice to its rights to recover from the defaulting party all costs, damages and expenses (...) incurred and/or suffered by the non-defaulting party in connection with the event of default (...).' In that case, the defaulting party is not be relieved of any liability it may have to the other party and/or the joint venture which liability arose to or on account of such termination.

The contracts also provide for warranties and accompanying indemnities concerning the duly establishment and existence of the parties and their authority, legal rights and power to execute and perform the agreement. Disputes are to be settled internally, through negotiation and conciliation procedures. If it is not possible to resolve the dispute within sixty days, parties must resort to arbitration. In any case, a party is not liable to the other party or its affiliates for any consequential damages suffered or incurred by that party or its affiliates.

\section{The non-equity partnerships}

Both non-equity partnerships are project-based collaborations. The parties agree to act collaboratively and shall use their commercially 'reasonable efforts' to fulfill their respective obligations. Project managers, appointed by both parties, are responsible for inter-firm communications. The partnerships are coordinated by a collaboration management committee, composed of two or more representatives of each party.

Under both partnerships, each party retains ownership of its contributed technology, of which it '(...) shall have sole and exclusive ownership of all right, title and interest.' For the partnership for which the contract is governed by California State law, a party making an improvement to the contributed technology of the other party during the collaboration is obliged to transfer the rights relating to the improvements to the party with initial ownership. In addition, the latter contract stipulates that each party shall own an undivided one-half interest in all 'joint technology'. Under US patent law, joint ownership implies that each party is free to utilize his/her interest in virtually any manner without consent of the co-owner, unless parties specify otherwise in a written agreement. The preferred solution is to assign all rights to one single party, who will then own the patent and control how it is used. While the parties to the foregoing contract have chosen joint ownership, they have restricted the co-ownership to the 
creation of 'joint technology'. In addition, the clause seems in line with the current increase of joint patenting in the US biotechnological and pharmaceutical industry. ${ }^{73}$ The contract governed by German law stipulates that the property rights that solely cover the 'product', arising out of the joint efforts, shall accrue to party $A_{\text {; }}$ whilst all other emergent intellectual property rights shall accrue to party $B$; the latter must grant party $A$ a non-exclusive, royalty-free, worldwide license for use to the 'product'. Under German law, in absence of any agreement which states otherwise, the principles of the 'Bruchteilsgemeinschaft' (section 741 and following of the German Civil Code) will apply and legal entities will share an undivided interest in the patent that is created. Although this seems similar to US law, the manner in which the parties may use the patent without the other party's consent is somewhat restricted. However, parties usually provide for a different allocation of rights through a written agreement, of which this contract is an illustration.

The partnerships are of a fixed duration, i.e. performance of the last required service automatically terminates the agreement, but either party may request an extension of one year. Actual termination of the partnership can be effectuated by a force majeure event (see previous section for the formulation of the clause) or through the impossibility to perform due to scientific or technical reasons. Parties may attempt to resolve the problem through negotiations during a thirty day period, if negotiations fail, ' (...) either party may terminate (the) agreement effective upon written notice (...)' The terminating party must pay the other party an amount in damages ' $(. .$.$) equal to all$ expenses reasonably incurred by (...) the other party (...) prior to such termination (...) and for a period of 8 (eight) weeks thereafter (....' Breach of a material provision of the agreement and bankruptcy of either party gives parties the right to terminate the partnership, whilst taking into account a period of thirty days for the other party to remedy the breach. During this thirty day period, neither party shall be relieved of any obligations.

Force majeure allows performance to be excused and extended for the period of delay or the period of inability to perform, if a party has used its best efforts to avoid the occurrence of such an event. The contracts explicitly stipulate that '(...) neither party shall incur any liability or compensation obligation for any damages, (...) losses or expenses of any kind suffered or incurred by the other (...) arising from or incident to any termination of (the partnership) by such party that complies with the terms of the agreement whether or not such party is aware of any such damage, loss or expenses.'

The contracts also include warranty and indemnity clauses regarding the existence, authority, legal rights and power of each of the parties to execute and perform the agreement. In addition, the contracts relate breach of a warranty to termination, as ' (...) each party shall be entitled (but not required) to terminate this agreement (...) in the event that (...) the other party shall have breached a covenant, representation or warranty made in this agreement $(. .$.$) .'$

${ }^{73}$ Hagedoorn 2003 
Disputes are resolved internally by senior officers or project managers. If the conflict cannot be resolved within thirty days, the dispute will be referred to a mediator, and thereafter to an arbitrator for ' (...) final and binding arbitration (...).' Arbitrators are not allowed to award punitive or other multiple damages to any of the parties. However, disputes concerning the validity or scope of patents ' (...) shall be set aside by the arbitrator(s) and shall not be decided by them (...)', these matters will be subject to litigation.

Furthermore, if any provision of these contracts is held to be invalid or unenforceable, all other provisions shall continue in full force and effect. Parties must attempt to substitute the respective term by a provision that pursues the economic and legal goal of the unenforceable term to the greatest extent.

\section{The licensing contracts}

Both licensing contracts incorporate a complex payment scheme consisting of '(...) a non-refundable initial licensing fee (...')', a type of lump sum, that is to be paid shortly after the conclusion of the licensing contract, and '(...) non-refundable annual minimum $(. . .)^{\prime}$ royalties based upon a percentage of the net sales of the licensed product.

The licensee is obliged to take 'reasonable efforts' to exploit the license and may be asked for a progress report. The licensing contracts also stipulate that ' $(. .$.$) any im-$ provement to the licensed patents shall be the property of the party inventing such improvement. Any improvement to the (...) system itself as patented in the licensed patents shall be the property of licensor and shall be licensed to licensee under the terms and conditions of this agreement.'

The terms of the licensing contracts extend to the last-to-expire valid claim to a licensed patent. However, the licensor can decide to dispose of the patent beforehand, under the condition that the licensee is offered the 'first right of refusal'. Taking into account a certain notice period, the licensee may terminate the agreement at al times, also if the licensor fails to enforce the patents or if patents are held to be invalid. The licensor may terminate the licensing contract if the licensee infringes the license or has not used its 'reasonable best efforts' to exploit the license. Each party has the right to terminate the contract when the other party ' (...) materially breaches a material provision of (the) agreement and has failed to cure, failed to commence with remedial action and the diligent prosecution of the same, or failed to demonstrate the non-existence of the breach within thirty $(30)$ days of receipt from the other party of a written notice and demand to cure such breach (...).'

The termination does not affect the rights of parties arising prior to the termination and does not relieve parties of any obligation or liability or rescind any actions or payments by parties that have accrued prior to the termination. The occurrence of wars, riots, insurrections, serious labour disputes, floods, fires, explosions, or other natural disasters which render performance impossible or unfeasible, temporarily excuse performance, but automatically effectuate termination if performance is prevented for three or six consecutive months. 
One of the licensing contracts contains a (partial) warranty concerning the rights of the licensor and the status and maintenance of the patent and subsequently an indemnification. The warranty does not cover the '(...) merchantability or fitness for a particular purpose (or) warranty as to the enforceability or scope of any licensed patent or licensed technology (...).' The second licensing contract does not provide for any warranties. In both cases, the licensee assumes the entire risk concerning both licensed and application products. The licensor is not liable for any claims made by the licensee, or claims that arise out of the contract or any actions taken there under.

These licensing agreements also state that each party '(...) shall bear its own costs and expenses in relation to the negotiation, preparation, execution and implementation (...)' of the contract. Disputes shall be tried in court and '(...) the prevailing party shall be entitled to reasonable attorney's fees in addition to costs and necessary disbursements (...).'

With respect to severability, the contracts state that if provisions are found to be contrary to the law, the law prevails and the provision is only affected to the extent necessary to bring it within applicable law, not affecting the remaining provisions.

\section{DISCUSSION}

The review of the different partnerships illuminates several major differences in the interpretation of contracts referring to dissimilarities between the classical contracting perspective and the relational contracting perspective. Similar types of contractual clauses, such as dispute resolution clauses, adaptation clauses, and damage clauses are employed for the various forms of inter-firm technology partnering. However, it turns out that these clauses are given a different content and thus have divergent effects for distinct forms of partnership. Also, property rights seem to play a manifest role by inducing credible commitments in order to mitigate opportunistic behavior. Table 1 provides an overview of the three modes of inter-firm technology partnerships, their contractual clauses and property rights. 
Table 1 Overview of modes of inter-firm technology partnerships, their contractual clauses, and property rights.

\begin{tabular}{|c|c|c|c|}
\hline & Equity joint ventures & Non-equity partnerships & Licenses \\
\hline $\begin{array}{l}\text { Adaptation clauses } \\
\text { (hardship and force } \\
\text { majeure clauses) }\end{array}$ & $\begin{array}{l}\text { - Any event beyond } \\
\text { reasonable control of } \\
\text { party } \\
\text { - Suspension of obliga- } \\
\text { tions for long period } \\
\text { before termination (one } \\
\text { year) } \\
\text { - Relational contracting } \\
\text { perspective }\end{array}$ & $\begin{array}{l}\text { Any event beyond } \\
\text { reasonable control of } \\
\text { party }\end{array}$ & $\begin{array}{l}\text { - Natural disasters and } \\
\text { war may allow for sus- } \\
\text { pension of obligations } \\
\text { for short period before } \\
\text { termination (three-six } \\
\text { months) } \\
\text { - Classical contracting } \\
\text { perspective }\end{array}$ \\
\hline Damage measures & $\begin{array}{l}\text { - Reliance damages plus } \\
\text { compensation for per- } \\
\text { formance already ren- } \\
\text { dered (restitution inter- } \\
\text { est) } \\
\text { - Difference between } \\
\text { agreed termination and } \\
\text { termination due to de- } \\
\text { fault of one party } \\
\text { - Relational contracting } \\
\text { perspective }\end{array}$ & $\begin{array}{l}\text { - Reliance damages plus } \\
\text { compensation for per- } \\
\text { formance already ren- } \\
\text { dered (restitution inter- } \\
\text { est) } \\
\text { - Expenses made by non- } \\
\text { defaulting party (limited } \\
\text { period) } \\
\text { - Relational contracting } \\
\text { perspective }\end{array}$ & $\begin{array}{l}\text { No explicit provision } \\
\text { Licensor not liable for } \\
\text { claims }\end{array}$ \\
\hline Warranties & $\begin{array}{l}\text { - Standard terms } \\
\text { - Indemnity with respect } \\
\text { to breach of warranty } \\
\text { - In principle classical } \\
\text { contracting perspective, } \\
\text { construed from a rela- } \\
\text { tional perspective }\end{array}$ & $\begin{array}{l}\text { - Standard terms } \\
\text { - Indemnity with respect } \\
\text { to breach of warranty } \\
\text { - Breach of warranty may } \\
\text { trigger termination } \\
\text { - In principle classical } \\
\text { contracting perspective, } \\
\text { construed from a rela.- } \\
\text { tional perspective }\end{array}$ & $\begin{array}{l}\text { - In general no warranties } \\
\text { - (Partial) warranties } \\
\text { concerning rights, status } \\
\text { and maintenance } \\
\text { - In general no indemnifi- } \\
\text { cation } \\
\text { - Indicates classical con- } \\
\text { tracting perspective }\end{array}$ \\
\hline $\begin{array}{l}\text { Dispute settlement } \\
\text { mechanisms }\end{array}$ & $\begin{array}{l}\text { - Internal dispute resolu- } \\
\text { tion, arbitration and } \\
\text { mediation second-best } \\
\text { options } \\
\text { - Relational contracting } \\
\text { perspective }\end{array}$ & $\begin{array}{l}\text { - Internal dispute resolu- } \\
\text { tion, arbitration and } \\
\text { mediation second-best } \\
\text { options } \\
\text { - Relational contracting } \\
\text { perspective }\end{array}$ & $\begin{array}{l}\text { - Classical contracting } \\
\text { perspective }\end{array}$ \\
\hline Property rights & $\begin{array}{l}\text { - Clear distribution of } \\
\text { equity ownership } \\
\text { - Several additional } \\
\text { safeguards regarding } \\
\text { regulation of exit }\end{array}$ & $\begin{array}{l}\text { - Regulation of ownership } \\
\text { of new technologv, de- } \\
\text { veloped throughipart- } \\
\text { nership }\end{array}$ & $\begin{array}{l}\text { - Property rights are with } \\
\text { licensor }\end{array}$ \\
\hline Revision clauses & $\begin{array}{l}\text { - Revision clause related } \\
\text { to unenforceable and } \\
\text { invalid provisions }\end{array}$ & $\begin{array}{l}\text { - Revision clause irelated } \\
\text { to wmenforcealble and } \\
\text { invalid provisions } \\
\text { - Revision linked to oocur- } \\
\text { rence of supervening } \\
\text { events }\end{array}$ & Not mentioned \\
\hline
\end{tabular}




\section{Distribution of property rights}

The role of property rights is most prevalent in the case of equity joint ventures as the distribution of equity ownership drives the division of gains and losses. According to property rights theory, an equal dispersion of property rights induces optimal investment decisions and mitigates opportunistic behavior. ${ }^{74}$ Additional provisions however, reinforce the allocation of property rights: parties may not withdraw from the venture before a certain period of time, shares may only be sold subject to a 'first right of refusal' and decisions affecting the structure of the venture can only be taken by affirmative majority vote. Apparently, the mere ex ante allocation of property rights does not suffice to create credible commitments.

Property rights also play an important role in non-equity partnerships, which lack a common equity ownership structure. The contracts explicitly refer to the division of property rights: parties retain ownership of self-developed and contributed technology and subsequently either share equally or divide the property rights to jointly developed technology. In licensing contracts, property rights play a less prominent role in securing cooperation and generally the licensor holds all property rights to the codified and transferable knowledge.

Companies that I interviewed stressed that equity joint ventures may be preferred over non-equity partnerships when parties seek to limit the financial risks involved, as equity joint ventures entail a common ownership structure and thus a clear definition of property rights. However, this specific form of collaboration is not always necessary, and increasingly, the preferred form for research collaborations is a non-equity partnership in particular when collaboration is short-term and project-based. Companies also indicated that they prefer non-equity partnerships when the (intellectual) property rights are clearly granted to the party which makes the discovery or the improvement to a technology. In general the companies and legal counsel stated that it is very important for parties to manage their rights to the outcome of the collaborative project and clearly define in the contract who will hold the rights to the research results. often ownership and use of the results are defined through the grant of an intellectual property right to one of the parties and a license to the other party.

Revision clauses

The equity joint ventures and non-equity partnerships do not explicitly provide for general revision clauses. However, it may be asserted that both the equity joint ventures and the non-equity partnerships have, to a certain extent, integrated a duty to revise or (re)negotiate in several other clauses. Both types of partnership allow for negotiations in case of severability, the 'new' and enforceable clause must pursue the economic and legal goals of the prior unenforceable term to the greatest extent Whilst one might characterize this ability to (re)negotiate as a type of 'revision', it

\footnotetext{
${ }^{74}$ Klein 1996, Klein et al. 1978.
} 
offers no real flexibility as severability as such already forces parties to adjust the specific clause under penalty of severance.

In contrast to the equity joint ventures and the non-equity partnerships, the licensing contracts adhere to a classical contracting approach and lack the possibility to negotiate an optimal replacement clause in case of severability.

The non-equity partnerships have also attached a 'revision clause' to the occurrence of a supervening event. Upon the occurrence of such an event, parties must start negotiations and termination of the partnership is restricted to the case in which negotiations and subsequently accommodation of the contract fail.

\section{Adaptation clauses: force majeure and hardship}

The equity joint ventures, non-equity partnerships and licensing contracts all foresee in an adaptation or force majeure clause. However, the extent to which supervening events excuse performance differs under the classical and relational contracting perspective. According to the classical contracting perspective, performance must be absolutely impossible and either suspend or terminate parties' obligations. The relational contracting perspective, on the other hand, extends force majeure events to include economic impossibility, i.e. hardship, whereas legal consequences are not restricted to direct termination but may range from excusing performance to adjustment. Indeed, the different partnerships seem to follow either a classical or relational approach. The licensing contracts only excuse performance if specifically identified events render performance absolutely impossible, during which the obligations of the party are suspended. However, the consecutive duration of the events for a relatively short period, may concede in termination of the partnership; there is no room for negotiations which may mitigate the effects of the supervening events.

The equity joint ventures and non-equity partnerships adhere to a relational approach, whilst the force majeure clause extends to include hardship. Both types of partnership provide for a 'best efforts' revision clause in order to resolve or accommodate the effects of supervening events. Under the equity joint ventures, termination may only be invoked if the event has lasted and obstructed performance for three hundred and sixty five consecutive days, a much longer period than the three months stated in the licensing contracts. This indicates that parties attempt to prevent termination as long as possible.

During the interviews it became clear that many companies often apply force majeure and hardship clauses as so called boilerplates. ${ }^{75}$ These boilerplate clauses are not a completely standard type of clauses, but are drafted for the particular type of rela-

${ }^{75}$ Boilerplate is defined as the '... language which is used commonly in documents having a definite meaning in the same context without variation; used to describe standard language in a legal document that is identical in instruments of a like nature ...' (Black's Law Dictionary 1990, p. 175). Using boilerplates, firms attempt to enshrine in the contract the decisions of the applicable cases decided in court. They thereby limit the to enshrine in the contract the decisions of the applicab
application of statute or common law as a default rule. 
tionship. Licensing contracts as well as non-equity partnerships incorporate boilerplates, but the type of boilerplate may vary. As a licensing contract is clearly of a different contractual nature compared to a non-equity partnership, it is possible to find both somewhat similar, but also very different boilerplate clauses in these inter-firm agreements.

\section{Damages}

The three types of partnership attach different consequences to breach of the contract. In the context of the equity joint ventures, termination related to a force majeure event implies that the affairs of the venture are 'wound up' and assets and equity of the venture are dispersed in proportion to each party's equity ownership. In principle, parties are not liable and they are assured of a reimbursement of part of their investments. The foregoing complies with a relational contracting perspective as termination is governed by a restitution interest and parties are willing to share the risks.

Breach and termination of the contract due to default has different implications: the non-defaulting party is awarded damages incurred due to the event of default and the defaulting party is not relieved of any liabilities that have risen due to termination. The non-equity partnerships extend the assignment of damages to include all expenses incurred by the non-defaulting party eight weeks after the termination has taken effect. The non-equity partnerships both include the designation of 'reasonable' consequential damages in relation to an event of default, but explicitly forbid the assignment of punitive and multiple damages, that are often over-compensatory and that do not coincide with the view of relational contracting. The equity joint ventures, however, explicitly state that a party is not liable for any consequential damages suffered by the other party.

The equity joint ventures and non-equity partnerships are generally based upon the notion of reliance and restitution interest, and the damages awarded thus comply with the relational contracting perspective: parties are merely compensated for performance already rendered (restitution), or costs already incurred (reliance).

The licensing contracts do not explicitly provide for the assignment of damages. The contracts merely stipulate that termination in general does not relieve parties of any obligations, liabilities, rescission of any actions or payments that parties have accrued prior to termination. The contracts allocate all risks with the licensee and explicitly exclude liability of the licensor regarding any claims made by the licensee. Furthermore, each party carries its own enforcement costs. Whilst no clear damage measures have been foreseen, one might assert that these terms indicate a classical approach to damages. Indeed, the contracts seem to allocate risks ex ante and let each party carry its own losses. The licensor is responsible for the licensed patent and the licensee for the exploitation. 


\section{Warranties}

Both the equity joint ventures and non-equity partnerships provide standard term warranties and accompanying indemnities concerning the characteristics of the parties. In addition, one of the non-equity partnerships relates breach of a warranty with the right to termination. The incorporation of warranties indicates that even in equity joint ventures and non-equity partnerships, parties are willing to allocate certain risks ex ante. The risk allocation does not relate to (unforeseen) future contingencies, but merely confirms companies' ability to become a duly established party to the partnership. The duly establishment of parties and legal rights to enter into the partnership are understood to be essential in an agreement, which entails long-term cooperation.

Contrary to my expectations (see the section on licensing contracts), warranties do not seem to be part of the standard contractual licensing terms. In the event that a warranty is incorporated, it is limited to the valid registration and ownership of property rights. The foregoing seems to indicate, and this was also confirmed during the interviews with companies, that parties to licensing contracts take the characteristics of the party to be of marginal importance compared to the object of the contract, namely the patent. Given the limited warranties, parties are assumed to contract at their own risk and consequently must bear the losses. This complies with the classical contracting perspective under which the characteristics of parties are of subordinate importance. Another possible explanation might be the fact that the licensor in essence holds a monopoly position with regard to the patented technology. The licensor has no incentive to take on certain risks, by means of guarantees, which would normally accrue to the licensee. The licensor's guarantees are thus limited to the bare minimum: the valid registration and ownership of the property rights. This makes sense, as risks pertaining to exploitation of the license are understood to be part of the normal business risks. A warranty covering the content and value of the patent might (partially) mitigate the informational disadvantage of the licensee regarding the true value of the patent. However, such a warranty would deprive the licensor of its informational advantage. The licensee is thus actually placed in a 'take-or-leave-it' position, where it is obliged to carry most of the risks inherent to the agreement or forgo the opportunity to contract.

\section{Dispute settlement}

The relational contracting perspective favors internal and private dispute resolution over court enforcement. Especially in equity joint ventures and non-equity partnerships, the cooperation of parties is of foremost importance, as specific assets accrue most value within the particular relationship. It is therefore not surprising that the equity joint ventures and non-equity partnerships that I reviewed incorporate private enforcement clauses, where internal dispute resolution is followed by arbitration and mediation, litigation is not even mentioned.

Licensing contracts attach less value to the prolongation of the specific relationship, whilst patents may easily be allocated to another use. Subsequently, the re- 
viewed licensing contracts stipulate court adjudication. This clearly complies with the classical contracting perspective: a court will assign damages and interpret the contract according to the law and in a way the court deems reasonable.

Companies I interviewed stated that several internal dispute resolution mechanisms are provided for in joint venture contracts and non-equity partnerships, such as bringing the dispute before an R\&D committee with members of both parties, or bringing the dispute before the CEOs of the partners. When these amicable settlements do not have an effect, parties will refer to third party dispute resolution through external arbitration. When no agreement can be reached via internal dispute resolution or later through external arbitration, disputes are finally referred to the court. While in the first place an attempt is made to resolve all disputes internally, an arbitration clause is merely incorporated into the contract to leave the option of arbitration open when a resolution cannot be reached through amicable settlements.

Companies and legal counsel that 1 interviewed experience litigation as more formal compared to arbitration. Arbitration has several advantages over litigation: the arbitration procedure is confidential, the arbitrator can take a closer look at the content of the contract, the relationship between parties itself is also taken into account, an arbitrator is usually chosen for his/her technical expertise, an arbitrator is not bound by the strict application of legal rules or case law. Also, arbitration is perceived as being quicker and more cost effective than litigation.

As stated by one of the companies: 'In general, our first preference is to solve al disputes internally, through amicable settlements, and then through arbitration. In international agreements, where parties are often unfamiliar with each others legal system, we prefer arbitration over litigation. The choice for arbitration over litigation also depends on the type of agreement. For example, disputes in light of non-equity partnerships often relate to the content or scope of the collaboration, while licensing contracts often involve patent infringements or disputes relating to payment schemes. In the case of a scope or content conflict we will emphasize the need to settle the dispute internally. In addition, in common law jurisdictions, where the discovery procedure plays a role, we find that litigation is a good option in case of a patent infringement in the context of licensing contracts, when we know that the infringing party possesses valuable information.

\section{CONCLUSIONS}

Different general perspectives on contract law indicate either a continuum from classical to relational contracting perspective ${ }^{76}$ or a more orthogonal setting for both perspectives. ${ }^{77} \mathrm{My}$ findings suggest that different modes of inter-firm technology part-

\footnotetext{
${ }^{76}$ Macneil 1978

${ }^{77}$ Ring and Van de Ven 1992
} 
nering are first and foremost governed by either a classical or a more relational contracting perspective (see also table 1). As I expected, inter-firm technology partnerships that are organized through equity joint ventures and non-equity partnerships largely follow a relational contracting perspective. The relational approach appears to play little or no role in licensing contracts which seem to be almost exclusively governed by a classical contracting perspective.

The relational contracting perspective is associated with the general understanding that contracts are to some extent incomplete from a social, economic and organizational point of view. ${ }^{78}$ This is particularly relevant in the context of the exchange or creation of new technology, where the commitment of parties is crucial. Relationa contract theory acknowledges that the contract is an element in a joint effort of parties that is not of a short-term nature but that focuses on the further development of the relationship where flexibility and adjustment can reduce the incentives for opportunistic behavior. In addition, the allocation of property rights can act as credible commitments that create investment incentives and stimulate mutual forbearance.

Although, most of my findings are largely in line with my expectations (see also Table 1) there are also a number of interesting surprises. Minor surprises refer to licensing contracts that do not contain extensive warranties and the clear division of property rights in the non-equity partnership contracts even though these partnerships do not entail a de facto common ownership structure. More substantial surprises were found in the contracts for equity joint ventures and non-equity partnerships that also include elaborate appendices with project plans, explicit task and responsibility description, and association agreements. In my opinion, this stresses the relational perspective of equity joint ventures but in particular of non-equity partnerships even further as such a package of various appendices places the actual collaboration and the inter-relationship of the partners in the realm of the contract itself. I also found that the time perspective for the joint ventures was set at a far distance as the contracts do not allow parties to withdraw before a particular anniversary of the venture (in practice ten years). This stresses how much companies can place their long-term relationship at the centre of the agreement. ${ }^{79}$

Also, by their nature, equity joint ventures and non-equity partnerships require flexibility in contractual provisions. Many obligations involve necessarily ambiguous commitments or agreements regarding the future direction of the relationship. In other words, I expected a number of revision clauses: however, this was not the case. Explicit revision clauses were not incorporated in the agreements; revision was merely integrated in other clauses such as force majeure, hardship and severability.

In the non-equity partnerships patent disputes were excluded from arbitration and made subject to litigation. This was not expected as non-equity partnerships are associated with 'softer' dispute resolution mechanisms such as arbitration and mediation.

${ }^{78}$ Lorenz 1999, Macaulay 1963, Macneil 1978, Williamson 1996.

${ }^{79}$ Eisenberg 2000a, Speidel 2000. 
However, this option might be preferred as many countries recognize special patent judges and a court's decision is open to appeal. In addition, the profits associated with a patent might outweigh the substantial costs associated with litigation. Furthermore, as some legal counsel have asserted, in such disputes valuable information may be gained from the other party due to the discovery procedure.

Finally, in the licensing contracts, the prevailing party is entitled to reasonable attorney's fees in case of a dispute or litigation. This does not comply with classical perspective that each party should bear his or her own costs. However, this type of cost allocation, when the losing party has to pay the expenses of the prevailing party, might be a way to refrain parties from initiating a procedure too easily.

Obviously, my research is only a small step on the long road leading to a more detailed understanding of, what Ronald Coase described as, the actual process of contracting between companies. The current contribution focuses on a limited number of modes of governance and their contractual setting found in a small number of sample contracts. However, my study is, to the best of my knowledge, also one of the first attempts to combine such a differentiated perspective on contract law with an indepth and detailed analysis of different forms of inter-firm partnering considering their contractual clauses.

There are some obvious suggestions for further research, which follow more or less directly from the limitations that were indicated in the above. My study clearly invites further study of legal and managerial implications of inter-firm technology partnerships based on larger samples of companies and contracts. Another suggestion is to study other forms of contracting, in particular inter-firm partnerships where technology is not of primary importance (e.g. marketing partnerships, customer-supplie relationships, outsourcing, co-production contracts). In addition to this, the analysis of a range of partnerships in other industries, with different regimes of intellectual property rights protection, can also improve our detailed understanding of the nature of inter-firm contracting. Future research would also benefit from a more in-depth understanding of the specific context in which the contracting and negotiation process takes place and the outcomes of these activities (the actual contracts), or when and how the parties to any of these contracts consider using any of the alternative partnerships as a means of governing their relationship. In this light, further research might analyze the effect of the applicable legal regime on contract design or choice of type of partnership. Finally, it would be interesting to investigate further whether either common law or civil law jurisdictions are predominantly classically or relationally oriented. 
CHAPTER 3

AN INSTITUTIONAL AND INTERNATIONAL COMPARISON OF THE COMPLEXITY OF CONTRACTS: A THEORETICAL FRAMEWORK 


\section{INTRODUCTION}

A commonly cited anecdote told by Louvain Professor of Law G. van Hecke in 1962 is the following:

'In one instance that is known to me an American company was to acquire a one-third interest in a European company (...) The lawyers of the American company had drafted two separate contracts with a total length approaching 10,000 words. This was the first experience of the European party with American lawyers and when he was presented with the drafts he nearly renounced the deal. Thereupon the American businessman asked his European counterpart to have a counterdraft prepared by a local counsel. The result was a document of 1400 words. It was found by the American party to include all the substance that was really needed, and it was readily executed by both parties and adequately performed. ${ }^{1}$

This anecdote was used by Van Hecke to indicate that American contracts are generally much more detailed than their European counterparts. In 1987, more than a decade later, American law professor J. Langbein noted that '[a]mong businessmen and lawyers familiar with commercial practice in complex transactions on both sides of the Atlantic, it is a common observation that a contract drafted in the United States is typically vastly more detailed than a contract originating in Germany or elsewhere on the Continent ${ }^{2}{ }^{2}$ Despite the fact that business lawyers on both sides of the Atlantic continue(d) to be confronted with a difference in contractual style, the latter did not appear to receive much further thought from legal scholars.

Recently the difference in contractual style has received renewed attention by legal scholars and practitioners. They contemplate that American and - to a lesser extent English business contracts differ substantially from their Continental European counterparts. ${ }^{3}$ Hill and King (2004) write that 'German business contracts are much shorter than their American counterparts'. ${ }^{4}$ Likewise, Conway (2005) states that 'Continental lawyers feel comfortable with short concise documents setting out the basics of the parties' deal'. ${ }^{5}$ Tjittes (2005) indicates that contracts subject to English law are very extensive and that thick contracts are common under an Anglo-American jurisdiction. ${ }^{6}$

\footnotetext{
Van Hecke 1962, see amongst others Langbein 1987 and Hill and King 2004.

Langbein 1987, p. 381

${ }^{3}$ Conway 2005, Lundmark 2001, Tjittes 2005.

Hill and King 2004, p. 889.

${ }^{5}$ Conway 2005, p. 119.

${ }^{6}$ See Tjittes 2005, p. 3: "[d]at naar Engels recht de nadruk bij de uitleg op de bewoordingen van een contract liggen, heeft bovendien tot gevolg dat contracten naar Engels recht zeer omvangrijk zijn' and Tjittes and Hartllef 2005, p. 1605-1623: '[d]e vaagheid van de vaderlandse uitlegnorm staat in schril contrast tot het Engelse recht, waarin vooral de tekst voorop staat en de bedoeling van partjen die darrvan afwilkt (...) nie relevant is. Dat scheelt een hoop geprocedeer (...) en dwingt partijen voortaan zorgvuldiger te letten op de
} 
Collins (1996) writes that he is 'not aware of any systematic study of this question of the length or complexity of written contracts, [but that] there is a wealth of anecdotal evidence to support Langbein's observation."

In addition, the issue of contract design has recently received attention in the business economic literature. Not aimed at country-level analyses, this literature has shown that different factors such as trust and reputation, information asymmetries and asset specificity affect the design of the contract in the sense that the contract may become more 'prolix', 'lengthy', 'complete', 'complex' or to the contrary, 'less explicit' or 'simple'.

Why is it important to address this difference in contractual style and how may it contribute to comparative contract law studies?

Most comparative contract law studies focus on the differences between legal systems in general and on the set of rules these systems provide in particular. These studies, for example, signal differences in contract formation and validity, and compare the different remedies for breach of contract. Contract law rules should, however, not be assessed in isolation; it is precisely in their application and the context within which they operate that the rules accrue meaning and become effective. I therefore consider it important to shift the attention from the study of conceptual systems to the contracting practice, while this may provide valuable insights into (comparative) contract law.

First of all, the study of contractual practice may have implications for the debate on the proper content of and role for contract law. It may demonstrate the extent to which parties opt out of the contract law provided for by the state, i.e. the default rules. More specifically, the detail and length of American contracts may signal a greater need for parties to contract around the default rules than their Continental European counterparts, whose contracts are regarded as 'short concise documents'. This 'opting-out' may point towards the sub-optimality of such rules. Such findings could enrich the debate on the role for contract law in the sense that either less rules or contract law rules tailored specifically to the needs of corporate parties are preferable. ${ }^{9}$ On the contrary, the lack of detail in Continental European contracts might also

formulering van hun contracten. Dit heeft dikke contracten tot gevolg, zoals in de Anglo-Amerikaans rechtssfeer gebruikelijk is.' Likewise Hartkamp and Tillema 2005, p. 50: ' $[\mathrm{g}]$ ]enerally speaking, the Dutch style of drafting of contracts more or less fits into the civillaw fhan the elaborate Werican contracts may fill complete books, Dutch contracts are often restricted to a few dozen (rather short) articles,'

${ }^{7}$ Collins 1996.

${ }^{8}$ Conway 2005, p. 119

'For the 'less law' argument see for example Schwartz and Scott 2003, Hill and King 2004. For the theory of a differentiated contract law, see amongst others Tjittes 1994, Smits 1998, Wightman 1996. 
indicate that Continental European parties are not wary to rely extensively on default rules.

Secondly, the analysis of commercial contracts may be able to signal to the courts information concerning the contractual goals of the parties, the negotiation process, and the characteristics of the parties. ${ }^{10}$ This information in turn may help courts decide in which manner they should interpret contracts: courts may choose to abide by either a strict and literal, or a liberal and active interpretation. ${ }^{11}$

In the third place, the study of contracts may serve as a normative implication directed at lawyers: more detail is not always good. ${ }^{12}$ Take the example of a contract which is relatively detailed due to the fact that each party is wary of the other and as a result attempts to incorporate as many terms ${ }^{13}$ as possible. Instead of promoting a sound contractual relationship, such a contract may signal distrust at an early stage.

Finally, the difference in contractual style may highlight the role that branches of the legal system such as procedural law may play.

The foregoing implications have led several authors to exchange the classical approach to contract law studies for a more practical one. ${ }^{14}$ I hope to contribute to this growing amount of literature through a critical examination of the difference in style of contracts in England, the Netherlands and the United States. This chapter will relate primarily to commercial agreements or commercial contracts, while the difference in contractual style is particularly eminent in these types of contracts. The question which I seek to answer is: What factors may explain the difference in contractual style between civil and common law jurisdictions? With the invocation of the business literature 1 hope to be able to provide the reader with a multidisciplinary perspective.

In the next section of this chapter, I will provide the reader with an overview of the terms which are used to qualify contractual style. Economic and legal scholars for example, have used the term 'incomplete contracting' and more recently 'complexity' and 'simplicity' in order to address the specific style of a contract. While it is now generally assumed that most real-world contracts are incomplete ${ }^{15}$, the current discussion focuses on whether these incomplete contracts are either complex or simple. I will

${ }^{10}$ Eggleston et al. 2000.

${ }^{11}$ A strict or literal interpretation refers to the situation where a court adheres to the contract law rules in a relatively mechanical way. Liberal or active interpretation refers to the case where the court also considers the context of the agreement and the partles' contractual goals (Schwartz 1992).

${ }^{12}$ Eggleston et al. 2000, p. 126.

${ }^{13}$ The words 'term', 'contractclause' and 'provision' will be used interchangeably in this chapter (in Dutch: 'contractsbedlngen' of 'contractsclausules').

${ }^{14}$ Supran. 113

${ }^{15}$ Craswell 2000, Williamson 1996, Hart and Moore 1998. 
therefore use the latter terms to qualify and explain the difference in contractual style across jurisdictions. The qualification of a contract along a continuum of increasing complexity is able to provide a point of departure for an inquiry into the factors which may give rise to complexity conversely simplicity. These factors, which predominantly emanate from the business economic literature on contracting practices, will be reviewed in more detail in this chapter. I will illustrate that these factors cannot be assessed in isolation, but must be placed within their legal and socio-cultural environment. The focus of this chapter will be predominantly on the effect of the legal environment. After a brief inquiry into the effect of the socio-cultural environment, a conclusion will be drawn.

\section{COMPLETENESS AND INCOMPLETENESS, COMPLEXITY AND SIMPLICITY OF CONTRACTS}

Scholars use the concepts of completeness and incompleteness and complexity and simplicity to refer to the style of a contract. While the foregoing concepts are related, they have been used interchangeably and interpreted differently dependent on the discipline - legal or economic - in which they are employed. This creates confusion with respect to the exact meaning of these terms, and I therefore find it important to define both of these groups of terms in this chapter. As most contracts are currently understood to be incomplete I will, in the following paragraphs, first provide a definition of incomplete and complete contracts before turning to the complexity and simplicity of contracts and their relationship to the former.

\section{The completeness and incompleteness of contracts}

The concept of an 'incomplete contract' has been defined by both legal and economic scholars, which has given rise to slightly different interpretations depending upon the particular context - legal or economic - in which it is applied. ${ }^{16}$ Over the past few years, the literature on incomplete contracting appears to have brought legal and economic scholars closer together and presently both groups of scholars seem to refer to a similar and more universal definition of an incomplete contract. In the following paragraphs, I will first provide an overview of these divergent descriptions and thereafter, I will present the current and more generally accepted definition.

Legal definition

Legal scholars use the term 'obligationally incomplete' to refer to an incomplete contract. An obligationally incomplete contract refers to a contract which fails to address a particular term of the exchange. ${ }^{17}$ Conversely, a contract is termed obligationally complete when it fully specifies (1) the obligations of parties for 2) all future states of the

\footnotetext{
${ }^{16}$ Tirole 1999, Ayres and Gertner 1992, Hadfleld 1994

${ }^{17}$ Ayres and Gertner 1992, p. 730. See also Goetz and Scott 1985, Scott and Triantis 2006, Katz 2004
} 
world. Whatever happens, the contract will stipulate how parties should act. A state of the world refers to an event that may or may not occur, and is also referred to as a contingency. ${ }^{18}$ Scott and Triantis (2005) further indicate that a 'state of the world' may refer to both endogenous and exogenous variables: the market price of oil would be an example of an exogenous variable, whilst the decision of a seller to sell or not is characterized as an endogenous variable. Ayres and Gertner (1992) provide the following example of what they define as an obligationally complete contract:

'A Seller promises to provide 100 gallons of $10 \mathrm{~W} 40$ oil to [specific address] before noon on the first day of each month for the next 10 years. Buyer agrees to pay Seller $\$ 1000$ in cash at the time of delivery. If Buyer or Seller breaches this contract for any month, the breaching party will owe the non-breaching party $\$ 1000$, and all other contractual obligations will be rescinded. ${ }^{19}$

This contract, according to Ayres and Gertner (1992), states the obligations of parties for all future states of the world, i.e. all possible contract terms are included. I cannot however, derive from their example that the obligations of the parties are specified under all future states of the world: what if an unforeseen event such as a war makes the delivery of oil temporarily impossible, should the buyer be allowed to claim $\$ 1000$ and rescind all other contractual obligations? Likewise, assuming that delivery has occurred on time for the past eight years, should the fact that the delivery of the oil is delayed by half a day due to an event beyond the control of the Seller, give the Buyer the right to claim $\$ 1000$ and terminate the contract? The example merely stipulates parties' mutual obligations in case of (1) performance and (2) breach. The reasoning that Ayres and Gertner (1992) follow in order to conclude that this contract is obligationally complete might become easier to comprehend, when I take into consideration that the authors understand a contractual promise to be a promise to either (1) perform or (2) pay damages; damages being the primary remedy for breach under common law. This leads me to conclude that - according to the authors - it is not relevant whether a contract distinguishes between different causes of breach, such as an un foreseen event, e.g. a war or strike, or some kind of damage to the object, e.g. the oil is of inferior quality, as long as the contract describes the parties' rights and obligations in case of breach and performance.

Hadfield (1994) refers to an incomplete contract as a contract that 'fails to specify the components of an exchange in some states of the world. ${ }^{20}$ Likewise, Katz (2004) refers to the situation in which 'a contract is incomplete, silent, or ambiguous with regard to a particular term of the exchange., ${ }^{21}$ In this light, Katz (2004) poses the question

${ }^{18}$ In this chapter I will use the terms 'contingency' and 'state of the world' interchangeably.

${ }^{19}$ Ayres and Gertner 1992, p. 731, n. 10.

${ }^{20}$ Hadfield 1994, p. 160

${ }^{21}$ Katz 2004, p. 502 
whether the court should fill the 'gap' in a sales contract which fails to specify the price, or whether the court should decline to enforce the contract entirely? ? $^{22}$

Finally, Goetz and Scott (1985) indicate that '[t]his 'incompleteness error' typically occurs when the parties inadvertently overlook a potentially important, but low probability contingency, ${ }^{23}$ In this light, they argue that the key purpose of the standard or default rules of contract law is to save parties the trouble of formulating a complete set of express conditions for specific events. More specifically, Goetz and Scott (1985) stipulate that 'courts will complete the instructions with a pre-formulated legal norm whenever the contingency in question was reasonably foreseeable. ${ }^{24}$ The authors refer to an example given by Holmes (1897): a lecturer had agreed to speak without mentioning the time and as a consequence both parties construed the promise in a different manner. Disagreement arose concerning the specific time at which the lecturer should appear. ${ }^{25}$ Holmes resolved this apparent incompleteness by stipulating that the lecturer should appear in reasonable time. ${ }^{26}$ it should be noted that legal scholars find almost every contract to be somewhat incomplete, either because of the constraints parties face in practice or because parties intentionally omit to contract on certain matters. The causes of incompleteness will be more elaborately discussed in the next paragraphs.

In light of the above, I understand a contract to be obligationally incomplete when the contract fails to specify the obligations of parties under a certain state of the world, i.e. fails to incorporate a specific term of the exchange. A contract then contains a 'gap' and courts will have to decide whether they will fill this gap or declare the contract void and unenforceable for matter of vagueness. ${ }^{27}$

Economic definition

The term incomplete contracting originally emanates from the economic literature. In order to be able to understand the economic definition of an incomplete contract, it is important to have some knowledge of economic theory.

A concept frequently used in economic theory as a basic unit of analysis is the market: a place in which sellers and buyers trade quantities of goods and services for a certain

${ }^{22}$ Katz 2004, p. 502, n. 20

${ }^{23}$ Goetz and Scott 1985, p. 270

${ }^{24}$ lbid., p. 270.

${ }^{25}$ Ibid., n. 17, Holmes 1897.

${ }^{26}$ One might argue that whilst the gap is filled - the contract now refers to a time period - the term 'reasonable' is actually a vague term which might still lead to interpretation difficulties: what exactly is understood

to be within 'reasonable time'?
${ }^{27}$ The literature on when and how courts should fill such gaps is extensive and lies beyond the scope of this ${ }^{27}$ The literature on when and how courts should fill such gaps is extensive and lies beyond the scope of this
chapter (see amongst others Schwartz 1992, Schwartz and Scott 2003, Hadfield 1994, Ayres and Gertner 1992, Ayres and Gertner 1989). 
price. Early micro-economic theory takes as point of departure that these markets are free and perfectly competitive, which means that the market satisfies the following conditions: (1) there are many buyers and sellers; (2) these buyers and sellers offer functionally identical goods, i.e. homogeneous goods; (3) the buyers and sellers face low entry and exit barriers; and (4) the buyers and sellers have perfect information, which is fully shared. According to economists, under these conditions, the market works perfectly, i.e. the market will reach equilibrium where a certain quantity of goods is offered against a specific price. ${ }^{28}$ In this market equilibrium, the goods produced are those most highly valued by consumers - this is referred to as an allocative efficiency - and the production of these goods is carried out at minimum cost - this is termed a productive efficiency or cost efficiency. The allocative efficiency is also known as Pareto efficiency. A situation is Pareto or allocatively efficient if it is impossible to make at least one person better off without making another person worse off. In practice, it is almost impossible to make a change without making at least one person worse off. Presently, economists often refer to the Kaldor-Hicks efficiency rather than the Pareto efficiency. Under the Kaldor-Hicks criterion, an outcome is efficient if those that are made better off, i.e. 'the winners' gain enough such that they can in theory compensate those that are made worse off, i.e. 'the losers'. The Kaldor-Hicks criterion does not require compensation to actually be paid, but merely requires that the winners can hypothetically compensate the losers. Under the Kaldor-Hicks criterion for example, a contractual clause is efficient if the savings it creates for sellers are such that the sellers could hypothetically compensate the harmed buyers and still retain some of the savings for themselves.

Under the competitive equilibrium, allocative efficiency implies that consumer and producer surplus are maximized. Consumer surplus refers to the benefits that the consumers receive from the market exchange of a good: the value of the good to the consumer (also referred to as the willingness to pay) minus the price of the good (payment to the seller). Producer surplus refers to the benefit the seller attains from participating in the market: the price paid to the seller minus the cost of production. The maximization of consumer and producer surplus implies that all the potential gains from trade are exploited. Consumer and producer surplus may be used to indicate a certain degree of welfare. For reasons of simplicity, I will assume that the maximization of consumer and producer surplus constitutes total welfare maximization.

Now that I have defined some basic concepts underlying economic theory, I will return to the economic definition of an incomplete contract. Economic scholars use the term 'contingently incomplete' or 'insufficiently state contingent' to refer to an incomplete

${ }^{28}$ In this equilibrium, the price of the goods offered is actually equal to their marginal cost of production The marginal cost of production is equal to the change in total cost when the quantity produced changes by one unit. 
contract. ${ }^{29}$ A contingently incomplete contract fails to efficiently allocate obligations across all states of the world, and thus fails to fully realize the potential gains from trade in each state. ${ }^{30}$ As Ayres and Gertner (1992) indicate, from an economic perspective, even if a contract specifies all future contingencies and is obligationally complete, a contract may be contingently incomplete if it fails to realize the potential gains from trade due to the fact that the contractual obligations are contingent on too many or incorrect contingencies. A contingently incomplete contract indicates that the contractual terms which have been incorporated in the contract are not the best terms, in the sense that they are not optimal from an economic point of view.

Let us take a look again at the example given by Ayres and Gertner (1992) of the contract relating to an oil delivery:

'a Seller promises to provide 100 gallons of $10 \mathrm{~W} 40$ oil to [specific address] before noon on the first day of each month for the next 10 years. Buyer agrees to pay Seller $\$ 1000$ in cash at the time of delivery. If Buyer or Seller breaches this contract for any month, the breaching party will owe the non-breaching party $\$ 1000$, and all other contractual obligations will be rescinded. ${ }^{, 31}$

Ayres and Gertner (1992) termed this contract obligationally complete, whilst it specified the price, date and place of delivery and the amount of damages to be paid upon breach. The same contract may however, not be termed contingently complete whilst the oil price is fixed at $\$ 1000$. The price of $\$ 1000$ will apply regardless of any change in circumstances or conduct by either party and the price of oil is thus not made dependent upon a state of the world, for example a change in demand for oil. I will illustrate this with an example. ${ }^{32}$

Assume that parties face a simple environment and merely two states of the world concerning the demand of oil can materialize: high demand and low demand. When demand for oil is high, the seller expects to sell the oil for $\$ 1100$. In contrast, when demand on the market for oil is low, the seller expects to sell the oil for $\$ 900$. The chance of the high demand state occurring is 0.9 and of the low demand state 0.1 . The profitability of the contract may be calculated as follows:

\begin{tabular}{lll}
\hline Profit in high demand state & Profit in low demand state & Total profit \\
\hline$(\$ 1100-\$ 1000)^{*} 0.9=\left(\$ 100^{*} 0.9\right)=\$ 90$ & $(\$ 900-\$ 1000)^{*} 0.1=\left(-\$ 100^{*} 0.1\right)=-\$ 10$ & $\$ 80$
\end{tabular}

${ }^{29}$ Eggleston et al. 2000 , p. 100 , term these contracts 'optimally state-contingent' or 'perfectly complete'.

${ }^{30}$ Ayres and Gertner 1992, Eggleston et al. 2000, Grossman and Hart 1986, Hart and Moore 1990, Hart and Moore 1998, Williamson 1985, Maskin and Tirole 1999.

${ }^{31}$ Supra n. 129.

${ }^{32}$ Similar examples are given by Schwartz 1998. 
With proceedings of $\$ 80$, the contract is indeed profitable. However, if the low demand state were to materialize, the seller would actually make a loss of $\$ 10$. A contingently complete contract would specify a different price for the low demand state and for the high demand state, in order for the seller to exploit all possible gains from trade. The aforementioned contract, however, does not distinguish between the two future states: it states a fixed price of $\$ 1000$. Contingently incomplete contracts then, give parties an incentive to, upon occurrence of a particular event or state of the world, renegotiate or breach the original contract in order to realize the additional gains. ${ }^{33}$ As the market demand for oil decreases, the seller will have an incentive to renegotiate the contract, in order to hedge against the subsequent fluctuation in his cost of performance.

A contingently complete contract is a contract in which all the contract terms have been formulated in an optimal manner, in the sense that they allow the contracting parties to reap all possible profits.

General definition

In the foregoing paragraphs I have illustrated that legal and economic scholars have attached slightly different meanings to the term incomplete contract. In this chapter, I will take on a definition which is increasingly accepted by both legal and economic scholars. In order to define this incomplete contract it is necessary to first specify the elements of - the generally accepted definition of - a complete contract.

A contract is complete when it allocates the rights and obligations of parties efficiently across all possible future contingencies. ${ }^{34}$ The foregoing definition seems similar to the economic definition, but actually consists of two elements. ${ }^{35}$ The first element refers to the fact that the contract contains terms regarding all possible future contingencies or states of the world. The second element refers to the fact that the contract allocates the rights and obligations of parties efficiently across these contingencies or states of the world, i.e. the contract is thus able to fully realize all potential gains from trade. A contract is considered incomplete if at least one of the foregoing elements is violated: (1) the contract does not specify parties' rights and obligations for all future contingencies or 2) the contract does not exploit all gains from trade. This definition actually incorporates both the former economic and legal definition of an incomplete contract: legal scholars tend to relate the incompleteness of a contract primarily with the first element, while economic scholars relate the incompleteness of a contract with the second element. ${ }^{36}$

${ }^{33}$ Ayres and Gertner 1992, p. 730.

${ }^{34}$ Eggleston et al. 2000, p. 100, Ayres and Gertner 1992, p. 730, Schwartz 1998, p. 277-278, Blard 1990

${ }^{35}$ Van Bijnen 2005.

${ }^{36}$ Van Bijnen 2005, p. 87-88 
In general almost all contracts are incomplete. ${ }^{37}$ Economic scholars ascribe this apparent incompleteness of contracts to the fact that perfect markets - the concept upon which they base complete contracts - actually do not exist: the markets 'fail'. This failure to create maximum efficiency in the market is ascribed to factors such as irrationality, information asymmetries and transaction costs; factors which subsequently undermine the ability of parties to construe contingently complete contracts. ${ }^{38}$ Similar factors, such as transaction costs and information asymmetries, have been used by legal scholars to explain why most contracts are obligationally incomplete. ${ }^{39}$ Thus, both economic and legal scholars have used comparable arguments to explain the incompleteness of contracts, even though the background of these arguments differs. In the following section, I will discuss three of these arguments in greater detail.

Transaction and enforcement costs

The incompleteness of contracts may be explained by transaction and enforcement costs. ${ }^{40}$ When parties engage in an economic exchange they incur costs. These costs may include:

(a) the costs of gathering and processing information, for example in search for the right contracting partner;

(b) the costs related with negotiating, specifying and drafting an agreement. These costs may relate to extensive negotiations and the need to consult a lawyer;

(c) the costs parties incur in order to ensure that each of them adheres to the agreement and fulfils his or her promise, e.g. hiring a manager who controls employees; and

(d) the costs related to the enforcement of the contract by a third party, e.g. court or arbitrator, including the uncertainty and error costs associated with such an enforcement. ${ }^{41}$

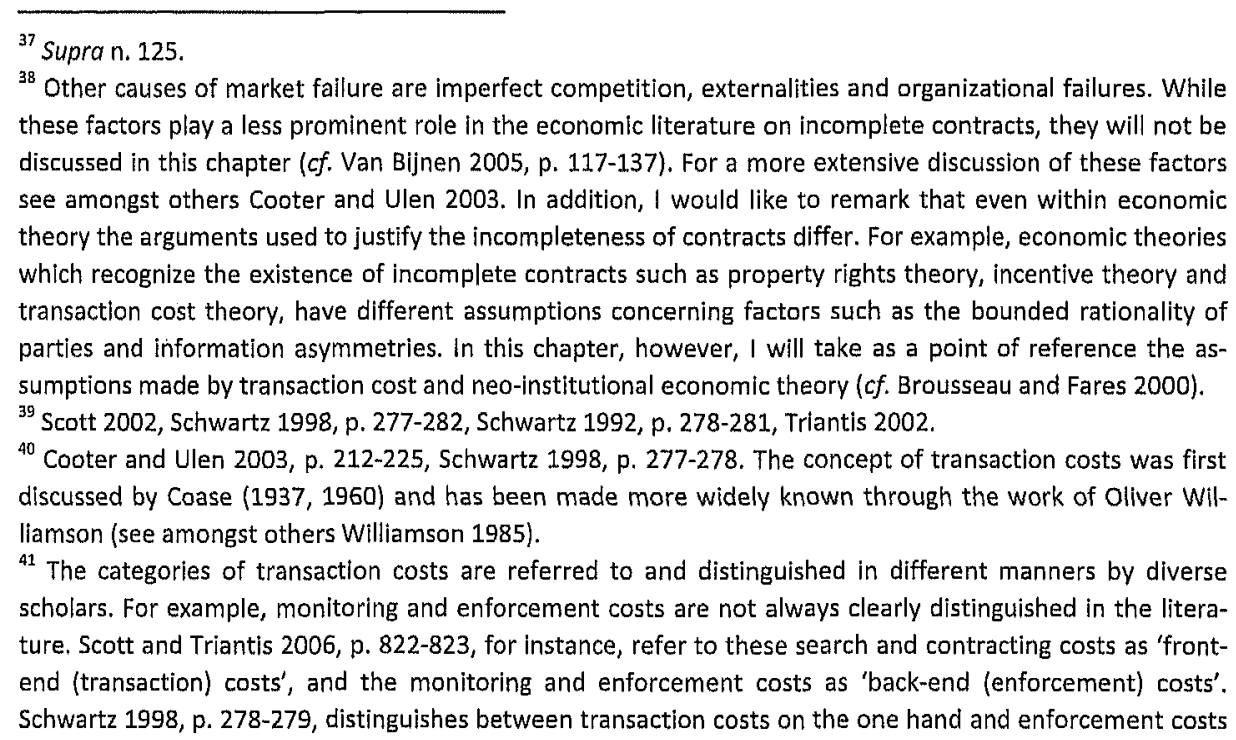


Following Scott and Triantis (2006), these costs may either relate to the front-end of the contracting process and be categorized as transaction costs and - above categories (a), (b) and (c) - or to the back-end of the contracting process - above category (d) and be referred to as enforcement costs. ${ }^{42}$ According to Scott and Triantis (2006), an important distinction between the front and back end contracting processes is that they are separated by the resolution of uncertainty: ' $(.$.$) the front-end is drafting the$ contract and the back-end is litigating disputes that arise when the contract turns out to be a losing proposition for one party ${ }^{43}$ Parties will continue to invest in contracting costs, which implies formulating precise terms and increasing the completeness of the contract, until the marginal cost of investment outweighs the accompanying marginal benefit. This also means that parties may draft a more complete contract in an attempt to reduce the level of expected back-end enforcement costs. Conversely if parties agree to a less complete contract, they accept a higher level of expected back-end enforcement costs in return for lower front-end transaction costs.

Bounded rationality

The bounded rationality of individuals may also increase the incompleteness of contracts. Rational choice or expected utility theory assumes that individual decisionmakers can compute (subjective) probability estimates of uncertain future events; that they perceive accurately the dollar cost or outcome of the uncertain outcomes; that they know their own attitudes toward risk; that they combine this information about probabilities, monetary values of outcomes, and attitudes toward risk to calculate the expected utilities of alternative courses of action and choose that action that maximizes their expected utility. ${ }^{44}$ In practice, however, actors are 'intendedly rational, but only limitedly $50 .{ }^{45}$ Individuals do not possess unlimited computational abilities which would allow them to comprehensively search for and process all available information in an optimal manner. This is especially evident when the uncertainty about the future is great and the number and nature of events to be considered infinitely large. ${ }^{46}$ As a result, parties will fail to incorporate certain relevant terms, creating gaps, and to construe contract terms which are optimal ex ante, i.e. at the time the contract is being

on the other hand. Dyer 1997, p. 538, distinguishes between (1) search costs; (2) contracting costs; (3) monitoring costs; and (4) enforcement costs. Cf. Williamson 1985, Ayres and Gertner 1989, p. 92-93: 'These transaction costs may include legal fees, negotiation costs, drafting and printing costs, the costs of researchtransaction costs may Include legal fees, negotiation costs, drafting and printing costs, the costs of research-
ing the effects and probability of a contingency, and the costs to the parties and the courts of verifylng whether a contingency occurred'.

${ }^{42}$ Scott and Triantis 2006, p. 822-825

${ }^{43}$ Scott and Triantis 2006, p. 823

${ }^{14}$ Ulen 1989, p. 386 cited in Eisenberg 1995, p. 213. While this notion of rational choice theory is most commonly applied in microeconomic theory, other conceptions of this theory exist. Cf. Korobkin and Ulen 2000.

${ }^{15}$ Simon 1955, p. 99-118, p. xxiv cited by Williamson 1996, p. 198.

${ }^{46}$ Korobkin and Ulen 2000, p. 1077-1078, refer to a game of chess where a plaver will have $10^{120}$ possible moves (assuming 30 possible moves each turn and 40 total turns per game). In such a situation an individual is forced to make a substantive satisfactory choice, which is not the maximizing choice. 
concluded. ${ }^{47}$ Some authors argue that bounded rationality alone does not suffice to explain the incompleteness of contracts while there is no worked-out theory of bounded rationality from which predictions about actual behavior can be made. ${ }^{48}$

Bounded rationality not only affects contracting parties, but also the third party enforcer, whose predictability and reliability may be impeded.

Information asymmetries

In the third place, individuals are confronted with information asymmetry; they do not have access to the same information. ${ }^{49}$ Under the condition of asymmetrical information, one of the parties involved in the transaction has relevant information which the other party does not possess. This information asymmetry gives rise to adverse selection and moral hazard. The concept of adverse selection refers to the situation where an actor cannot observe, or imperfectly observes, certain characteristics of another actor or product. Infamous is the example given by Akerlof (1970): buyers of second hand cars generally possess much less information on the quality of the car than the sellers. Due to this asymmetry in information, buyers of second hand cars do not know whether they are purchasing a 'lemon' (a car in bad condition) or a 'cherry' (a car in good condition). As a consequence, buyers of second hand cars are willing to pay a price that lies in between the price for a lemon and a cherry. The average value of goods in a market characterized by information asymmetries will thus tend to decrease, even for high or standard quality goods, while buyers will avoid the risk of paying too much for a low-quality product. ${ }^{50}$ In the contracting process, information asymmetries may lead to incomplete contracts while one of the parties may possess certain information which it is not willing to disclose, in order to retain a strategic advantage or to transact at a lower price. ${ }^{51}$ I will discuss this in more detail in the section on the factors relating to the complexity of contracts.

The concept of moral hazard refers to the situation where one party $(A)$ is imperfectly informed on or cannot observe the action taken by another party $(B){ }^{52}$ Party $A$ only observes the outcome, an imperfect signal of the action taken by Party $B$. Consider the relationship between a franchisor and a franchisee. The franchisee must manage the franchise in the best possible way. A McDonald franchisee will have to use its best efforts to sell as much hamburgers as possible. If the franchisor would be able to di-

${ }^{47}$ Anderlini and Felli 2004.

${ }^{18}$ Schwarz 1998, p. 278.

${ }^{49}$ Arrow 1971, Akerlof 1970, Williamson 1985, Schwartz 1998, p. 277-278.

${ }^{40}$ Akrow 1971, Akerlof 1970,

${ }^{51}$ Ayres and Gertner 1989, p. 99-100, Van Bijnen 2005, p. 123-125.

${ }^{52}$ Williamson $(1985,1996)$ in this sense refers to opportunism. More specifically, Williamson assumes that contracting agents exhibit opportunism, meaning that they act in their self-interest with an allowance for guile (Williamson 1996, p. 43-48). I will use the terms 'opportunistic behaviour' and 'moral hazard' interchangeably in this chapter. 
rectly observe the level of effort the franchisee exerts, it could make payment dependent on the level of effort. However, while the level of effort is not observable, the franchisor must make payment dependent on production or another observable variable which will induce the franchisee not to shirk.

Related to the foregoing is the fact that third parties are also confronted with limited rationality and imperfect information. This implies that while some variables might be perfectly well observable by the parties to a contract, these variables are difficult to measure and specify in such a manner that they can be proven to the satisfaction of a third party, the court. The variables are non-verifiable. ${ }^{53}$ The distinction between observability and verifiability is illustrated by Hart (1995):

'The quality of [my] book is observable, in the sense that anybody can read it. (...) However, it would have been difficult for Oxford University Press and me to have written a contract making my royalties a function of quality, since if a dispute arose it would be hard for either of us to prove that the book did or did not meet some prespecified standard. (For this reason my royalties are made to depend on some (more or less) verifiable consequences of quality, e.g. sales.) In other words, quality is not verifiable. ${ }^{54}$

Therefore, even if transactors know which performance they desire and can personally observe whether this performance has occurred, the written contract is incomplete because performance needs to be specified in terms of an easily measurable and imperfect proxy that can be readily observed by courts. Verifiability is often associated with the cost of communicating relevant information, e.g. establishing the truth, to the court. Scott and Triantis (2005) term as non-verifiable a factor for 'which the information cost at trial outweighs the incentive benefit of the related contractual provision..$^{55}$ Both economic and legal scholars postulate that parties will avoid contracting on unverifiable factors. ${ }^{56}$ While third parties such as courts or arbitrators are also confronted with imperfect information, the performance of contracts is not guaranteed by external institutional mechanisms.

I discussed separately three factors which may give rise to incomplete contracts. I believe that these factors are interrelated. Bounded rationality and information asymmetries may raise transaction and enforcement costs. The bounded rationality of parties to the contract more raises the costs parties incur in order to search and proc-

${ }^{53}$ Schwartz 1992, Triantis 2002, p. 1068-1069, Williamson 1985, Bernheim and Whinston 1998, Maskin 2002 ${ }^{54}$ Hart 1995, p. 37-38, n. 15 cited in Triantis 2002, p. 1069.

${ }^{55}$ Scott and Triantis 2006, p. 4.

${ }_{56}^{5}$ Segal 1999, Schwartz 1992, p. 304. On the other hand, Scott and Triantis 2006, p. 814 and p. 835-836, and Triantis 2002, p. 1067, indicate that vague expressions such as 'reasonable efforts', are very common in commercial agreements and thus frequently adopted by parties. 
ess information. The bounded rationality and inability of third parties to observe information on the other hand, gives rise to uncertainty and thereby increases the costs of enforcement. Likewise, information asymmetries raise transaction and enforcement costs. Under conditions of imperfect information, a party will, for example, need to discover relevant product prices and search for the right contracting partner (search costs). While these costs may be reduced by the emergence of specialists who sell this information, these costs may never be completely eliminated. ${ }^{57}$

Given these costs, most, if not all, real-world contracts can never be complete, in the sense that the contract optimally allocates obligations for all future contingencies. More specifically, economists argue that these transaction costs prevent the market from functioning perfectly, restricting the design of an optimal contract. In this light, economic theory argues that whilst optimality in the sense of a first-best outcome is no longer achievable, parties will have to resort to second-best optimality: the best that can be done taking into account the constraints. ${ }^{58}$ Legal scholars argue that transaction costs induce parties to conclude incomplete contracts and expect contracting parties to complete the contract to the best extent possible. ${ }^{59}$ This implies that a party will try to exploit all verifiable distinctions between states creating what Eggleston et al. (2000) consider to be a functionally complete contract. ${ }^{60}$ In addition, parties may intentionally forego to arrange for certain matters in their contract, either because they do not find these matters important enough or because they perceive that the costs of incorporation do not outweigh the expected benefits. The foregoing observations will lead to 'gaps' in contracts, and thus add to their incompleteness.

\section{The complexity and simplicity of contracts}

In practice, most contracts are incomplete. This incompleteness generally becomes apparent only when a dispute arises between the parties, signifying that either (1) not all relevant terms have been included; or (2) one or more terms have not been optimally specified, creating problems of interpretation and motivating one party to favor breach of the contract over adherence. Ex ante, without the backdrop of a dispute, it will be difficult to discern the relative incompleteness of a contract simply by readin it, while at that time it is not possible to know which contingencies will actually materialize or which terms appear to have been sub-optimally specified ex post. ${ }^{61}$ The foregoing renders it difficult to use the concept of incompleteness to measure differences

\footnotetext{
${ }^{57}$ Coase 1937, p. 390-391. I would like to remark that even when specialists reduce the effective search costs, they will impose on the party the new costs, namely the costs of using their information service. ${ }^{58}$ Eggleston et al. 2000, p. 103-104

Triantis 2002, p. 1068-1069.

Eggleston et al. 2000, p. 100-103.

${ }_{61}^{61}$ While 1 assume actual contracts can never be complete due to constraints such as transaction and enforcement costs, bounded rationality and information asymmetries, I use the term 'relative incompleteness' to indicate the degree of incompleteness.
} 
in contractual style, especially across jurisdictions. The incompleteness of a contract is also not able to provide us with detailed information on contract structure, while it merely points to either a lack of terms or sub-optimality. I therefore believe - in accordance with several other authors ${ }^{62}$ - that an alternative, more adequate measure must be sought to analyze differences in contractual style. A concept which has been developed in the literature is 'contractual complexity'. Contractual complexity refers to a measure for the degree of complexity conversely simplicity of a contract. In the following paragraphs, I will review the most important literature on contractual complexity, where after I will present a refined measure of contractual complexity and relate the latter to the completeness and incompleteness of contracts.

Diverse scholars have attempted to define and develop measures for complexity. Macneil (1978), Joskow (1988), Poppo and Zenger (2002) and Robinson and Stuart (2007) for example, use the term complexity to relate to the level of specification or detail of the terms of a contract. ${ }^{63}$ The diverse authors, however, use different tools to measure this complexity. Joskow (1988) uses the amount of pages of the contract as a proxy for complexity. Poppo and Zenger (2002) asked firms to indicate, on a scale from 1 to 7 , to what extent a specific contract was highly customized and required considerable work ${ }^{64}$, and Robinson and Stuart (2007) refer to the size of the digital contract file in kilobytes. The foregoing studies relate the complexity of a contract to a single factor or dimension, and may thus be considered as relatively simple measures of contractual complexity.

A more advanced measure of complexity is used by Reuer and Ariño (2007) based on a study by Parkhe (1993)..$^{65}$ Through a computer-assisted search of the legal literature, Parkhe extracted a list of eight contractual terms, which may act as safeguards against opportunistic behavior: (1) periodic written reports of all relevant transactions; (2) prompt written notice of any departure from the agreement; (3) the right to examine and audit all relevant records through a firm of Certified Public Accountants (CPAs); (4) designation of certain information as proprietary and subject to confidentiality provisions of the contract; (5) non-use of proprietary information even after the contract; (6) termination of the agreement; (7) arbitration clauses; and (8) lawsuit provisions. The provisions are listed in an increasing order of strength or severity, with the first clause being the weakest and the lawsuit provisions being the most severe safeguard

\footnotetext{
${ }^{62}$ Eggleston et al. 2000, Reuer and Ariño 2007.
${ }^{63}$ Macneil 1978, Joskow 1988, Poppo and Zenger 2002, Robinson and Stuart 2007.

${ }^{64}$ Macneil 1978, Joskow 1988, Poppo and Zenger 2002, Robinson and Stuart 2007.
${ }^{64}$ addition, the authors also asked the firms to indicate the length (in pages) of the contract. However, the low response rate on this item precluded it as a second indicator (Poppo and Zenger 2002, p. 717). ${ }^{65}$ Reuer and Ariño 2007, Reuer et al. 2006 (the authors appear to use this measure of complexity in different papers).
} 
against opportunistic behavior. ${ }^{66}$ Reuer and Ariño (2007) count the number of clauses included in each contract and the degree to which they bundle together, taking into account the stringency of each provision. The complexity of contract increases with (1) the number, and (2) the type of provision, i.e. higher stringency of the term, included in the contract. ${ }^{67}$ Their measure of complexity may be qualified as a multidimensional concept as they measure both (1) the number and (2) the stringency of the provisions employed. ${ }^{68}$ While the measure of complexity as applied by Reuer and Ariño (2007) is multidimensional, their construct remains limited to the eight provisions which they chose to use as a proxy for complexity. A contract is however, not only concerned with contractual safeguards such as lawsuit provisions, arbitration clauses and auditing rights, but consists of a large number of different provisions which collectively shape the relationship between parties. Examples are definitions and recitals, performance provisions which specify the duties and obligations of parties and define the scope of the agreement, ownership provisions, representations and warranties, provisions on unforeseen circumstances, etc.

Another example of a multidimensional measure of complexity is given by Eggleston et al. (2000). ${ }^{69}$ Their measure of complexity refers to three dimensions: (1) the number of states or contingencies which have been incorporated in the contract (2) the variance in pay-offs between the states, and (3) the cognitive load necessary to understand the contract. The following table illustrates the three dimensions:

${ }^{66}$ In accordance with this stringency and statistical analysis, Reuer and Ariño (2007) label the first three provisions 'coordination provisions', and provisions four through eight 'enforcement provisions' (Reuer and Ariño 2007, p. 19).

${ }^{67}$ The model assigns the inclusion in the contract of provision (1) with a value of 1 , provision (2) with a value of 2 etc., such that if all eight provisions are included this yields a total value of $36(1+2+3+4+5+6+7+8)$. The authors then divide the total value by 36 such that the outcome variable ('complexity') can range from 0 to 1. When the variable has a value of 1 , all eight provisions are included $(1+2+3+4+5+6+7+8 / 36=1)$. In contrast, a value of 0 indicates that none of the provisions have been included. The measure for example, returns a lower value for complexity when a contract includes only provisions (5), (6) and $(8)(5+6+8 / 36=0.53)$, but this contract is still more complex than a contract which includes less stringent provisions, e.g. provisions (1), (4) contract is stil more complex than a contract which includes less stringent provisions, e.g. provisions (1), (4) and $(5)(1+4+5 / 36=0.28)$

${ }^{68} 1$ would like to note that I use the concept of 'multidimensionality' in a different manner than the authors. In their paper Reuer and Ariño (2007) consider their measure of complexity to be multidimensional while the eight provisions which are used as a proxy for complexity, relate to or load on two different factors in their statistical analysis. Subsequently the authors characterize these provisions as either 'coordination' (provisions 1-3) or 'enforcement provisions' (provisions 4-8) (Supra n. 176).

${ }^{69}$ Eggleston et al. (2000) actually argue that most contracts appear to be simple instead of complex: '[i]n practice, however, many contracts are quite simple. They divide the future into very crude partitions; they provide for constant or close to constant payments across different outcomes; and the terms are easy to understand', (Eggleston et al. 2000, p. 91). 


\begin{tabular}{lll}
\hline Dimension of complexity & Example of Simple K & Example of complex K \\
\hline $\begin{array}{l}\text { Number of contingencies } \\
\text { (or states, } G H \text { ) }\end{array}$ & 'widget for $\$ 1$ ' & $\begin{array}{l}\text { 'widget for } \$ 1 \text { if it rains, but for } \$ 2 \\
\text { if it does not rain' }\end{array}$ \\
\hline Variability in payoffs & $\begin{array}{l}\text { 'widget for } \$ 1 \text { if it rains, for } \$ 2 \text { if } \\
\text { it does not rain' }\end{array}$ & $\begin{array}{l}\text { 'widget for } \$ 1 \text { if it rains, for } \$ 10 \text { if } \\
\text { its does not rain' }\end{array}$ \\
\hline Cognitive load & 'widget for $1 / 2$ of your profits' & $\begin{array}{l}\text { 'widget for } 15 \% \text { of your profits } \\
\text { beyond a normal return' }\end{array}$ \\
\hline Eggleston et al. 2000, Table 1, p. 99. &
\end{tabular}

A contract which merely states 'widget for $\$ 1$ ' is less complex along the first dimension than a contract that differentiates between two states: (1) rain and (2) no rain. ${ }^{70}$ In addition, Eggleston et al. (2000) stress that only the expected number of states is relevant: the authors exclude pay-offs that are 'specified in the contract but are contingent on events that are not expected to occur'. ${ }^{71,72}$ According to the second dimension, the contract with a large variance in payoffs $\$ 9(\$ 10-\$ 1)$ is more complex than the contract where the variance in payoffs is $\$ 1(\$ 2-\$ 1)$. Finally, it is probably easier to understand a clause which defines the payment as 'widget for $1 / 2$ of your profits' than a clause which states 'widget for $15 \%$ of your profits beyond a normal return' ${ }^{73}$ Eggleston et al. (2000) indicate that the cognitive load is difficult to measure as it is a subjective concept and overlaps with the first two dimensions. ${ }^{74} \mathrm{I}$ agree with the authors that although it is preferable to advance cognitive load as a dimension of complexity, it is prone to create a bias: a contract which person A finds difficult to understand might be relatively simple to understand for person $B$. In addition, I find it difficult to include the variability in pay-offs, the second dimension proposed by the authors, as a measure of contractual complexity. Let me illustrate this with the earlier example of the oil contract. Under this contract, high demand for oil allows the seller to sell the oil for $\$ 1100$. In contrast, when demand for oil is low, the seller will be able to trade at a price of $\$ 900$. The variance in payoffs is $\$ 200(\$ 1100-\$ 900)$. Another contract might stipulate a price of $\$ 1500$ in case the high demand state materializes, and a similar price of $\$ 900$ in the low demand state. This second contract brings the variance in pay-offs back to $\$ 600(\$ 900-\$ 600)$. Does this make the first contract much different from the second contract? I do not believe so: the first contract merely offers a better deal.

The first dimension as proposed by Eggleston et al. (2000) seems more likely to be able to capture the complexity of contracts. This dimension does not, in contrast to the

${ }^{70}$ For the reader with a non-economic background: economists often use the term 'widget' to describe a generic 'thing' when there is no real name for it, i.e. unnamed or hypothetical articles.

${ }^{11}$ See Eggleston et al. 2000, p. 7, n. 21: '[f] or contracts $A$ and B, both with two contingencies, $B$ is more complex than $A$ if its contingencies occur with a probability of $50 \%$, whereas $A$ 's contingencies occur with probabilities of $90 \%$ and $10 \%$.'

probabilities of $90 \%$ and $10 \%$.
${ }^{72}$ Eggleston et al. 2000, p. 98 .

${ }^{73} \mathrm{Cf}$. Lafontaine 1992, who studies franchise contracts, and assimilates the complexity conversely simplicity

of a contract with nonlinear respectively linear front fees and rovalty rates.

${ }^{74}$ Eggleston et al. 2000, p. 91. 
study by Reuer and Ariño (2007), limit the type of provisions that may be included in the contract. However, Eggleston et al. (2000) do exclude any states of the world which are mentioned in the contract but are not expected to occur. This strikes me as odd. The fact that parties have included a certain pay-off relevant state in the contract indicates that they found this contingency important or relevant enough to incorporate. I will devote further attention to this dimension in the following paragraph, in which I propose an alternative measure of contractual complexity.

An alternative model of contractual complexity

As has become apparent from the foregoing paragraphs, numerous authors have attempted to define the complexity of contracts, but a common definition is still lacking. While complexity remains a subjective concept, I would like to propose an alternative definition of contractual complexity. This alternative definition will build upon existing conceptualizations, and I hope to overcome the signaled limitations of the latter. In addition, I aim to propose a measure of complexity which may be applied in empirical comparative legal research.

My measure of complexity consists of multiple dimensions, while I believe that a single dimension does not suffice. Contractual complexity may be computed as an aggregate of the following three dimensions: (1) the number and different types of terms incorporated in the contract; (2) the specificity or detail of these terms; and (3) the cognitive load necessary to understand the contract. This aggregate function measures complexity along a continuum, and contracts may be either more or less complex. The first dimension prescribes a positive relationship between the number of terms and complexity. This dimension may be measured in practice by counting the number and types of terms in a contract. This means that the degree of complexity captured along this first dimension will depend on the categorization of contract terms. What constitutes a separate contract term? I assume that every part of a contract which can be identified as relating to a sufficiently distinguishable matter of the contract in relation to the rest of the agreement constitutes a separate contract term. For example, consider the formerly mentioned contract on the sale of oil, to which I will add a few additional terms:

A Seller promises to provide 100 gallons of $10 \mathrm{~W} 40$ oil to [specific address] before noon on the first day of each month for the next 10 years. Buyer agrees to pay Seller $\$ 1000$ in cash at the time of delivery. If Buyer or Seller breaches this contract for any month, the breaching party will owe the non-breaching party $\$ 1000$, and all other contractual obligations will be rescinded. The Seller does not in any way, expressly or impliedly, give any warranties to Buyer; the Seller expressly disclaims any implied warranties of merchantability or of fitness for a particular purpose. This Agreement and the performance hereunder shall be governed by the laws of the State of New York. The parties hereto agree that all actions or proceedings arising in connection with this Agree- 
ment shall be tried and litigated exclusively in the State and Federal courts located in the State of New York of the United States of America. ${ }^{75}$

This agreement would in my opinion consist of the following clauses: (1) definition of the object of sale; (2) terms of delivery; (3) terms of payment; (4) remedies for breach; (4) warranties; (5) governing law; and (6) choice of forum/dispute resolution. All of these clauses constitute a separate contract term, while these clauses relate to different parts of the relationship between parties. A contract for example, which does not contain a governing law clause or a term identifying the remedies in case of breach, will be considered less complex. Conversely, American and English contracts, in contrast to Dutch contracts, often contain an entire agreement clause. ${ }^{76}$ The incorporation of such a clause would increase the complexity of the foregoing contract. The types of warranties specified in the above contract do not constitute separate contract terms but relate instead to the specificity of the warranty provision itself and fall within the second category of complexity, which will be discussed below.

The second dimension of complexity refers to the detail or specificity of a contractual term. Let me illustrate this with an example. I have singled out the provisions on force majeure from two contracts in my contract database:

Provision A:

'Neither Pfizer nor Gensia shall be liable for failure of or delay in performing obligations set forth in this Agreement, and neither shall be deemed in breach of its obligations, if such failure or delay is due to natural disasters or any causes reasonably beyond the control of Pfizer or Gensia.'

Provision B:

'Performance of a party's obligations hereunder (other than the payment of money or the failure by Oclassen to provide insurance pursuant to Section 12.5) may be delayed if (a) such performance is delayed by causes beyond that party's reasonable control, including, but not limited to, acts of God, war, riot, epidemics, fire, flood, insurrection, or acts of civil or military authorities, and (b) such delaying party is at all times working diligently to correct the matter causing the delay and otherwise performing as required under the Agreement. Notwithstanding the foregoing, the parties shall remain liable for all obligations incurred by them prior to any termination of this Agreement.'

Regardless of the different liability regimes (non-liability under A and liability under B), provision $B$ can be considered complex relative to provision $A$ under the second di-

${ }^{75}$ Adapted in part from Ayres and Gertner 1992, p. 731, n. 10.

${ }^{76} \mathrm{~A}$ merger or entire agreement clause stipulates that parties acknowledge the written contract to contain the complete and final agreement between the parties. The clause precludes parties to invoke any evidence which would modify or add to the agreement in writing. 
mension of complexity. Provision A refers only to non-liability if the breach of obligations is due to a natural disaster or any cause reasonably beyond the control of either party, while provision B includes a non-exclusive list of causes which may be considered beyond the party's reasonable control and specifies additional conditions which either party must fulfill to remedy such breach of obligations. Provision $B$ is thus more specific than provision $A$.

The foregoing dimensions: (1) number and different types of terms incorporated in the contract, and (2) the detail or specificity of these terms, may be compared to the first dimension of complexity as proposed by Eggleston et al. (2000): the number of contingencies incorporated in the contract. Different contingencies namely, may be either incorporated in separate provisions of a contract or included in one single provision, increasing the detail of a specific provision.

Eggleston et al. (2000) have pointed to the difficulty of including the cognitive load necessary to understand the contract as a measure for contractual complexity. would, subject to similar reservations, like to include this element as a third dimension of complexity. I recognize that in absolute terms, the cognitive load may differ across groups of individuals. For example, an individual who is trained as an attorney may read a contract and see structures and language that would require little extra effort, while another individual may need to employ a much greater effort to detect similar structures and language, assuming this individual would be able to uncover such legal implications at all. If the cognitive load were to be measured in practice, it should be done by controlling for different groups within society. Contracts are namely not only employed by attorneys or legally trained individuals, but also read and used by businessmen and consumers. For example, in testing for the cognitive load, a distinction may be made between two groups: group 1 which consists of attorneys and group 2 which consists of businessmen. Group membership is based on a member's background: in-depth legal knowledge versus no or little legal knowledge. While average between-group cognitive load may differ in absolute terms, it would be interesting to test whether within-group differences in cognitive load are similar between groups, i.e. whether similar parts of a contract necessitate a greater effort of understanding by members of each group.

Even if a contract induces a higher degree of cognitive load, it remains to be seen how this would be observable without taking into account the contracting context. This problem may, however, be partially eliminated by applying and controlling for the reasonable person standard. This standard derives from common law where it is used in the light of contract interpretation. When a dispute concerning the interpretation of a contract arises, the court may, in certain situations, interpret the contract according to the meaning that a reasonable person in the position of the parties would have attached to the matter, if the latter had given the matter thought. 'The reasonable 
man connotes a person whose notions and standards of behavior and responsibility correspond with those generally obtained among ordinary people in our society at the present time, who seldom allows his emotions to overbear his reason and whose habits are moderate and whose disposition is equable. He is not necessarily the same as the average man - a term which implies an amalgamation of counter-balancing extremes. ${ }^{77}$ Interpreting the cognitive load against the backdrop of a reasonable person, allows for incorporation of the contracting context. A court must construct the expected actions of the reasonable person based upon the information they receive from the contracting parties during trial. Controlling for the reasonable person standard in cognitive load measurements, could be achieved in practice by providing the different test groups with information on the particular contracting context.

The relationship between complexity/simplicity and completeness/incompleteness of contracts

I have defined complexity as: (1) the number and types of terms incorporated in the contract; (2) the specificity of these terms; and (3) the cognitive load necessary to understand the contract. The degree of completeness on the other hand is dependent on: (1) the terms relating to all possible future contingencies; and (2) an optimal allocation of these terms. How should we characterize the relationship between complexity conversely simplicity and completeness conversely incompleteness of contracts?

First of all, these two groups of terms relate to two distinct concepts, and refer to different aspects of a contract. ${ }^{78}$ The concept of complexity does not incorporate any reference to the optimality of a contract term: this is irrelevant. The concept of complexity seems to have more in common with the first dimension of completeness: the amount of possible future contingencies included in the contract. While completeness assesses whether all relevant terms have been included (which is very difficult to measure ex ante) complexity does not assess whether and which relevant terms have been left out, but merely how many different terms have been incorporated. A compilation of the two concepts reveals four different contract styles: (1) complex and complete; (2) complex and incomplete; (3) simple and complete; and (4) simple and incomplete. A complex and complete contract (1) will incorporate many detailed and difficult terms, which are specified in an optimal manner and refer to all relevant future contingencies. A complex and incomplete contract (2) will incorporate many detailed and difficult terms which are, however, not optimally defined and/or do not distinguish between relevant contingencies. A simple and complete contract (3) will contain few concise terms which distinguish between all relevant contingencies in an optimal manner. Finally, a simple and incomplete contract (4) contains few concise

"Black's Law Dictionary (2004) on the definition of a 'reasonable person', citing: R.F. Heuston, Salmond on the Law of Torts, 17 th edition, 1977, p. 56

${ }_{78} \mathrm{Cf}$. Eggleston et al. 2000, p. 102-103. They make a similar observation with regard to the functional comCf. Eggleston et al. 2000, p. 102-103.
pleteness and complexity of a contract. 
terms, and fails to incorporate all relevant contingencies in an optimal manner. In light of the foregoing, a contract which is complex might sooner be characterized as obligationally complete, while such a complex contract will contain a large number of detailed terms. In contrast, a relatively simple contract:

' $X$ will deliver 100 widgets [to specific address] on [specific date] at a price of $\$ 2$ per widget. The breaching party will pay the non-breaching party $\$ 200 . '$

is not per se incomplete in the general sense of the word, while it might just as well optimally specify the rights and obligations of the parties for every state of the world. ${ }^{79}$ As mentioned, - and in accordance with the general assumption present in both the legal and economic literature - I presume that contracts can never be perfectly complete, and I will thus consider the conditions which may give rise to the relative complexity of the incomplete contract.

\section{FACTORS THAT GIVE RISE TO THE COMPLEXITY AND SIMPLICITY OF CONTRACTS}

In this paragraph I will discuss the factors which may affect contractual complexity. In an attempt to define contractual complexity, scholars have addressed several factors which may influence the degree of complexity. While the complexity and completeness of contracts both denote a certain contractual style, some of the factors which are used to justify the (in)completeness of contracts, have been carried over to the inquiry of contractual complexity conversely simplicity.

Limits of cognition

A factor which may affect the complexity of the contract is bounded rationality. The bounded rationality of parties may not only lead to less complete contracts, but may also decrease the complexity of contracts. Rational and perfectly informed individuals are able to discern all feasible alternative actions open to them, the probability of their occurrence and their price or cost. As a result, these individuals are not only able to anticipate exactly which terms must be included in their contract, but they may also enforce utility maximizing behavior through these terms. In an uncertain environment with numerous feasible actions, the complexity of a contract may increase.

In practice, however, contracts embody a simplified reflection of the actual contracting environment, while individuals, limited in their rationality, will inadvertently forego to contract on all relevant events. Parties to an agreement do not possess perfect information or unlimited computational abilities instead, 'individuals are cognitive misers

${ }^{79}$ This assumption might hold in a relatively simple environment, where the states to be anticipated are few and information asymmetries are low. 
who endeavor to simplify the world through use of cognitive shortcuts. ${ }^{80}$ Limited by their information processing abilities, individuals apply heuristics to process information efficiently. These heuristics may lead to systematic bias in decision-making. One of these heuristics, overconfidence, leads individuals to systematically underestimate risks and/or ignore low-probability risks. Ninety-seven percent of consumers for example, believe that they have an average or above average ability to avoid accidents involving power mowers and bicycles. ${ }^{81}$ Likewise, individuals tend to be overly optimistic in judging the success of their relationships: while American couples correctly estimate the divorce rate at 50 percent, they estimate the chance their own relationship will end in divorce at zero. ${ }^{82}$ The representativeness heuristic on the other hand, encourages individuals to judge the likelihood of a future event by similarity of the present evidence to it. ${ }^{83}$ Applied to the drafting of contracts, overconfidence and representativeness may lead parties to forego to exonerate or limit their liability for certain events which they either estimate at low risk or judge unlikely to occur in light of the present evidence. In the same manner, parties might omit to designate certain events as unforeseen circumstances or not foresee in a change of circumstance clause at all, while they do not believe that certain events will occur or affect their relationship. Furthermore, overconfidence of the success of parties' relationship may lead parties to draft less watertight contracts, regardless of the awareness that numerous relationships end up in court. ${ }^{84}$ Parties appear to perceive the risk of a dispute and subsequent termination of their relationship unlikely. Subject to the foregoing constraints, individuals will inadvertently forego the incorporate certain contingencies, leading to less, or less specific, terms. Under these conditions, even in a relatively simple environment, parties will construe a contract which is less complex compared to the contract which would have been concluded under conditions of perfect rationality.

Boundedly rational individuals will find renegotiation and gap-filling important instruments. However, renegotiation carries costs and risks of its $\mathrm{own}^{85}$ : 'what turns out to be mutually beneficial or ex post efficient - that is, the outcome of renegotiation - is

\footnotetext{
${ }^{80}$ Eggleston et al. 2000, p. 122 in reference to S. Taylor, 'The interface of cognitive and social psychology' in: Harvey, J. (ed.) Cognition, social behovior, and the environment, NJ: Lawrence Erlbaum 1981.

${ }^{81}$ Eisenberg 1995, p. 216 in reference to W. Viscusi, W. Magat, Learning about risk: consumer and worker responses to hazard Information, Harvard University Press: Cambridge 1987, p. 95.

${ }_{82}$ Eisenberg 1995, p. 21.7 in reference to L. Baker, R. Emery, 'When every relationship is above average: perceptions and expectations of divorce at the time of marriage', Law and Human Behaviour 17(4), 1.993, p. 443.

${ }^{83}$ There are several other heuristics such as hindsight bias, anchoring and the self-serving bias, but these will not be discussed in this paragraph.

not be discussed in this paragraph.
${ }^{84}$ For example, of the 11,908 cases disposed of by trial in 75 of the largest counties in the USA in 2001, $31.1 \%$ related to cases dealing with allegations of breach of contract (Bureau of Justice Statistics Bulletin 'Civil justice survey of state courts 2001', April 2004).

${ }^{85}$ See also Ariño and Reuer 2004, who argue that complex contracts have less need for renegotiation than simple contracts, while the former contemplate a larger range of contingencles and procedures.
} 
often not optimal from the ex ante point of view [that is, the moment in time when parties initially enter into the contract, $\mathrm{GH}] .^{, 86}$

I understand limits of cognition to include the fact that parties are limited in their information search and processing techniques as well as the fact that their decisionmaking is affected by cognitive shortcuts.

I conclude that parties' limits of cognition are negatively related to the complexity contracts.

\section{Asymmetric information}

A second factor which may affect the complexity of contracts is asymmetric information, ${ }^{87}$ Previously defined as an impediment to the drafting of complete contracts, information asymmetry refers to the situation where one party (the informed party) possesses more information than the other party (the uninformed party). Information asymmetries may affect the complexity of a contract in different ways. First of all, information asymmetries allow parties to conceal information which otherwise would have been incorporated in the contract. In the second place, information asymmetries give rise to monitoring or measurement difficulties, which induce parties to draft detailed payment schemes and incorporate supplementary contractual safeguards.

Non-disclosure of information

Information asymmetries or discrepancies in private information between contracting parties, may lead to the non-disclosure of information. When a party has an informational advantage over another party, the former may decide to reveal this information to the uninformed party and incorporate the relevant term in the contract at a relatively low cost. ${ }^{88}$ However, there are several reasons why the informed party may decide precisely not to reveal this (extra) information. First of all, the informed party may want to keep the information - and thereby the advantage - secret, whilst the revelation of the information may decrease the party's bargaining position and subsequently potential profits. ${ }^{89}$ Strategic concealment of information will thus generate a contract which is relatively simple, as terms which would have been incorporated upon revelation of the information are now omitted. Furthermore, a party may not want to disclose the risks that it brings to the transaction and which the other party will thus become exposed to. A manufacturer of a particular product for example, may not disclose all the risks associated with the use of the product. Finally, the party with the informational advantage may forego to disclose particular information in order to

${ }^{86}$ Eggleston et al. 2000, p. 123-124. See also Ariño and Reuer 2004, p. 38

${ }^{87}$ Eggleston et al. 2000, p. 109-110.

${ }^{88}$ bgid.

${ }^{89}$ Eggleston et al. 2000, Van Bijnen 2005, Ayres and Gertner 1989. Concealment of information may give rise to problems of adverse selection. 
avoid exploitation by the uninformed party. This non-disclosure leads to relatively simple standard contracts instead of custom-tailored contracts. Eggleston et al. (2000) illustrate this with the following example:

'If a shipper demands a warranty from a carrier, the carrier might realize that the shipper places a high value on the shipment. If the carrier has market power, it can charge a high price. To avoid being victimised by such price discrimination, the shipper opts for the standard contract offered by the carrier, which is simpler because it does not contain a warranty. ${ }^{90}$

Concealment of information, however, becomes increasingly difficult when nondisclosure is legally sanctioned. ${ }^{91}$ Legally enforceable rules on the disclosure of information will thus have a negative effect on (strategic) concealment of information. The doctrines of duress, mistake, deceit and misrepresentation are examples of mandatory law which seek to limit non-disclosure. Likewise, liability rules drafted in light of buyer protection may hold the manufacturer liable when the latter does not warn effectively against the risks associated with the use of a product.

I assume that the non-disclosure of information negatively affects the complexity of contracts.

Monitoring difficulties

Monitoring difficulties may raise the complexity of a contract. ${ }^{92}$ Subject to the condition of asymmetric information, party $A$ is not always able to directly observe the action taken by party B. A common example is the employer-employee relationship. An employer cannot directly observe and thus monitor the behavior of the employee, which may give the employee an incentive to shirk or act in a manner which is suboptimal from the point of view of the employer: instead of a lunch-break of $1 / 2$ hour, the employee takes 2 hours off. Monitoring difficulties may thus increase the risk of opportunistic behavior. Likewise, in a commercial collaboration agreement, monitoring difficulties might encourage one of the parties to attempt to free-ride on the efforts of

${ }^{90}$ Eggleston et al, 2000, p. 109

${ }^{91}$ In addition, specialized agents and instltutions dedicated to the reduction of information asymmetries can limit the negative effects of disclosure. For example, lawyers and consultants are employed precisely to combat information asymmetries. In some industries such as consumer electronics or pharmaceutical products, commercial databases containing detailed product information may be consulted for similar reasons. See also Bessy and Brousseau 1998, p. 469.

See also Bessy and Brousseau 1998, p. 469 .
${ }_{92}$ Eggleston et al. 2000 , p. 110-112, note that monitoring difficulties may also lead to simple contracts. This is particularly the case when (1) the contract concerns the simultaneous performance of multiple tasks, e.g. a technician must repair machinery both swiftly and carefully; (2) a principal has multiple agents, or (3) an agent has multiple principals. These situations are, however, especially common in (temporary) employment and consumer contracts and do not play such a prominent role in commercial contracts. I will not discuss these situations in this chapter. 
its partner or make a lower commitment to the collaborative research project in relation to wholly-owned projects. In order to constrain such opportunism, parties may take several precautions which lead to relatively complex contracts. They may, for example, choose to construct complex contracts, in the sense that the contract foresees in complicated payment schemes which give rise to extensive payment provisions and increase the cognitive load necessary to understand the contract. ${ }^{93}$ Consider in this light the relationship between a franchisor and a franchisee. The franchisee must manage the franchise in the best possible way. A McDonald franchisee should exert its best efforts to sell as much hamburgers as possible. If the franchisor would be able to directly observe the level of effort the franchisee exerts, the former could suffice with a relatively simple payment contract based on a fixed remuneration. However, effort is often not directly observable; the amount of hamburgers sold could be a product of chance as well as effort. In such a case, the franchisor may prefer a complex over a simple payment contract. Such a complex payment contract will make the remuneration dependent on the amount of hamburgers sold and thus offer the franchisee an incentive to exert a certain level of effort. ${ }^{94}$ In addition, economists generally argue that in order to combat opportunistic behavior, parties must incorporate extra contractual safeguards. Collaborative research agreements for example, often incorporate (detailed) clauses concerning the establishment of a committee which must monitor the research efforts and progress made by the parties to the agreement. Other examples are clauses which require parties to submit a progress-report periodically, the inclusion of elaborate research plans as exhibit to the official legal document (contract), extensive provisions on termination, and confidentiality of information clauses. ${ }^{95}$ The incorporation of contract clauses which endeavor to safeguard parties against opportunism increases the number and types of terms included in the contract and thus the complexity of the contract. ${ }^{96}$

I conclude that monitoring difficulties are positively related to the complexity of contracts.

Asset specificity and strategic importance of the contract

When contracts involve the investment in specific assets - assets which are difficult to deploy elsewhere - parties become locked into their relationship and the potential value loss in case of termination increases. In other words, the asset specificity of the

${ }^{93}$ Eggleston et al. 2000, p. 105

${ }_{94} \mathrm{Cf}$. Bessy and Brousseau 1998, p. 464, who indicate that payments in licensing agreements are generally ${ }^{2} C f$. Bessy and Brousseau $1998, p .464, w h o$ in
based on royalty rates instead of a fixed fee.

${ }^{95}$ Reuer and Ariño (2007) refer to a diverse range of provisions in relation to their measure of complexity. Argyres et al. (2007) refer to a combination of provisions on task description, contingency planning and termination clauses.

${ }_{96}$ Business economics, more specifically transaction costs economics, assumes that the risk of opportunistic behaviour and the need for (additional) contractual safeguards increases not only with monitoring difficulties, but also with uncertainty of the environment and asset specificity (Williamson 1985, Klein et al. 1978). 
contract, like monitoring difficulties, increases the risk of exchange hazards or opportunism. An example of such a lock-in effect is given by Klein et al. (1978). ${ }^{97}$ General Motors ('GM') had entered into a 10-year contract with a company called Fisher Body ('Fisher') for the production and delivery of car bodies. At a certain point in time, GM became unhappy with the price it paid and demanded that Fisher move their production facilities closer to the GM assembly plant in order to enhance production efficiency. The relocation would involve considerable investments on the part of Fisher. The investment in plant and equipment would, however, have no other value except for manufacturing bodies for GM. Fisher refused to admit to the relocation, while it feared that once Fisher had made the investment, GM would reduce the price per body to a level at which Fisher could cover the costs of running the plant, but not the investment in assets, which could not be deployed elsewhere. ${ }^{98}$ Fisher thus was afraid that GM would exhibit opportunistic behavior once it had made the specific investments. In order to limit the risks of such behavior, parties who face specific investments, especially in long-term relationships, will find it beneficial to negotiate more complex contracts. ${ }^{99}$ These kinds of contracts will contain detailed terms regarding the project description, the division of ownership rights, the consequences of breach and termination and the dispute resolution processes. ${ }^{100}$

Likewise, when a contract is of great strategic importance, parties have an incentive to specify clearly the scope of the agreement and their rights and obligations, specifically with respect to the exchange of information. About half of the alliances formed today are among competitors. ${ }^{101}$ Where parties operate in similar markets or are embedded in a strategic network or rely on multiple partners, they will have an extra incentive to

\footnotetext{
${ }^{97}$ Klein et al. 1978, p. 308-310.

${ }^{98}$ In the end, the dissatisfaction with the situation led GM to acquire the remaining outstanding stock of Fisher in 1926 .

${ }^{99}$ will 1926. ownership over nonhuman assets should reside with the firm who makes the specific investments. Such ownership will also give thls firm the residual control rights over the asset. For example, if a firm is given the ownership rights of particular machinery, this firm will also be allowed to choose the maintenance policy for machine, production line speed etc. Property rights theory stipulates that such ownership rights will reduce opportunistic behavior and act as self-enforcement mechanisms. The distribution of property rights is given in ex mercer and acquisition or joint venture apreements, where shat holdines provide for he allocation of ne.g. merger and acquiltion ar joint venoce abention awnership rights. In other types of agreements, such as collaborative research, marketing, supply and distrbution agreements, partles will have to incorporate a speciffc clause which grants a party these ownership rights, increasing the complexity of the contract.

${ }^{100}$ Oyer 1997, p. 537, Poppo and Zenger 2002, p. $708-709$ and p. 720-722, Ariño et al, 2006, p. 309-310 However, Arlño et al. (2006) found the relationship between asset specificity and complexity to be nonsignificant (p. 320). In a second paper, Reuer and Ariño (2007) distinguish between enforcement and cooperative provisions, and do find a positive relationship between asset speciflclty and the number and strlnerative provisions, and do find a positive relationship between asset specificity and
gency of the provisions incorporated in the contract (Reuer and Ariño 2007, p. 327).

gency of the provisions incorporated in the contract (Reuer and Arino $2007, \mathrm{p} .327$ ).
${ }_{101}$ This proportion ranges from 25 percent in the entertainment industry to as high as 75 percent in the airline industry (CriticalEYE, June-August 2005).
} 
specify clearly how the agreement will end to guard against valuable resources falling into the hands of a competitor or third party. ${ }^{102}$

I conclude that both asset specificity and strategic importance are positively related to the complexity of contracts.

\section{Uncertainty of the environment}

A fourth factor which affects contractual complexity is environmental uncertainty Environmental uncertainty relates to the degree of change in economic conditions facing an organization. ${ }^{103}$ Such conditions may for example relate to the instability or unpredictability of markets, factors which lay beyond an organization's control and are hard to anticipate. ${ }^{104}$ Environmental uncertainty is positively related to the complexity of a contract. In general, parties enter into a contract which specifies the rights and obligations of parties, based upon a certain state of the world or status quo. However in a complex environment, parties face uncertainty with respect to the future state which will materialize. The foregoing will induce parties to incorporate all those states which they expect to materialize - subject to the constraint of bounded rationality during their contractual relationship. ${ }^{105}$ Economists argue that under a condition of increasing environmental uncertainty, the potential for opportunism will increase, and necessitates the incorporation of additional contractual safeguards. The uncertainty of the environment may then be positively related to the complexity of a contract.

\section{Trust and reputation effects}

Trust and reputation constitute the fifth factor which may lead parties to construe les complex contracts. Traditionally, the notion of trust has been difficult to define and measure. Based on a review of the literature, Rousseau et al. (1998) define trust as:

'A psychological state comprising the intention to accept vulnerability based upon positive expectations of the intentions or behavior of another., ${ }^{106}$

While some scholars regard trust as a static concept, either trust or no trust, in this article I take the view that trust exists along a continuum; trust is present in varying degrees. Even though it is the individual who is ultimately able to propagate expectations of trust, it is possible to think of inter-firm trust in economic exchange. ${ }^{107}$ This inter-firm trust refers to the ability of a party to rely on its partner not to exploit its

${ }^{102}$ Ariño et al. (2006) find support for the relationship between their measure of complexity and the strategic importance of the agreement (p. 312 and p. 321).

${ }^{103}$ Dess and Beard 1984.

${ }^{104}$ Wholey and Brittain 1989

Eggleston et al. 2000, p. 104, Stuart and Robinson 2002, p. 33-34, Mayer and Argyres 2004. Poppo and Zenger 2002, p. 709 , refer explicitly to the technological uncertainty of the environment

${ }^{108}$ Rousseau et al. 1998, p. 395

${ }^{107}$ Gulatl 1995, p. 92 
vulnerabilities. ${ }^{108}$ Trust involves placing reliance on the knowledge of the character of the other party, and from this knowledge a party can establish that the other will not act opportunistically. Trust thus counteracts the fear of opportunism and influences confidence in partner cooperation. For example, low degrees of trust will engender an increased fear of opportunistic behavior and therefore effectuate lengthy and difficult negotiations over unforeseen contingencies. The contract will augment in complexity due to parties' attempt to put in place contractual and structural safeguards to protect their relational investments. In contrast, under conditions of high trust, firms are less inclined to rely on these safeguards for specifying, monitoring, and enforcing their contract. High(er) levels of trust will therefore lead less complex contracts in the form of eased negotiations. ${ }^{109}$

Trust may be endorsed by prior encounters and social networks of strong ties. Social networks raise the awareness of firms' existence and serve as referral networks. In general, social networks and prior ties allow firms to learn about each other and develop trust around norms of equity ('knowledge-based trust'). ${ }^{110}$ Trust generated through prior ties and knowledge of the other party will allow parties to establish routines to coordinate their relationship. The more positive information a party possesses concerning cooperation with a specific partner, the less will this party tend to invest in contractual safeguards. ${ }^{111}$ This trust is engendered in part because the parties know that if one of them breaches the agreement, this will have negative effects on the reputation of the non-performing firm. ${ }^{112}$ The extent to which trust may affect the complexity of the contract is thus partly dependent on credible sanctions of deterrent behavior, such as negative reputation effects. Robinson and Stuart (2004) argue that firms with stronger reputations write less detailed contracts while firm reputation and contractual control act as substitutes. ${ }^{113}$ Reputation effects, however, are dependent on communication mechanisms and geographical dispersion. Social networks and more formal mechanisms such as trade associations are necessary in order to communicate and disperse information regarding an actor's reputation and consequently

${ }^{108}$ Gulati 1998. See also Ring and Van de Ven 1992.

${ }^{109}$ Zaheer et al. 1998.

${ }^{110}$ Gulati 1995, p. 105. Ryall and Sampson, 2003, p. 31-33, do not find significant effects for the relationship between prior alliances and the detail of the agreement but do find that the number of concurrent alliances between partles negatively influences the detail of the alliance agreement.

111 Dyer 1997, p. 549, Gulati 1995, p. 85-112, Collins 1999. See otherwise Argyres et al. 2007, p. 5-6, who hypothesize that as the relationship between parties evolves over time, the level of detail in the contracts willincreas, while the leming effect stronger then the thet effect. Popo anc tenger 2002 , p. 719 , find that increases in the level of relational governance (defined as a composite measure of open communication and sharing of information, trust, dependence and cooperation) are associated with greater levels of contractual complexity and vice versa.

${ }^{12}$ Stuart and Robinson 2002, p. 4, Gulati 1995, p. 93.

${ }^{113}$ Supra n. 223. 
sanction deterrent behavior. ${ }^{114}$ The existence of these types of informal and formal enforcement mechanisms is inherent the structure of society and depends on cultural contexts. Collins (1996) indicates for example, that in London the chartering of vessels by shipbrokers is conducted through informal rather than formal agreements: "the "fix" is arranged by phone and the ship sails, only to be followed by the later paperwork usually in the form of standard charter parties'. ${ }^{115}$ Another example of a high trust society are the diamond merchants in the Jewish community in New York City, where firms are embedded within a social network of strong ties which motivates good behavior; deterrent behavior has severe consequences. ${ }^{116}$

Eggleston et al. (2000) furthermore add that the simplicity of a contract may engender and reflect trust. Similarly Macaulay (1963) observed: '[n]ot only are contracts and contract law not needed in many situations, their use may have, or may be thought to have, undesirable consequences (...) detailed negotiated contracts can get in the way of creating good exchange relationships between business units. ${ }^{117}$ Poppo and Zenger (2002) on the other hand, argue that well-specified, complex contracts actually promote more cooperative, long-term trusting exchange relationships. Such contracts narrow the demand and severity of risk to which an exchange is exposed and thereby encourage cooperation and trust. They argue that the drafting of complex contracts positively effects future exchange through the development of social relations. ${ }^{118}$

I conclude that the interaction between trust and reputation is negatively related to the complexity of contracts.

Contracting costs

A sixth factor which influences contractual complexity and may give rise to relatively simple contracts, are contracting costs. I stated that contracting costs are part of the overall transaction costs parties incur when they engage in market transactions. I re-

${ }^{114}$ Collins 1999, p. 5-6 refers to comparative studies of similar market transactions in the German, Italian and UK which reveal that an important contribution to formation of trust is provided by trade associations, quality assurance organisations and industry standards for quality and safety of products (in reference to $C$ Lane, R. Bachmann, 'The social construction of trust: supplier relations in Britain and Germany', Organization Studies 17, 1996, p. 365, C. Lane, 'The social regulation of interfirm relations in Britain and Germany: market rules, legal norms, and technical standards', Cambridge Journal of Economics, 21, 1997, p. 214, A. Arrighetti, rules, legal norms, and technical standards', Cambridge Journal of Economics, 21, 1997, p. 214, A. Arrighetti,
R. Bachmann, S. Deakin, 'Contract law, social norms and inter-firm cooperation', Cambridge Journal of Economics 21, 1997, p. 182)

${ }^{115}$ Collins 1996, p. 5 .

${ }^{116}$ Bernstein 1992 .

${ }^{117}$ Macaulay 1963, p. 64. See also Reuer et al. 2006, p. 310-311.

${ }^{118}$ Poppo and Zenger 2002, p. 719, actually find that increases in relational governance are associated with greater levels of contractual complexity (in the sense of greater specification of promises, obligations and dispute resolution mechanisms) and that increases in contractual complexity are related to increases in relational governance. Likewise, Arreghetti et al. (1997) contend that loosely structured interpersonal understandings will increase the risk of litigation and hence signal distrust. 
ferred to amongst others the search costs - the costs incurred gathering and processing information, and contracting costs - the costs related with negotiating, specifying and drafting an agreement. In light of the complexity of contracts, I will not make such an explicit distinction but incorporate the search costs under the heading of contracting costs. Contracting costs then refer to all the costs parties incur in the process that leads to the establishment of the actual written contract. These contracting costs include, but are not limited to, searching for information, conducting negotiations and drafting terms. Contracting costs are invoked by scholars in order to explain the incompleteness of contracts. Parties will draft an incomplete contract when the contracting costs necessary to draft a complete contract, outweigh the associated benefits of the latter contract. Economists add to this argument by stipulating that whenever the contracting costs outweigh the benefits, parties will prefer to remove the transaction from the market, and vertically integrate, by way of a merger or acquisition. ${ }^{119}$

Contracting costs, as defined above, may prevent parties from including many different types of terms, or terms which are very detailed in their contract, thereby affecting the relative complexity of the contract. In line with the argumentation used in the incomplete contracting literature, I stipulate that parties will not find it worthwhile to negotiate complex contracts when the contracting costs parties incur, outweigh the associated benefits. A method to measure the contracting costs of, and the benefits associated with, the incorporation of additional or more detailed terms is, however, lacking. This is not wholly incomprehensible as certain costs are not always apparent. How do we observe and measure for example the costs associated with the parties' search for information? In addition, these costs are dependent on the type of contract the characteristics of the parties and the contracting environment. Every sector, country and type of contract would actually warrant a specialized function or formula for measurement.

I conclude that contracting costs are negatively related to the complexity of contracts.

Enforcement costs

Enforcement costs are a final factor, which may affect the relative complexity of contracts. Like contracting costs, these costs are part of the more general category of transaction costs. 1 defined enforcement costs as the costs associated with ex post bargaining and the sanctioning of non-performance of a contracting partner through a third party. These enforcement costs do not primarily refer to the administrative costs payable into court, but more in particular to the costs of communicating information to the court and the uncertainty and error costs of enforcement. In general, various scholars recognize that courts will not always enforce contracts accurately, especially where it concerns long-term agreements or relational contracts, while courts, like

${ }^{119}$ Williamson 1985. 
individuals, face imperfect information and rationality constraints. ${ }^{120}$ These factors raise the costs of communicating information to court and decrease judicial reliability. In light of the foregoing, parties will forego to condition their rights and obligations on information which is difficult to verify. For example, a contract between an author of a book and his publishing house is unlikely to include a term which makes royalties dependent on the quality of the book, while quality is not verifiable: the claimant for example, will have to incur costs in order to prove that a certain quality standard was or was not met, while the chance that the court will find in favour of the claimant is uncertain. As a result, parties prefer to contract on a more or less verifiable consequence of quality, such as sales. Likewise, several authors argue that parties will avoid or reduce the use of vague terms such as 'best efforts' and 'commercial reasonableness'. ${ }^{121}$

Eggleston et al. (2000) argue that enforcement costs will push toward simple contracts. More specifically, parties will prefer to use simple terms which judges have no difficulty to understand or draft broader terms that apply to several contingencies or events at the same time: '(...) suppose seller and buyer agree that seller should replace the goods if they break down after reasonable use by the buyer (state $X$ ) but not if the buyer's use is unreasonable (state $Y$ ). The parties know that they will be able to tell whether the buyer's use was reasonable or not, but have no confidence that a court will be able to do so. So they agree to a simpler contract that either contains a warranty for all states or no warranty at all. ${ }^{122}$ On the other hand, enforcement costs may just as well give rise to contractual complexity: instead of the decision to incorporate a very broad warranty or no warranty at all, parties may draft a very specific warranty, in the sense that the clause specifically provides what is understood under 'reasonable use' or under which particular conditions a party can rely on the warranty. I am inclined to believe that, in general, enforcement costs are more likely to give rise to complex than simple contracts. This choice is also justified by the following arguments.

First of all, the fact that courts are boundedly rational and employ heuristics can raise judicial uncertainty. Even though institutions such as courts recognize the bias caused by such decision-making rules and adapt to these cognitive illusions of judgment, for example by allocating the burden of production and formulating ex ante norms of compliance, total elimination of the bias caused by heuristics is not possible. ${ }^{123}$ When a dispute concerning a contract is brought before court, there are different ways in

\section{${ }^{120}$ Posner 2000.}

${ }^{121}$ Eggleston et al. 2000, p. 119-121, supra n. 163

${ }^{122}$ Eggleston et al. 2000, p. 120

123 Indition, the same incentives to adapt. Courts lack adequate pressure to improve quality of decision-making and rarely encounter feedback; few cases reach appeal, parties rather opt for settlement. As such, courts both ignore and adapt to illusions. 
which a court may attempt to resolve the dispute. A court may seek to identify the norms, such as fairness, that govern the relationship and enforce the contract according to those norms. ${ }^{124}$ Limited cognition, however, will not always allow courts to discern these particular norms or may cause misinterpretation of the agreement in light of these norms. Other authors argue that a court should enforce contracts in a manner that maximizes the value of the relationship. For example, if a party fails to deliver a widget, the affected party should be awarded an amount in damages in reference to the current market price for a similar widget. The court, however, can only attempt to maximize the value of the relationship ex post. This maximization is often not consistent with the actual intention of parties: ex ante maximization. In addition, in thei attempt to maximize contract value, courts are often oblivious to the structure of the actual relationship between parties.

Schwartz $(1992,1998)$ on the other hand, advocates a passive or literal enforcement of the agreement. ${ }^{125}$ Consider the contract for the oil delivery. As pointed out earlier, this contract does not anticipate for a change in circumstances. Schwartz argues that even if an event radically changes the scope of the agreement, the court should go ahead and enforce the contract anyway while parties knew that certain events would have a negative effect on the relationship. This view foregoes to incorporate the fact that parties are subject to information and cognitive constraints. More importantly, how ever, the hindsight bias can induce courts to consider some things as evident while they were not, as Baruch Fischoff (1.982) states:

In hindsight, people consistently exaggerate what could have been anticipated in foresight. They not only tend to view what has happened as having been inevitable but also to view it as having appeared "relatively inevitable" before it happened. People believe that others should have been able to anticipate events much better than was actually the case. They even misremember their own predictions so as to exaggerate in hindsight what they knew in foresight (...).126

In addition, the representative heuristic can lead judges to misinterpret evidence in contract proceedings. The representative heuristic refers to the fact that in determining whether an event belongs to a particular category, courts will underestimate background statistics and classify the event to a category based on general features: 'if a bird looks like a duck, quacks like a duck, and walks like a duck, it's a duck'. ${ }^{127}$ But what about geese? Overconfidence finally can lead judges to believe that they are less prone to make mistakes and underestimate the probability of errors in judgment.

${ }^{24}$ Macneil 1978, p. 854-905.

${ }^{125}$ Schwartz 1992, Schwartz 1998, p. 277-278.

${ }^{126}$ Fischoff 1982, p. 335.

${ }^{22}$ Rachlinski 2000, p. 85 
As a response to the foregoing biases in judicial decision-making, parties will try to specify their rights and obligations as precisely as possible, drafting complex contracts in order to preclude a dispute from happening or necessitate the inference of a court in the first place. A complex contract serves to guide parties' collaborative behavior precisely because parties forget what they agreed upon and parties tend to testify consistent with a self-serving reality they have created in their minds about the events leading to litigation. ${ }^{128}$ In addition, parties will draft their contract in such a manner as to decrease the uncertainty involved in litigation when the dispute does come before a court. The more specific or complex parties draft their contract, the less room to maneuver they leave for the court to misinterpret the agreement.

I conclude that enforcement costs are positively related to the complexity of contracts.

Figure 1 Overview of factors affecting contractual complexity

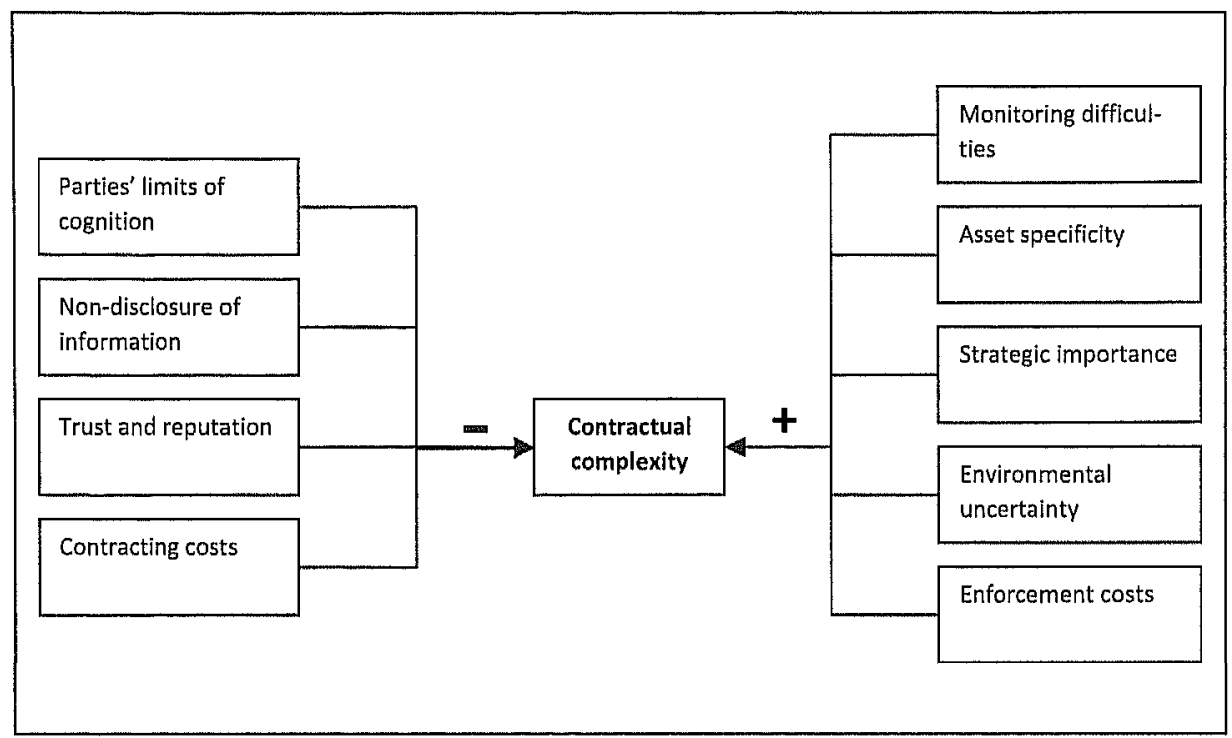

\section{THE RELATIONSHIP BETWEEN THE DIFFERENT FACTORS}

In the foregoing paragraphs, I reviewed nine factors and their effect on contractual complexity. In practice, an interaction takes place between these factors. The degree of complexity is a function of the aggregate effect of the factors. Factors may reinforce or offset each other. Some examples may serve to illustrate this.

${ }^{128}$ Solan 2000 
First of all, factors which have opposing correlations with contractual complexity may mitigate each other's effect. Information asymmetries for example, give rise to monitoring difficulties, which increase the risk of opportunism. Subsequently, parties may commit to incorporate additional safeguards in their contract, in the sense of extra or more detailed terms. This raises the complexity of the contract, which in turn may lead to a rise in contracting costs. While this increased complexity may offer benefits in the sense that opportunistic behavior is deterred, the costs of drafting a complex contract will add to the total expenditure of the deal. It seems reasonable that as long as the associated benefits outweigh the additional costs, parties will increase the complexity of the contract through the inclusion of extra or more detailed terms. A similar reasoning holds for the relationship between contracting and enforcement costs. Enforcement costs are positively related to contractual complexity. Parties may combat the expected level of enforcement costs through the construction of a relatively complex contract. Parties will favor the higher degree of complexity, as long as the associated costs do not outweigh the benefits. The foregoing examples illustrate that any increase in complexity in principle implies a rise in contracting costs, however slight this rise in costs may be. Underlying each factor is thus a cost-benefit analysis: contracting parties will weigh the contracting costs of increased complexity against the potential benefits.

In addition, monitoring difficulties and non-disclosures are both caused by information asymmetries. While these factors are positively and negatively related to contractual complexity, their independent effects may offset each other. In the second place, factors can reinforce each other's impact on contractual complexity. Levels of trust, for example, may influence contract negotiations and thereby the level of contracting costs: negotiations are less costly under conditions of high inter-organizational trust because parties are able to come to terms much faster. Trust reduces the complexity of a contract, but also has a negative effect on the contracting costs and thereby reinforces the total effect of these factors on contractual complexity.

\section{USING FACTORS TO EXPLAIN NATIONAL DIFFERENCES}

I have examined nine factors which may affect the relative complexity of a contract. However, without placing them in context, these factors may explain complexity in general, but not the difference across countries. Authors point out that the latter differences in contractual complexity are predominantly found in three parts of the contract: (1) boilerplates ${ }^{129}$; (2) provisions for contingencies in performance; and (3) detailed definitions of terms. ${ }^{130}$ Boilerplate clauses refer to the standard provisions, often preceded by the heading 'General provisions' or 'Miscellaneous ${ }^{131}$ Boilerplate clauses

${ }^{129}$ Tjittes and Hartlief 2005, p. 1607.

${ }^{130}$ Lundmark 2001, p. 122-123. Cf. Langbein 1987, p. 384-385, Hill and King 2004, p. 893-897.

${ }^{131}$ McKendrick 2003. 
are a recitation of black-letter rules and are often copied into different contracts within the same company, across firms, the legal profession and even states, and must be distinguished from the set of standard terms which a business incorporates in all of its contracts. ${ }^{132}$ Some examples of boilerplates are: notice, force majeure, entire agreement, and severability. The provisions for contingencies in performance refer to the regulation of parties' performance obligations. ${ }^{133}$ Examples are the provisions mentioned by Reuer and Ariño (2007) on the periodic written reports of relevant transactions and the examination of records. Performance obligations also include the planning of meetings, hiring of staff and research obligations. Finally, the definition of terms refers to the list of definitions at the beginning of a contract. Other contractual provisions, such as the description of the subject matter of the contract, may also reflect differences in contractual style.

In order to explain the fact that contracts in England and the US comprise a greater level of complexity than similar types of contracts in the Netherlands and Continental Europe in general, the level of the factors - dependent on their positive or negative relation with regard to complexity - must differ between the countries. In addition, the cost-benefit analysis underlying each factor implies that parties contracting in countries characterized by relatively complex contracts, must encounter lower contracting costs or experience greater benefits at similar cost levels.

The main similarity between the US and England, and concurrently their major difference with the Netherlands, seems to be that the US and England are both common law jurisdictions while the Netherlands is a civil law jurisdiction. I believe therefore, that the jurisdiction, and more generally the legal environment, may be identified as the primary influence on the level of the factors and thereby indirectly the degree of contractual complexity. ${ }^{134}$ In short, the legal environment encompasses the historical background and development of the legal system, the mode of thought, and the manner in which the legal order is organized and the law is established and enforced. I will examine the distinguishing characteristics of the relevant legal environments in greater detail in Section 6. In addition, the US, England and the Netherlands are each set apart by their own unique culture, economy and social and political structures and processes. The foregoing elements constitute the socio-cultural environment. The sociocultural environment may also impact upon the level of the factors and thereby contractual complexity. Trust and reputation effects are for example dependent on the extent to which institutional frameworks and social networks constitute credible trust

\footnotetext{
${ }^{132}$ In Dutch these standard terms are referred to as 'algemene voorwaarden'

${ }^{133}$ Przerackl 1989, p. 173 and n. 151, Lundmark 2001, p. 121 and p. 127. the concept of 'legal culture' which can be understood in different ways.
} 
enforcing mechanisms. ${ }^{135}$ In this chapter the focus will be on the legal environment, but I will pay some attention to the socio-cultural environment as well.

An analysis of the factors within their legal and socio-cultural environment makes it clear that the parties' limits of cognition, monitoring difficulties, asset specificity, and strategic importance, remain largely unaffected by variations in the legal and sociocultural environment. Parties' limits of cognition may vary across individuals, but on average every individual is affected by this constraint, regardless of the particular legal or socio-cultural environment. A similar reasoning holds for the level of monitoring difficulties, caused by information asymmetries. Ceteris paribus, all individuals are faced with information asymmetries and thus monitoring difficulties. While the precise degree of monitoring difficulties may vary with each transaction, this variation can be ascribed primarily to the characteristics of the transaction or the parties. Likewise, the asset specificity and strategic importance of a transaction remain largely unaffected by disparities in the legal or socio-cultural environment. Parties contracting to collaborate in the high-tech industry may each contribute specific intellectual property rights to the relationship, increasing asset specificity, and thereby the complexity of the contract. In contrast, parties who conclude a contract for the sale of 100 barrels of oil face very low asset specificity and therefore may abide by a simpler contract structure. Finally, the strategic importance of a transaction is judged by the party who enters into the transaction. In principle, the legal and socio-cultural environments do not directly influence this subjective judgment. The aforementioned factors will not receive any specific attention in the sections which deal with the legal and socio-cultural environments.

In the following paragraphs I will furthermore assume that contractual complexity relates predominantly to three elements of the contract: boilerplates, performance contingencies, and extensive definitions. $I$ also assume that every written contract in principle contemplates the risk of a lawsuit in the event of breach of contract. Therefore, parties will pay attention to the drafting of the contract, while the written document will provide security in event of a dispute. ${ }^{136}$

${ }^{135}$ See for example Hill and King 2004, p. 915, who establish that '[t]rade associations are far more important in Germany than they are in the United States',

${ }^{136} \mathrm{Cf}$. the study by Arreghettl et al. 1997, p. 186: '[n]umerous respondents saw contract formality as an aspect part of doing business.' 
Figure 2 Overview of factors affecting contractual complexity and the legal and social-cultural environment

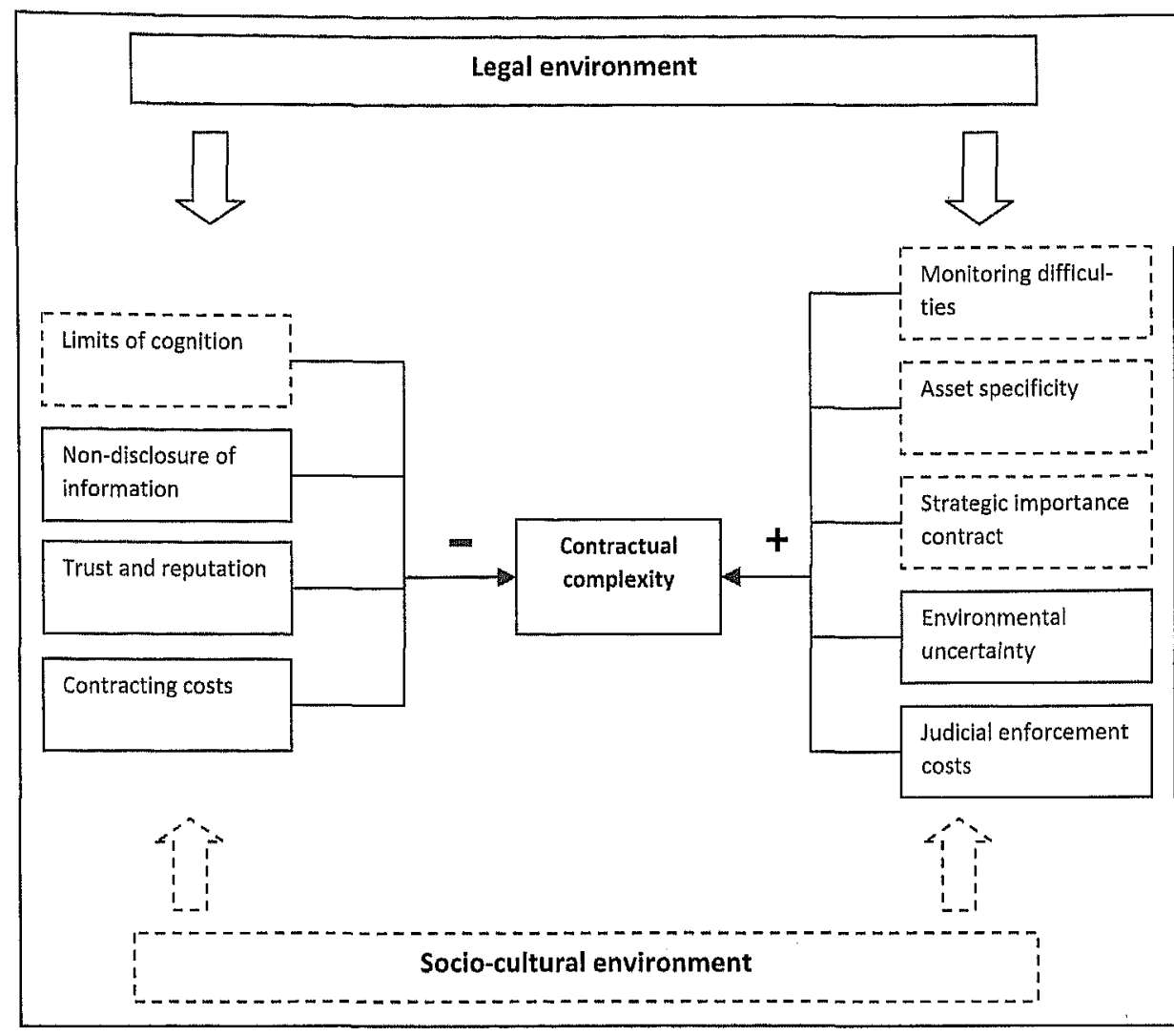

\section{THE LEGAL ENVIRONMENT}

There are numerous aspects of the legal environment which I would be able to address in this chapter. While this chapter seeks to explain differences in contractual complexity between countries, the focus of this paragraph will be on those elements which are commonly recognized as the distinguishing characteristics of the legal environments of the three countries under scrutiny. In the first place, these legal systems may be classified as based either on a general codification of the law or on case law. It is this distinction which lies at the root of the categorization of a legal system as either common or civil. In the second place, the US and England give a different reading to rules on contract interpretation and good faith in comparison to the Netherlands. Rules on contract interpretation and good faith play a prominent role in defining the scope of the relationship and the rights and obligations of the parties once a dispute is brought before court. In the next paragraphs, I will offer a comparison of the rules on contract interpretation and the application of good faith. Finally, I will briefly review some other 
distinguishing aspects of the respective legal environments, which have been addressed in the literature: default rules relating to non-performance and liability for non-performance, and rules of civil procedure.

\section{The divide between civil and common law}

A distinction in the legal environment may be sought in the classification of the former as either a civil or common law jurisdiction. Civil law jurisdictions are based on a code, while common law jurisdictions are based primarily on judicial decisions and remain largely uncodified. ${ }^{137}$ Most Western European countries may be characterized as civil law systems. Dutch private law for example, is predominantly found in the Dutch Civil Code (Burgerlijk Wetboek 1992) ('DCC'), supplemented by detailed authoritative commentaries. The DCC offers a single body of law and supplies contracting parties with a set of well-defined standardized rules. ${ }^{138}$ The DCC is divided into seven different sections or books. Book 3,6 and 7 contain provisions related to the law of contracts. Book 3 concerns the law of obligations in general, Book 6 contains rules on (bilateral) contracts, and Book 7 incorporates rules for specific types of contracts. The DCC comprises both default and mandatory law. Default law refers to rules which can be modified by agreement. Rules of mandatory law on the other hand, apply to a contract and will be enforced regardless of the intention of the parties; an attempt to modify these rules by contract has no effect.

In contrast to the Netherlands, England and the US may be categorized as common law jurisdictions. In general, rules and principles are not based on statute, but derive from court decisions which reflect the gradual development of the law. In constructing rules of law, a common law judge will start with an assessment of the facts of the case at hand and test his solution against the background of similar cases before rendering his final judgment. A judge is obliged to take note of previous decisions and follow them whenever this seems proper on the facts of the case. ${ }^{139}$ This is referred to as the binding force of precedent or stare decisis. Every court is bound by all decisions handed down by courts superior in hierarchy. When a precedent has been set by a court lower

${ }^{137}$ See also Van Hecke 1962. Cf. Hill and King 2004, p. 912-915. Differently Langbein 1987, p. 384: 'I do not mean to deny the bearing that the gulf between case-law and code-law legal cultures may have on the contrast between American- and Continental-style contracting (...) But comparative law long ago recognized how much case law was being generated in the code systems (...) Accordingly, it seems unrealistic to attribute a practical difference as fundamental as the discrepancy between American- and Continental-style contracting to that tired contrast between code and case law.'

${ }^{138}$ In addition, each proposal of law which is sent to the Parliament for approval, including any revision of the DCC, is accompanied by a 'Memorie van Toelichting' or detailed commentary which serves as an important reference guide once the proposal of law has been enacted as statute. Finally, the Council of State, a special advisory board for the government, advises on proposed bills and regulations.

${ }_{139}$ 'A judicial precedent...ls then considered as furnishing the rule for the determination of a subsequent case involving identical or similar material facts [emphasis added, GGH] ( ... ).' (Allegheny General Hospital v. NLRB, 608 F.2d 965, 969-970 (3 ${ }^{\text {rd }} \mathrm{Cir}$. 1979), as quoted in United States Internal Revenue Serv. V. Osborne (In re Osborne), 76 F.3d 306, 96-1 US Tax Cas. (CCH) paragraph. 50, 185 (9 $9^{\text {th }} \mathrm{Clr}$. 1996). 
in hierarchy, the judge is not obliged to follow the rule, but cannot overrule without due consideration. In the US and England, the most important cases and judgments by the highest courts are compiled in readily accessible Law Reports.

The claim that the distinction between common and civil law jurisdictions is primarily based on the existence or not of a general codification must not be made to swiftly. The French Code civil became effective only in 1804, while the Bürgliches Gesetzbuch was not generally enacted until 1900 . In addition, Greece only adopted a civil code after WWII. Surely this does not imply that these countries could not be characterized as civil law jurisdictions before 1804,1900 or WWII respectively ${ }^{140}$ On the other hand, countries categorized as common law systems are not unfamiliar with the codification process: California appears to have quite a few codes, while all US states have adopted some version of the Uniform Commercial Code ('UCC') and England has enforced a Sales of Goods Act 1979 ('SGA 1979') ${ }^{141}$ and a Supply of Goods and Services Act 1982 ('SGSA 1982') 142. Furthermore: ' $t$ ] he usual distinction to be made between the two systems is that the common law system tends to be case centered and hence judge centered, allowing scope for a discretionary, ad hoc, pragmatic approach to the particular problems that appear before the courts, whereas the civil law system tends to be a codified body of general abstract principles which control the exercise of judicial discretion. In reality, both these views are extremes, with the former over-emphasizing the extent to which the common law judge can impose his discretion and the latter under-estimating the extent to which continental judges have the power to exercise judicial discretion. ${ }^{143}$ The assertion that the distinction between civil and common law jurisdictions lies in the (modern) codifications of the law, must be viewed in the proper light. ${ }^{144}$ To this account, three remarks must be made.

First of all, civil law systems may be categorized as composing a family of legal systems where 'parts or the whole of Justinian's Corpus juris civilis have been in the past or are at present treated as the law of the land or, at the very least, are of direct and highly persuasive force; or else it derives from any such system..$^{145}$ At the base of the legal orders which we presently regard as civil law jurisdictions, lies the codifica-

\footnotetext{
${ }^{140}$ Watson 1981, p. 3.

${ }^{141}$ As amended by the Sale and Supply of Goods Act 1994 and the Sale of Goods (Amendment) Act 1995.

142 Other statute law applicable to contracts is the Unfair Contract Terms Act 1977 and the Unfair Terms in Consumer Contracts Regulation 1999.

${ }^{143}$ Watson 1981, p. 2

${ }^{144}$ Cf. Von Mehren and Gordley 1977, p. 3: '[t]he legal systems of the western world are, for purposes of comparisons, frequently divided into two groups: the civil law system, seen in French and German law, and the common law system developed in England. Two points of difference are usually emphasized in comparing the civil and the common laws. First, in the civil law, large areas of private law are codified. Codification is not typical for the common law. Second, the civil law was far less profound and in no way pervasive. These points of difference should not be allowed to obscure the extent to which civil and the common law share points of difference should not be allowed to obscure the extent to which clvil and the common law share a
common tradition. Both systems were developments within Western European culture; they hold many values in common. Both are products of western civilization.

${ }^{145}$ Watson 1981, p. 4
} 
tion of Roman law, and Roman law rules, which have continually developed during the centuries to serve the needs of successive generations and societies. ${ }^{146}$ Despite the acknowledgement that Roman law has played an important role in the development of modern civil law systems, the fact that Roman law has had a profound influence on the structure of these legal systems as a whole, on the conceptualization of rules of private law in particular, as well as on the manner in which lawyers approach the law, has consistently been underestimated. ${ }^{147}$ And while it may be argued that elements of the English common law, such as the law of easements and the contract of sale, were at various times affected by Roman law rules and doctrines, it is not possible to claim that the Corpus juris civilis was ever there treated as binding or as directly persuasive. ${ }^{148}$ Although the successful codification in some jurisdictions and its failure in others may be explained by factors inherent the legal systems themselves - both natural law and revolutionary ideology have played their part - the immediate ancestors of most modern civil codes with their systematic structure and sharp divisions between branches of law, are without doubt the institutes of local law themselves which derive directly from Roman law and long centuries of study of the Corpus juris civilis. ${ }^{149}$

This brings me to my second remark. Although the phenomenon of a code is not unknown to common law jurisdictions, the underlying ideology, the conception of what a code is and the functions it should perform in the legal process, does not correspond with that in civil law jurisdictions. The code as the expression of an ideology makes it easier to understand why it makes sense to address codes from a comparative perspective. ${ }^{150}$ In civil law systems, law-making is seen as the exclusive task of the legislator. The codification of the law is regarded as a 'legislative enactment which entirely pre-empts the field and which is assumed to carry within it the answers to all possible questions: when a court comes to a gap or an unforeseen situation, its duty is to find, by extrapolation and analogy, a solution consistent with the policy of the codifying law ${ }^{\prime} .{ }^{151}$ When a case is brought before court, a civil law judge will begin with an examination of statute law which might govern the case at hand. A common law judge in contrast, will start with an examination of the facts of the case and any relevant precedent. While a civil law judge has the function of interpreting and applying the

\footnotetext{
${ }^{146}$ Watkin 1999, p. 9 and p. 450. See also Slapper and Kelly 2006, p. 2: 't t] he use of the term "common law" ( ... ) refers to all those legal systems which have adopted the historic Engllsh legal system (...) The term "civi law" refers to those other jurisdictions which have adopted the European continental system of law derived essentially from ancient Roman law, but owing much to the Germanic tradition.'

${ }^{147}$ Watson 1981, p. 179.

${ }^{148}$ Watkin 1999, p. 2. Civil law may still be found in parts of the US and Canada. The State of Louisiana for example, still employs a civil system based on French law, while the province of Quebec in Canada maintains the civil law system as part of its French inheritance.

${ }^{149}$ Watson 1981, p. 144 and p. 180

${ }^{150}$ Merryman 1985, p. 26.

${ }^{151}$ G. Gilmore, 'Legal Realism: its cause and cure', Yale Law Journal (70) 1961, quoted by Farnsworth 1996, p.
} 
law, it is not his/her function to "create" law in any way."." it is inevitable of course that, in interpreting the law, civil law judges are bound to supply detall to legishative enactments which the legislator has not foreseen. Aithough there exists no formal rule of stare decisis: '[i]t would violate the rules against judicial lawmaking if decisions of the courts were to be binding upon subsequent courts ${ }^{3}$, the decisions of courts, in particular those of the Dutch Supreme Court ('Hoge Raad') do encompass substantial persuasive force in providing examples of how the law is being interpreted and ap. plied. In addition, high value is placed upon ensuring that each rute is interpreted and applied in conformity with the other provisions of the legal system as a whole.

In the US and England, the present codifications have no pretense of completeness: they do not purport to abolish all prior law in the field. Moreover, even in legislation such as the UCC, one does not find the systematic structure and the relatively high degree of generalization and conceptualization typical of codes in civil law systems. ${ }^{154}$ And although there has been a significant increase in statute law in the 20th and 21st centuries, the courts still have an important role to play in creating and operating law generally and in determining the operation of the legislation in particular. ${ }^{155}$ English and American statutes refiect the 'Swiss cheese theory': '[the code is regarded] as a piece of Swiss cheese with all its holes, and if, when you search for a solution to your case, you find a hole in the Code, look through it to the backdrop of case law. ${ }^{155}$ If a provision is in possible conflict with a deeply rooted rule of common law, the aim will be to interpret the relevant provision in the code in such a manner as to avoid conflict. While the regime of precedent exists, a judge is not compelled to find a basis for deciding a given case within a particular statute.

These aforementioned differences in legal thought and the role of statutes in shaping the law have been well expressed by Weber and Trubek. Weber (1968) characterized European civil law as having 'logically formal rationality', which Trubek (1972) explains as follows: '[l] egal thought is rational to the extent that it relies on some justification that transcends the particular case, and is based on existing, unambiguous rules; formal to the extent that the criteria of decision are intrinsic to the legal system; and logical to the extent that rules or principles are consciously constructed by specialized

\footnotetext{
This separation of legislative from judicial power may be primarily traced to the Revolutionary period in Europe, where the judicial aristocracy was targeted for their failure to distinguish between applying and making the law (see also Merryman 1985, p. 14-18). This strict separation stands in contrast to judicial tradition in the United States and England, where the judiciary has often constituted a progressive force on the side of the individual as counterweight to the control of the ruler. The power encumbered upon the judges to develop the law was well received and not a target of the American Revolution in contrast to the French revolutionary reform.

${ }_{253}$ Merryman 1985, p. 46.

${ }^{3.34}$ Von Metren 2000, p. 10

45. Slapper and Kelly 2006, p. 4 .

13. Farnsworth 1996, p. 231.
} 
modes of legal thought which rely on a highly logical systematization, and to the extent that decisions of specific cases are reached by processes of specialized deductive logic proceedings from previously established rules or principles. ${ }^{157}$ As a consequence, court decisions in civil law jurisdictions are based on rules that are general, have been previously established, and derive from autonomous legal sources. Formal rationality means that the law exists as a system in its own right, but law is not an end in itself. The presence of this formal rationality in European civil law systems may be ascribed in large part to the historical authoritative role of the Corpus juris civilis. ${ }^{158}$

In the third place, and related to the foregoing, a difference may be found in the scope of the codification. As mentioned earlier, civil law codifications are extremely systematic and highly articulated. They are intended to set out authoritatively at least the principles and basic rules of a wide field of law, such as the whole of private law. The DCC codifies, in principle, the whole of contract law rules in the Netherlands, encompassing general rules of contract law as well as rules applicable to particular types of contracts. In contrast, codifications in common law jurisdictions carry no pretense of completeness; the UCC and the SGA 1979 are limited to specific types of contracts, primarily the sale of goods and provision of services. ${ }^{159}$ The UCC is not in itself law unless it has been enacted by the legislature of a state. ${ }^{160}$ Any state can decide not to adopt certain provisions of the UCC or make revisions to the Code. However, all fifty states have adopted the UCC with substantial uniformity. Article 1 UCC is of general application and relates to issues of interpretation and uniformity of the Code, but the main provision is Article 2, which governs the sale of goods between merchants. The sale of goods under Article 2 only applies to the transfer in property (sale) of movables; transactions concerning e.g. real estate transactions and the supply of services are excluded from application. ${ }^{161}$ The SGSA 1982 is concerned with contracts for the

${ }^{157}$ Watson 1981, p. 23 citing D.M. Trubek, 'Max Weber on law and the rise of capitalism', Wisonsin Law Review 1972, p. 730

${ }^{158}$ Watson 1981, p. 23

${ }^{159} \mathrm{Cf}$. Cooter and Ginsburg 2004, p. 1: '[c]ompared to the great codes of the continental tradition, the common law provides a less predictable set of rules because it is dynamic and because its sheer volume renders it imprecise.'

${ }^{160}$ The UCC is a product of the National Conference of Commissioners on Uniform State Laws and The American Law Institute in an attempt to unify the laws concerning commercial transactions with the goal of facilltating interstate commerce. The UCC, in one or another of its several revisions, has been enacted in all of the 50 states, as well as in the District of Columbia, Guam and the US Virgin Islands. Louisiana has enacted most provisions of the UCC with the exception of Article 2 , giving preference to its own civil law tradition for the governance of the sale of goods (www.all.org, last accessed September 18, 2006).

${ }^{161}$ Agreements concerning the transfer of information such as licensing agreements are precluded from Article 2. A revision of the UCC was envisaged to incorporate such agreements under a new Article $2 B$. However, the project met resistance of the American Law Institute and the provisions have now been incorporated as the Uniform Computer Information Transactions Act, which as of October 12, 2004 had only been adopted by 2 states: Maryland and Virginia. 
transfer in property in goods ${ }^{162}$, for the hire of goods, and for the supply of services. Both Article 2 UCC and the SGA 1979 regulate only general aspects of contracts such as formation, effects of the contract, performance and breach. The SGSA 1982 on the other hand, incorporates a list of implied terms concerning conditions and warranties as to title, quality or fitness, and correspondence with description by sample. These terms do not constitute mandatory law, and may be varied by express agreement unless this is prohibited under the Unfair Contract Terms Act 1977. In addition to the UCC, the American Restatements of the Law are published by the American Law Institute in order to organize the increasing flood of precedent. The Restatements are recognized as scholarly refinements of black letter law, including the law of contract. In their systematic structure of abstractly formulated rules, the Restatements seem like civil codes, however, the former do not compose primary sources of law and the judge is not bound to follow the Restatements in any way that he or she is bound to follow binding statute or case law.

Implications for the complexity of contracts

The foregoing account on the divide between common and civil law affects the level of contracting and enforcement costs.

First of all, a blunt categorization of civil and common law systems based on the presence respectively absence of a general codification of private law, implies that parties in civil law jurisdictions have access to a large resource of contract law rules. In these jurisdictions, the legislator has incurred the bulk of the contracting costs by identifying and specifying relevant rules of law in a freely accessible code. Of course, lawyers will incur certain costs while they may have to look up particular rules and related court decisions. I assume, however, that these costs are relatively small compared to the costs of formulating and enforcing legal rules. Let us assume that parties are not wary to rely on the general codification of the law. A justification for this assumption may be found in the fact that the legislator has access to a large amount of resources which allow him to identify and lay down in a national code the rules most relevant for the largest group of parties. The DCC 1992 in many aspects reflects case law developed under its predecessor, but also incorporates new rules which are the result of comparative legal study in order to find the rule which fits 'best' within the Dutch legal culture. Parties themselves do not have the resources and time to conduct such indepth (comparative) research. They will therefore often rely on default law, which is tailored to appeal to the largest part of the population. This 'ability to rely' implies that the costs for parties at the front end of the contracting process are small. Parties only have to incorporate particularities which are not foreseen for in the national code and can suffice with a reference to this code for other matters. For example, Article 6:265

${ }^{162}$ This is broader than the 'sale of goods' under the SGA 1979, also including contracts where the consideration consists of something other than money. 
and further of the DCC encompass detailed rules on the termination of contracts. Under the reliance assumption, parties could suffice to briefly refer to these Articles in their contracts, without incorporating the whole of the statutory rules. In addition, parties may forego to reference these legal rules at all and just rely upon the DCC to fill these gaps in their contract. The foregoing would be able to explain the existence of relatively simple contracts in the Netherlands. In accordance with this point of view, participants at the Association of Corporate Counsel Europe's 2006 Annual Conference established that civil law jurisdictions are characterized by a heavy reliance and reference to the civil code which allows for a practical approach to drafting issues. ${ }^{163}$ It becomes clear that in this case, even a relatively low level of contracting costs does not give parties an incentive to write complex contracts. Apparently, the expected benefits of copying extensive contract law rules into a contract do not outweigh the associated costs. It seems parties will rely upon the judge to apply the correct default rules to their contracts in case of a dispute. The ability to rely on the third party enforcer indicates that enforcement costs are expected to be low. This postulation relates to the back end of the contracting process and will be more elaborately investigated in the section on the interpretation of contracts.

In England and the US, case law substitutes for a national code. In first instance, it appears that this judge made law - of which the most prominent cases are made easily accessible through the compilation of Law Reports - and the system of precedent, complemented in particular areas by statute law, ought to be able to provide for a similar resource of contract law rules as offered by a general codification under a civil law system. The doctrine of precedent offers predictability and cohesion: '[u]nder a system of strict precedent, it is not merely the applicable legal principles which are predictable, but, more vitally, the precise interpretation which will be placed upon a particular clause in a contract is also predictable, since this issue of interpretation is a question of law governed by precedent. ${ }^{164}$ The foregoing implies that similar civil law jurisdictions, parties can suffice with relatively simple contracts. However, empirical evidence illustrates that contracts in the US and England are relatively complex compared to their counterparts in the Netherlands. While this complexity might be explained by relaxing the assumption that parties are not wary to rely on default rules. Without abandoning the reliance-assumption, an explanation might be found in the fact that the doctrine of precedent and the established statutes cannot be assimilated with the supply of contract law rules in a national code. Three arguments may be made in this respect.

First of all, judges in common law jurisdictions built their decisions on the particular facts of a case. When a case goes to court, a judge will first examine the facts in order

${ }_{103}^{163}$ Cf. Przeracki 1989, p. 174, Hill and King 2004, p. 928.

${ }^{164}$ Collins 1996, p. 3. 
to decide whether a precedent can apply or whether a different judgment should be rendered. If parties do not specify precisely and correctly the black-ietter rules which apply to their contract, the risk that the judge will find differently is increased. English and American judges have devised various ways to distinguish precedent. Sometimes, there are no precedents to rely on and a court will draw analogies from other areas of law to come to a just decision, which then becomes precedential, In addition, courts may overrule precedent. In England, the issuance of the Practice Statement 1966 has given the highest court, the House of Lords, the freedom to overrule its own decisions where it appears right to do so. ${ }^{165}$ The English Court of Appeals is free to overturn precedent when two cases conflict with each other ${ }^{155}$ and when it has previously taken a decision in ignorance of some authority which would have led to a different conclu$\operatorname{sion}^{167}$, or which has been expressly or impliedly overruled by the House of Lords. ${ }^{168}$ Likewise the US Supreme Court is able to depart from its prior decisions when historical conditions change or the philosophy of the court undergoes a major shift. ${ }^{169}$ The US appellate courts are divided into circuits and each panel of judges on the court of appeals of a certain circuit is bound by prior decisions of the same circuit. However, precedents may be overruled by the court en banc, a session of all active appellate judges of a particular circuit. This undermines the certainty of black letter rules and their consistent application, even if they are compiled in law reports. Both Van Hecke (1962) and Langbein (1987) argue that the lack of a systematic codification indeed reduces the predictability and precision of the law ${ }^{170}$ which has a positive effect on the level of enforcement costs. Likewise, Collins (1996) states that the incorporation of black letter law is the only way that predictability can be achieved. ${ }^{171}$ It seems that the system of case law inherent common law jurisdictions offers parties a smaller ability to rely on established rules of law than parties in civil law jurisdictions. In the latter jurisdiction, established rules of law may be interpreted by judges, but can be less easily altered or overturned.

In the second place, it may be postulated that the UCC or SGA have a function similar to a national code which would allow parties to suffice with simple contracts. A second explanation for the relative complexity in the US and England may be sought in the divergent function of a code in civil and common law jurisdictions. In civil law jurisdictions, a code endeavors to embody the complete and coherent representation of the law. A judge will attempt to apply the codified rules to the case at hand. In common

${ }^{165}$ Actually, it was not until 1898, with the case of London Street Tramways v London County Council in 1898 (AC 375) that the House of Lords became bound by its own decisions. The Practice Statement has seldom been applied. As of 2005, the House of Lords has rejected its past decisions no more than 20 times.

been applied. As of 2005, the House of Lords

${ }^{157}$ Tiverton Estates Ltd V We

${ }_{1.58}^{1.8}$ Family Housing Association v Jones (1990)

Brown v. Board of Education, 347 US 483, 74 S. Ct. 686, 98 L. Ed. 873 (1954).

Lord Macmillan in Tennyson, Aymler's Field 146, 1894, cited by Langbein 1987, p. 383.

:" Collins 1996, p. 2 
law jurisdictions on the other hand, codes are fragmentary, applying only to the sale of goods for example and the judge is not compelled to find basis for a decision in the code. This means that parties cannot wholly rely on the judge to apply the rules as embedded in the UCC or SGA to the case at hand. The foregoing implies that parties will prefer to incorporate black letter rules in their contracts for those areas which are not covered by statute law and even for the cases covered by statute law; this law is not necessarily leading.

An additional argument concerns the US in particular. Some authors argue that parties, who draft a contract subject to American law, draft to combat the diversity in jurisdictions. These authors state that the precise adoption and the interpretation of the UCC may vary across states, and that lawyers are not familiar with the law of each state. find this argument less convincing. First of all, the UCC $\$ 1-102$ contains a mandate to interpret law as uniformly as possible. In addition, scholarly writing concerning the interpretation of the UCC, is usually addressed to the Official version of the UCC and therefore uniform. Secondly, the UCC has been enacted in all fifty states to a substantial uniformity making the UCC virtually identical in all states. Finally, as Langbein (2001) indicates: 'the lengthy contractual terms seldom, if ever, mention the few substantive areas of difference that exist among the jurisdictions [GH: states]. Rather, the contractual terms that address substantive law recite "black letter rules",172

Concluding, when parties in a common law jurisdiction draft a contract, the incorporation of black-letter law will enhance certainty when a case is brought before court. To the contrary parties in civil law countries, despite low contracting costs, do not find it worthwhile to incur even the costs of copying relevant provisions of law into their contract, while the degree of enforcement costs which they encounter are substantially lower than those of their counterparts in common law jurisdictions. The expected level of enforcement costs is also affected by the manner in which contracts are interpreted by the courts. This aspect will be examined in the next section.

\section{The interpretation of contracts}

When corporate parties bring a dispute concerning the rights and obligations arising from their contract before court, the latter must decide what constitutes the precise content of the contract and how this content must be interpreted. The manner in which these issues are addressed is dependent upon the legal system in which the case is brought forward. While most common law systems restrict the types of evidence which may be used to establish and interpret the content of the contract, civil law systems usually do not place limits on the kind of admissible evidence. Furthermore common law generally takes an objective approach toward the interpretation of contracts, i.e. the focus is on the terms as expressed in the contract, while civil law sys-

\footnotetext{
${ }^{172}$ Langbein 2001, p. 127
} 
tems mostly apply a subjective theory of interpretation, i.e. the court will inquire into the actual intentions of the parties. Finally, parties may have omitted to foresee in a particular term of the agreement. Dependent on the jurisdiction in which the dispute arises, courts may be more or less lenient to supply a term to remedy this omittance.

The differences in the establishment of contractual terms, their interpretation and the implication of omitted terms, may have an effect on enforcement costs and thereby the relative complexity of commercial contracts. Restriction of the types of evidence that may be used to establish the terms of a contract, encourages parties to carefully consider whether they have incorporated their whole agreement in writing. In order to avoid any doubt as to whether the contract encompasses the whole agreement, parties may add additional terms, thereby increasing contractual complexity. A similar effect may be caused by the reluctance of a court to imply terms. Likewise, parties whose contract is subject to an objective approach may benefit from writing a complex contract which contains numerous and detailed clauses. A subjective approach to contract interpretation may induce parties to rely on a relatively simple contract. In the following paragraphs, I will first discuss the manner in which the different jurisdictions establish the terms of a contract and the manner in which this may affect the relative complexity of a contract. Thereafter I will examine in greater detail the different approaches with regard to contract interpretation and the manner in which England, the US and the Netherlands deal with omitted terms.

The establishment of the terms of the contract in England, the US and the Netherlands Before a court can commence with the actual interpretation of a contract, it must establish the precise content of the contract, i.e. which written terms have the parties agreed upon, and decide whether there any other terms which add to, or modify these terms. This distinction is especially relevant in England and the United States, where the rule of parol evidence restricts all evidence of agreements or negotiations, whether written or oral, prior to the time of contract conclusion that may supplement, contradict, or vary the terms of the agreement in writing. In the US, the parol evidence rule is recognized in all states and has been embodied in the UCC \$2-202 and Restatement (Second) of Contracts ('Restatement Second') $§ 215 .{ }^{173}$ In England, the parol evidence rule is not embodied in any statute, but is apparent from various cases. ${ }^{174} \mathrm{De}-$ spite its name, the parol evidence rule is a substantive rule of contract interpretation

\footnotetext{
${ }^{173}$ UCC $\$ 2-202:$ 'Terms (...) set forth in a writing intended by the parties as a final expression of their agreement (...) may not be contradicted by evidence of any prior agreement or of a contemporaneous oral agreement but may be explained or supplemented (...) (b) by evidence of consistent additional terms unless the court finds the writing to have been intended also as a complete and exclusive statement of the terms of the agreement.' See also the case of Gianni v R. Russel and Co., Inc., Supreme Court of Pennsylvania 1924, 281 Pa. 320, 126 A. 791.

${ }_{174}^{281}$ Gass v Lord Nugent (1833) 110 Eng. Rep. 731, Evans v Roe [1872] LR 7 CP 138, Jacobs v Batavia and Gen174 Goss v Lord Nugent (1833) 110 Eng.
eral Plantations Trust [1924] 1 Ch 287.
} 
rather than a rule of evidence. Although the rule has encountered quite some criticism, it has much to commend it, especially for commercial parties: '[The] policy of upholding the integrity of written contracts (...) is particularly relevant in cases (...) between two large corporations presumably represented by competent counsel'. ${ }^{175}$

The parol evidence rule only applies once it has been established that the written document represents a 'complete' contract: a document which contains all the terms of the parties' agreement. When is a contract considered to be 'complete'? Under English law, the party relying on a written document has the benefit that, upon appearance of completeness to a party taking a reasonable view of it, the document is presumed to represent the complete contract, subject to the other party's right of rebuttal. ${ }^{176}$ In the US on the other hand, a major area of conflict relates to the question of what constitutes a complete contract or total integration. ${ }^{177}$ In the US, the parol evidence rule may be said to operate in two steps ${ }^{178}$ : a court will first ask whether the writing is integrated, meaning it is intended to represent the final expression of the parties' agreement. ${ }^{179}$ Only if it has been established that the writing is integrated are parties obstructed from introducing any prior evidence that may contradict the terms in writing. When the written document also represents the complete and exclusive expression of the terms of the agreement, it will be considered 'completely integrated', and no prior or contemporaneous evidence may be introduced to either: (1) contradict; or (2) add to the written terms. ${ }^{180}$ It can be argued, that the ability under English law for a party to prove that the written agreement did not constitute the entire contract between parties, renders English law more flexible than US law on this matter. ${ }^{181}$ Although the rule of parol evidence restricts any evidence of prior or contemporaneous oral or written agreements which may supplement, contradict or vary the terms of the written contract, the rule has been limited in several ways in both the US and England.

First of all, the parol evidence rule applies only once it has been established that there is a valid and complete or completely integrated agreement; it does not preclude evidence which might indicate that no valid agreement was reached in the first place. Thus prior evidence may be invoked to prove that the written agreement is condi-

${ }^{175}$ Empire Gas Corp. V UPG, 7815 W.2d 148 (Mo. App. 1989).

${ }^{176}$ Treitel 2003, Wetherburn [1959] Cப 58

${ }^{177}$ See also Fuller and Elsenberg 2006, p. 591-595 and the discussion between Professor Corbin and Williston referenced therein.

${ }^{178}$ See Farnsworth 1999, p. 431-432.

${ }_{179}$ In contrast to a detailed and signed document, notes or draft agreements will usually not be deemed Integrated (Farnsworth 1999, p. 431-439) and Restatement Second \$209.

${ }^{180}$ Restatement Second $\$ 213-\$ 216$. In the US, courts have used different methods to determine whether a writing is 'completely integrated'. Most courts presently follow the approach taken by Restatement Second $\$ 210, \S 216$. The UCC has adopted a similar approach: UCC \$2-202 comment 1 (a).

${ }^{181}$ Fontaine and De Ly 2006, p. 118 
tional, unenforceable for lack of consideration ${ }^{182}$ or avoidable due to fraud ${ }^{183}$, duress, mistake $^{184}$ or misrepresentation ${ }^{195}$. Second, the parol evidence rule does not preclude evidence of 'collateral agreements', i.e. side agreements which are entirely separate and distinct agreements between parties, as long as these side agreements qualify as a contract and do not contradict the completely integrated or complete agreement. ${ }^{185}$ In addition, parol evidence is generally still admissible for the purpose of interpreting the terms found in the latter agreements. This rule will be discussed in greater detail below.

In order to indicate that their agreement encompasses a complete and final integration of the terms and to ensure that reliance will not be placed on representations made prior or contemporaneous to the execution of the writing, parties in the US and England often incorporate an entire agreement clause. ${ }^{187}$ An example of such a clause is the following:

'Except as specifically contemplated in this Agreement and except for the CDA and the Supply Agreement, this Agreement sets forth the entire understanding of the parties with respect to the subject matter hereof and supersedes all prior agreements, written and oral, between the parties.'

While it may be argued that such clauses should not simply be taken at face value ${ }^{188}$, courts in England currently seem to have decided otherwise. ${ }^{189}$ It is argued that these types of clauses provide certainty 'since the parties have by the clause expressed their

${ }^{182}$ US: Kay v Spencer, 213 P. 571 (Wyo. 1923) and Restatement Second \$ 214(d). England: Solly v. Hinde

(1834) $2 \mathrm{Cr}$ and $\mathrm{M} 516$, Abbott $v$ Hendricks (1840) I Man and G 791 475 N.W. $2 d 640$ (lowa App. 1991). England: Pickering v Dowson (1813) 4 Taunt 779.

${ }_{184}^{184}$ England: Pym v Campbell (1856) $6 \mathrm{E}$ and B 370, Raffles $v$ Wichelhous (1864) $2 \mathrm{H}$ and C 906. US: Bollinger v Central Pennsylvania Quarry Stripping \& Construction Co. 229 A.2d (Pa. 1967)

${ }^{185}$ England: Pennsylvania Shipping Co v Compagnie Nationale de Navigation [1936] 2 All ER 1167. US: Guardian State Bank v Stangl 778 P.2d 1 (Utah 1989).

${ }^{185}$ England: De Lassalle v Guilford [1901] 2 KB 215, Mendelssohn v Normand Ltd [1970] 1 QB 177, Lord Moulton in Heilbut, Symons \& Co v Buckleton [1913] AC 30: '[i]t is evident, both on principle and on authority, that there may be a contract the consideration for which is the making of some other contract. "If you will make such and such a contract, I will give you one hundred pounds," is in every sense of the word a complete legal contract. it is collateral to the main contract, but each has an independent existence, and they do not differ in respect of their possessing to the full the character and status of a contract. Us: Masterson v Sine Supreme Court of California 196868 Cal. 2d. 222, P.2d. 561, Mitchill v Lath, 160 N.E. 646, 647 (N.Y. 1928), Restatement Second.

${ }^{187}$ The term 'entire agreement' seems to have been developed in England. The clause is also known as 'merger' or 'integration' clause (see Fontaine and De Ly 2006, p. 117).

188 Beale 2004.

${ }^{189}$ Deepak Fertilisers v. Imperial Chemicals Industries plc [1999] 1 Lloyd's Rep. 387. 
intention that the document is to contain all the terms of their agreement ${ }^{\prime 190}$ In the US, the value attached to entire agreement clauses varies. Some courts are of the opinion that the weight to be given to an entire agreement clause depends on the precise circumstances. ${ }^{191}$ Although entire agreement clauses are often not regarded as 'absolutely conclusive' they are considered to be 'indicative of the intention of the parties to finalize their complete understanding in the written contract (...) that there was no other prior or contemporaneous agreement not included in the written contract. $^{192}$ This conclusion may be supported by the length and detail of the contract as well as evidence of extensive negotiations prior to contract conclusion. While the parol evidence rule applies only to prior or contemporaneous evidence, subsequent evidence, for example agreements or negotiations which arise after the conclusion of the contract, are not excluded from examination. ${ }^{193}$ Such evidence may in principle modify, add or supplement the terms of the written agreement. Under the parol evidence rule and the ensuing entire agreement clause, parties spend a lot of effort to reduce all arrangements in one written document. These efforts and attempts to concentrate the entire agreement in one written document may be frustrated if oral arrangements subsequently concluded between parties or written agreements concluded by unauthorized employees, officers or sale representatives would permit parties to deviate from the written contract. In order to make their contracts immune to such changes, no-oral modification (NOM) clauses have been devised by parties as to 'provide a parallel formalism regarding changes to the written contract and require that amendments be made in writing ${ }^{194}$

'No modification of any of the terms of this Agreement shall be deemed to be valid unless it is in writing and signed by both parties.'

\footnotetext{
${ }^{190}$ Chitty on Contracts 2004, p. 758 and n. 443 which refers to McGrath v Shah (1989) 57 P. \& CR 452. The approach is somewhat different when the entire agreement clause extends to prevent liablity for representations (Furmston 2003, p. 528 and Chitty on Contracts 2004, p. 758). In addition, an entire agreement clause may be waived by a party who might otherwise have relied on it (Chitty on Contracts 2004, p. 758 and n. 446 which refers to SAM Business Systems Ltd v Hedley \& Co [2002] EWHC (TCC) 2733, [2003] 1 All. ER. (Comm.) 465

(Comm.) 465 .
${ }^{191}$ Fuller and Eisenberg 2006, p. 602.

192 Pumphrey v. Kehoe, 261 Md. 496, 505, 276 A.2d 194, 199 (1971) cited in ARB (American Research Bureau), Inc. v. E-Systems, Inc. 663 F.2d 189, 198099 (D.C. Cir. 1980. See also Farnsworth (1999) who states that one must be aware however, that a basic merger clause may extend to (1) prevent liability for representation; (2) bar evidence of a condition to the written agreement taking effect; (3) bar evidence of course of dealings or usage of trade; or (4) include a no-oral-modification clause. The enforcement of such extensive merger clauses may vary accordingly. In this light, which extends to exclude pre-contractual liability or liability for representations under Dutch law is in principle enforceable, unless invocation of the clause is contrary to good faith

${ }^{193}$ US: Kelso v McGowan, 604 So. 2d 726 (Miss. 1992\}. England: Furmston 2003, par. 3.5, p. 523 ,

${ }^{194}$ Fontaine and De Ly 2006, p. 159.
} 
NOM clauses are generally assumed to be enforced in England although there is no authority on this point. ${ }^{195}$ The common law rule in the US traditionally has been that a court will not enforce these types of clauses. ${ }^{196}$ The underlying reasoning was that: '(1) Parties can, by later contracts, change their earlier contracts. (2) An oral modification is a later contract. (3) An implied provision of the later contract is to abrogate the n.o.m. provision of the earlier contract. ${ }^{197}$ The fact that New York state law and UCC $\S 2-209(2)^{198}$ do give effect to such provisions, have led courts to adapt a more liberal approach to these NOM clauses and presently, unless the defendant has waived the benefits of such a clause by acting in contravention of such a clause, the court will usually enforce them. ${ }^{199}$

There is no equivalent of the parol evidence rule in Dutch law. In principle prior evidence of oral or written agreements is always admitted: the Dutch court is free to assess any extrinsic evidence, including evidence of prior negotiations, in order to establish the terms of the contract. ${ }^{200}$ In the case where one party claims that the written document does not contain the entire agreement, Tjittes (2000) illustrates that certain rules of evidence in the Dutch Code of Civil Procedure (Wetboek van Burgerlijke Rechtsvordering) ('DCCP') have an effect comparable to the parol evidence rule. ${ }^{201}$ Tjittes (2002) states that a written agreement between parties may be qualified as an

${ }^{195}$ See also World Online Telecom U.K. Ltd. V I-Way Ltd., [2002] EWCA (Civ) 413, [1]-[17] in which a lowe court decision was upheld not to determine in the summary judgment phase whether a contractual clause prohibited oral modifications (cited by Davis 2006, p. 490-491, n. 9)

${ }_{196}$ Autotrol Corp. v. Continental Water Sys. Corp. 918 F. 2d 689 (7) $7^{\text {th }}$ Circuit 1990), Clark v Clark 535 A.2d 872 (DC 1987), Beaty v Guggenheim Exploratio Co. 122 N.E. 378 (NY 1919). See also Restatement Second $\$ 31$ comment a: ' $[\mathrm{t}$ ]he parties to a contract cannot by agreement preclude themselves from varying their duties

to each other by subsequent agreement.
${ }_{197}$ Fuller and Eisenberg 2006, p. 608 .

${ }^{198}$ 'A signed agreement which excludes modification or rescission except by a signed writing cannot be otherwise modifled or rescinded $(. .$.$) .$

${ }^{199}$ Cf. UCC \$2-209(4): '[a]lthough an attempt at modification does not satisfy [Section 2-209(2)] it can operate as a waiver' (a waiver is the process of giving up any right on anything with a voluntary action or non action). Beware, however, that Section 2-209(4) may be limited by Section 2-209(5) that under particular

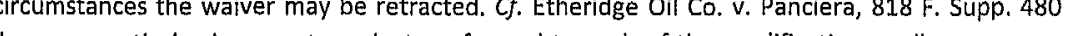
'because parties' subsequent conduct conformed to each of the modifications, seller cannot now question the validity of those modifications'. Indeed, doctrines of 'waiver', estoppel in English law and Rechtswirkung or principles of implied renunciation in other national legal systems may act to derogate from entire agreement and NOM clauses (Fontaine and De Ly 2006, p. 163). In order to preclude the foregoing effects, parties will often complement an entire agreement and/or NOM clause with an anti-waiver or non-waiver clause. The enforcement of these anti-waver clases is dependent on the juristiction: under English law, which The enes a predor takes a predominantly objective and Iteral approach to interpeta lion, these clauses wilgenerally be enforced. Under Dutch law, however, good faith and fair dealing may be imposed to limit the application of the anti-waiver clause.

200 HR 13 March 1981, NJ 1981, 635 (Haviltex).

${ }^{201}$ Tjittes 2000 . 
evidence agreement according to Article 153 DCCP. ${ }^{202}$ The judge is obliged to regard the content of such an agreement as correct and true. The party who disputes the written terms of the agreement, and asserts that he has orally agreed otherwise, is granted the right to prove that the written agreement does not encompass the actual and complete agreement. Providing this evidence is a difficult task, while the party will have to call upon witnesses and search for documents which prove that oral arrangements contrary the written document have been made. The judge is entrusted with the valuation of the alleged evidence. ${ }^{203}$ Tjittes (2002) illustrates that, while Dutch law thus not recognize the parol evidence rule as such, Dutch rules of evidence may effectuate similar results in practice. The effect in Dutch law seems comparable to the case of parol evidence in English law, which will swiftly acknowledge that the agreement is complete, subject to a party's right of rebuttal. It should be noted however, that, similar English and American law, the Dutch rules of evidence exist and apply independently of the substantive law regarding the interpretation of contracts.

When Dutch parties incorporate an entire agreement clause in their contracts, this clause may be regarded as a substantive waiver clause under which parties sign away their rights and obligations emanating from agreements, negotiations or promise made prior to the main agreement. ${ }^{204}$ It has been argued that such a clause may be held to be invalid, especially when it is found in general conditions of contract. ${ }^{205} \mathrm{Un}$ derlying this reasoning is the overriding principle of good faith (redelijkheid en billijkheid) in Dutch contract law. This principle, laid down in Article 6:2 DCC in general and in Article 6:248(1) DCC for contracts in particular, stipulates that good faith may act to supplement, modify or extinguish parties' obligations and thus the written terms of the agreement. A court may thus use the principles of good faith and fair dealing to strike down a clause which excludes prior evidence for the establishment of contract terms.

Published case law relating to the incorporation of NOM clauses does not yet seem to exist in the Netherlands. Tjittes (2005), states that nothing seems to prohibit parties contracting under Dutch law to include a NOM clause in their contract. When parties orally modify an agreement subject to such a clause, the oral modification will be 'estopped' by the agreed upon formality: the requirement that any modification must be put into writing. However, the principle of good faith may interfere with the validity of such a clause. A party may waive his right to invoke the NOM clause for example, by conduct, agreement or unreasonable behaviour.

${ }^{202}$ Actually Tjittes (2002) still refers to the old Wetboek van Burgerlijke Rechtsvordering, Articles 183 and 184. See on this issue also Fontaine and de Ly 2006, p. 115 and p. 138 .

${ }^{203}$ HR 5 January 2001, RvdW 2001, 23 (Brooke Holland/Mr Overes q.q.)

${ }^{204}$ Tjittes 2005, p. 26, Fontaine and De Ly 2006, p. 139

${ }^{205}$ Hondius 1986. 
Implications for the complexity of contracts

The establishment of the relevant terms by the court places us at the back end of the contracting process. Rules of parol evidence, entire agreement and NOM clauses affect the level of enforcement costs. Failure to put all the relevant terms in writing creates uncertainty and unpredictability for parties who bring suit in England or the US. This means that these parties will incorporate detailed performance obligations, as any elements which are not comprised in their written document will not be regarded as part of their agreement. ${ }^{206}$ The incorporation of an entire agreement clause ensures that reliance will not be placed on representations made prior or contemporaneous to the execution of the writing, while NOM clauses warrant that any oral modifications ex post are invalid. The rule of parol evidence, entire agreement and NOM clauses, may reduce the expected enforcement costs, but increase the complexity of the contract. Dutch parties are not focused on including absolutely everything in contract, while presentation of evidence which adds or modifies the terms in writing is in principle not precluded. Subsequently, the inclusion of entire agreement and NOM clauses is not standard practice, leading to a reduction in contract terms and thereby complexity.

The interpretation of the established contract terms

When the terms of the contract have been established, the courts must decide which meaning must be given to the terms of the contract. Language is not always clear, but may be (1) ambiguous: susceptible to more than one interpretation (e.g. parties sign a contract for the sale and delivery of cotton by a ship which sales under the name 'Peerless': do parties refer to the Peerless that sails in October or the ship of similar name that sails in December?) or (2) vague: unclear in the specific context (an American seller and a Swiss buyer agree upon the sale of 'chicken': does stewing chicken conform?. ${ }^{207}$ In the following paragraphs, I will discuss the approach taken by England, the US and the Netherlands towards the interpretation of contract terms.

\section{England}

The overriding objective of the interpretation of contracts in English law is to find the parties' common intention. ${ }^{208}$ This seems to indicate that the English judge will consider the parties' actual intention and hence take a subjective approach to the interpretation of contracts. However, the court's endeavor into the parties' intention is highly objective: '[t]o ascertain the intention of the parties the court reads the terms of the contract as a whole, giving the words used their natural and ordinary meaning in the context of the agreement $(. .$.$) the court does not of course inquire into the par-$ ties' subjective states of mind but makes an objective judgment based upon the mate-

${ }^{205}$ Przeracki 1989, p. 174.

207 The examples have been taken from Farnsworth 1999, p. 454-458.

${ }^{208} M^{\prime}$ Cowan v Baine, \& Johnson [1891] AC 401, 403, Pioneer Shipping Ltd. v B.T.P. Tioxide Ltd. [1982] AC 724, 736, Lord Bingham in BCCl v Ali [2001] 1 All ER 961. 
rial already identified. ${ }^{209}$ The court associates the parties' mutual intention with the words as expressed in the contract. This approach may be justified by the certainty it creates. Under a subjective approach, parties would be able to provide in hindsight, any evidence to their benefit. Historically, the majority of cases, which came before the English courts, were of a commercial nature. The certainty created by the objective approach advances the interests of trade and serves the needs of commerce. ${ }^{210}$ Finally, it is believed that an objective approach leads to inexpensive judicial rulings while reference to extrinsic evidence is limited. I am of the opinion however, that this last argument is not so strong, while discovery procedures in England and the US, in which parties may bring forward any evidence they deem necessary to support their position in court, can increase litigation costs enormously.

Under an objective rule of interpretation, court must ascertain the intention of the parties from the words as expressed in the written agreement. Traditionally, the focus of the court was to find the plain and ordinary meaning of the words as understood by ordinary and reasonable persons. ${ }^{211}$ This was achieved by looking within the four corners of the written document. The ordinary grammatical meaning of the language was given the greater weight, except in case of a technical or special use of a word. An examination of extrinsic evidence was only allowed when the judge was not able to establish the meaning of the words from the document itself. ${ }^{212}$ This extrinsic evidence precluded any evidence of prior negotiations. ${ }^{213}$ This is still recognized as the golden rule of interpretation. ${ }^{214}$

Canons of construction were developed in order to help judges ascertain the meaning of the words within the immediate context of the contract. These canons are still used. The rule expressio unius est exclusio alterius, requires the court to interpret a number of listed items to the exclusion of others. For example, a court may apply it to read a contract for the sale of a firm together with 'cattle and hogs' to exclude the seller's sheep and house-dog. ${ }^{215}$ Another rule relates to the expression ejusdem generic (of the same kind). Where a contract lists specific classes of persons or things and then refers to them in general, the general statements only apply to the same kind of persons or things specifically listed. For example, if a clause refers to automobiles, trucks, tractors

${ }^{209}$ Ibid.

${ }^{210}$ Steyn 2003. See more recently for a critical view with regard to the objective contract interpretation: Lord Nicholls of Birkenhead 2005.

${ }^{211}$ Lake v Simmons [1927] AC 487, Hayward v Norwich Ins. Ltd. [2001] Lloyd's Rep. I.R. 410 (C.A.)

${ }^{212}$ Bank of New Zealand $v$ Simpson [1900] AC, p. 189. The court in this case indicates that where words are clear, extrinsic evidence cannot be invoked to explain their meaning. Such evidence is only admissible when words or phrases are ambiguous (Robertson v Jackson (1854) 2 CB 412)

${ }^{213}$ Prenn v Simmonds [1971] 1 WLR 1381, p. 1384.

${ }^{214}$ Lord Wensleydale in Grey v Pearson (1857) 6 HL Cas 61, p. 106, Caledonian Ry v N British Ry (1881) 6 App Cas 114, 131.

${ }_{215}$ Home Ins. Co. v Victoria-Montreal Fire Ins. Co. [1907] AC 59, 64. 
and other motor-powered vehicles, the term 'vehicles' would not include airplanes, since the list referred only to land-based transportation. ${ }^{216}$ Furthermore, courts will attempt to interpret the language of the contract in a consistent manner. Words that are used more than once are assumed to have the same meaning throughout the contract, which is consistent with the sense of the contract as a whole. Subsequently, more attention will also be paid to non-standard terms of the contract than standard terms. ${ }^{217}$ When words are susceptible to two different meanings within the contract, one which validates the contract and the other which renders it void or unenforceable, then the meaning which validates the contract shall prevail. ${ }^{218}$ Finally, an important rule of interpretation is the interpretation contra proferentem. When the language supplied by one party is susceptible to two interpretations, one of which favors each party, the one that is less favorable to the party that supplied the language is preferred. ${ }^{219}$ This rule is based on the ground that the party against whom the rule operates has had the possibility of drafting the language in such a manner to avoid the dispute.

In recent years, contract interpretation in England has developed in the sense that the context in which the contract is concluded should play an important role in light of contract interpretation. Instead of ascertaining the plain and ordinary meaning of the language within the direct context of the contract itself, courts now recognize and accept that the language of the contract is influenced by the surrounding circumstances. Despite these developments, it is important to note that the objective ap proach to interpretation remains unchallenged and still represents the overriding principle. ${ }^{220}$ In Investors Compensation Scheme Ltd $v$ West Bromwich Building Society ${ }^{221}$, Lord Hofmann referred to the fundamental change that has overtaken the process of interpretation - particularly as a result of speeches by Lord Wilberforce in Prenn v Simmonds ${ }^{222}$ and Reardon Smith Line L.td $\vee$ Yngar Hansen-Tangen ${ }^{223}$ - and seeks to restate the principles of contemporary contract interpretation:

The principles may be summarized as follows:

1. Interpretation is the ascertainment of the meaning which the document would convey to a reasonable person having all the background knowledge which would

\footnotetext{
${ }^{216}$ Young v Sun Alllance \& London ins. Ltd. [1976] 2 Lloyd's Rep. 189, 191 (CA).

${ }^{217}$ Woolfall \& Rimmer Ltd. V Moyle [1942] 1 KB 66, 73 ff. (CA).

${ }^{218}$ Fausset v Carpenter (1831) 2 Dow \& Cl 232, when there are two possible interpretations, one which is lawful and the other which isn't, the court will apply the lawful interpretation, WN Hillas \& Co v Arcos (1932) LT 503: in case of a possible invalid and valid interpretation, the valid interpretation will prevail.

${ }_{219}^{219}$ Savill Bros Ltd v Bethell [1902] 2 Ch 523 .

${ }^{220}$ Kornet 2006, chapter 5.

221 [1998] 1 WLR 896

${ }^{222}$ [1.971] 1 WLR 1381

${ }^{223}$ [1976] 1 WLR 989.
} 
reasonable have been available to the parties in the situation in which they were at the time of the contract.

2. The background was famously referred to by Lord Wilberforce as the "matrix of fact", but this phrase is if anything, an understated description of what the background may include. Subject to the requirement that it should have been reasonably available to the parties and to the exception to be mentioned next, it includes absolutely anything which would have affected the way in which the language of the document would have been understood by a reasonable man.

3. The law excludes from the admissible background the previous negotiations of the parties and their declaration of subjective intent. They are admissible only in an action for rectification. The law makes this distinction for reasons of practical policy and, in this respect only, legal interpretation differs from the way we would interpret utterances in ordinary life. The boundaries of this reception are in some respects unclear. But this is not the occasion on which to explore them.

4. The meaning which a document (or any other utterance) would convey to a reasonable man is not the same thing as the meaning of its words. The meaning of words is a matter of dictionaries and grammars; the meaning of the document is what the parties using those words against the relevant background would reasonably have been understood to mean. The background may not merely enable the reasonable man to choose between the possible meaning of words which are ambiguous but even (as occasionally happens in ordinary life) to conclude that the parties must, for whatever reason, have used the wrong words or syntax (see Mannai Investment Co. Ltd. V Eagle Star Life Assurance Co Ltd).

5. The 'rule' that words should be given their "natural and ordinary meaning" reflects the commonsense proposition that we do not easily accept that people have made linguistic mistakes, particularly in formal documents. On the other hand, if one would nevertheless conclude from the background that something must have gone wrong with the language, the law does not require judges to attribute to the parties an intention which they plainly could not have had.'

The first principle emphasizes that the background or 'matrix of facts' is attributed a increasingly important role in the interpretation of contracts: it is no longer necessary to establish that the language is ambiguous or vague in order to introduce evidence of surrounding circumstances: " $[\mathrm{t}$ ] he starting point is that language in all legal texts conveys meaning according to the circumstances in which it is used. It follows that the context must always be identified and considered before the process of construction or during it. It is therefore wrong to say that the court may only resort to evidence of the contextual scene when ambiguity has arisen', ${ }^{224}$ This means that words are given the meaning ascertained from the document itself and the admissible background knowledge which could reasonably have been available to the parties at the time of

${ }^{224}$ Lord Steyn in Westminster City Council v National Asylum Service, [2002] 1 WLR. 2956, par. 5. 
contract conclusion. If the matrix of fact indicates that parties actually assign to the language a meaning which is disparate from the plain meaning, the court is willing to give effect to the latter meaning. ${ }^{25}$

While the starting point for interpretation is the actual wording of the contract in light of the background or surrounding context, the second principle attempts to give guidance as to what may be included within this background. Lord Hoffman in his second principle, however, creates confusion, by stating that the 'background' may include 'absolutely anything which would have affected the way in which the language of the document would have been understood by a reasonable man. ${ }^{226}$ In Bank of Credit and Commerce International v All he attempts to clarify this and affirms: 'I did not think it necessary to emphasize that I meant anything which a reasonable man would have regarded as relevant. I was merely saying that there is no conceptual limit to what can be regarded as background (...) I was certainly not encouraging a trawl through "background" which could not have made reasonable person think that parties must have departed from conventional usage. ${ }^{.227}$ In general, the relevant background includes the factual, legal and commercial context known to the parties. This includes, but is not limited to, evidence of industrial and commercial practices, technical terminology as understood by experts and professionals, market conditions and the state of law. ${ }^{228}$ Another aspect to consider is the underlying purpose of the agreement ${ }^{229}$. The court will seek to reveal the commercial purpose of the contract and adopt a meaning which is congruent with this purpose. The meaning of the words as expressed remains the primary focus. Courts may not use the commercial purpose of the transaction to rewrite the contract.

Information may be included as background subject to the condition that such information is reasonably available to parties: common knowledge to both parties at the moment of contract conclusion. Apart from this underlying condition, what may, and will be considered part of the matrix of facts depends on the nature of the contract. For example, third parties who are not involved in the drafting process, but do derive rights from a contract, are unlikely to be aware of the surrounding circumstances at the time of contract conclusion. It seems that where more parties are involved, the background should be limited to the written agreement and factual, legal and com-

\footnotetext{
${ }^{225}$ Investors Compensation Scheme v West Bromwich Building Society [1998] 1 WLR 896, Mannai Investment Co. Ltd. v Eagle Star Life Assurance Co, Ltd [1997] 2 WLR 945.

${ }^{226}$ Lord Hoffman in Investors Compensation Scheme v West Bromwich Building Society [1998] 1 WLR 896.

227 [2002] 1 A.C. 251, par. 39. See also Lord Steyn in Mannai Investment Co. Ltd. v Eagle Star Life Assurance

Co. Ltd [1997] 2 WLR 945.
${ }_{228}$ Steyn 2003, p. 7, Chuah 2001, p. 295.

${ }^{229}$ Lord Wilberforce in Prenn v Simmonds [1971] 1 WLR 1381 and Reardon Smith Line Ltd v Yngar HansenTangen [1976] 1 WLR 989.
} 
mercial knowledge of a general nature. In a contract involving only two parties, more detailed information may be considered. ${ }^{230}$

The third principle limits what may be included in the background. Excluded from consideration are parties' previous negotiations and declarations of subjective intent. This is a corollary of the parol evidence rule. The exclusion of prior evidence for the interpretation of the contract is justified in that it seeks to '(...) discourage curial exploration of the unfathomable depths of subjective intentions'. ${ }^{231}$ In addition, parties' negotiating positions may alter during the negotiation process, and these developments cannot be directly understood from the final written agreement; to admit evidence of prior negotiations, would introduce uncertainty and unpredictability into the process of dispute resolution. On the other hand, prior evidence may shed light on facts which would clarify certain questions of interpretation.

The boundaries of the foregoing rule are not always clear. In Prenn $v$ Simmonds ${ }^{232}$ for example, Lord Wilberforce appears to admit evidence of prior negotiations as part of the matrix of fact, while it supplies a commercial purpose for the agreement, which would be frustrated by the suggested interpretation of the contract. In Partenreedere M.S. Karen Oltman v Scarsdale Shipping Co. Ltd ${ }^{233}$ evidence of pre-contractual negotiations was admitted to show that parties had reached consensus concerning the particular meaning to be given to certain words used in the final contract. Likewise, in Bank of Scotland v Dunedin Property Investment $\mathrm{Co}^{234}$, the Court of Session admitted prior evidence relating to a loan transaction to establish the state of both parties knowledge of the surrounding circumstances at the time of contract conclusion.

The fourth principle emphasizes the focus on the meaning of the contractual document as a whole as opposed to the meaning of the words alone: ' $t$ ] a document (or any other utterance) would covey to a reasonable man is not the same as the meaning of its words. ${ }^{235}$ While words cannot be taken from their context, the emphasis lies with the contextual meaning of the contract as opposed to the textual meaning of individual words. Even where words of a document are clear, the court must interpret these words against the objective surrounding circumstances known to the parties at the time of contract conclusion. ${ }^{236}$

\footnotetext{
${ }^{230}$ Associatlon of British Travel Agents Ltd v British Airways plc [2000] 1 Lloyd's Rep 169

${ }^{231}$ B\&B Constructions (Aust) Pty Ltd. v Brlan A Cheeseman Associates Pty Ltd (1994) 35 NSWLR 227

${ }^{232}$ [1971] 1 WLR 1381, p. 1385.

${ }^{233}[1976] 2$ Lloyd's Rep, 708, p. 712

${ }^{234}$ [1998] 5.C. 657

${ }^{235}$ See Lord Hoffman's fourth princlple in Investors Compensation Scheme Ltd v West Bromwich Building

Society [1998] I WLR 896

${ }^{236}$ Westminster City Council v National Asylum Service [2001] EWHC Admin 138.
} 
Finally, the fifth principle attempts to shed light on the question whether the approach to seek the natural and ordinary meaning of the words is entirely abandoned. Lord Hoffman points out that if the language of the contract can be given its natural and ordinary meaning, this provides a strong indication that the words must be interpreted in this manner. However, in the end, the contractual language is ascribed a meaning which makes sense in the light of the surrounding circumstances and underlying purpose of the contract. While the ascertainment of the ordinary and plain meaning remains the natural starting point for the interpretation of contracts, the court is not obliged to attribute this ordinary meaning to the parties' intention, while the parties may have had another intention: parties can make mistakes. ${ }^{237}$

Concluding, English law adheres to a predominantly objective approach to the interpretation of contracts. Words can only be given meaning within the context in which they appear. Despite the traditionally literal interpretation, courts now look beyond the four corners of the contract at the object and purpose of the parties' agreement in order to clarify the contractual language. More in particular, they may take into account the surrounding circumstances and give preference to parties' common intention, even if this diverts from the text in writing. ${ }^{238}$

\section{The United States}

American law emanates from the English common law tradition. In the two hundred years since the American Declaration of Independence, however, the law has developed in its own distinct way, independent of the English model which lies at its base. ${ }^{239}$

When a dispute concerning the interpretation of a contract arises before an American court, the court will attempt to give effect to the common intention of the parties. The intention is to be determined as of the time and place that the contract was concluded. Like English law, this does not mean that the court will inquire into the parties' actual state of mind at the time of contracting: 'if the "actual state of the parties' minds" is relevant, then each litigated case must become an extended factual inquiry into what was "intended", "meant", "believed" and so on [while if] we can restrict ourselves to the "externals" (...) than the factual inquiry will be much simplified and in time can be dispensed with altogether as the courts accumulate precedents about recurring types of permissible and impermissible "conduct". ${ }^{240}$ The court will give the contract terms their plain and ordinary meaning, interpreting them as ordinary, average, or reasonable persons would understand them. ${ }^{241}$ The common intention of the parties then is assimilated with the terms as expressed in the written document.

${ }^{237}$ Investors Compensation Scheme Ltd $v$ West Bromwich Building Society [1998] I WLR 896

${ }^{238}$ Adamastos Shipping Co. Ltd. v Anglo-Saxon Petroleum Co Ltd [1959] AC 133.

${ }^{239}$ Zweigert and Kötz 1998, p. 239

${ }^{240}$ Gilmore 1999.

${ }^{241}$ Rains v. Becton, Dickinson \& Co., 246 Neb. 746, 523 N.W.2d 506 [Neb. 1994]. 
Traditionally, like English law, American courts placed a strong emphasis on the plain meaning of the contract language. The court was not willing to give effect to any meaning which was disparate from this plain meaning. Even if witness testimony was able to show that the parties assigned a different but common meaning to the contractual language, the plain meaning triumphed. ${ }^{242}$ Presently, however, the courts have taken a more liberal approach toward contract interpretation. For example, where parties have attached the same meaning to a term of the contract, this common meaning will prevail, regardless of the ordinary meaning of that term. ${ }^{243}$ The cases in which parties share a common meaning, however, are rare. More often, parties will have attached a different meaning to the same contractual term, or have given little or no thought to the precise meaning of the former term at the time of contract conclu sion. The court then is obliged to search for a meaning which might not accord with parties' intentions at all. While the approach to contract interpretation has become less strict, the court in these situations will still take a predominantly objective approach to contract interpretation and 'turn on the meaning that reasonable persons in the position of the parties would have attached if they had given the matter thought. ${ }^{244}$ Similar to English law, American law recognizes several principles and rules that guide the courts in their task of interpretation.

The overarching principle of contract interpretation is that a court may take into ac count all the relevant circumstances surrounding the transaction. It is no longer necessary for the contract language to be qualified as ambiguous and vague in order to admit evidence of surrounding circumstances for the purpose of interpretation. ${ }^{245}$ It is indeed questionable whether language can be ascribed a meaning at all when divorced from its context: '[t]here is no surer way to misread any document than to read it literally. ${ }^{246}$ These surrounding circumstances may include any oral or written statements and other conduct which manifested the parties' assent, any evidence of an applicable course of dealing, performance or trade usage. In addition, the court may have reference to the state of the world, including the state of law. ${ }^{247}$ The importance of the surrounding circumstances is reflected in the judicial emphasis on purpose in terpretation. ${ }^{248}$ In resolving interpretation disputes, a meaning which favors the purpose of the agreement will prevail rather than a meaning which would frustrate this

${ }^{242}$ Conway 2005, p. 119, Hotchkiss v National Clty Bank, 200 Fed. 287, 293 (SDNY 1911), affirmed 201 Fed.

664 (2d Cir. 1912) affirmed 231 US 60 (1913).
${ }_{243}$ Berke Moore Co. v Phoenix Bridge Co., 98 A.2d 150, 156 (NH 1953) and Sunbury Textile Mills v. Com${ }_{243}$ Berke Moore Co. v Phoenix Bridge Co., 98 A.2d 150, 156 (NH 1953) and
misioner, 585 F.2d 1190 ( $3^{\text {td }}$ Cir. 1978). See also Restatement Second \$201(1).

misioner, 585 F.2d 1190 ( 3 Cir. 1978). See also Restatement Second \$201(1). ${ }^{244}$ Farnsworth 1999, p. 465-466. See also Southern Bell Tel. \& Tel. Co. v Florida EC Ry, $339 \mathrm{~F} .2 \mathrm{~d} 854 \mathrm{k} 5^{\text {th }} \mathrm{Cir}$. 1968).

${ }^{245}$ Florida East Coast Ry. Co. v CXS Transp., 42 F.3d 1125 ( $7^{\text {th }}$ Cir. 1994, Berg v Hudesman, 801 P.2d 222, 230 (Wash. 1990). Cf. The first principle of contract interpretation under English law.

${ }^{246}$ Judge Learned Hand in Guiseppi v Walling 144 F.2d 608 (2d Cir. 1944).

${ }^{247}$ Maryland-National Capital Park \& Planning Commn. V Lynn, 514 F.2d. 829 (DC Cir. 1975).

${ }^{248}$ Farnsworth 1999, p. 468. See also New England Structures v Loranger, 234 N.E.2d. 888 (Mass. 1968). 
purpose. ${ }^{249}$ In addition, the conduct of the parties after the conclusion of the contract might illuminate the meaning attached to contract language. Such practical construction is given great weight by the courts: 'the interpretation placed upon a contract by the parties themselves, before a dispute has arisen, is entitled to the greatest weight. ${ }^{, 250}$ Sometimes the court may also be able to discern the meaning of the words from the context of the contract itself; contract recitals, referring to the surrounding circumstances and the objectives of the parties-even though regarded as subordinate to the operative part of the contract-may help to ascertain the meaning of contractual language. As stated by a court: 'Although they [the recitals] do not ordinarily form any part of the real agreement, they do indicate the background of the contract, and may be referred to in determining the intent of the parties where its operative parts are ambiguous. ${ }^{251}$ The language itself however, poses a natural limit on the extent to which the court can take in to account surrounding circumstances: ' $[t]$ he more bizarre and unusual an asserted interpretation is, the more convincing must be the testimony that supports it. At what point the court should cease listening to testimony that white is black and that a dollar is fifty cents is a matter for sound judicial discretion and common sense. ${ }^{252}$

I have indicated that the court may take into account all relevant surrounding circumstances in order to ascertain the meaning to be given to the language of the contract. However, a corollary of the parol evidence rule, which restricts prior evidence to be invoked in order to add or contradict contract the terms of a completely integrated agreement, acts to exclude from the surrounding circumstances evidence of prior negotiations. This rule, referred to as the plain meaning rule, limits the type of evidence to be included under the surrounding circumstances. Justification for this rule is sought in arguments similar to those under English law. First of all, the exclusion of prior evidence may allow for a faster trial while the pre-trial process is shortened. In addition, if prior evidence is excluded, issues concerning contract interpretation will be increasingly left to judges as issues of law rather than issues of fact. The former are addressed by a trial judge instead of a jury and reviewed on a plenary rather than erroneous basis. ${ }^{253}$ Similar to English law, the rule that prior negotiations are excluded from the surrounding evidence in light of contract interpretation, has been subject to several exceptions.

In the US, two approaches have been taken with regard to the application of the plain meaning rule. Under both approaches, the court will first assess whether the language

${ }^{249}$ Restatement Second §201(1): 'if the principle purpose of the parties is ascertainable it is given great weight.'

${ }^{250}$ Farnsworth 1999, chapter 7

${ }^{251}$ Ohio Valley Gas v. Blackburn, 445 N.E.2d 1378 (Ind. App. 1983), p. 1383.

${ }^{252}$ Corbin 1944, p. 623.

${ }^{253}$ Federal Deposit Ins. Corp. v WR Grace \& Co., 877 F.2d $614\left(7^{\text {th }}\right.$ Cir. 1989). 
in dispute lacks clarity, i.e. is ambiguous or vague, before continuing to the second stage, namely the interpretation of this ambiguous or vague language. Under the old and more restrictive view of the plain meaning rule, incorporated in Restatement First ${ }^{254}$, the court can only look at the language itself in light of surrounding circumstances, but is not allowed to resort to evidence of prior negotiations in order to establish whether the language lacks clarity (stage 1). The judge may use evidence of prior negotiations to interpret the language only if this language is found to be ambiguous or vague. While this restrictive view still finds expression in judicial opinions, the rule has gradually been relaxed under the recognition that the meaning of contract language is often dependent upon its context. The liberal view, incorporated in Restatement Second (\$212), does admit evidence of prior negotiations in order to determine whether the meaning of the language lacks clarity (stage 1). ${ }^{255}$ Both Restatement First and Second will allow the court to invoke evidence of prior negotiations in order to ascertain the meaning of language which is ambiguous or vague (stage 2 ). It is important to note that even under the liberal approach, evidence of prior negotiations is only admissible if it is offered for the purpose of interpreting the terms in writing, and not to contradict or add to them.

In interpreting contract language, the court may also rely on various other rules of interpretation. Many of these rules are also found in English law and I will therefore not explicate in detail the meaning of each of these rules in this paragraph. First of all, the rule expressio unius est exclusio alterius, requires the court to interpret a number of listed items to the exclusion of others. ${ }^{256}$ Another rule relates to the expression ejusdem generic (of the same kind). ${ }^{257}$ A contract must, to the extent possible, be interpreted as a whole, giving effects to all of its parts, Interpretations which would negate or give no effect to a provision are to be avoided. ${ }^{258}$ From the foregoing rule, emanates the principle that the court will attempt to interpret the language of the contract in a consistent manner: words that are used more than once are assumed to have the same meaning throughout the contract ${ }^{259}$ in addition to a meaning that is consistent with the meaning of the contract in general. ${ }^{260}$ Contractual clauses which have received greater attention in negotiations and drafting are considered to be more likely to reflect the parties' intentions. In accordance with the foregoing, separately

\footnotetext{
${ }^{254}$ Restatement First $\$ 230$. See also WWW Assocs. V Giancontieri 566 NE.2d 639 (NY 1990). ${ }_{255}$ Pacific Gas \& Electric Co, v G.W. Thomas Drayage \& Rigging Co. 442 P.2d, 641, 644 (Cal. 1968).

${ }^{256}$ See Farnsworth 1999, p. 471 in reference to Central Hous. Inv. Corp. v Federal Natl. Mortgage Assn., 248 P.2d 866 (Ariz, 1952), where the court held that mortgage covering 'all heating, plumbing and lighting flxtures and equipment' did not cover cooling and refrigerating equipment.

${ }^{257}$ See Farnsworth 1999, p. 471 in reference to State ex rel. Commissioners of Land Office v Butler 753 P. 20 1334 (Okl. 1987) where the court held that the 'reservation of an interest in 'oil, gas and other minera rights' did not include coal.

${ }^{258}$ Brinderson-Newberg Joint Venture v Pacific Erectors, 871 F.2d $272\left(9^{\text {th }}\right.$ Cir. 1992).

${ }^{259}$ Taracorp, Inc. v NL. Indus., 73 F.3d $738\left(7^{\text {th }} \mathrm{Cir}\right.$. 1996).

${ }_{200}$ Barco Urban Renewal Corp. v Housing Auth., 674 F2.d 1001 (3 ${ }^{\text {rd }} \mathrm{Cir}$. 1982).
} 
negotiated terms are given greater weight than standardized terms. ${ }^{261}$ Important also, is the contra proferentem rule. ${ }^{262}$ When the language supplied by one party is susceptible to two interpretations, one of which favors each party, the one that is less favorable to the party that supplied the language is preferred. ${ }^{263}$ This rule is based on the ground that the party against whom the rule operates has had the possibility of drafting the language in such a manner to avoid the dispute. While this rule is most commonly applied in consumer contracts, it has also been made applicable to commercia agreements. ${ }^{264}$ In addition, an interpretation of a term which favors the public interest is preferred over any other interpretation of the term. The justification for this rule may be found in the argument that terms which are contrary to public policy are invalid, a justification unrelated to the intentions of the parties. Finally, in reference to standard terms, Restatement Second (\$211) states that '[s]uch a writing is interpreted whenever reasonable as treating alike all those similarly situated, without regard to their knowledge or understanding of the standard terms of the writing.' The effect of this provision is that standard terms will be interpreted in a manner such that the equal treatment of parties in similar situations prevails over any meaning an individual party may have ascribed to the term.

\section{The Netherlands}

In contrast to the US and England, Dutch law takes a primarily subjective approach towards contract interpretation: the common or actual intention of the parties will prevail and contract interpretation is governed by reasonableness and equity. The celebrated Dutch Haviltex-case ${ }^{265}$ lays down the criteria for the interpretation of contracts. In this case, the court rejects both an approach based solely on the literal expression of parties' intentions, as well as a purely subjective approach to contract interpretation. Instead, the court stipulates that a contract should be interpreted according to parties' intentions and expectations in the given circumstances. Even when the words seem clear on their face (plain meaning), the court should take into account both the intention of the parties as well as the surrounding circumstances in order to determine if the words really are clear. The parties' intention stretches beyond party's own intentions, to comprise what each party believed and could reasonably have believed that the other intended with the contract. As such, each party is granted protection in their justified reliance on the meaning they gave to the words as well as their justified reliance that the other party meant the same.

${ }^{261}$ Restatement Second $5203(d)$

${ }^{252}$ Farnsworth 1999, p. 472 distinguishes this rule from the foregoing rules, while the contra proferentern rule helps to determine the legal effect which must be given to the language independent from the meanin that parties may have attached to it. This is in line with his distinction between the interpretation of contracts, i.e. giving meaning to the language of the contract and the construction of the contract, i.e. giving legal effect to the language of the contract. I do not make this distinction in this chapter.

${ }^{263}$ Production Credit Assn. v Wynne, 474 N.W.2d 735 (S.D. 1991).

${ }^{254}$ Bay State Smelting Co v Ferric Industries $292 \mathrm{~F} .2 \mathrm{~d} 96\left(1^{\mathrm{s}} \mathrm{C}\right.$ Cir. 1961).

205 Supra n. 311. 
The Haviltex-standard is generally characterized as a subjective-objective criterion. The primary goal is to find the common meaning that parties have attached to the language of the contract, and if this is not possible, e.g. because parties have not agreed to a common meaning, courts will take a more objective approach towards interpretation. When parties have agreed to a common meaning, this meaning will prevail, even though the latter might not coincide with the ordinary linguistic meaning of the term. Tjittes (2005) argues that while it is difficult to discern the internal will of parties, the common intention must be found in extrinsic evidence. Extrinsic evidence includes, but is not limited to, the nature of the contract, evidence of prior negotiations, and parties' subsequent conduct. Most often however, parties will not have attached the same meaning to a contract term, or not given the meaning of the term specific thought at all. In this case, the Haviltex-standard allows a court to invoke parties' reasonable or justified expectations. In order to ascertain parties' reasonable or justified expectations, the court does not invoke the 'eye' of the reasonable person, but instead investigates which meaning parties acting in a reasonable manner could have given to the terms expressed in the contract. The reasonableness thus reflects an objective element: the ascribed meaning must be reasonable in the given context. In order to determine this reasonable meaning, the court may take into account the surrounding circumstances such as the nature and purpose of contract ${ }^{266}$, negotiation and drafting history ${ }^{267}$, parties' statements and (subsequent) conduct, the nature of the parties, trade usages and other relevant facts surrounding the transaction. ${ }^{268}$ For example, a court may consider the recitals or preambles in order to shed light on the interpretation which must be given to a specific term. ${ }^{269}$ Discerning the underlying intention of the parties, however, remains the determinative element in giving meaning to the language of the contract.

In principle the interpretation of contracts is governed by the Haviltex-norm. In two cases concerning collective labour or employment agreements in $1993^{270}$ the Dutch Supreme Court ruled, however, that in particular circumstances, the text of the agreement may be decisive. A collective employment agreement ('Collectieve arbeidsovereenkomst') ('CAO') is an agreement which is negotiated between employee and employer organisations and regulates their rights and obligations. While this contract creates rights and obligations for employees, they are not themselves involved in the negotiations and drafting of the contract terms; the negotiations are conducted by representatives of the former. When a contract creates rights for third parties, who were not present during the negotiations of the contract, the court will prescribe an

${ }^{266}$ HR 1 July 1985, NJ 1986, 692 (Frenkel/KRO), HR 26 June 1998, NJ 1998, 660, HR 17 December 1976, NJ 1977, 241 (Bunde/Erckens).

${ }^{267}$ HR 13 January 1978, NJ 1978, 302 (Swimming pool/diligentia), HR I July 1982, NJ 1983, 682 (Codicil).

${ }^{268}$ Wissink 2002.

${ }^{269}$ HR 30 November 1951, NJ 1953, 76 (Van Stijverden/Olst)

270 HR 17 September 1993, NJ 1994, 173 (Gerritse/Has), HR 24 September 1993, NJ 1994, 174 (Hol/ ElMK). 
interpretation according to an objective standard. Under this standard, the focus is on the wording of the contract. Consideration is given primarily to the parties' intention as expressed in the written document, explanatory texts available to third parties and other relevant information that is publicly available. ${ }^{271}$ While this method of interpretation was specifically developed for the interpretation of CAO agreements, it has been extended to apply to other types of contracts that affect third parties. A third par $y$ refers o a par $y t^{\prime}$ at 'as 'ecome nvolve; ' ut was no presen 'uring nego iations and thus could not influence the content of the agreement (e.g. compensation agreements, contracts concerning the transfer of property and arbitration regulations). It is important to note that the mere fact that the rights and obligations of a third party are affected does not justify the application of the CAO interpretative standard per se; it must lie within the nature of the contract to affect or influence the legal position of third parties. ${ }^{272}$

In DSM/Fox, the Dutch Supreme Court attempted to reconcile the two different views with regard to contract interpretation laid down in the cases of Haviltex and CAO, and indicated that these should not be seen as opposing and contradictory, but rather as a continuum.

The standards of interpretation discussed above should be read while keeping in mind that the interpretation of contracts under Dutch law is governed by the principle of good faith, regardless of the specific approach taken. ${ }^{273}$ Parallel English and American law, general principles of contract interpretation exist in order to aid the process of interpretation: (1) a contractual stipulation must be understood in sense that it has effect rather than no effect; (2) the contra proferentem rule establishes that in case of

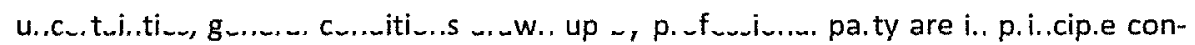
strued in favour of the other party, especially when the other party is a consumer; (3) written or typed additions to general conditions prevail over printed conditions; (4) a contractual provision must be interpreted in the light of the contract as a whole ${ }^{274}$; and (5) when the main part or 'body' of an agreement contradicts with the recitals or appendix, greater weight will be given to the meaning of the terms as defined in the body of the agreement.

\section{Implications for the complexity of contracts}

The interpretation of contract terms takes place at the back end of the contracting process and has an effect on the level of enforcement costs. English and American courts take a predominantly objective approach toward the interpretation of contracts in contrast to the subjective approach adhered to in many civil law jurisdictions. The

\footnotetext{
271 Wissink 2004.

${ }^{272}$ HR 9 July 2004, NJ 2005, 496 (Hoeves/van Dijk).

${ }^{273}$ HR 20 February 2004, NJ 2005, 493 (DSM-Chemie/Fox).

${ }^{274}$ HR 18 November 1983, N/ 1984, 272.
} 
modern development of contract interpretation in the US and England has created an increasing role for surrounding circumstances, which seems to close the gap between civil and common law systems with regard to rules on contract interpretation. Despite this development, the common intention as objectively expressed by the parties, remains leading. An elaborate and precise account of parties' intentions and thereby obligations and rights, will produce substantial benefits for parties contracting in the US and England once a dispute arises before court. The general preclusion of prior negotiations with regard to the interpretation of contracts may for example induce parties to pay greater attention to the drafting of Recitals. Even though Recitals are generally not given legal effect, they are able to shed light on the surrounding circumstances, e.g. the positions of parties, and parties' negotiations and objectives upon entering into the contract. ${ }^{275}$ In addition, definitions of specific terms and words will guide the courts in the interpretation of the language of the contract, giving the language its special or technical sense if so specified. The contracting costs associated with a detailed description of parties' rights and obligations and the specific use of language, will be offset by the benefits. A predominantly objective approach to contract interpretation enables parties to rely upon the judge to strictly adhere to the writing of the said document.

In contrast to common law judges, judges in the Netherlands will seek the actual intention of parties and are permitted to take into account any evidence, including evidence of prior negotiations, to establish this intention. Parties will not be restricted in the provision of evidence in order to establish and prove the definition of the language of the contract. The rules of contract interpretation do not seem to provide the parties with an incentive to specify their obligations and rights in great detail. ${ }^{276}$ Such a liberal interpretation, however, seems to provide the parties with the opportunity to strategically advance a favorable interpretation of the contract. A detailed written account of the parties' agreement on the other hand supplies the court with an instruction on how parties' rights and obligations must be construed and may assist in recovering the actual intentions of parties. A detailed account of parties' agreement thus reduces the risk that one of the parties will strategically advance a favorable interpretation. However, contracts governed by Dutch law and litigated in the Netherlands, more often than not, do not include detailed lists of definitions, rights and obligations or extensive recitations of black letter law. Obviously the associated contracting costs are not justified. A reason might be that the advancement of a particular interpretation of the terms ex post, becomes less attractive due to the existence of general conventions of

275 Under English law, recitals may be invoked in order to ascertain the meaning of an amblguous or vague term in the body of the agreement. However, when the language in the operative or main part of the agreement is clear, recitals will not be accepted as determinative (see Fontaine and De Ly 2006, p. 89 and p.

$89, \mathrm{n} .50)$.
${ }^{770} \mathrm{An}$ exception can be made for the case of CAO agreements and comparable cases, where the judge has taken a more objective approach. 
fairness such as the principle of good faith. These comventions serve to prevent unjust outcomes. In addition, a greater level of trust might exist between the contracting parties on the one hand, and the contracting parties and the third party adjudicator on the other hand. The former assumption will negatively affect strategit advancement of interpretation, while the latter situation implies that parties entrust the judge to inter. pret the language of the contract in a fair and just manner. The level of trust in the respective countries will and conventions of fairness such as good faith will be discussed in other sections of this chapter.

Dealing with omitted cases (implied terms)

in addition to the interpretation of the written and established terms of a contract. circumstances may arise for which parties have not provided in their contract. There are two types of situations in which omissions may occur. in the first place, parties may foresee a potential circumstance or dispute, but make the decision not to deal with the specific situation in the contract as it is unlikely that the precise circumstance will arise. Businessmen will often 'pay more attention to describing the performance in an exchange than to planning for contingencies or defective performance or to obtaining legal enforceability of their contracts. ${ }^{277}$ The conscious omittance may also relate to the reluctance of one party to disclose certain information. in the second place, the specific situation may simply not have been foreseen by either of the parties. Some situations are so unlikely to occur such that neither party gives these situations any thought. In addition, circumstances likely to arise may be overlooked due to haste or inadvertence; such unforeseeability increases with the lifespan of the contract. In either of the two foregoing cases, the courts may decide to supply a term in order to fill the gap left by the parties. These terms which are to be supplied by the courts, are traditionally referred to as 'implied terms'. The associated rules are commonly described as 'default rules' or 'gap-filling rules'. In the following paragraphs, I will discuss the manner in which each legal system attempts to deal with this omission of terms.

England

Closely linked and not always easily distinguished from contractual interpretation, is the power of the English Courts to imply terms where parties have omitted them. Terms may be implied by statute, custom or usage, or may be developed by the courts. The terms implied by courts may be divided into two groups: (1) terms implied in fact and (2) terms implied in law. Whereas the distinction between these two terms is not always clear, terms implied in fact are created for detailed contracts on an individual basis. These terms are implied in order to give effect to parties' intention on matters which they omitted to express in their contract. Terms will be implied in law where precedent or statute has incorporated such terms in particular types of contracts. Terms implied in law are used to incorporate into contracts certain basic rules of law,

${ }^{27}$ In the US such tendency is enforced by the parol evidence rule. 
for example to achieve greater fairness. When the term implied in law is of a mandatory nature, parties' intentions play a secondary role; parties cannot contract around such a term.

Terms implied by custom or trade usage

Terms may be implied by custom or trade usage. A custom is often local and idiosyncratic and most customs have existed for a long time. When parties both understand the custom to be part of their contract, such a customary term will generally be enforced. However, such a term must be consistent with the express terms of the agreement and the rules of common law. In addition, such customary rules should be reasonable. ${ }^{278}$ Trade usage on the other hand, is assimilated with a particular area of business. Transacting on basis of a certain trade usage is often so straightforward that parties do not bother to explicitly incorporate this usage into their contract. In order to be enforced, trade usages must be both reasonable and certain. A court will generally not enforce an unreasonable trade usage. However, if a party is aware of the usage and agrees to its incorporation, albeit not as an explicit written term in the contract, then this party is considered bound, even if the usage is unreasonable. In addition, trade usages should be generally recognized in the trade or industry and not only by the parties themselves. Finally, parties must show that they both intended to be bound by the trade usage even though they did not explicitly incorporate this usage into their contract. ${ }^{279}$

Terms implied by statute

Statute may also serve as a source of implied terms. Depending on the type of contract, different kinds of terms may be implied. The SGA 1979 for example, implies a number of terms into all contracts for the sale of goods, most of which refer to conditions of quality. These conditions apply to all contracts, whether the buyer is a private party or acts in business capacity. Examples are s.13, which regulates that goods must strictly respond with their description, and s.14(2a) and (3b) which determine that the goods sold must be of 'satisfactory quality' and 'reasonably fit for their purpose'. The breach of such conditions is strict, i.e. the buyer is not obliged to prove fault on the side of the seller. ${ }^{280}$ Contracts for services are governed by the SGSA 1982, which implies terms with regard to the quality and fitness of the transfer of goods (excluding the transfer of property and ownership) and supply of services. ${ }^{281}$

${ }^{278}$ Hutton v Warren (1836) M and W 466, 150 ER 517.

${ }^{279}$ Cunliffe-Owen $v$ Teather and Greenwood [1967] 1 WLR 1421.

${ }^{280}$ Under the Unfair Contract Terms Act 1977 ('UCTA 1977') it is not possible to contract out of liability fo breach in light of $5.14(2 a),(2 b)$ and $(2 c)$ or s.13 when it concerns consumer sales. The terms are thus mandatory. In case of non-consumer sales, any exclusion or limitation of llabllity for breach of the foregoing sections is subject to a 'reasonableness' test (UCTA 1977, s.6).

${ }_{281}^{2}$ SGSA 1982, s.11 stipulates that the terms may be 'negatived or varied by express agreement, or by the ${ }^{281}$ SGSA 1982, s.11 stipulates that the terms may be 'negatived or varied by express agreement, or by the
course of dealing between parties, or by such usage as binds both parties to the contract' (unless prohibited under the UCTA 1977). 
Terms implied by the courts

With regard to terms implied by courts, it can be concluded that the law is 'vague and lacking in definite principles'. ${ }^{282}$ The importance of the distinction between terms implied in fact and terms implied in law seems to be that the test for terms implied in law appears to be less stringent than for terms implied in fact. ${ }^{283}$ Conventionally, courts would only commit to imply a term in fact where it was necessary to do so, while the test for the implication of a term in law seems to lie somewhere between 'necessity' and 'reasonableness'.

Traditionally, English courts have taken a cautious approach with regard to the implication of terms ${ }^{284}$, while freedom of contract and parties' autonomy presides: ' $(. .$.$) it is a$ dangerous thing lightly to imply what they [the parties] have not expressed (...) [T]he court ought not to imply a term into a contract unless there arises from the language of the contract itself $(. .$.$) such an inference that the parties must have intended the$ stipulation in question [so] that the Court is necessarily driven to the conclusion that it must be implied. ${ }^{285}$ Whenever the court implies a term, it will need to consider amongst others, the type and nature of the contract, the economic particularities of the situation, the compliance with existing law, parties' respective bargaining positions, the burden imposed on one of the parties, and the general principles and values of the legal system. In the following paragraphs I will give an overview of the developments with regard to the implication of terms by courts.

The case of the Moorcock ${ }^{286}$, one of the more traditional cases with regard to the implication of terms, refers to (1) the source of the implied term: the implied term must emanate from the presumed intention of the parties and (2) the circumstances under which a court may imply a term: the court may imply a term when this is necessary in order to give business efficacy to the transaction. With regard to the first element Lord Justice (U) Bowen determined that a term should be implied to give effect to parties' unexpressed intention: 'the presumed intention of the parties with the object of giving to the transaction such efficacy as both parties must have intended that at all events it should have. ${ }^{287}$ The courts thus become involved in discovering the hypothetical or actual intention of the parties, and with regard to the implication of terms take a subjective approach. With regard to the second element: a court may only imply a term if this is necessary in order to make the contract work. In this particular case the

${ }^{282}$ Peden 1998, p. 131 referenced by Kornet 2006, p. 213

${ }^{283}$ Mckendrick 2003, p. 375

${ }^{284}$ Easton v Hitchcock [1912] I KB 535, which illustrates the reluctance of the court to imply a confidentiality clause. As a consequence, parties now frequently incorporate explicit confidentiality clauses into their contracts.

${ }_{285}^{285}$ Hamlyn and Co. v. Wood and CO. Kay L.J., [1891] 2 QB, p. 494.

${ }^{286}(1889) 14$ PD 64.

${ }^{287}$ lbid. p. 68. 
term was necessary in order to give business efficacy to the contract. In the years following the Moorcock, the necessity test established itself in case law.

The necessity test also played a role in Shirlaw $v$ Southern Foundries where Lord Justice Mackinnon found that: 'Prima facie that which in any contract is left to be implied and need not be expressed is something so obvious that it goes without saying; so that, if while one of the parties were making their bargain, an officious bystander were to suggest some express provision for it in the agreement, they would testily suppress him with a common, "oh, of course". ${ }^{288}$ The necessity test in the foregoing case was one of the 'officious bystander'. Both of the foregoing tests, the business efficacy test and the officious bystander test, take into account the necessity of implying a term and import a subjective element into the reasoning of the court. ${ }^{289}$ These tests reinforce the fact that English courts exercise restraint with regard to the implication of terms. They will not imply a term merely because it would be reasonable: 'they will not (...) improve the contract which the parties have made for themselves, however desirable the improvement might be. ${ }^{290}$

In contrast to the foregoing, Lord Denning is of the opinion that a court should not only imply a term if parties would have agreed to such a term, but whenever it would be reasonable to do so, taking into account the surrounding circumstances of the case. ${ }^{291}$ In Liverpool City Council v Irwin ${ }^{292}$, the House of Lords rejected Lord Denning's (wider) test of reasonableness. ${ }^{293}$ The case concerned the question whether a term, relating to the obligation of the tenant to keep the common parts of the property in repair and properly lit, should be implied in a tenant agreement. The House of Lords did imply a such a term, but argued that such a term may not be implied solely on reasonableness, but that it must also be necessary to do so: 'I cannot go as far as Lord Denning MR and hold that the courts have any power to imply a term into a contract merely because it seems reasonable to do so. Indeed, I think that such a proposition is

\footnotetext{
${ }^{288}$ [1939] 2 KB 206, p. 227. See also Scrutton $U$ in Relgate v Union Manufacturing Co. [1918] 1 KB 592, p. 605: ' $[i] t$ is such a term that it can confidently be said, that if, at the time the contract was being negotiated, some one had said to the parties, "What will happen in such a case?" they would have replied: "Of course, so and so will happen; I did not trouble to say that; it is too clear." Unless the court comes to some such conclusion as that, it ought not to imply a term which the parties themselves have not expressed.' ${ }^{289}$ While the relation between the two tests has not always been clear, the general rule currently is that satisfaction of either test Is sufficient (Treitel 1999, p. 185).

${ }^{2.90}$ Trollope \& Colls Ltd. v N.W. Metropolitan Hospital Board [1973] 1 WLR 601, p. 609.

${ }^{291}$ Greaves and Co (Contractors) v Baynham Meikle and Partners [1975] 1 WLR 1095, and in the Court of Appeal in Liverpool City Council v Irwin [1.976] 1 QB 319

${ }_{202}^{202}$ [1977] AC 239.

${ }^{293}$ In addition to rejecting the reasonableness test as put forward by Lord Denning, Lord Cross of Chelsea In this case also addressed the issue put forward by the counsel of the defendants of whether the term concerned a term Implied in fact or in law. I will not explicitly address this issue in this chapter. The case is generally regarded as an authority on terms implled in law conform the decision of Lord Cross.
} 
contrary to all authority. ${ }^{294}$ The difficulty of the necessity analysis relates to its application to the facts. ${ }^{295}$ The question may be asked if it was really necessary to imply such a term into a tenancy agreement, or that it actually concerned a matter of social policy regarding the scope of a tenant's obligations. Professor Atiyah rightly states that the difference between reasonableness and necessity is not very clear: The difference in opinion between the judges on this point seems, however, to have been somewhat unreal. For it is evident that the formula that implications can only be made when necessary is not to be taken too literally. It is not necessary to have lifts in blocks of flats ten storeys high (...) though it would no doubt be exceedingly inconvenient not to have them. So 'necessary" really seems to mean "reasonably necessary", and that must mean, "reasonably necessary having regard to the context and the price". So in the end there does not seem to be much difference between what is necessary and what is reasonable. ${ }^{296}$

At the same time Liverpool City Council v Irwin was addressed at the House of Lords, BP Refinery (Westernpoint) Pty Ltd. $v$ Shire of Hastings ${ }^{297}$ was on appeal from the Supreme Court of Victoria in Australia. In the latter case, a compilation of criteria was given which may guide the decision to imply a term in a contract; the different criteria may overlap and are not cumulative. The criteria establish that a term must: (1) be reasonable and equitable; (2) be required for business efficacy; (3) be obvious; (4) be capable of clear expression; and (5) not contradict the express terms of the contract. The first criterion is quite straightforward and designates simply that the implied term must be reasonable and equitable. The second criterion refers to the business efficacy test, e.g. it does not suffice that a term simply improves contractual performance. The obviousness of the term refers to the fact that the term must be so obvious that it goes without saying; parties must have intended for one and only one particular term to be implied. ${ }^{298}$ The fourth criterion reflects the fact that the term must be capable of clear expression; a person without technical or special knowledge should be able to understand the term. Finally, an implied term may not contradict an express term of the agreement. Sir Bingham accepted the BP Westernpoint criteria in Phillips Electronique $v$ BSky Broadcasting Ltd as 'an accurate and comprehensive statement of the law on the implication of terms in to commercial contracts. ${ }^{299}$

\footnotetext{
${ }^{294}$ Lord Salmon in Liverpool City Council v Irwin [1977] AC 239, p. 262.

${ }^{295}$ McKendrick 2003, p. 385.

${ }^{296}$ Atiyah 2005.

297 (1977) 180 CLR 266.

${ }^{298}$ For example in the case of Codelfa Construction Pty Ltd v. State Rail Authority of New South Wales (1982) 149 CLR 337, a term concerning the inability of a construction firm to work three shifts a day, could not be implied because such a term could have taken numerous forms.

299 [1995] 3 EMLR 472 at p. 480-482
} 
The United States

How do US courts decide whether to fill in omitted circumstances in contracts? The first step the court will take is to interpret the contract in order to assess whether the language of the contract does not cover the situation at hand. The greater the detail and comprehensiveness of the agreement, the more reluctant the court will be to imply a term. If the court reaches the conclusion that the contract does not provide for the specific situation at hand, the court will generally resort to the implication of such a term. ${ }^{300}$ The terms supplied by court have been labeled implied terms or constructive terms. The corollary of such a term is a default rule.

The primary basis for implication of a term is the actual expectation of the parties. If the parties share a common expectation with respect to the omitted case, the court will give effect to that expectation. Reminiscent of English law, the implication of terms entails a subjective test: the actual intention of the parties is sought. However, if parties' expectations diverge or if one party has no expectation, the court will apply an objective test of expectation. The court will then inquire whether the party which carried no expectation should reasonably have been aware of the other party's expectation with regard to the case at hand. Expectation may be inferred from the agreement itself; recitals or provisions dealing with related situations may shed light on the parties' intention with respect to the situation at hand. Parties' intention may also be deduced from a course of performance, course of dealing or usage ${ }^{301}$, or from the negotiations that led up to the agreement, less the parol evidence rule permits such prior evidence to be included. Often, however, no reliable indication of expectation can be found and the court must then seek some other basis for implication. It is sometimes suggested that if the actual expectations of the parties cannot be determined, the courts should place itself in the position of the parties and imply a term which the parties would have incorporated had they considered the case. However, we must keep in mind that courts are faced with bounded rationality and it is questionable whether they can remedy 'the shortsightedness of individuals, by doing for them what they would have done for themselves if their imagination had anticipated the march of nature. ${ }^{302}$ Farnsworth (1999) argues that in such cases, the court should rely on basic principles of justice, such as fairness. Principles of fairness are able to effectuate a fair bargain. This means that a term implied may be used to neutralize the bargaining position between the parties. Depending on the facts of the case, a judge may imply a term such that the burden of expression is placed upon the party that is better able to cope with it because of its greater bargaining power and drafting skill.

${ }^{300}$ Haines v City of New York, 364 N.E.2d 820, 822 (N.Y. 1977).

${ }^{301}$ Columbia Nitrogen Corp. v Royster Co., $451 \mathrm{~F}, 2 \mathrm{~d} 3\left(4^{\text {th }} \mathrm{Cir}\right.$. 1971).

${ }^{302}$ Bentham, J., 'A General View of a Complete Code of Laws' in J. Bowring (ed.), 3 Works of Jeremy Bentham

1843 , p. 191, quoted by Farnsworth 1999, 67.16. 
Recurring situations often lead to the development of standard terms, which have often been laid down in statute and may serve as a source of terms to be implied. Such default rules may bring certainty, in the sense that parties may rely on these rules and consequently make the decision to forego explicit incorporation of the particular issue in their contract. On the other hand, these rules do not always confer with parties' expectations and may encourage parties to contract around the particular rule. The term penalty default rule has been used to describe default rules which effectuate this type of evasive behavior. ${ }^{303}$ The avoidance of the application of default rules through the incorporation of other provisions is costly. Farnsworth (1999) indicates that as an increasing number of complex and refined terms exist as defaults, variation by express agreement becomes increasingly difficult and costly. Subsequently the court's tendency to treat state-created rules as presumptively fair often leads to judicial disapproval of efforts to vary standard implied terms by agreement. ${ }^{304}$

\section{Examples of implied terms}

In this paragraph I will discuss some of the terms which have been implied on a regular basis by American courts. Examples are the duty of good faith and best efforts, unilateral termination, terms making a party's duties conditional on performance by the other party, and terms relating to impracticality and frustration which subsequently excuse a party's performance.

Courts have often supplied terms which require the parties to a contract to exercise good faith or fair dealing with regard to the performance and enforcement of the contract. $^{305}$ Article $\$ 1-203$ UCC imposes such an obligation of good faith to noncommercial and commercial contracts. Article $\$ 1-203$ has a general application while, unlike Article 2, it is not restricted to agreements governing the sale of goods. The duty of good faith under the UCC has a mandatory character and it may thus not be disclaimed by agreement. However, parties may in their contract agree upon other standards of performance as long as these standards are in accordance with good faith and are thus not manifestly unreasonable. ${ }^{306}$ This mandatory nature of the duty of good faith under the UCC is not easily reconcilable with the common law principle that an express provision of a contract will supersede the duty of good faith, if the former provision is in conflict with the latter. In Riggs Ntl. Bank of Washington v Linch for example, the court held that the implied duty of good faith cannot be used to override or modify explicit contractual terms. ${ }^{, 307}$ While it concerns an implied duty of good faith, such a duty will only arise once an agreement has come into existence; the duty

${ }^{303}$ Farnsworth 1999, p. 501, citing Ayres and Gertner 1989, p. 91

${ }^{304}$ Ibid., Goetz and Scott 1985, p. 298.

${ }^{305}$ Antony's Pier Four v HBC Associations, 583 N.E.2d 806 (Mass, 1991).

${ }^{306}$ UCC $51-102(3)$

${ }^{307} 36$ F.3d 370 (4th Cir. 1994) 
will not bind parties during their earlier negotiations. ${ }^{308}$ The duty does apply to negotiations concerning the modification of an existing contract. The precise scope of the duty depends on the nature of the contract and parties' characteristics.

In addition, courts often imply a term which imposes on parties a duty to exert best or reasonable efforts in the execution and performance of the agreement. Such efforts are deemed reasonable in the light of party's abilities and means at its disposal, taking into account the justified expectations of the other party. Although the scope of this duty is just as vague as the duty of good faith, it is clear that the duty of best efforts is more onerous than that of good faith. Courts have implied a duty to exert reasonable efforts in a diverse range of agreements such as exclusive dealing agreements and percentage leases.

A judge may also imply rights relating to the termination of an agreement. Unilateral termination right may for example be implied in an agreement with an otherwise indefinite duration. Courts have traditionally applied a termination right in diverse business contracts, such as franchise and distributorship agreements, and employment contracts, on the ground that parties ordinarily do not intend to maintain their business relationships forever and should not be required to continue a relationship once it has gone sour. ${ }^{309}$ An implied right of termination will often include the condition that a reasonable period of notice must be taken into account before the right is exercised.

Terms implied by custom and course of dealing

Finally, it is important to note that the Article \$1-205 UCC establishes that a course of dealing and usage of trade may not only be used to aid in the interpretation of a contract term, but may also act to supplement or qualify parties' agreement. More specifically, Article \$1-205(2) UCC describes a usage of trade as a 'practice or method of dealing having such regularity of observance in a place, vocation or trade as to justify an expectation that it will be observed with respect to the transaction in question.' A usage may be limited to a particular sector or area. Article UCC \$1-205(1) describes a course of dealing as 'a sequence of previous conduct between the parties to a particular transaction which is fairly to be regarded as establishing a common basis of understanding for interpreting their expressions and their conduct.' In order for a course of dealing to come into existence, parties must have conducted comparable previous transactions. While the supplementary function of both the course of dealing and usage of trade has been 'criticized as an unwarranted encroachment on the general rules of law that would otherwise be used to perform this task ${ }^{\prime 310}$, the commentary of the Code rejects those cases where usage of trade or course of dealing acts to displace

${ }^{308}$ Husmann, Inc. v Triton Coal Co., 809 P.2d 796 (Wyo. 1991).

${ }^{309}$ Delta Services \& Equipment v Ryko Manufacturing Co., 908 F.2d 7, 11 (5 ${ }^{\text {th }}$ Cir. 1990), Clty of Homestead v Beard, 600 So. $2 d 450$ (Fla, 1992) and Bak-A-Lum Corp. v Alcoa Bldg. Prods. 351 A.2d 349 (N.J. 1976).

${ }^{310}$ Farnsworth 1999, p. 485 
established rules of law. The existence of a usage of trade or course of dealing is a proof of fact. Parties must produce evidence which may establish the practice or method of dealing and prove that the other party had knowledge of this course of dealing or usage of trade.

\section{The Netherlands}

English and American courts apply the doctrine of implied terms to deal with these gaps in contracts. Article 6:248(1) DCC stipulates that additional duties and rights can be established when parties have failed to provide for a particular term in their contract. Article 6:248(1) DCC states that a contract not only has the legal effects agreed to by the parties, but also those effects which, according to the nature of the contract stem from legislation, custom or good faith. ${ }^{311}$ Dutch legal scholars generally do not refer to $6: 248(1)$ DCC as a gap filling provision, but rather refer to the supplementary function of legislation, custom or good faith. ${ }^{312}$

\section{Article 6:248(1) and statute law}

Hartkamp (2005) argues that the most important function of 6:248(1) DCC is to supplement the terms of a contract through legislation. ${ }^{313}$ The application of Article 6:248(1) DCC presents parties with a source of default rules whenever they have omitted to foresee particular circumstances in their contracts. For example, a contract for the sale of goods can be concluded and given legal effect even though parties have not stipulated a place of performance or manner of payment. Likewise, Article 6:248(1) provides for the ability to imply a right to terminate into an agreement whenever the parties themselves have not incorporated a comparable right.

\section{Article 6:248(1) and custom}

Dutch legal scholars usually distinguish between a custom (gewoonte/gebruik) and customary condition (bestendig gebruikelijk beding). ${ }^{314}$ Custom refers to the course of behavior followed after the conclusion of a contract, while a customary condition reflects the fact that parties assume a particular term to apply to their relationship or transaction without expressly incorporating this term in their contract. ${ }^{315}$ Under Dutch law, a custom is regarded as a regularly and generally followed pattern of behavior within a certain group, to which the group expects adherence. ${ }^{316}$ While repetition of the behavior is generally required, there are no strict rules concerning the frequency or duration. ${ }^{317}$ In order for a customary condition to develop it is required that the

${ }^{311}$ Besides the supplementary function of good faith, in the sense that good faith can imply terms of the contract, article 6:248(1) DCC, also establishes a restrictive and interpretative function of good faith. ${ }^{312}$ Kornet 2006

${ }^{313}$ Asser-Hartkamp 4-3! 2005 , p. 294.

${ }^{314}$ Kornet 2006, p. 49

${ }^{315}$ Asser-Hartkamp 4-11 2005, p. 297

${ }^{316}$ Asser-Hartkamp 4-II 2005, p. 295, Kornet 2006, p. 47.

${ }^{17}$ Hof Amsterdam, 23 April 1920, NJ 1921, 80, Kornet 2006, p. 47. 
condition or clause is incorporated regularly when the particular type of contract is concluded. ${ }^{318}$ It must also be obvious that the condition is part of the contract although it has not been made explicit. In addition, for the condition to have effect, both parties should belong to the same group or if one of the parties is not a member of the particular group, this party should at least be aware that the particular condition applies to the contract between itself and the member. ${ }^{319}$ The reader should be aware that the mere membership of a particular trade association which applies standard terms and prescribes these to its members is not sufficient to constitute a customary condition or create a custom. ${ }^{320}$

Article 6:248(1) and good faith

Article 6:2 DCC stipulates that every obligation is subject to the requirements of good faith, while Article 6:248(1) DCC repeats this explicitly for contracts. The principle of good faith is an open-ended norm and it is thus not possible to indicate to which extent this norm is able to supplement the terms of a contract. Under the supplementary function of good faith, the court will take account of the nature of the legal relationship, the justified interests of the parties and other particular circumstances of the individual case. The duty of good faith will often supplement a parties' contract with duties to consult, to account, to disclose, to make information available, to compensate and to not compete. In insurance relationships, relationships characterized by high levels of trust, the court will often imply duties to disclose, due to the high trust character of the contract. Similar duties have been implied in contracts between landlord and tenant: a landlord is obliged to investigate the tenant's complaints ${ }^{321}$, while the tenant must inform the landlord of any necessary maintenance which must be done, before suspending the rent. ${ }^{322}$ Parties have also been obliged to make information available in order to facilitate the enforcement of contractual performance. ${ }^{323}$ Furthermore, the DCC for example does not contain a provision on the unilateral termination of a contract or relationship. In contracts with an indefinite duration, good faith may supply such a right to terminate the relationship. ${ }^{324}$ However, the implication of such a right is made dependent on the circumstances of the case and the justified interests of the parties involved. ${ }^{325}$ Similar to the US, such a unilateral right of termina-

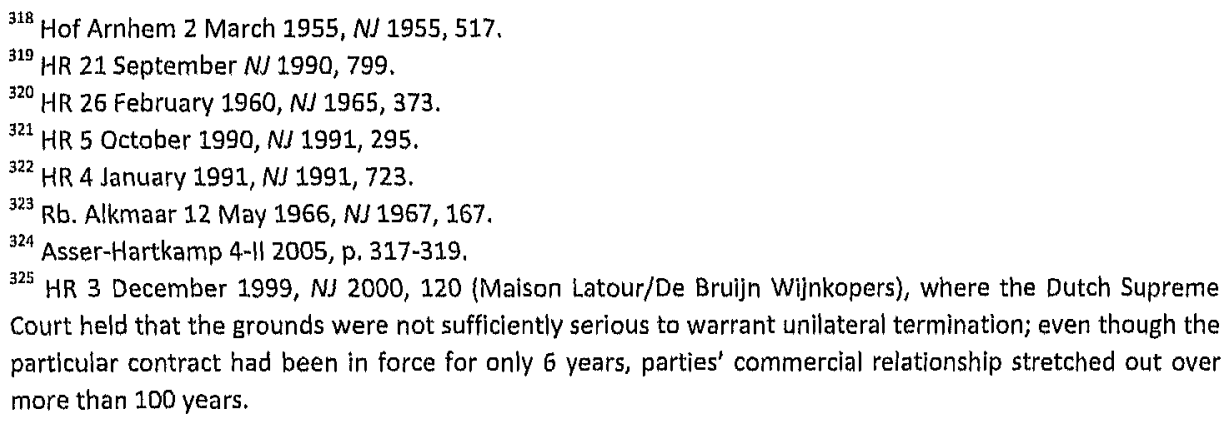


tion is often made subject to a reasonable notice period. ${ }^{326}$ In case of a contract of definite duration, a court will generally not imply a term relating to unilateral termination, except if the change of circumstances is such that under the principle of good faith it would be unreasonable to hold the party to the contract. ${ }^{327}$ Finally, if a contract does not stipulate a price or fee, good faith can be invoked in order to imply a reasonable fee or price and good faith can stipulate that parties must cooperate in order to render effective performance.

Implications for the complexity of contracts

Generally, English and American judges will give effect to the express contract terms and refrain from supplementing or qualifying those terms. Anglo-Saxon lawyers believe foreign courts have greater disposition to meddle with terms of the contract. This fear also relates to the extensive application of the doctrine of good faith to the performance and interpretation of contracts in most civil law jurisdictions: "[p]erhaps the most important difference lies in the attitude towards incompleteness in contracts: whereas common law assumes that the contract has allocated all the risks which may arise, civil law systems tend to start with an assumption that the contract may be incomplete, that it rests on assumption of market conditions remaining the same, res sic stantibus, which requires the courts to intervene by rewriting and supplementing contracts in order to cope with changes in circumstances. ${ }^{328}$ The restricted implication of terms in the US and England - terms will often be implied only if this is reasonable - will strengthen the motivation of parties to incorporate all the terms which they believe are necessary to describe their relationship. The accompanied costs are offset by the benefits. A Dutch judge, in contrast, is not wary to imply a term, and even where statute or custom may not be used to imply a term, good faith may act as a basis for supplementation. Regardless of parties' efforts to incorporate the relevant terms, the court may add to these contractual terms. Parties will thus take less effort to fully specify their relationship in a written document.

Good faith

In the foregoing paragraphs I already touched briefly upon the duty of good faith and fair dealing in relation to the interpretation of contracts and the implication of terms. The objective notion of good faith, or the redelijkheid en billijkheid in Dutch law, imposes upon parties the general duty to take into account each other's interest. It is an open norm of which the precise content depends on the circumstances of the case to which it must be applied. ${ }^{329}$ The principle of good faith is often ascribed three functions in the sphere of contract law: it may aid in the interpretation of contracts, and may be used to either supplement or restrict contract terms.

\footnotetext{
${ }^{326}$ HR 23 December 1994, NJ 1995, 263.

${ }^{327}$ Asser-Hartkamp 4-11 2005, p. 318, HR 21 October 1988, N/ 1990, 439 (Mondia/Calanda).

${ }^{328}$ Collins 1996, p. 4.
}

${ }^{329}$ Hesselink 1998. 
Good faith is recognized in most civil law jurisdictions, but traditionally lacking in common law. ${ }^{330}$ In the Netherlands, the duty of good faith is laid down in Articles 6:2 and 6:248(1) DCC. In England by contrast, the House of Lords in Walford $v$ Miles held that: 'a duty to negotiate in good faith is as unworkable in practice as it is inherently inconsistent with the position of a negotiating party. ${ }^{331}$ The absence of a general duty of good faith is often justified by the fact that this would unsettle the commercial bargaining process, undermine values of security and certainty and present a too large opportunity for personal values to obstruct otherwise well-reasoned judicial decisions. ${ }^{332}$ Above all, common law jurisdictions greatly value the freedom of contract and fear that a general duty of good faith will impinge upon this hallowed autonomy of contracting parties. England and the US have instead developed piecemeal solutions to demonstrated problems of unfairness. Concepts such as frustration, misrepresentation and promissory estoppel often enact solutions similar to those achieved under the application of good faith in civil law. In addition, the implication of contract terms and the increasingly liberal approach to the interpretation of contracts in common law, are based on comparable notions of fairness. Presently, the US have embodied a principle of good faith and fair dealing in UCC \$1-203: “[e]very contract or duty within this Act imposes an obligation of good faith in its performance or enforcement' and Restatement Second \$205: '[e]very contract imposes upon each party a duty of good faith and fair dealing in its performance and its enforcement'. ${ }^{333}$ Due care must be taken, however, in assimilating these piecemeal solutions and this codification of the duty of good faith with the application of the general duty of good faith in civil law systems. Common law jurisdictions for example, do not apply the duty of good faith to contract negotiations and thereby generally refuse to impose pre-contractual liability when negotiations are broken off. In the US and England, the duty of good faith does not arise unless an agreement is already in existence, since it is only then that the court may supply a term. ${ }^{334}$ The UCC $\$ 1-203$ and Restatement Second $\$ 205$ refer only to the enforcement and performance of contracts and not to their formation. ${ }^{335}$ in most civil law jurisdictions, the application of good faith to contract negotiations, does impose a liability for breaking off negotiations. Furthermore, common law jurisdictions, which embody the view that parties should look after their own interests, are also very reluc-

${ }^{330}$ See also Smits 2002, p. 190-193, who states that most civll law systems recognize in some manner the duty of good faith, but points towards differences between German and Dutch, and French law with regard to the restrictive function of good faith and the absence of a general duty of good faith in common law. to the restrictive function of good fath
${ }^{331}$ Walford $\mathrm{V}$ Miles [1992] $2 \mathrm{AC} 128$.

${ }^{332}$ Zweigert and Kötz 1998, McKendrick 2003, p. 543-556.

${ }^{333}$ The first Restatement of Contracts in contrast, did not acknowledge such a good faith duty. See also Summer1982, and Eisenberg and Fuller 2006, Chapter 14.

${ }^{334}$ US: Hoffman v. Red Owl Stores, Inc., Supreme Court of Wisconsin, 1965, 26 Wis.2d 683, 133 N.W.2d 267; Channel Home Centers v. Grossman, United States Court of Appeals, Third CIrcuit, 1986, 795 F.2d 291 and England: Walford $v$ Miles [1992] 2 AC 128.

${ }^{335}$ See also Carter and Furmston 1994, Farnsworth 1999, chapter 7. 
tant to recognize duties of disclosure. ${ }^{336}$ Presently, the complete absence of any duty to disclose has been mitigated by the legal obligation to disclose relevant information in particular types of contracts, e.g. contracts uberrimae fidei, fiduciary contracts and consumer contracts. In addition, misrepresentations during the formation of contracts may lead to liability. ${ }^{337}$ In most civil law jurisdictions to the contrary, the general duty to disclosure derives from the good faith principle.

I will not discuss and compare the particularities of these piecemeal solutions and the application of good faith in any further detail in this chapter. The question which is interesting in the light of this chapter is how conventions of fairness such as good faith may (indirectly) affect the complexity of contracts.

Implications for the complexity of contracts

The recognition of a general duty of good faith may provide a basis for cooperative behavior and reduce the risks of opportunism: 'as good faith finds a place in the law, and as the contractual environment becomes more congenial to trust and risk-taking, it is possible that these reciprocal influences will work together to promote ever more co-operative thinking in both legal doctrine and contracting practice. ${ }^{338}$ Conventions of fairness such as good faith will give contracting parties a greater sense of security and flexibility in the way that they can do business. In Dutch law, the application of good faith to the pre-contractual stage embodies a risk of liability for a party who breaks off negotiations in bad faith. ${ }^{339}$ This potential liability will induce parties to enter negotiations with due consideration of each other's interests, which creates an environment of trust and mutual respect. The recognition of a duty of good faith in the formation of contracts may thus exert a positive influence on the level of trust between parties, which in turn negatively effects contractual complexity. In contrast, English law and the US are reluctant to extend good faith to the pre-contractual stage, which may reduce the level of trust and cooperation and thereby increase the complexity of a contract. The absence of a general duty of disclosure in the aforementioned jurisdictions may also give parties a greater incentive to withhold information and thereby exploit information asymmetries. Non-disclosure of information is negatively related to contractual complexity.

Good faith may also apply to the performance and enforcement of contracts. In many civil law jurisdictions, conventions of fairness such as the duty of good faith are applied to all aspects of the contracting process including performance and enforcement. Notwithstanding the absence of a general principle of good faith, courts in the US and England are also increasingly recognizing and invoking conventions of fairness

${ }^{336}$ Smith v Hughes (1871) LR 6 QB 579; e.g. Restatement Second \$161.

England: Hedley Byrne Co Ltd v Heller [1964] A.C. 465 and the Misrepresentation Act 1967

${ }^{338}$ Furmston 2003, p. 83.

${ }^{39}$ HR 18 June 1982, NJ 1983, 723 (Plas/Valburg), HR 23 October 1987, NJ 1988, 1017 (VSH/Shell), HR 14 June 1996, NJ 1997, 481 (MBO/Ruiterij) and HR 12 August 2005, NJ 2005, 467 (CBB/JPO). 
such as good faith with regard to the performance and enforcement of contracts in order to achieve fair results. Conventions of fairness have the ability to raise the level of trust between parties during the performance of their obligations. Parties enter into a contract in order to gain a certain contractual surplus or benefit. The total contractual surplus or benefit is also referred to as the transactional pie. While each party wishes to obtain as large a portion of the transactional pie as possible, a party will attempt to contractually safeguard its portion of the pie by allocating its rights and obligations as precisely as possible for every potential contingency. This elaborate specification creates a relatively complex contract. In a long-term relationship, however, the level of trust may induce parties to instead rely on conventions of fairness to guide the distribution of the pie. ${ }^{340}$ As a result, simple contracts substitute for complex contracts.

In case of a dispute, the enforcement of a contract will involve a third party adjudicator. The acknowledgment by parties that the third party adjudicator will take into account good faith in interpreting and supplementing their agreement may reduce the incentive to construct relatively complex contracts. More specifically, this may prevent parties from incorporating terms which they know will be struck down by the notion of good faith in case the contractual dispute is presented to a judge. Furthermore, parties may omit to arrange for certain matters in their contract while they trust the judge to apply the principle of good faith to achieve a fair interpretation of their contract. This signifies that the notion of good faith may reduce enforcement costs. When good faith allows contracting parties to rely on the adjudicator to achieve a fair outcome, the contracting costs which are incurred in constructing a complex contract ex ante will not deliver sufficient ex post gains.

The duty of good faith plays a greater role in the Netherlands than in the US and England. The positive effect of good faith on the level of trust may explain in part why contracts in the Netherlands are simple compared to their counterparts in the US and England. In the latter jurisdictions, however, the absence of a general duty to disclose may negatively affect contractual complexity. In addition, account must be taken of the fact that conventions of fairness such as the duty of good faith are increasingly gaining ground in countries governed by common law systems. It is thus questionable whether the mere existence conversely absence of a general duty of good faith is able to justify the observed differences in contractual complexity.

The role of default rules

In the foregoing paragraphs, I have discussed general differences between the legal environment in England and the US on the one hand and the Netherlands on the other hand, including a more in-depth comparison of the rules on contract interpretation. In

${ }^{340}$ See also Eggleston et al. 2000, p. 114 and further. 
the previous sections I also assumed that parties are not wary to rely on contract law default rules. Some authors argue, however, that the observed differences in contractual complexity across jurisdictions may be ascribed in part to a divergence in default rules. These scholars state that parties may designate particular default rules as disadvantageous and will thus attempt to circumvent the direct application of these rules. In this respect, contracting parties may either completely avoid the application of these rules by replacing them with their own creations, or attempt to mitigate the disadvantageous effects. It is impossible to systematically analyze the whole of the contract law rules of the respective countries, and the popularity of and the differences between these rules, in this chapter. But I will attempt to substantiate the aforementioned argument with some examples, which have been given in the literature.

Collins (1999) for example argues, that parties will enter into relatively complex contracts in order to avoid the liability regime ensued upon them by law. Collins (1999) hereby refers to the difference between strict liability, which sets the standard in common law jurisdictions, and fault liability, the primary liability regime in many civil law jurisdictions, including the Netherlands. In light of breach of contract, fault liability will necessitate the fulfillment of four conditions: (1) breach of contract; (2) damage; (3) a causal link between the breach and the damage; and (4) the breach of contract must be attributable to the breaching party. A regime of strict liability lacks the fourth condition: any breach of contract will give the creditor a right to claim damages regardless of the fault of the non-performing party. Common law in principle treats every contract as containing a guarantee for performance: non-performance renders the debtor liable, whether he was at fault or not. This strict liability may induce a party to mitigate the effects of such a liability regime through the incorporation of provisions which designate particular contingencies as unforeseen circumstances or as lying outside the control of the party in default. Such provisions will exculpate the defaulting party from liability, while simultaneously adding to the complexity of the contract. In contrast, under a rule of fault liability, see e.g. articles 6:74-75 of the DCC, parties may forego to incorporate the aforementioned clauses. Collins (1999) acknowledges that the difference in liability regimes may explain only part of the difference in contractual complexity, while divergent liability schemes find expression in exclusion and disclaimer clauses of the contract only. In addition, the distinction between strict and fault liability in the different legal systems is subject to so many exceptions and qualifications that the distinction is not always as clear in practice. ${ }^{341}$ The DCC for example, recognizes strict liability in a number of cases, while the general rule of strict liability in England has been mitigated in numerous ways.

\footnotetext{
${ }^{341}$ Zweigert and Kötz 1998, p. 510. For a detailed comparison see Treitel 1988, Cohen and McKendrick 2005,
} p. 326. 
Lundmark (2001) points to the divergence in rules on remedies for breach of contract. ${ }^{342}$ In numerous civil law jurisdictions, including the Netherlands, the law grants the aggrieved party the right to choose from a range of remedies in case of breach: damages, performance, termination, or a combination of the foregoing. The aggrieved party may choose to either claim damages or specific performance, whichever best suits his situation, provided that the specific conditions for each remedy are fulfilled. In the Netherlands, the right to resort to termination is obstructed only when the nonperformance, given its special nature or minor importance, does not justify the termination of the contract and its consequences. ${ }^{343}$ In common law on the other hand, the claim for damages constitutes the primary remedy for breach of contract. An order for specific performance is only granted in cases where monetary damages form inadequate compensation for the loss incurred. The right to grant specific performance resides with the judge. Traditionally, specific performance has been awarded in cases concerning the sale of unique goods or the transfer of land. In contrast, damages have been found to offer an adequate remedy when the plaintiff is able to obtain the promised performance from another source. ${ }^{344}$ Furthermore, a party may resort to terminate the contract only if its counterparty has breached a condition of the contract, i.e. a term which relates to the essence of the contract. This restriction attempts to reduce the incentive to appeal to termination, which is regarded as the most profound remedy. This restriction may be compared with the constraint in Dutch law, where the non-performance must be of significance in order to justify termination. Lundmark (2001) contends that in case of a dispute, parties who have contracted under English and US law will, in principle, not be able to force performance of a specific clause. These parties will thus take care to stipulate in detail what performance is expected and what the relevant law is. Lundmark (2001) states furthermore that common law jurisdictions, in contrast to for example Dutch law, often do not enforce in terrorem penalty or punitive damage provisions. ${ }^{345}$ Penalty clauses are used to coerce the debtor to perform the principal obligation. This makes the aggrieved party even more dependent on the monetary damages awarded by the court. ${ }^{346}$ Under these conditions, parties will draft elaborate performance provisions such that in case of a dispute, it is clear what performance was expected of the parties, increasing the relative complexity of the contract.

Implications for the complexity of contracts

The examples on the distinctive default rules between the jurisdictions have consequences for the observed levels of contractual complexity. The example given by

\footnotetext{
${ }^{342}$ Likewise Farnsworth 1996, p. 235. See also Hesen and Hardy 2007. ${ }^{343}$ See Article 6:265(1) DCC and HR 24 November 1995, NJ 1996/160 (Tromp/Regency)

${ }^{344}$ Hesen and Hardy 2007.

${ }_{345}$ See also Farnsworth 1996, p. 236. Dutch law for example does recognize the validity of such clauses (articles 6:91-94 DCC)

(articles 6:91-94 DCC).
${ }_{340}$ See also Hill and King 2004, p. 914.
} 
Collins (1996) suggests that contracting parties will generally prefer a regime of fault liability over strict liability. This places parties in England and the US at a disadvantage compared to parties contracting under Dutch law: in contrast to the former, the latter are not wary to rely on default rules concerning liability for breach. Parties in England and the US will on the other hand, attempt to avoid the regime of strict liability imposed on them by law. As a consequence, these parties will carefully enunciate what circumstances are considered beyond their control and therefore exculpate them from any liability. Parties will incur additional contracting costs in drafting force majeure and other types of disclaimer clauses. However, the fact that parties proceed to incorporate these types of clauses in their contracts, must signify that the contracting costs are worthwhile in light of the advantages which these clauses bring. In addition, although the initial costs of drafting these clauses may be relatively high, their recurrent use and thereby standardization means that in the long run, the costs of incorporation will be marginal. Low contracting costs increase complexity.

The example relating to differences in available remedies for non-performance, illustrates that particular default rules may encourage greater contractual specification, in order to (1) avoid to the greatest extent possible a dispute and (2) ensure a correct application of the rule by the court once a dispute has arisen. More specifically, parties in England and the US will describe as precisely as possible each other's performance obligations in order to minimize any chance of incorrect performance. The associated increase in contracting costs is counters the expected enforcement costs. The liability regimes and remedies for non-performance constitute only a small part of the whole of contract law rules. In these particular cases, an additional contracting burden seems to be placed on parties contracting in the US or England as opposed to parties contracting in the Netherlands. It is not apparent from these cases, however, which way the scales are tipped if the whole of contract law rules is taken into account. These specific cases may thus only attempt to explain a small part of the divergence in contractual complexity.

\section{Civil procedure}

The focus of this chapter is on rules of contract law. However, several authors argue that the variations in contractual complexity may be explained by a difference in civil procedure rules in Continental Europe on the one hand and the US and England on the other hand. ${ }^{347}$ These authors point to the inefficiency of American, and to a lesser extent English ${ }^{348}$ civil proceedings. Empirical evidence seems to support the aforemen-

${ }^{347}$ Langbein 1987, p. 385-392, Collins 1996, p. 4-5, Hill and King 2004, p. 904-906

${ }^{348}$ In England, new Civil Procedure Rules 1998, often referred to as the Woolf Reforms, entered into force on 26 April 1999. This revision, which was primarily aimed at increasing efficiency, has radically transformed English civil procedure. Amongst others, case control and court allocation and tracking have been improved and documentation requirements and procedures have been simplified (Slapper and Kelly 2006). 
tioned statement. According to the World Business Environment Survey $(2000)^{349}$, court systems are found to be consistent and reliable, 'sometimes', 'seldom' or 'never' by approximately seventy-two percent of US and sixty percent of UK respondents. ${ }^{350}$ In addition, the survey revealed that approximately eighty-two percent of US and eightynine percent of UK respondents 'sometimes', 'seldom' or 'never' experience the court system as quick. ${ }^{351}$ The inefficiency and unpredictability of the Anglo-Saxon civil procedure increases enforcement costs, which in turn positively affect the incentive of parties to raise the complexity of their contract. In the following paragraphs, I will briefly review some of the factors which have been cited in the literature as possible sources of this inefficiency.

First of all, several authors contend that the inefficiency of American civil procedure may be sought in the quality of the judiciary. ${ }^{352}$ In most European countries, and certainly in the Netherlands, judges receive specialized judicial training. In addition, these judges are likely to have expertise in commercial matters. ${ }^{353}$ In the US in contrast, judges are politically elected ex-lawyers and cases are in principle tried by jury: 'on the Continent, a complex transaction that results in litigation will be decided by people who are expert in the law governing such affairs - a notable contrast to the amateurs who populate the American generalist judiciary. ${ }^{354}$ On the other hand, many civil law judges miss the practical experience of being an attorney due to the fact that they typically serve a professional lifetime as a judge. ${ }^{355}$ In relation to the foregoing, account must be taken of the fact that trial by jury has been abolished for commercial transactions in England, and the State of New York allows parties to opt out of jury trial. Empirical research indeed shows that this is one of the reasons why most foreign commercial parties prefer to dissolve their disputes in New York and have the law of the state of New York applied to their American contracts.

In the second place, American and English civil procedure differ in structure from the Dutch process. In the Netherlands, like most civil law jurisdictions, a typical civil pro-

${ }^{349}$ The World Business Environment Survey (2000), Washington D.C.: The World Bank. The World Business Environment Survey refers to a questionnaire which was administered to over 10,000 firms in 80 countrles (http://info.worldbank.org/governance/wbes/). Unfortunately, The Netherlands did not take part.

${ }^{350}$ The question was: '[h]ow often do you associate the following descriptions with the court system in resolving business disputes? Consistent and Reliable'. The remaining twenty-elght (US) and forty (UK) percent answered either: 'always', 'mostly' or 'frequently'.

${ }^{351}$ The question was: "[h]ow often do you associate the following descriptions with the court system in resolving business disputes? Quick'.

${ }^{352}$ Langbein 1987, p. 386-387, Hill and King 2004, p. 905-906, Stürner 2001.

${ }^{353}$ In most European countries, complex commercial matters are usually tried by specialized courts or divisions (Ondernemingskamer in The Hague and the Commercial court division of the Queen's Bench Division in England).

${ }^{354}$ Langbein 1987, p. 387

${ }^{355}$ ALI/UNIDROIT Principles of Transnational civil procedure, Cambridge: Cambridge University Press 2006, $\mathrm{p}$ 
ceeding is divided into three stages: (1) a brief preliminary stage where parties submit their pleadings and the hearing judge is appointed; (2) an evidence-taking stage; and (3) a decision making stage. ${ }^{356}$ American civil procedure is characterized by an elaborate pre-trial process, referred to as 'discovery', in which parties are allowed to gather the evidence they may need at trial. ${ }^{357}$ This discovery phase is followed by a trial at which all the evidence is received consecutively. This process leads to a duplicative and inefficient process of witness examination and cross-examination: witnesses are examined and cross-examined at pre-trail and once again at trial. Whilst the facts to be investigated and their sequence are not limited, and there is no opportunity to search for further information once the trial-phase has set in, American lawyers strain to investigate everything that could possibility arise at trial. American discovery procedure allows parties to search and fish for information. ${ }^{358}$ Such aggressive discovery procedures are unknown to Continental European, and since the Woolf Reforms, even to English civil procedure. ${ }^{359}$ In this light, it is also important to indicate that the role assigned to judges in these jurisdictions varies. In many civil law jurisdictions, the civil procedure is characterized as an inquisitorial model, in contrast to the adversarial nature of the civil process in common law. ${ }^{360}$ This means that in most Continental European countries, the judge carries the primary responsibility for eliciting the facts and the gathering of evidence, whilst in the United States and England the trial takes the form of a contest between two private parties, who are granted a large responsibility in both the legal definition of the facts and the discovery. ${ }^{361}$ The discovery procedure and the fact that parties lead the way in the development of evidence, may lead to the advancement of strategic misinterpretations in countries such as the US and England.

Not all authors, however, emphasize the aforementioned inefficiency of Anglo-Saxo systems. Although Djankov et al. (2003) assert that '[r]ules of evidence are sometimes considered to be a key factor in differentiating the overall efficiency of legal procedures among countries ${ }^{362}$, these authors conclude that the efficiency of courts is highest in countries as England and the US. Djankov et al. (2003) analyzed civil proceedings relating to the eviction of a nonpaying tenant and the collection of a bounced check in 109 countries. ${ }^{363}$ The authors measured the degree of formalism, i.e. 'the substantive

${ }^{356}$ See also Merryman 1985, p. 111

${ }^{357}$ Längbein 1987, p. 387-389, Kötz 2003, Stürner 2001, p. 871-878.

${ }^{358}$ Langbein 1987, p. 389, Kötz 2003, p. 61-77.

${ }^{359}$ Formerly England did recognize a more elaborate pre-trail/discovery procedure, but the Woolf reforms have limlted the scope of the discovery and now foresee in a greater judicial control over parties.

${ }^{360}$ See also Jolowicz 2003

${ }^{361}$ Hill and King 2004, p. 904-906, Langhein 1987, p. 388-389, Ferrarese 1997, p. 167

${ }^{362}$ Djankov et al. 2003.

${ }^{363}$ The participants in this study were attorneys at Lex Mundi and Lex Africa member firms, who received a questionnaire which covered the step-by-step evolution of an eviction and a check collection procedure before local courts in the country's largest city. 
and procedural statutory intervention in judicial cases at lower level civil trail courts ${ }^{364}$ and predicted that formalism can enhance weaker party protection, fairness, accuracy, and public welfare, but can also lead to delays, unfairness and inefficiency. The authors measure a higher degree of formalism for civil law jurisdictions, especially for systems of French legal origin, which includes the Netherlands, than common law jurisdictions. ${ }^{365}$ In addition, formalism appears to be positively related to the duration of proceedings ${ }^{366}$ and has a negative effect on the level of fairness and impartiality, consistency and honesty, confidence in the legal system, and access to justice and judicial efficiency. ${ }^{367}$ Their findings are confirmed by a comparable study of the World Bank in $2006{ }^{368}$ This study, which is based on the earlier study of Djankov et al. (2003), investigates the efficiency of the judicial system, which is measured as an aggregate of the number of procedures ${ }^{369}$, the duration ${ }^{370}$ and cost (court and attorney costs) ${ }^{371}$, in resolving commercial disputes. On a scale of increasing efficiency, the Netherlands ranks thirty-first out of one hundred and seventy-five countries, compared to the US with rank six and the UK with rank twenty-two. Within the list of twenty-two OECD high income regions ${ }^{372}$, the Netherlands can be found only at position nineteen. ${ }^{373}$ The World Bank concludes that ' $[\mathrm{t}]$ he main reason to regulate procedures in commercial dispute resolution is that informal justice is vulnerable to subversion by the rich and powerful. But heavy regulation of dispute resolution has negative consequences.

\footnotetext{
${ }^{364}$ The formalism index is formed by adding up the following indices: '(i) professional versus laymen, (ii) written versus oral elements, (iii) legal justification, (iv) statutory regulation of evidence, (v) control of superior review, (vi) engagement formalities, and (vii) independent procedural actions. The index ranges from zero to seven where seven means higher level of control or intervention in the judiclal process.' (Djankov et al. 2003, p. 469).

${ }_{365}$ Djankov et al. 2003, p. 510. The data show that dispute resolution in socialist and French orlgin civil law countries is more formalized than in common law countries, even holding per capita Income constant.

${ }^{366}$ The duration is a composite measure of (1) the duration until completion of the service of process; (2) the duration of the trail; and (3) the duration of enforcement. The 'duration' as such signifies the number of calendar days from the moment the plaintiff files the lawsuit until the actual moment of repossession (Djankov et al. 2003, p. 501).

${ }_{367}$ Data for the variables is taken from the World Business Environment Survey, which unfortunately does not include data from the Netherlands (Supra n. 460).

${ }^{368}$ Doing business in 2006, OECD high income region, regional profile, The International Bank for Reconstruction and Development / The World Bank (http://www.doingbusines5.org/, last accessed July 23 2007).

${ }^{369}$ 'Any interaction mandated by law or court regulation between the parties, or between them and the Judge (or administrator) or court officer.'

Judge (or administrator) or court officer.'
${ }_{370}$ The number of calendar days, counted from the moment the plaintiff files the lawsuit in court until pay.

ment.

${ }^{371}$ Cost is recorded as a percentage of the claim, which is assumed to equal $200 \%$ of income per capita.

${ }^{372}$ Tunisia, Netherlands, New Zeealand, Japan, France, Denmark, Norway, Belgium, Greece, Australia, Iceland, Spaln, Switzerland, Germany, Sweden, Ireland, Finland, United States, UK, Portugal, Canada, Austria and italy.

${ }_{373}$ The total number of procedures in the Netherlands amounts to 22 ( $f$. UK count of 19 and US count of 17) and the costs constitute $15.9 \%$ of debt - predominantly caused by attorney costs (cf. UK: $16.8 \%$ and US: $7.7 \%)$.
} 
Across countties, the more procedures it takes to enforce a contract, the longer the delays and the higher the cost. Less wealth is created. ${ }^{374}$

These empirical studies seem to contradict the general assumption in the literature that civil procedures in Anglo-Saxon jurisdictions are less efficient, effective and reliable than comparable procedures in civil law jurisdictions. With regard to the Netherlands in particular however, some remarks must be made in light of the results presented by Djankov et al. (2003) and the World Bank study (2006). Data collected by Djankov et al. (2003) reveal that, of the forty states classified as French legal origin countries, the Netherlands scores below average on formalism. ${ }^{375}$ In addition, both the study by Djankov et al. (2003) and the World Bank (2006) demonstrate that the duration of proceedings in the Netherlands is extremely low. In the study of Djankov et al. (2003) proceedings amount to 52 and 39 days for eviction and check collection, ${ }^{376}$ (cf. French legal origin mean of 266 and 272 days and English legal origin mean of 199 and 176), while the World Bank study (2006) reveals an average duration of 48 days for the Netherlands compared to 229 and 300 days for the UK and US. The foregoing illustrates that for the Netherlands in particular, a high degree of formalism may actually be associated with 'fast justice'. In addition, the measures relating to fairness, impartiality, consistency, honesty and confidence in the legal system, which are included in the study by Djankov et al. (2003), are lacking for the Netherlands. This makes it difficult to extrapolate their conclusions to the Netherlands more in particular.

Implications for the complexity of contracts

Inefficient and unreliable civil proceedings may increase expected enforcement costs and thereby positively affect contractual complexity. Elaborate discovery procedures and adversarial models of procedure increase the opportunities for strategic misinterpretation and therefore parties will be tempted to draft complex contracts to prevent litigation from taking place. An unreliable administrative adjudication system and the absence of relevant expertise may incite parties to include in their contracts clauses which instead refer disputes to arbitration or other alternative dispute resolution mechanisms. In this light, Adams and Brownsword (1999) state that for technical commercial cases, parties will often entrust the settlement of the dispute to experts in the field. ${ }^{377}$ The referral of disputes to alternative mechanisms is enforced by the higher degree of privacy, the adversarial nature, less elaborate discovery procedures and reduced costs of the latter procedures.

${ }^{374}$ World Bank Report 2006, p. 28.

${ }^{375}$ A score of 3.00 for eviction (cf. French legal origin mean of 4.38 and US score of 2.97 ) and 3.07 for check collection (cf. French legal origin mean of 4.29).

${ }^{36}$ Cf. US: 49 and 54 days and UK: 115 and 101 days for eviction and check collection.

${ }^{37}$ Adams and Brownsword 1999. 
While the literature seems to relate inefficiency and unreliability primarily with American and English civil procedures, recent empirical data seem to suggest otherwise. American and English civil procedure by contrast, seems quite reliable. However, the duration of American and English civil procedures is very long compared to the Netherlands. This is probably due to the lack of elaborate (pre-trial) discovery proceedings and the greater role for the judge to guide the adjudication process. The foregoing factors reduce chances of strategic misinterpretation and allow for greater reliance on the adjudication system. This may cause parties to perceive the level of expected enforcement costs to be higher in the US and UK than in the Netherlands. However, the literature and recent empirical studies are not conclusive in this respect.

\section{THE SOCIO-CULTURAL ENVIRONMENT}

In this chapter, I have placed an emphasis on the manner in which the legal environment affects different contracting factors and thereby contractual complexity. However, some authors attribute the differences in contractual complexity to the (indirect) influence of the socio-cultural environment. In the following paragraphs, I will discuss briefly some aspects of the socio-cultural environment which have been addressed in the literature in this respect.

American 'excessiveness' and 'perfectionism'

Przeracki (1989) states that Americans write detailed (i.e. complex) contracts due to their character 'defect' of excessiveness. Przeracki (1989) refers to the fact that Americans are given excess to all things '[they] earn the most money, drive the largest cars, commit the most crimes etc ${ }^{378}$ and as a consequence, they write contracts 'so detailed as to make any applicable law (...) as unimportant as is possible and that frequently end by making [American] law applicable anyway in the unlikely event that it makes any difference. ${ }^{379}$ Van Hecke (1962) establishes that the American lawyer, in contrast to legal experts in Continental Europe, is driven by a certain desire for perfection and is willing to incur the costs associated with this perfectionism. As a consequence, the American lawyer aspires to handle all eventualities in the contract, rather than leave them to the decision of the judge. The European client on the other hand, seems to realize that this perfection of a watertight contract cannot be reached anyway and is not willing to pay for such an unachievable objective: simplicity is preferred to the costs of perfectionism. ${ }^{380}$ Hill and King (2004) use a similar argument, namely that the

${ }^{378}$ Przeracki 1989, p. 170 and Przeracki 1989, p. 169, n. 124 in reference to Farnsworth 1969, p. 117

${ }^{379}$ Farnsworth 1996, p. 117 cited by Przeracki 1989, p. 173.

${ }^{380}$ Van Hecke 1.962. See also Farnsworth 1996, p. 231, who in this respect points out that common lawyers, and especially Americans, are more prolix compared with Continental European lawyers. Cf. Langbein 1987, p. 382: ' $t$ t $]$ o speak of differing propensities for perfectionism merely restates the problem, which is to underp. 382: ' $t \mathrm{t}$ ] speak of differing propensities for perfectionism merely restates the problem, which is to under-
stand why the Americans strive for contractual terms that are, in van Hecke's apt phrase "perfectly waterstand why 
presence of highly customized contracts in the US is due to 'a failure to create and accept "good enough" solutions to non-adversarial (and some adversarial) issues parties commonly face'. ${ }^{381}$ In addition, these authors argue that due to parties' fear for opportunistic behavior by their counterpart, parties become locked 'into an arms race in which each seeks to ferret out the other's possible strategic handles at every turn. The result is U.S.-style extensive custom tailoring of contracts. The participants in the process either believe, or persuade themselves to believe, that "every semicolon matters" ${ }^{\prime \prime}{ }^{382}$ This tendency to draft watertight and elaborate contracts might also be reflected in the number of lawyers per capita. In 2006, the Netherlands encompassed a lawyer-inhabitant ratio of 1:1148, compared to a ratio of 1:267 in the US and 1:398 in the UK. ${ }^{383}$ Inverse reasoning is applied by Cooter and Ginsburg (2004) who indicate that the number of lawyers is likely to positively affect contractual specificity (i.e. complexity). They argue that a small legal profession is less monopolistic which prevents free-rider problems and thereby produces shorter contracts for the same level of income. In the second place, a smaller number of lawyers will have a positive impact on legal fees and thereby reduce the demand for long contracts. Finally, a smaller legal population will increase the number of repeated games, which can lead to the development of implicit understandings and thereby less contractual specificity. ${ }^{384}$

\section{Social norms of trust and trust- enforcing mechanisms}

As mentioned, trust and reputation are positively related to the complexity of contracts. Laws and other mechanisms can act as basis for the creation of trust, and a deterrent for opportunism. ${ }^{385}$ The degree of trust, and the extent to which institutional frameworks and social networks constitute credible enforcement mechanisms capable of enforcing relations of trust, vary from one society to another. ${ }^{386}$

Fukuyama (1995) characterizes Germany and the US as relatively high trust societies compared to countries such as France and Italy. However, there are numerous ways to measure the degree of trust within a society. The World Values Survey 1999 demon-

\section{Hill and King $2004, p .890$}

${ }^{382}$ ibid., p. 902.

${ }^{383}$ Sources: ABA Market Research Department 6/2006 (http://www.abanet.org/marketresearch/resource.htmll; Conseil des Barreaux Europeens / Council of Bars and Law Societies of Europe 2006 (http://www.ccbe.org/); Centraal Bureau voor de Statistiek (CBS) 2006 (http://www.cbs.nl/nl$\mathrm{NL} / \mathrm{menu} / \mathrm{themas} /$ veiligheid-recht/publicatles/artikelen/archief/2007/2007-2195-wm.htm) and The World Factbook (https://www.cia.gov/library/publications/the-world-factbook/) (all websites last accessed on July

24 2007).

Cooter and Ginsberg 2004, p. 21. See also their compiled list of lawyers per 10.000 inhabitants on p. 9 The mean of 14 Continental European countries is 7.98 lawyers per 10.000 inhabitants (outliers Spain: 15.87 and Luxembourg: 16.67) compared to 15.38 lawyers per 10.000 inhabitants in the UK. Data covers the mid1990 s.

${ }^{385}$ Rousseau 1998, p. 397 and p. 400 . See also Gulatl 1995, p. 93, Ring and Van de Ven 1992, p. 483-498, who indicate that institutional factors can act as support for the critical mass of trust that sustains risk taking.

${ }_{386}$ Shane 1994, p. 628. 
strates that approximately only thirty-six percent of the respondents in the US and Germany, compared to twenty-one percent in France and thirty-two percent in Italy, believe that most people can be trusted. Fifty-nine percent of Dutch respondents on the other hand, find their fellow countrymen trustworthy. ${ }^{387}$ These survey results do not seem to substantiate Fukuyama's assumptions. Trust is difficult to render operational and levels of trust are not easily calculated. Hofstede (1980) takes another approach and classifies societies on dimensions of (amongst others) individualism (IDV), uncertainty avoidance (UA), Power Distance (PD) and Long-Term Orientation (LTO). ${ }^{388}$ IDV and PD may serve to reference the degree of trust within a society. Individualism measures the extent to which individuals are integrated into groups. In individualist societies, ties are loose and individuals are expected to look after themselves, whereas collectivist societies are characterizedi by strong, cohesive in-groups, in which protection is granted in exchange for loyalty. Collectivist cultures, in contrast to individualistic cultures, are dictated by high levels of trust and cooperation. ${ }^{389}$ PD measures the extent to which the members of organizations and institutions expect and accept power to be distributed equally. Hofstede (1997) finds that PD represents societal trust: PD societies are characterized by low levels of interpersonal trust and have a greater need for behavioral controls. ${ }^{390}$

The Netherlands has an IDV score of eighty, compared to a value of ninety-one for the US and eight-nine for the UK (on a scale to one hundred). The US and UK appear to be only slightly more individualistic than the Netherlands. These relatively high IDV scores indicate a lower standard of trust, which Hofstede (1997) positively relates to the specificity of contracts. ${ }^{391}$ In contrast, the relatively low and similar PD scores - values of thirty-eight for the Netherlands, thirty-five for the UK and forty for the US (compared to a mean of 56.8) - seem to point to a relatively high level of trust within these societies. In addition, Burchell and Wilkinson (1997) demonstrate that firms perceive trust as being established by the preference for and perceived importance of longterm personal and trading relations. The latter preferences and perceptions relate to the LTO measure developed by Hofstede (1980). The Netherlands has a LTO score of forty-four compared to a score of twenty-five for the UK and twenty-nine for the US. This relatively high LTO score for the Netherlands (compared to the UK and US) might

${ }^{387}$ The question asked was: '[g]enerally speaking, would you say that most people can be trusted or that you need to be very careful in dealing with people?' Other answer categories were: 'can't be to careful', 'don't know' and 'no answer'. In addition, twenty-nine percent of respondents in Great Britain believe that most people can be trusted.

people can be trusted.
${ }_{388}$ Hofstede 1980, p. 327

${ }^{388}$ Hofstede $1980, p .327$ with regard to benevolence from strangers.

${ }^{390}$ Hofstede 1980, p. 327, Shane 1994, p. 629-630

${ }^{391}$ Hofstede 1997, p. 60, concludes that the high level of indlvidualism in the US may be a cause of the increased length of American contracts, compared to their counterparts in Japan, which is a collectivistlc society. 
point to the tact that Dutch individuals and thereby contracting parties, are more apt to trust one another and rely on this trustworthiness.

It appears, however, difficult to derive a conclusive answer on (any difference in) the level of trust in each of the countries from these measures: in any case, trust seems present to some extent. However, the manner in which trust is enforced may differ across these countries and thereby serve to explain differences in contractual complexity.

Hill and King (2004) stipulate that compared to the US, the German business community is smaller and trade associations play a more important role. They argue that Americans may also have good business norms, but that these norms may not work as well due to the less homogeneous and less repeat community. Langbein (1987) indeed states: '[c]ommercial dealings in Europe may have been conducted within a smalle and socially homogeneous group, and hence may have had more of the considerate overtones that Americans think are confined to long-term (that is, relational, or re peat-player) contracts. ${ }^{392}$ This assumes that European parties are to a greater extent embedded in social networks in which trust may substitute for complex contracts. The findings of Hill and King and Langbein are confirmed by Arreghetti et al. (1997) and Burchell and Wilkinson (1997) for Germany, Italy and Britain more specifically. ${ }^{393}$ These authors indicate that the norms shaped and created by trade associations effect the relationship between parties by reinforcing cooperative trust-based behavior, and that institutional enforcement is greater in countries as Germany and Italy compared to Britain. Similar conclusions are reached by Collins (1999). ${ }^{394}$ However, even in countries where institutional bodies appear to play a smaller role in enforcing trust-based behavior in general, specific communities within these countries may proof otherwise. Bernstein (1992) for example, studied communities of Jewish diamond merchants in New York City and the cotton industry, where she examined mechanisms by which trade associations and other trading networks enforce private legal systems. ${ }^{395} \mathrm{Com}$ plementary studies show how merchant communities recognize non-legal reputation mechanisms, which are most often enacted through social networks that induce mu tually and socially beneficial behavior. ${ }^{396}$ These communities are characterized by repeat transactions and every exchange comprises a feasibility to cheat, however, misconduct will be known throughout the community and no one will transact with cheat

${ }^{392}$ Langbein 1987, p. 394

${ }^{393}$ Arreghetti et al. 1997, Burchelf and Wilkinson 1997.

${ }^{394}$ Supra n. 225. See also Hill and King 2004, p. 915, who generally establish that ' $[t]$ rade associations are far more important in Germany than they are in the United States' (they then use this observation to indicate that German companies often incorporate trade association forms by reference, enabling them to reduce the length of their contracts in comparison to American firms).

the length of their contracts in

${ }^{396}$ Greif 1993, 1989, Greif et al. 1994, Milgrom et al. 1990, Richman 2004. 
ing individual. Effectively, '[t]he assurance of ex post sanctions against cheaters allows transactors to commit credibly to fellow merchants that they will fulfill their contractual duties, ${ }^{397}$

Institutional bodies such as trade associations do not only function as reputation enforcing mechanisms. As briefly mentioned above, they may produce trade standards and develop trade usage, which supplement enacted legislation. Arreghetti et al. (1997) and Hill and King (2004) indicate that trade associations create and circulate standard forms which are frequently used and applied by commercial parties. ${ }^{398}$ These forms enhance the possibility to adopt standardized solutions. The ability to incorporate these standard forms and trade practices by reference reduces the need to construct complex contracts. Such an elaborate practice of forms is not as evident in England or the US.

\section{Perceptions of uncertainty}

As mentioned earlier, Hofstede uses several measures to reference values and norms within cultures. One of these measures is the Uncertainty Avoidance Index (UAI). This index refers to a society's tolerance of environmental uncertainty and ambiguity. The UAl reflects an individual's perception of environmental uncertainty and thus influences the level of the latter factor and thereby contractual complexity. Cultures with a high UAl demonstrate less tolerance for uncertainty. Hofstede (1997) argues that in these cultures, uncertainty and risks are minimized to the greatest extent possible through the enforcement of detailed and specific laws and rules. ${ }^{399}$ Ginsburg and Cooter (2004) illustrate that the specificity of legislation is positively correlated with the specificity (i.e. complexity) of contracts. ${ }^{400}$ The Netherlands scores fifty-three on the UAI compared to the US with a score of forty-six and the UK with a score of thirtyfive ( $c f$. world average of sixty-four). The high UAl indicates that the Netherlands is characterized by a lower tolerance for uncertainty than the US and the UK, and according to Hofstede (1997), the Netherlands should thus display more detailed and a greater amount of legislation. However, Ginsburg and Cooter (2004), in relating specificity of legislation to the specificity of contracts, find that the specificity of both contracts and legislation is higher in e.g. the UK than in the Netherlands; this is also confirmed by my observation that contracts in the US and UK are relatively more complex than their Dutch counterparts. The effect of the level of UA on the complexity of contracts is thus not conclusive.

${ }^{397}$ Richman 2004, p. 2335.

${ }^{398}$ Arreghetti et al. 1997, p. 19-21, Hill and King 2004, p. 915

${ }^{399}$ Hofstede 1997, p. 120-121.

${ }^{100}$ Cooter and Ginsberg 2004, p. 8-9. 


\section{DISCUSSION AND CONCLUSION}

I began this chapter with the observation that American and English contracts display a contractual style which deviates from the Continental European and Dutch style of contract drafting. While this divergent style has been addressed in the literature, a consistent terminology to describe and explain these different styles is still lacking. In this chapter I reviewed the current theories and concepts and subsequently developed a notion of contractual complexity, which can be used to explain jurisdictional divergences in contract design. This concept of complexity also allows me to extend my analysis to both legal and business economic theory. Business economic studies concerned with the subject of contract design do not comprise international comparisons, but seek to explain why and when parties will conclude relatively complex contracts. In contrast, the legal literature is focused on international differences in contractual complexity and relates these variations to divergent legal environments in general and lawyers' perceptions and values concerning contracting in particular. This chapter was written in an attempt to reconcile both views and provide the reader with a multidisciplinary perspective on contract design.

In principle, the design of a contract can be measured using the concept of complexity Contractual complexity, which is measured along a continuum, comprises three dimensions: the number and types of terms incorporated in the contract, the specificity of these terms and the cognitive load necessary to understand the contract. The level of complexity is affected by a diverse range of factors. These factors derive mainly from the business economic literature and may be either positively related: trust and reputation, non-disclosure, parties' limits of cognition and contracting costs, or negatively related: monitoring difficulties, asset specificity, strategic importance, environmental uncertainty and enforcement costs, to contractual complexity. Most of these factors cannot, however, explain variations between countries in the complexity of contracts by themselves. They must be assessed in light of their legal and sociocultural environment. Some factors are not significantly influenced by the legal and socio-cultural operating context. These factors relate to limits of cognition, monitoring difficulties, asset specificity and the strategic importance of the contract.

The legal environment affects both contracting and enforcement costs. In the Netherlands, parties are able to rely on extensive codifications of the law. The ability to rely on default rules together with a subjective approach towards the interpretation of contracts, enables parties to briefly refer to these default rules in their contracts or forego explicit incorporation altogether. This leads to relatively simple contracts, in contrast to contracts concluded under English or American law, where extensive codifications of the law are lacking. A system of case law and the primarily objective approach toward the interpretation of contracts, in conjunction with a rule of parol evidence, leads to higher expected enforcement costs and induces parties in these juris- 
dictions to increase contractual complexity. Parties incorporate extensive boilerplate clauses, plan for performance contingencies and accommodate for detailed business definitions. This increased complexity secures a party's interests once a dispute arises. The associated contracting costs thus appear worthwhile. However, notice must be taken of the fact that part of this complexity arises due to the incorporation of boilerplate clauses. Boilerplates are standardized terms which are used across the industry and legal profession. Parties will therefore be able to commit to their incorporation at relatively low costs. Concluding, contracting costs do not appear to vary extremely between the Netherlands, England and the US. More importantly, parties in both the US and England appear to perceive higher expected levels of enforcement costs, which justify the construction of complex contracts.

Another recognized element of variation within legal environments is the recognition of the good faith principle. Good faith advances norms of fairness, trust and cooperation regarding contractual practices. These norms reduce the necessity to draft contracts with numerous detailed terms. The principle of good faith is awarded a larger role in the Netherlands, where it applies to contractual negotiations, performance and enforcement. In England and the US, piecemeal solutions substitute for the traditional absence of a general principle of good faith. Presently however, good faith, especially in the US, is increasingly recognized with regard to the performance of contractual obligations; this is exemplified by the more liberal approach to the implication of terms and the interpretation of contracts in general. Regardless of these observations, good faith does not permeate the English and American contracting practice in a similar manner as the Dutch. Due to the general and sustained recognition of good faith, parties contracting in the Netherlands traditionally place greater reliance on conventions of fairness to guide their transactions. This gives rise to the construction of relatively simple contracts.

Some authors argue that rules of civil procedure may influence expected enforcement costs and thereby contractual complexity. Civil procedures in the US and England are often designated as unreliable and inefficient. This raises expected enforcement costs and encourages parties to specify their performance obligations and sanctions. In contrast, the shorter duration of proceedings and lack of extensive discovery in the Netherlands allows for fast and reliable justice, which lowers the expected level of enforcement costs. The basis of this longstanding comparison is questioned, however, by the modern reforms in England and some recent empirical studies. The latter studies seem to attribute efficiency primarily to the civil procedure in common law jurisdictions. It may be stated that data concerning the efficiency and reliability of civil procedures is not conclusive. Another observation may also point to the relatively small ability of civil procedure rules to affect contractual complexity through increased en forcement costs. Many commercial disputes, especially in relation to international or American contracts, are referred to arbitration. Arbitration and other alternative dis- 
pute resolution mechanisms are favored over litigation because the former decrease the possibilities for discovery, duration and costs, and are characterized by expert adjudicators. The contracts which incorporate arbitration clauses and thereby evade litigation appear to maintain a similar level of complexity as the contracts that incorporate litigation clauses.

The focus of this chapter is on variations in the legal environment, which influence the level of the complexity factors. However, I briefly touched upon several aspects of the socio-cultural environment which may vary between countries. First of all, while studying different societies, cultural differences in attitudes toward the drafting of contracts become apparent. The American drafting style is characterized by excessiveness and perfectionism, which feeds the desire to draft watertight, complex contracts. Dutch parties on the other hand, seem to take satisfaction with short concise documents which set out the basic elements of the deal. The desire in England and the US to draft complex documents is reinforced by the large population of lawyers.

The socio-cultural environment also relates to the manner in which institutions such as trade associations, and informal social networks, are able to enhance and enforce trust. Trust and reputation may substitute (in part) for complex contracts. Several authors have attempted to measure the general level of trust across countries. These empirical studies illustrate, however, that it is difficult to determine whether one culture is more trusting than another. The ability of institutions and networks to enforce trust affects the extent to which trust actually plays a role in cooperative relationships. Studies have undisputedly demonstrated that trade associations play a larger role in civil law jurisdictions such as Germany, which are also categorized by a larger number of small business communities, compared to the US and England. Trust and reputation are able to affect contracts to a considerable extent in these civil law countries. This element of the socio-legal environment interacts with elements of the legal environment to reinforce the negative effect on contractual complexity. More specifically, norms and standards produced by trade associations are supplemented and strengthened by the reliance on the Code, e.g. the BGB or DCC. ${ }^{401}$ However, account must also be taken that the aforementioned arguments are generalizations: within any country, particular communities may exist where trust is very important and trustworthiness strictly enforced.

I related a range of factors to contractual complexity. Standard conditions such as limits of cognition, monitoring difficulties, asset specificity and the strategic importance of the contract are specifically related to the characteristics of parties and the particularities of the exchange transaction. These factors may serve to explain conditions of contractual complexity in general. However, in order to explain national varia-

${ }^{402}$ Burchell and Wilkinson 1997, p. 217-237, Hill and King 2004, p. 916. 
tions in contractual complexity it is necessary to evaluate some of these factors within their specific legal and socio-cultural context. The analysis makes clear that both legal and business perspectives are necessary to explain variations in contract design, more specifically contractual complexity between countries. This study offers only a preliminary investigation into the design of contracts from a multidisciplinary perspective. 1 have discussed elements of the legal environment in a very broad manner. It would be interesting, also in light of business economics, to analyze why and how particular rules of contract law and (intellectual) property law affect the terms of the contract. In addition, this study calls for a more detailed examination of different elements of the socio-cultural environment. Furthermore, empirical statistical analysis might be able to further substantiate the suggested effects of the different factors, controlling for the influence of the legal environment. I hope that this chapter has provided the reader with a greater understanding of contract design in general and contractual complexity in particular from a multi-disciplinary perspective. 
CHAPTER 4

CONTRACTUAL COMPLEXITY AND THE COGNITIVE LOAD OF R\&D

ALLIANCE CONTRACTS

A modified version of this chapter has been accepted for publication in the Journal of Empirical Legal Studies.

Of course, the limits of cognition are not a universal explanation of either contract law or the limits of contract. Other teachings of experience, as well as concepts of efficiency and morality, also play leading roles. Even those other elements, however, can be given appropriate weight only when we know the psychological framework within which actors operate when making chaices.

Melvin Eisenberg

Professor of Law 


\section{INTRODUCTION}

Inter-organizational contractual arrangements, such as those set up to govern interfirm alliances, have become important mechanisms through which firms exchange products, services, and knowledge. Mayer and Argyres (2004) and Sampson (2004) argue that sophisticated contractual relationships are an increasingly important feature of the business landscape, particularly where high technology is involved. While previous research has focused predominantly on the manner in which firms govern these relationships, legal scholars, economists and business scholars have more recently attempted to study ' (...) the actual formalized documents that we call contracts $(\ldots)^{\prime}{ }^{1}$ These studies have generally been based on transaction cost economics and property rights theory, which has led to an extensive examination of particular control rights $^{2}$ and/or ownership rights ${ }^{3}$.

Several authors have called for a more in-depth investigation of contract structure and have in that sense attempted to describe contracts in terms of the degree of 'complexity'. This understanding of the complexity of contracts is relevant as this complexity indicates the costs that companies face in terms of designing, writing, implementing, controlling, and enforcing contracts that govern the relationship with their contractual partners. ${ }^{5}$ Measures that authors have used to determine contractual complexity include the length of contracts in terms of the number of pages ${ }^{6}$, the 'amount' of kilobytes of information in contracts ${ }^{7}$, or the number of provisions in contracts and their stringency ${ }^{8}$.

Although the complexity of contracts has received quite some attention in the literature, the actual understanding and conceptualization of contractual complexity as such remains a challenge. First of all, complexity is typically one of those concepts that are often used, yet difficult to define. Also, attempts to measure complexity are laden with intricacies. As stated by Kades (1997): '(..) scholars have not had an easy time defining complexity, and some have been disarmingly honest about this difficulty. One author admitted that he was tempted to define complexity by averring, "I know when I read it. ${ }^{\prime 9}$ My understanding of complexity is influenced by Simon, who defines complexity in terms of the '(...) large number of parts that interact in a nonsimple way (...) [where] (...) the whole is more than the sum of its parts, not in an ultimate, metaphysi-

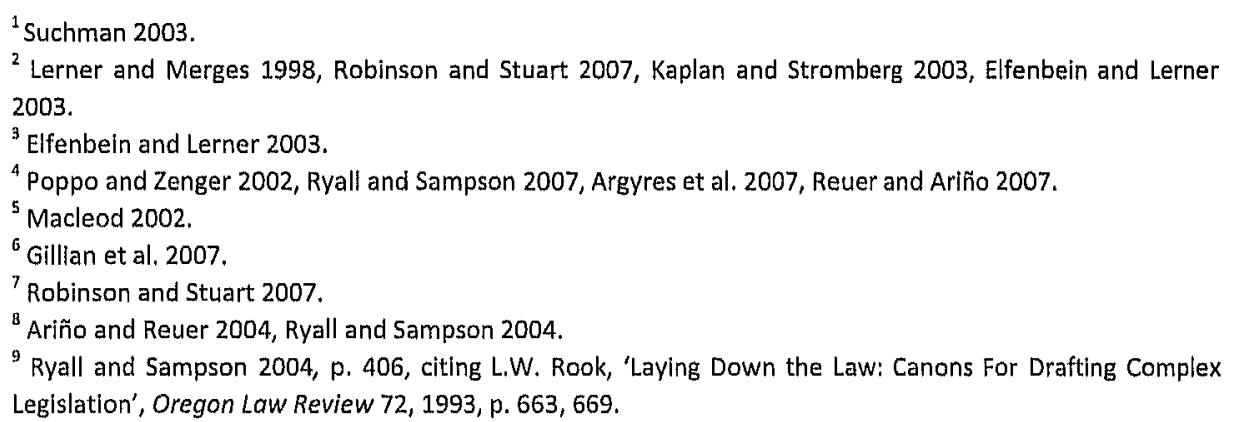

9 Ryall and Sampson 2004, p. 406, citing L.W. Rook, 'Laying Down the Law: Canons For Drafting Complex Legislation', Oregon Law Review 72, 1993, p. 663, 669. 
cal sense but in the important pragmatic sense that, given the properties of the parts and the laws of their interaction, it is not a trivial matter to infer the properties of the whole. $^{10}$

For contracts, this implies that the more complex contracts are, the more they are characterized by many parts, e.g. provisions, with a large number of interdependencies. ${ }^{11}$ More complex contracts also refine and increase the number of events, enforcement mechanisms and clauses that would otherwise be sparsely mentioned in a less complex contract. ${ }^{12} \mathrm{~A}$ higher degree of interdependency between provisions in a contract increases the information processing costs, caused by the limits of human cognition. ${ }^{13}$ Kades (1997) argues that legal rules ' (...) the length and detail of (...) rules, along with their interconnectedness, (...) are directly related to their elaborative complexity $(. .)^{\prime 14}$ and as such this complexity goes beyond the mere length of contracts. ${ }^{15}$ in that light, it becomes apparent that straightforward measures of length of contracts are probably not sufficient to fully capture the construct of complexity.

In related work, some scholars from the field of law and economics, e.g. Schuck (1992) and Eggleston et al. (2000) suggest that objective measures of the complexity of contracts should be complemented by subjective measures related to the degree of cognitive load of contracts, i.e. the degree of difficulty that people face when they attempt to understand contracts. ${ }^{16}$ In other words, these authors argue that the complexity of contracts has to be seen from a multidimensional perspective where both objective and subjective dimensions are taken into account. In order to better comprehend contractual complexity, as discussed in the above, I therefore follow up on these suggestions to include both subjective and objective elements within the construct of contractual complexity as I investigate the feasibility of a multidimensional measure of the complexity of contracts.

Given the general goal of this chapter, I attempt to make several contributions to the existing literature. First, I investigate whether different objective measures of complexity, such as the number of words, the number of pages, and the amount of kilobytes of contracts, are substitutes or complements. Second, I introduce a new measure of contractual complexity that has both an objective element, e.g. the length of contracts, and a subjective element based on the perception of the cognitive load of contracts. Third, my study also has some interesting interdisciplinary features, in the sense that I build upon the understanding of the complexity of contracts in business,

\footnotetext{
${ }^{10} \operatorname{Simon} 1981$.

${ }^{11}$ See also Rasmusen 2001

${ }_{12}$ Macleod 2000.

${ }^{13}$ Macleod 2000.

${ }^{14}$ Kades 1996, p. 413.

${ }^{15}$ Smith 2006.

${ }^{16}$ Schuck 1992, p. 3, indicates that a definition of complexity of the legal system and its rules might center on '(...) whether the people who are subjected to that legal rule, process, or institution percelve and experience it as complex (....).' (Miller 1993, cited by Kades 1997, p. 413).
} 
economics, and law in combination with an understanding of the role of cognitive load as developed in the psychology and education literatures.

The empirical analysis that I present is based on a combination of a sample of nearly $400 \mathrm{R} \& D$ alliance contracts in the biopharmaceutical industry and a measurement of the perception and assessment of the cognitive load of these contracts. My findings indicate that diverse objective measures of contractual complexity, based on the length or size of contracts, are interchangeable. In addition, objective and subjective measures do indeed refer to different dimensions of contractual complexity where the cognitive load of contracts carries both objective and subjective characteristics. My expanded conception thus allows contractual complexity to vary simultaneously across an objective as well as a subjective dimension.

The remainder of the chapter is organized as follows: in the next section I will give an overview of the different measures of contractual complexity currently discussed in the literature. This is followed by an introduction of the concept of cognitive load as this has been defined and researched in the psychology and education literatures. Methods and research design are discussed in the next section, after which I present the findings of my research. Finally, the section with the discussion and conclusions not only discusses my findings in the context of the literature on cognitive load, bounded rationality, and contractual complexity but also suggests some steps for further research that links up to other recent contributions that advocate an in-depth understanding of the content of inter-firm contracts.

\section{OBJECTIVE AND SUBJECTIVE MEASURES OF CONTRACTUAL}

\section{COMPLEXITY}

So far, a relatively large number of economists and business scholars have defined contractual complexity in rather general terms and measured the degree of this complexity through straightforward objective and quantitative indicators. Klein discusses how the greater specification of elements of performance in contracts and the increasing number of contingencies lead to more complex contracts, to which he refers as 'thicker' contracts, or 'thinner' contracts with fewer elements of performance and decreasing numbers of contingencies. ${ }^{17}$ In Rasmusen's reading cost model of contracting, length of contracts is taken as a proxy for their complexity. ${ }^{18}$ Joskow (1998) and Lumineau and Oxley (2007) take the length of supplier contracts in vertical inter-firm relationships, i.e. the number of pages in these contracts, as a proxy for their contractual complexity. Similarly, Gillan et al. (2007) measure the complexity and length of CEO employment contracts by means of the number of pages of these contracts. Poppo and Zenger (2002) asked firms to indicate on a Likert scale to what extent a

${ }^{17}$ Klein 1996.

${ }^{18}$ Rasmusen 2001. 
specific contract was highly customized and required considerable work, where higher values indicate higher levels of complexity. In addition, they also asked firms to indicate the length of their contract, in terms of the number of pages. ${ }^{19}$ Robinson and Stuart (2007) approximate the complexity of alliance contracts in bio-pharmaceuticals through the size of the digital (ASCII) contract files in kilobytes. Their contribution suggest that larger ASCII files indicate that more future contingencies are identified in these contracts and that each possible contingent action requires more complex language to describe these contingencies.

Obviously, economists and business scholars are not the only ones who have studied contractual complexity. Legal scholars have focused on the complexity of contracts from the perspective of the optimal design of contracts in terms of the benefits of either simpler or more complex contracts. These benefits of different levels of the complexity of contracts are assessed in the context of the information asymmetry between contract parties, the circumstances of contractual enforcement, and court rulings that each affect the efficiency of the degree of contractual complexity. ${ }^{20}$ In an interesting response to calls for a broadening of the understanding of contractual complexity, Eggleston et al. (2000) propose a multidimensional construct for contractual complexity. Their contribution suggests that, apart from dimensions related to objective measures, the degree to which a contract imposes a significant cognitive load upon contract parties should be taken as another important dimension of contractual complexity. More in particular, this cognitive load refers to the extent to which parties relevant to a contract are able to understand this contract, i.e. a significant cognitive load implies that a contract is more complex and more difficult to understand. $^{21}$

The basic idea behind this particular understanding of the role of the cognitive load of contracts is that increasing incorporation of expected contingencies will raise the cognitive load of contracts. In addition, calculating relevant payoffs for contingencies which might arise, demands an amount of mental effort needed to understand the intricacies of contracts. Cognitive load also represents something more, as e.g. '(...) a detailed schedule of payment amounts (...) will be more difficult to understand than a simple payment formula (for example, a $25 \%$ commission). And a payment of $\$ X$ per widget will impose less cognitive load than an otherwise identical contract that bases payment on a fraction of profits which may be difficult to calculate $(. . .)^{22}{ }^{22}$ Thus, apart from the number of contingencies and variability in payoffs, the way in which contract terms are formulated will influence the cognitive load and thereby the level of complexity of contracts. In that context, it is important to note that, as argued by amongst others Smith (2006), there is not necessarily a linear relationship between the length

${ }^{19}$ However, the low response rate on this item precluded it from being used as a second indicator in their empirical analysis (Poppo and Zenger 2002, p. 217).

${ }^{20}$ Eggleston et al. 2000 , Hill and King 2004.

${ }^{21} \mathrm{lbid}$.

${ }^{22}$ ibid. p. 91. 
of contracts and the degree to which contracts impose cognitive difficulties. The increased length of a contract provision may actually promote simplicity through modularity and the extensive use of standard boilerplate provisions as also applied in a range of contracts. Although these different contributions point at various aspects of a more intricate understanding of contractual complexity, they share a common message that suggests that an empirical analysis of contracts might need to go beyond a simple equation of length of contracts with complexity and also incorporate a cognitive dimension of contractual complexity (see Appendix 1).

\section{COGNITIVE LOAD AS A DIMENSIONS OF CONTRACTUAL}

\section{COMPLEXITY}

Scholars in law, economics and business do recognize that human actors possess bounded rationality which is, amongst other things, affected by limitations to the effort and costs of processing information. ${ }^{23}$ Cognitive load refers to the effort and mental activity imposed on a person's ability to process information. This cognitive load can therefore be seen as an important aspect of bounded rationality and, as suggested by Eggleston et al. (2000), an understanding of the role of cognitive load as the information processing capacity and information processing efforts of contract parties could inform our perception of contractual complexity. However, cognitive load has yet to be empirically examined and applied in the study of contracts at the crossroads of economic, business and legal research. This stands in sharp contrast to some other academic disciplines such as psychology and education, where cognitive load plays a prominent role in research and theory development. In these disciplines, cognitive load is, given differences in individual cognitive abilities, e.g. cognitive processing speed, considered as a crucial factor in understanding a subject's ability to process information, to learn and to understand complex tasks. ${ }^{24}$

Following Paas et al. (2003b) and Paas et al. (1993), I understand cognitive load as a complex construct in terms of three elements, i.e. mental load, mental effort and performance. 'Mental load' is the element of cognitive load, which is imposed by task or environmental demands, e.g. the structure of a task, its novelty, and the conditions under which a subject comprehends and completes a task. 'Mental effort' is defined as '(...) the aspect of cognitive load that refers to the cognitive capacity that is actually allocated to accommodate the demands imposed by the task; thus it can be considered to reflect the actual cognitive load (...). ${ }^{25}$ Mental effort can be measured during or shortly after the execution of a task. 'Performance' is the element of cognitive load,

\footnotetext{
${ }^{23}$ Simon 1955, Williamson 1996, Eisenberg 1995, Korobkin and Ulen 2000

${ }^{24}$ Brunken et al. 2003
}

${ }^{25}$ Paas et al. 2003a, p. 64 
which can be defined in terms of a subject's achievements, e.g. the time spent on performing a particular task, i.e. its time-on-task. ${ }^{26}$

So far, different methods have been developed to measure cognitive load. ${ }^{27}$ In that context, both objective and subjective measures of cognitive load have been introduced. An objective method of measurement refers to the time-on-task that produces an indication of the cognitive load that typically increases with task complexity. Increasing time-on-task then points towards a higher cognitive load of a task. ${ }^{28} \mathrm{~A}$ wellknown indirect subjective assessment of cognitive load uses a questionnaire where respondents are asked to report the invested mental effort in understanding particular materials. ${ }^{29}$ The relationship between the invested mental effort and cognitive load is indirect as a low level of mental effort could be the result of either a low cognitive load or, of such a disproportionately high cognitive load that the respondent subsequently decreased the invested mental effort. ${ }^{30}$ Despite this indirect relationship, numerous studies have shown that most people are quite capable of rating their invested mental effort on a numerical scale. ${ }^{31}$ Other subjective measures of cognitive load include the rating on a numerical scale of the difficulty of the materials that subjects have to evaluate $^{32}$ and the reporting of their experienced stress level $\left.\right|^{33}$.

Most of these subjective measures are multi-factoral in the sense that they are assessed as groups of associated variables with both indirect and direct subjective measures. Paas and Van Merriënboer (1994) have demonstrated that reliable measures for cognitive load can be found using simple scales, such as ratings based on invested mental effort. Subjective workload measurement techniques using rating scales are also widely used as they provide various benefits in the sense that they are easy to use and reliable, they do not interfere with primary task performance, they are inexpensive, they can detect small variations in workload, and they provide decent convergent, construct, and discriminate validity. ${ }^{34}$ In other words, a substantial body of literature on the measurement of cognitive load indicates that cognitive load as a multifaceted construct can be measured in three main elements (mental load, mental effort, and performance) that represent both objective and subjective elements of this cognitive load (see Appendix 1)

\footnotetext{
${ }^{26} \mathrm{lbid,}$, Corbalan et al. 2006.

${ }^{27}$ Whelan 2007.

${ }^{28}$ Corbalan et al. 2006

29 Borg et al. 1971, Paas 1992, Paas et al. 1994

${ }^{30}$ Brünken et al. 2003.

Gopher and Braune 1984, Paas et al. 2003a, Paas 1992.

${ }^{32}$ Kalyuga et al. 1998, Kalyuga et al. 1999, Kalyuga et al, 2000, Kalyuga et al, 2001, Kalyuga et al. 2004.

${ }^{33}$ Reid and Nygren 1988, Hart and Staveland 1988.

${ }^{34}$ Paas et al. 2003a, Paas 1992.
} 


\section{METHODS AND RESEARCH DESIGN}

If I follow contributions such as those by Schuck (1992), Kades (1997) and in particular Eggleston et al. (2000), who suggest that contractual complexity has both objective and subjective dimensions, with a strong impact of the cognitive load of contracts, the question remains to what extent these dimensions represent very different aspects of contractual complexity or whether these dimensions are to some extent related to each other. If all elements of the cognitive load of contracts are highly correlated, not only with each other, but also with objective measures of complexity such as the length of contracts, then it should suffice to measure contractual complexity with a simple, straightforward indicator of the length of contracts measured through e.g. the number of words, pages or kilobytes. If not, these different dimensions and elements would suggest that contractual complexity is indeed a multidimensional phenomenon, in particular if there is some level of overlap between objective, quantitative measures of complexity and objective aspects of cognitive load. The latter aspect is relevant because conceptually it is important that contractual complexity in terms of the content of contracts is to some extent related to the cognitive load of contracts, which otherwise would only indicate that we are dealing with two very different and completely unrelated aspects of contracts.

Following the above, the main research question that l address in the remainder of this chapter is then: to what extent do quantitative objective measures of complexity (e.g. length), objective elements of cognitive load (e.g. time-on-task), and subjective elements of cognitive load (e.g. mental effort) measure different aspects of contractual complexity? In order to answer this question, I analyze a sample of nearly 400 inter-firm R\&D alliance contracts with regard to their contractual complexity in terms of their length as well as in terms of their cognitive load. To measure the cognitive load of these contracts I set up a study where a large number of participants were asked to read the contracts and fill out a short questionnaire with various items related to the cognitive load of each contract.

Data

The dataset on contracts that I analyze in this chapter refers to a set of 387 contracts in the biopharmaceutical sector. The contracts were obtained from the PharmaDeals database, managed by PharmaVentures, a UK-based specialized consultancy firm serv ing the global pharmaceutical industry. The information on the actual contracts is based on contract filings with the US Securities and Exchange Commission (SEC). ${ }^{35}$ The collected contracts fall within one of either two categories identified by PharmaDeals co-development contracts and collaborative R\&D contracts. Co-development is de-

35 Issuers of US publicly traded securities are required to disclose all contracts deemed 'material' in filling with the SEC. See Overdahl (1991) for more information on the specific requirements and issues concerning contract filings with the SEC. 
fined as ' $(.$.$) two (or more) companies working together with the aim of developing a$ clinical-stage compound (...). Collaborative R\&D is as co-development but used for preclinical or earlier stage research (...)' (PharmaDeals). The agreements refer to 219 US (domestic) contracts, i.e. the contracting parties are both US-based firms, and 168 international contracts, i.e. a US-based firm collaborates with a non-US based firm. A total of 342 firms were involved in these contracts and roughly two thirds of the agreements are concluded between an established pharmaceutical company and a start-up or emerging firm. All the agreements were set up between 1996 and 2005 . The contracts in my sample represent the first interaction between the companies as filed with the SEC within this time period.

\section{The 'objective' measure of the complexity of contracts}

As shown by previous studies, a one-dimensional objective measure of contractual complexity can be constructed in terms of either the number of kilobytes of the ASCII file of a contract, the number of pages of a contract or the number of words in a contract. The electronic copies of the contracts provide by PharmaDeals are presented in a comparable layout in PDF-format. I used the document conversion feature of a text miner to convert all the documents into a readable ASCIl file. The text miner provides us with information on the number of words and a page count was obtained by opening the ASCll files with Microsoft Word. The number of kilobytes of each file was retrieved from the file properties report.

To see whether there was indeed a difference between the various objective measures of complexity in terms of length, I first performed a correlation test to investigate the possible association between these three measures (see table 1). Table 1 illustrates that for my sample these measures (kilobytes, number of words, and number of pages) are almost perfectly correlated, ranging from 0.951 to 0.987 . In my empirical analysis, the number of words was taken as a first quantitative, objective proxy for contractual complexity in terms of the length of these contracts.

Table 1 Correlations between Kilobytes, Number of Words, and Number of Pages in R\&D Alliance Contracts $(n=387)$

\begin{tabular}{llccc}
\hline & & kilobytes & words & pages \\
\hline kilobytes & Pearson Correlation & 1.000 & & \\
\hline words & Pearson Correlation & $.987^{* *}$ & 1.000 & \\
\hline pages & Pearson Correlation & $.951^{* *}$ & $.961^{* *}$ & 1.000 \\
\hline
\end{tabular}

** Correlation is significant at the 0.01 level (2-tailed).

Research design

The study was conducted at Maastricht University in The Netherlands. In both the pilot study and the actual study, my participant pool consisted of graduate students from 
Maastricht University. ${ }^{36}$ This choice might raise some concern as, compared to professionals, students lack professional experience and are generally younger, which may lead to a different attitude than one would expect for managers and corporate lawyers who would otherwise deal with these contracts. However, as Siegel and Harnett (1964) have shown, attitudes are not necessarily related to behavior. Research has provided significant evidence that students are indeed valid surrogates for professionals. Comparing professional and student behavior, many studies do not find a substantial difference in behavior. ${ }^{37}$ In addition, Levitt (1965) and Khera and Benson (1970) find that students tend to behave more like businessmen and businesswomen or other relevant professionals when they have an adequate background for the research task.

In the pilot study, the group of participants consisted of six students from the Faculty of Law, three students from the Faculty of Economics and Business Administration, and two students from the Faculty of Medicine and Health Sciences. Each of the students completed their JD, MSc. and MD respectively and had entered the second or third year of their PhD program. Each PhD student received two contracts.

I developed a questionnaire for the pilot study with a total of five questions based on validated and widely used items found in the cognitive load literature (see Appendix 2). I used scale-based reporting to investigate the degree of cognitive load in relation to the contracts. As mentioned earlier, cognitive load comprises mental load, mental effort and performance. Therefore, a meaningful interpretation of cognitive load can only be given through the measurement of indicators of these different elements of cognitive load.

As a direct subjective measure of cognitive load, I asked the participants to rate the perceived level of complexity of the contract (question 1). This question is based on Marcus et al. (1996) and Van Gog and Paas (2008). The cognitive load of information is amongst others defined by the extent to which various elements interact. High element interactivity imposes a heavy load on working memory, which translates into a high level of perceived complexity. ${ }^{38}$

As an indirect subjective measure, I asked participants to report the invested mental effort necessary to understand the materials (question 2), adopted from a scale as first developed by Paas (1992) and Paas and Van Merriënboer (1993). Mental effort relates to the effort made to process and comprehend information. Mental effort measurements account for task characteristics, subject characteristics and their inter-

\footnotetext{
${ }^{36}$ Although I did consider the option of having these contracts read by managers, corporate lawyers, and legal counsel to assess the cognitive load of the sample of contracts, both my reading of the relevant literature and the consultation of a number of experts convinced me that in practice It would be impossible to have a survey of nearly 400 contracts read by practitioners.

${ }^{37}$ Abbink and Rochenbach 2006, Siegel and Harnett 1964, Banks et al. 1994, King et al, 1992, DeJong et al. 1988, Burnett and Dunne 1986, Alderfer and Bierman 1970, Cunningham et al. 1974, Park and Lessig 1977, Hughes and Gibson 1991

${ }^{38}$ Pollock et al. 2002 .
} 
action, and provide information that is not rendered by mental load and performance measures.

I also asked participants to report the perceived level of information in the contract (question 3) and to assess the length of the contract given objectives (question 4). Both questions are based on Brünken et al. (2003) and Paas et al. (2003b). The perceived level of information and the length given objectives are indicators of the amount of information, format and manner in which information is presented. These factors measure task demands imposed by information design and presentation. ${ }^{39}$

The measurement of experienced stress levels (question 5), was adopted from the Subjective Workload Assessment Technique (SWAT) ${ }^{40}$ and the National Aeronautics and Space Administration-Task Load Index (NASA-TLX) ${ }^{41}$. Stress is a direct subjective measure of cognitive load and as such complements mental effort, which is an indirect objective measure of cognitive load. Experienced stress levels measure setting, situation and context effects on the subject; i.e. a degree of effort may be required to manage discomfort and as such affect perceived workload.

In cognitive load research, 7-point Likert scales are frequently used to measure the invested mental effort ${ }^{42}$ and the difficulty of the materials ${ }^{43}$. In compliance with this literature, the students were asked to record their responses on a 7-point Likert scale. The scale ranges from very low (1) to very high (7) or from very clear (1) to very unclear (7), depending on the question.

The PhD students were also asked to report the time spent reading each contract and as such I obtained an objective indirect measure: time-on-task (see Appendix 2). Paas et al. (2003a) indicate that time-on-task is often neglected in cognitive load measurements. Corbalan et al. (2006) argue that time-on-task provides a meaningful measurement as this reflects the difficulty or ease of a task. Time-on-task typically increases with complexity and a high time-on-task points towards a high cognitive load. See also Brünken et al. (2003) who argue that time-on-task can be seen as an indicator of different cognitive load levels. In addition, the length of the contracts was recorded: each student was given one longer and one shorter contract in terms of the number of words.

The pilot study led to some adjustments to the questionnaire for the actual study. The question on the level of information in the contract (question 3) was eliminated as the feedback from the test group indicated that 'the level of information' was subject to different interpretations. The word 'stress' in the final question was redefined as merely 'irritated, annoyed' in order to reduce the chance of divergent interpretations. Several participants remarked that it was easier to read the second contract, since the first contract created a learning effect, i.e. by reading the first contract the participants

${ }^{39}$ Ibid.

${ }^{40}$ Reid and Nygren 1988

${ }^{41}$ Hart and Staveland 1988

${ }^{42}$ Corbalan et al. 2006, Tindall-Ford et al. 1997, Marcus et al. 1996, Moreno 2004

${ }^{43}$ Haydee et al. 2002, Kalyuga 2000. 
gained a sense of the structure and content of this sort of contractual agreements. Other studies have also shown that prior knowledge partly determines the level of cognitive load that an individual will experience. ${ }^{44}$ Therefore, I controlled for this learning effect by first administering one additional single contract of medium size to every participant in the study, i.e. all participants received the same contract first. This additional contract was obtained from another source but given its content, it is representative for the other R\&D alliance contracts given to the participants in the study. The function of this contract, that was administered to all participants separately, is somewhat similar to a 'practice task' in psychological experiments. In the final questionnaire I also included some clear instructions for the task (see Appendix 3). This questionnaire contained a total of four questions.

The actual study was conducted with two groups, each with 60 students. The first group consists of students from the Faculty of Law at Maastricht University. These students were enrolled in a masters-level course on 'European contract law', pursuing either a JD in 'European and Comparative law' or 'Dutch law'.

If I were to only consider this group of participants, i.e. law students, one could wonder whether results would be only relevant for that particular group. In absolute terms, the cognitive load may differ across groups of individuals. For example, individuals trained as attorneys may read a contract and see structures and language that would require little extra effort, while others may need to employ a much greater effort to detect similar structures and language, assuming these individuals would be able to uncover such legal implications at all. If the cognitive load were to be measured in practice, it should be done by controlling for different groups within society. Contracts are not only employed by attorneys or legally trained individuals, but also read and used by managers and other relevant professionals. These groups of professionals use, understand and manage contracts in different ways. See a recent paper by Argyres and Mayer (2007), in which the authors indicate that the management of contract design capabilities resides differentially with managers, engineers and lawyers. In order to control for this potential bias, I also conducted a second study with a group of students from the Faculty of Economics and Business Administration at Maastrich University. These students participated in a course on 'Alliances and Mergers \& Acquisitions' which is part of an MSc program in International Business. Students in both groups have a Western European background, English is a foreign language to them but it is also a major language of instruction, which they had experienced during at least three years of university education.

The students in both groups were given general information on the types of contracts and they received a brief instruction on the reading of the contracts and how to fill out the questionnaire. Ideally, each student should have received the complete set of contracts. However, with a sample of nearly 400 contracts with an average length of about 50 pages per contract, this would lead to a reading load of nearly 20,000 pages 
per participant. Therefore, each student was randomly administered a total of six or seven contracts. To avoid group pressure, these contracts were read and the questionnaires filled out in a private setting.

Before these six or seven contracts were distributed to each student, as explained in the above, one contract, representative of the sample of 387 contracts, was administered to all students in a first round in order to control for learning effects. The scores of the students on the various questions for this representative contract were also used to consider the within-group variance for both groups. ${ }^{45}$ As demonstrated by the data on the coefficient of variation for the various questions, see table 2 , the within-group homogeneity was relatively large for both groups. This implies that a single participant can be seen as representative of his or her group. ${ }^{46}$ This finding is important as it indicates that, in a second round, I could ask students in each group of 60 students to read 6 or 7 contracts from the sample of 387 contracts in order to get valuable information on the cognitive load of each contract. ${ }^{47}$ During this second round, students were asked to read each contract they were given and answer the four questions from the questionnaire in addition to reporting the time-on-task for each contract.

Table 2 Results on the Scores (Mean, Standard Deviation, and Coefficient of Variation) for the Questions on the Representative Contract, Both Groups ( $n=60$ for Both Groups).

\begin{tabular}{llrrrr}
\hline & $\begin{array}{l}\text { Law and } \\
\text { Business }\end{array}$ & Mean & $\begin{array}{r}\text { Std. } \\
\text { Deviation }\end{array}$ & $\begin{array}{r}\text { Std. } \\
\text { Error Mean }\end{array}$ & CV \\
\hline Q1: level of complexity & Law & 4.825 & 0.986 & 0.127 & 0.204 \\
\cline { 2 - 7 } & Business & 4.683 & 1.186 & 0.153 & 0.253 \\
\hline \multirow{2}{*}{ Q2: mental effort } & Law & 4.900 & 1.203 & 0.155 & 0.246 \\
\cline { 2 - 7 } & Business & 4.483 & 1.334 & 0.172 & 0.298 \\
\hline Q3: length given objectives & Law & 4.842 & 1.155 & 0.149 & 0.239 \\
\cline { 2 - 7 } & Business & 4.797 & 1.126 & 0.147 & 0.235 \\
\hline Q4: stress level & Law & 4.350 & 1.696 & 0.219 & 0.390 \\
\cline { 2 - 7 } & Business & 4.333 & 1.724 & 0.223 & 0.398 \\
\hline Length (words) & Law & 1.4528 .000 & 0.000 & 0.000 & 0.000 \\
\hline Time (minutes) & Business & 14528.000 & 0.000 & 0.000 & 0.000 \\
\hline & Law & 59.833 & 36.309 & 4.687 & 0.607 \\
\cline { 2 - 7 } & Business & 81.500 & 44.979 & 5.906 & 0.552 \\
\hline
\end{tabular}

${ }^{45}$ See also Mason 2006.

${ }^{46}$ Bedeian and Mossholder 2000, Sorenson 2002.

${ }^{47}$ In theory, a random distribution of these contracts in both groups should have been sufficient but for this experimental setting I prefer to remain strict and test the degree to which there is within-group homogeneity. 


\section{RESULTS}

In the following, I will, given the similarity of the outcomes for the two groups, concentrate the discussion of the results of my empirical research on the group of law students and discuss the results for the group of business students only in reference to diverging results. ${ }^{48}$ The descriptive statistics for each of the four questions, the length of contracts in number of words, and the time-on-task are presented in Table 3. The average length in words for these contracts is 14972 with a standard deviation of 9407. The average time necessary to read these contracts was 50.58 minutes with a standard deviation of 39.19 for the group of law students and 67.42 with a standard deviation of 52.06 for the group of business students.

Table 3 Descriptive Statistics (Means and Standard Deviation) for Contractual Complexity (Cognitive Load and Time and Length) of Contracts, Law and Business Students ( $n=387$ ).

\begin{tabular}{llrrrr}
\hline Group & Items & Minimum & Maximum & Mean & Std. Deviation \\
\hline Law & Q1: level of complexity & 1.000 & 7.000 & 4.386 & 1.391 \\
\hline & Q2: mental effort & 1.000 & 7.000 & 4.310 & 1.428 \\
\hline & Q3: length given objectives & 1.000 & 7.000 & 4.528 & 1.378 \\
\hline Q4: stress level & 1.000 & 7.000 & 3.806 & 1.726 \\
\hline Time (minutes) & 2.000 & 270.000 & 50.576 & 39.192 \\
\hline Length (words) & 601.000 & 74415.000 & 14972.103 & 9407.515 \\
\hline Business & 1.000 & 7.000 & 4.129 & 1.620 \\
\hline Q1: level of complexity & 1.000 & 7.000 & 4.104 & 1.537 \\
\hline Q2: mental effort & 1.000 & 7.000 & 4.311 & 1.523 \\
\hline Q3: length given objectives & 1.000 & 7.000 & 3.803 & 1.830 \\
\hline Q4: stress level & 5.000 & 300.000 & 67.419 & 52.064 \\
\hline Time (minutes) & 601.000 & 74415.000 & 14972.103 & 9407.515 \\
\hline Length (words) & & & &
\end{tabular}

A first step in the analysis was to look at the inter-item correlations for the six item scores for the group of law students. The correlation matrix demonstrates that, as also suggested by the literature on cognitive load, several measures of cognitive load do correlate substantially: the level of complexity with mental effort and stress level, and the mental effort with stress level. In addition, relatively high correlations are found between the number of words and the length given objectives. For the group of business students, I also find higher correlations between the perceived complexity and length given objectives, as well as the number of words and time-on-task.

\footnotetext{
${ }^{48}$ I also performed the same analyses with both groups for the contracts between US companies and between US and non-US companies separately, to see whether the domestic or international context of these contracts might impact the complexity of contracts. However, the results for these sub-samples are Identical to those for the overall sample.
} 
Table 4a Item Correlations for Contractual Complexity (Cognitive Load and Time and Length) of Contracts, Law Students ( $n=387$ ).

\begin{tabular}{|c|c|c|c|c|c|c|c|}
\hline & & $\begin{array}{l}\text { Q1: } \\
\text { level of } \\
\text { complexity }\end{array}$ & $\begin{array}{l}\text { Q2: } \\
\text { mental } \\
\text { effort }\end{array}$ & $\begin{array}{l}\text { Q3: } \\
\text { length } \\
\text { given } \\
\text { objectives }\end{array}$ & $\begin{array}{l}\text { Q4: } \\
\text { stress level }\end{array}$ & $\begin{array}{l}\text { Time } \\
\text { (minutes) }\end{array}$ & $\begin{array}{l}\text { Length } \\
\text { (words) }\end{array}$ \\
\hline Q1: level of complexity & $\begin{array}{l}\text { Pearson } \\
\text { Correlation }\end{array}$ & 1.000 & & & & & \\
\hline Q2: mental effort & $\begin{array}{l}\text { Pearson } \\
\text { Correlation }\end{array}$ & $.777^{* *}$ & 1.000 & & & & \\
\hline Q3: length given objectives & $\begin{array}{l}\text { Pearson } \\
\text { Correlation }\end{array}$ & $.463^{* *}$ & $.394^{* *}$ & 1.000 & & & \\
\hline Q4: stress level & $\begin{array}{l}\text { Pearson } \\
\text { Correlation }\end{array}$ & $.639^{* *}$ & $.645^{* *}$ & $.457^{* *}$ & 1.000 & & \\
\hline Time (minutes) & $\begin{array}{l}\text { Pearson } \\
\text { Correlation }\end{array}$ & $.255^{* *}$ & $.223^{* *}$ & $.283^{* *}$ & $.173^{* *}$ & 1.000 & \\
\hline Length (words) & $\begin{array}{l}\text { Pearson } \\
\text { Correlation }\end{array}$ & $.315 * *$ & $.225^{* *}$ & $.533^{* *}$ & $.227^{* *}$ & $.429 * *$ & 1.000 \\
\hline
\end{tabular}

** Correlation is significant at the 0.01 level (2-tailed).

Table 4b Item Correlations for Contractual Complexity (Cognitive Load and Time and Length) of Contracts, Business Students $(n=387)$

\begin{tabular}{|c|c|c|c|c|c|c|c|}
\hline & & $\begin{array}{l}\text { Q1: } \\
\text { level of } \\
\text { complexity }\end{array}$ & $\begin{array}{l}\text { Q2: } \\
\text { mental } \\
\text { effort }\end{array}$ & $\begin{array}{l}\text { Q3: } \\
\text { length } \\
\text { given } \\
\text { objectives }\end{array}$ & $\begin{array}{l}\text { Q4: } \\
\text { stress level }\end{array}$ & $\begin{array}{l}\text { Time } \\
\text { (minutes) }\end{array}$ & $\begin{array}{l}\text { Length } \\
\text { (words) }\end{array}$ \\
\hline Q1: level of complexity & $\begin{array}{l}\text { Pearson } \\
\text { Correlation }\end{array}$ & 1.000 & & & & & \\
\hline Q2: mental effort & $\begin{array}{l}\text { Pearson } \\
\text { Correlation }\end{array}$ & $.768^{* *}$ & 1.000 & & & & \\
\hline Q3: length given objectives & $\begin{array}{l}\text { Pearson } \\
\text { Correlation }\end{array}$ & $.549^{* *}$ & $.430^{* *}$ & 1.000 & & & \\
\hline Q4: stress level & $\begin{array}{l}\text { Pearson } \\
\text { Correlation }\end{array}$ & $.621^{* *}$ & $.690^{* *}$ & $.449^{* *}$ & 1.000 & & \\
\hline Time (minutes) & $\begin{array}{l}\text { Pearson } \\
\text { Correlation }\end{array}$ & $.384^{* *}$ & $.334^{* *}$ & $.427^{* *}$ & $.304^{* *}$ & 1.000 & \\
\hline Length (words) & $\begin{array}{l}\text { Pearson } \\
\text { Correlation }\end{array}$ & $.461^{* *}$ & $.337^{* *}$ & $.591^{* *}$ & $.330^{* *}$ & $.500^{* *}$ & 1,000 \\
\hline
\end{tabular}

** Correlation is significant at the 0.01 level (2-tailed).

Based on the correlation matrix as found in Table $4 a, I$ use the scores of the law students to conduct a Principal Component Analysis (PCA) with Varimax rotation with the following items: perceived complexity, mental effort, length given objectives, stress level, time-on-task and the length in words. The PCA renders two components and a high discriminant validity for all of the items. Perceived complexity, mental effort and stress level load high on component 1 and time-on-task and the number of words on component 2. Length given objectives (Q3), however, cross-loads on both components with loadings of .461 and .616 respectively. I eliminated this item from my analysis and ran the PCA with Varimax rotation again (see table 5). 
Table 5 Principal Component Analysis of Contractual Complexity with Varimax Rotation, Law Students

\begin{tabular}{lll}
\hline & Component & \\
\cline { 2 - 3 } & 1 & 2 \\
\hline Q1: perceived complexity & 0.884 & 0.217 \\
\hline Q2: mental effort & 0.903 & 0.128 \\
\hline Q4: stress level & 0.854 & 0.086 \\
\hline Time (minutes) & 0.100 & 0.846 \\
Length (words) & 0.165 & 0.822 \\
\hline
\end{tabular}

a. Rotation converged in 3 iterations.

Table 6 Principal Component Analysis of Contractual Complexity with Varimax Rotation, Business Students

\begin{tabular}{lll}
\hline & Component & \\
\cline { 2 - 3 } & 1 & 2 \\
\hline Q1: perceived complexity & 0.832 & 0.326 \\
\hline Q2: mental effort & 0.907 & 0.176 \\
\hline Q4: stress level & 0.855 & 0.154 \\
\hline Time (minutes) & 0.175 & 0.850 \\
\hline Length (words) & 0.225 & 0.833 \\
\hline Ritation
\end{tabular}

a. Rotation converged in 3 iterations.

This PCA also resulted in two components, with similar loadings as the first analysis (exclusive of length given objectives (Q3)), and it also generated high discriminant validity. The analysis reveals a Kaiser-Meyer-Olkin (KMO) score of .732 and a significant Bartlett's test. The total variance explained by both components is $76.53 \%$. For each item the communality and thus common variance is above .700 . The internal reliability measured by Cronbach's Alpha for the level of complexity, mental effort and stress level is .860. Cronbach's Alpha for both of the items that load on the second component, the time-on-task and the number of words, is somewhat lower at .600

I find similar results for the group of business students (see Table 6). A preliminary PCA with Varimax rotation led me to eliminate length given objectives (Q3) due to crossloadings. A second PCA with Varimax rotation reveals two components, with comparable item loadings as for the group of law students. The data for the business students show a lower discriminant validity as the 'level of complexity' (Q1) loads to some extent on both components (.832 vs. .326). The test for internal reliability on the level of complexity, mental effort and stress level generates a Cronbach's Alpha of .866, which indicates that these three items load on component 1 and measure the same latent construct. I find a Cronbach's Alpha of .667 for the number of words and time-on-task.

\section{DISCUSSION AND CONCLUSIONS}

My findings indicate that, as suggested by Eggleston et al. (2000), contractual complex ity is indeed a multidimensional phenomenon with both objective and subjective aspects. The length of contracts as a simple count-based indicator of complexity has 
some clear overlap with the time-on-task as a performance measure of the cognitive load of contractual complexity. Despite their conceptual differences, both these elements of contractual complexity point at one particular objective dimension of contractual complexity.

However, there is more to contractual complexity than just length and time-ontask as objective indicators of the complexity of contracts. My research indicates the relevance of another dimension of contractual complexity, based on a number of subjective elements of the cognitive load of contracts, for understanding the complexity of contracts. The mental effort that people have to make to understand the content of contracts can be broken down in two sub-elements: the actual cognitive effort they make to understand contracts and the degree of stress that they experience as they have to read through contracts. The perceived level of the complexity of contracts suggests a more subjective perception of the mental load and the task difficulty that people face when they 'digest' these contracts. These different elements indicate the intricacy of cognitive load as such. ${ }^{49}$ This intricacy of the cognitive load is apparent in the context of inter-firm contractual agreements where mental load and mental effort are related to a more subjective dimension of contractual complexity whereas the performance element of the cognitive load of contracts (time-on-task) is part of an objective dimension of contractual complexity.

Returning to the central question of this chapter, I find that the quantitative, objective measures of complexity, such as length, and objective as well as subjective elements of cognitive load do indeed measure different aspects of contractual complexity. Both components of contractual complexity (an objective, quantitative dimension and a more subjective cognitive load-based dimension) and their individual elements suggest that contractual complexity is indeed a multidimensional phenomenon. Also, the relatedness of the objective aspect of cognitive load to the other objective aspect of contractual complexity, i.e. the length of contracts, suggests that a multidimensional understanding of complexity which encompasses cognitive load is indeed relevant for understanding the complexity of contracts.

These findings do indicate that it is worthwhile for scholars to not only 'measure' the complexity of contracts that establish inter-firm relationships through objective measures, even when these measures go beyond simple counts of pages or words. My study suggests that there is a cognitive dimension to the complexity of contracts, which expresses the degree to which contracts impose a cognitive load on contract parties. If the groups in my study are representative for managers and corporate lawyers, who represent companies as contract parties, then the cognitive load of contracts does indeed affect the degree to which these managers and lawyers experience the complexity of their alliance contracts beyond the mere length of such contracts.

My understanding of the complexity of contracts that incorporates cognitive load as an important dimension of complexity has some interesting implications for the

${ }^{49}$ Paas et al. 2003a, Paas and Van Merriënboer 1994 
broader perspective of bounded rationality and its impact on contracts. Bounded rationality is expected to affect the degree to which economic actors (e.g. companies, managers, corporate lawyers, legal counsel) are limited in their cognitive capabilities to design and write contracts with an effective degree of contractual complexity that would fit all current and future contingencies that might affect the context of a contract. $^{50}$ In other words, bounded rationality has a front-end impact on the effectiveness of contract design due to the limitations and costs of information processing. However, the cognitive load of contracts has some post-design implications for the bounded rationality with which contract parties are able to implement and monitor their contracts. If the cognitive load of contracts affects the complexity of contracts, this implies that higher levels of the cognitive load of contracts increase the likelihood that economic actors do not fully comprehend contracts or are limited in their interpretation of the consequences of the content of their contract. As such, it appears that the cognitive load of contracts affects the bounded rationality with which contract parties have to govern their inter-firm contractual arrangements such as R\&D alliance contracts.

Another implication of my research is that my findings qualify a basic assumption of the economics of law literature and the managerial contract literature which state that with increasing levels of economic risk in inter-firm transactions, greater levels of contractual complexity are necessary to safeguard these transactions. However, in the context of the bounded rationality that contract parties face and given the cognitive load of contracts and its implications for the information processing ability of contract parties, there may very well be an upper limit to the actual level of complexity of contracts that contract parties are able to absorb. ${ }^{51}$

Although, my research generates some interesting insights regarding the complexity of inter-firm contracts, it is important to note that my contribution is based on an experimental research design that leaves ample room for improvement and directions for further research. One line of future research would be to consider a broader set of indicators for contractual complexity that might lead to additional dimensions of this complexity. A number of recent contributions point at some interesting, possibly additional, indicators of contractual complexity. This line of work considers the complexity of contracts through counts of the number of particular groups of clauses and provisions incorporated in a range of contracts, e.g. R\&D alliances, human resource outsourcing contracts, standard outsourcing contracts, and vertical inter-firm agreements. ${ }^{52}$ The complexity of these contracts is expected to increase with the number and the type of clauses and provisions, the monitoring mechanisms, and the description of specific tasks included in these contracts.

\footnotetext{
${ }^{50}$ Eisenberg 1995, Korobkin and Ulen 2000.

${ }_{51} 1$ am indebted to Laura Poppo for drawing my attention to this implication of my findings,

${ }_{52}$ See Ariño and Reuer 2004, Barthélemy and Quélln 2006, Lumineau and Oxley 2007, Mellewigt et al. 2007,

Reuer and Ariño 2002, Reuer et al. 2006, Ryall and Sampson 2006, Ryall and Sampson 2003.
} 
In an alternative approach, Hansen and Higgins (2007) mention that the number of provisions included in a contract do not consistently define contractual complexity while focusing only on certain provisions may ignore other relevant aspects of contracts. These authors define contractual complexity along a multidimensional framework of functional and technological scope. Functional scope provides a measure of breadth of the alliance contract, while technological scope provides a measure of depth of the alliance contract. This complexity indicator is a measure of the activities and technologies chosen to be in the alliance, which is subsequently specified in the contract. In particular, functional scope (breadth) identifies the extent of value chain activities, such as manufacturing, marketing and distribution while technological scope (depth) relates to firm capabilities and overall uncertainty of focal projects. ${ }^{53}$

As with the other recent attempts to deepen or broaden my understanding of the complexity of contracts, briefly discussed in the above, it appears worthwhile for future research to investigate the degree to which we can identify such additional dimensions of the complexity of contracts. However, in the end the value of such a multidimensionalization has to be found in studies that indicate the degree to which the complexity of contracts, in terms of the size of contracts, their cognitive load, the weight of different contractual terms, their value chain coverage, and their technological scope, tells us something about the actual contracting behavior of companies. More in particular, the ultimate aim of such a multidimensional perception of contractual complexity is the understanding of the implications of different levels of contractual complexity for the costs of inter-firm contracts in terms of design, writing, implementation, control, and enforcement. In that light, my current chapter, although limited to two dimensions of contractual complexity, has to be seen as a first step towards a more in-depth understanding of the complexity of inter-firm contracts, in terms of its objective and subjective characteristics, that can benefit future empirica research on this aspect of the contracting behavior of firms in various legal, industrial, and inter-firm settings. 
APPENDIX 1

OVERVIEW COGNITIVE LOAD AND CONTRACTUAL COMPLEXITY CONSTRUCTS

\begin{tabular}{|l|l|l|l|l|l|}
\hline CONSTRUCT & SUBJECTIVE/OBJECTIVE & SUBCONSTRUCTS & SUBJECTIVE/OBJECTIVE & $\begin{array}{l}\text { SUBCONSTRUCT- } \\
\text { ELEMENTS }\end{array}$ & INDICATORS \\
\hline & & & & MENTAL LOAD & Perceived task \\
difficulty/complexity
\end{tabular}


APPENDIX 2

QUESTIONNAIRE PILOT STUDY - PHD STUDENTS

Questions

(1) How do you perceive the level of complexity of the contract?

(2) How much effort did you have to invest in order to understand the contract?

(3) How do you perceive the level of information contained in the contract?

(4) How would you rate the length of the contract, given the objective of the agreement?

(5) How stressed (insecure, discouraged, irritated, annoyed) did you feel while reading the contract?

Time needed for reading the contract.

Question 1: see Marcus et al. (1996), Van Gog and Paas (2008)

Question 2: see Paas (1992).

Question 3: see Brünken et al. (2003), Paas et al. (2003b).

Question 4: see Brünken et al. (2003), Paas (2003b).

Question 5: adopted from the SWAT (Reid and Nygren 1988) and NASA-TLX (Hart and Staveland 1988) scales. 
APPENDIX 3

FINAL QUESTIONNAIRE - LAW AND BUSINESS STUDENTS

Instructions:

'Imagine you are a legal counsel at an international company. One of your main tasks is to draft and conclude alliances. Please read the attached contract and answer questions 1-4.

Please be aware of the following while reading the contract:

(1) The page numbers indicated in the table of contents (if included), do not correspond with the actual page numbers of the contract due to formatting.

(2) The stars $\left[{ }^{* *}\right]$ in the contract designate confidential information which has been omitted.'

\section{Questions*}

(1) How do you perceive the level of complexity of the contract?

(2) How much effort did you have to invest in order to understand the contract?

(3) How would you rate the length of the contract, given the objectives of the agreement?

(4) How stressed (irritated or annoyed) did you feel while reading the contract?

Time needed for reading the contract.

* See Appendix 2 for the references to these questions. 
CHAPTER 5

THE CONTRACTUAL COMPLEXITY OF R\&D ALLIANCE CONTRACTS 


\section{INTRODUCTION}

In the last decade inter-firm collaborative agreements have gained importance in the international economy and are the most common organizational form through which firms engage in joint research and development (R\&D). ${ }^{1}$ For 2000 for example, roughly $25 \%$ of $\$ 26$ billion US based financed pharmaceutical R\&D can be traced to over 700 inter-firm collaborative agreements. ${ }^{2}$

Various economic theories have developed which attempt to explain the growth of these organizational forms. However, our understanding of these contractual collaborations does not mirror the expanding role these arrangements play in the business landscape. Little is known about precise contract structure and operation. ${ }^{3}$ This might be caused in part by the fact that contracts have long been regarded as rather low-dimensional constructs. ${ }^{4}$ Contracts, however, are not only a collection of promises as classical theory asserts, but also governance structures which regulate relationships over time. ${ }^{5}$ The degree of diversity in these contractual arrangements is large and scholars have attempted to determine this heterogeneity by measuring the degree of contractual completeness. But as Furlotti (2007) asserts, heterogeneity cannot be captured effectively by variations along a single dimension. A more in-depth investigation of contract structure is necessary and consequently scholars have recently introduced the concept of contractual complexity.

Complexity theory argues that as a result of parties' drafting effort, contracts should include a higher number of clauses and provide for a larger array of enforcement mechanisms. Drawing on a study by Parkhe (1993), several authors model complexity by counting a certain number of pre-defined clauses in a contract and rank them according to their stringency. ${ }^{6}$ In a similar manner, Anderson and Dekker (2005) and Ryall and Sampson $(2006,2007)$ refer to complexity as the number and extensiveness of included contract terms. Other authors use the number of pages or amount of kilobytes of information to measure complexity. 'Hansen and Higgins (2007) argue that 'broad measures such as contract length and number of provisions included in contract do not consistently define contractual complexity across heterogeneous contractual relationships and focusing only on certain provisions may be too limited and ignore other relevant aspects of contract design. ${ }^{8}$ Hansen and Higgins (2007) define contractual complexity along a multidimensional framework of functional and technological scope. Other scholars such as Eggleston et al. (2000) propose a three-dimensional

\footnotetext{
Robinson and Stuart 2007, Hagedoorn 2002, Faems et al. 2008.

2 Robinson and Stuart 2007,

${ }^{3}$ Robinson and Stuart 2007, Mayer and Teece 2008, Argyres et al. 2007.

${ }^{4}$ Furlotti 2007

${ }^{5}$ ibid.

${ }^{6}$ Ariño and Reuer 2004, Reuer and Ariño 2007, Reuer et al. 2006, Barthélemy and Quélin 2006.

${ }^{7}$ Robinson and Stuart 2007.

${ }^{8}$ Hansen and Higgins 2007, p. 7 .
} 
construct of complexity which comprises the expected number of specified pay-off relevant contingencies, the variance in the level of pay-offs, and the cognitive load necessary to understand the contract.

Although the concept of complexity has received quite some attention in literature, the understanding and conceptualization of complexity remains a challenge. As Masten and Saussier (2002) indicate: theory so far does not offer a '(...) unifying structure for the specification and testing of contract design hypotheses. ${ }^{9}$ In this chapter I take the foregoing limitations as point of departure. I use a multi-dimensional construct of contractual complexity as developed in my recent paper. ${ }^{10}$ Based in part on Eggleston et al. (2000), I define complexity to consist of two dimensions: an objective dimension and a subjective dimension. A well-defined construct of complexity will give us a better insight into contract structure.

I am also interested to learn under which conditions firms are inclined to increase contractual complexity. Most studies which try to understand and explain the diversity in contractual design, are heavily influenced by transaction cost economics and property rights theory. These theories contend that contractual agreements may serve several important functions in managing exchange hazards. ${ }^{11}$ Exchange hazards in turn are represented by transaction characteristics such as size, asset specificity, (environmental) uncertainty, task complexity and particular partner characteristics. Dyer (1997), Poppo and Zenger (2002), Reuer and Ariño (2007), Barthélemy and Quélin (2006) and Anderson and Dekker (2005), find that for example the transactional attribute of asset specificity generates greater contractual complexity. Other research findings illustrate that the strategic importance of the collaboration is positively related to the complexity of contracts. ${ }^{12}$ Finally, several studies focus on aspects of (environmental) uncertainty, indicating that the latter raises contractual complexity. ${ }^{13}$ At the level of company experience, authors have found that prior collaborations may give rise to either more or less complex contracts. Some authors find that prior collaborations lead to the development of inter-organizational routines and/or trust, which allow firms to draft less detailed contracts. ${ }^{14}$ Argyres et al. (2007) and Ryall and Sampson $(2006,2007)$ find on the contrary that prior (partner specific) experience is correlated with more detailed contract terms.

Based in part on this prior research, but also on other approaches found in empirical industrial organization, finance, strategic management, law and economics, and legal theory, I focus on three levels of conditions that impact contractual complexity: company characteristics, transaction characteristics, and the organizational routines of firms. For company characteristics I look at size asymmetry, R\&D capability asymmetry

${ }^{9}$ Masten en Saussier 2002, p. 282

${ }^{10}$ Chapter 4.

${ }^{11}$ Reuer and Ariño 2007

${ }_{12}^{12}$ Ariño and Reuer 2004, Reuer et al. 2006

${ }^{13}$ Barthélemy and Quélin 2006, Reuer and Ariño 2007, Hansen and Higgins 2007

${ }^{14}$ Reuer et al. 2002, Reuer and Ariño 2007, Ciccotello and Hornyak 2000, and Hansen and Higgins 2007. 
and information asymmetry. Concerning transaction characteristics, I evaluate the impact of strategic importance and asset specificity of the R\&D alliance. At the level of organizational routines, I analyze how general and partner-specific experience with $R \& D$ alliances affect the complexity of contracts.

This chapter is part of a growing literature regarding empirical work on contracting. Given the general goal of my chapter 1 attempt to make several contributions to the existing literature. First, I draw on prior work of Eggleston et al. (2000) and several other authors to come to a multidimensional concept of complexity. Second, I investigate the impact of transactional and company characteristics, and organizational routines on the complexity of contracts. Finally, my chapter also incorporates interesting interdisciplinary features, while I use arguments from different disciplines to substantiate my hypotheses and findings.

The objectives of my chapter are primarily to improve the understanding of contracting practices, more in particular in the area of research and development collaborations. Creating a better insight of the facts that surround strategic alliance contracts enriches the already vibrant theoretical and empirical literature on inter-firm contracting. I argue that contracts are about far more than mere legal formality: they define the framework for a relationship ${ }^{15}$ and more attention should thus be paid to contract structure.

In the empirical analysis that I present, I study more than 300 contracts in the biopharmaceutical sector which are coded along two dimensions of contractual complexity. My findings indicate that company characteristics, transaction level attributes, and the organization routines of contract parties define the degree of complexity of inter-firm R\&D alliances. More specifically, my results reveal that asymmetries between contracting parties in terms of their size, R\&D capabilities, and information asymmetry, raise the complexity of the contract. At the level of transactional attributes, my findings indicate that the higher partners perceive the strategic importance and asset specificity of an R\&D alliance, the more complex these R\&D alliances become. Contrary to my expectations, learning to contract through a history of previous alliances or repeated ties leads to more complex contracts. Finally, my findings suggest that the subjective dimension of contractual complexity is mainly affected by two factors: the size asymmetries of firms and the asset specificity of the technology to which the contract refers.

The remainder of this chapter is organized as follows: in the next section I will give an overview of the different hypotheses. This is followed by a discussion of the data and sample description, and research design. The results of my research are discussed in the section thereafter. Finally, my discussion and conclusions section does not only discuss my findings in the context of the literature on complexity, but also suggests some steps for further research that links up to other recent contributions that advo cate an in-depth understanding of the content of inter-firm contracts.

${ }^{15}$ Mayer and Teece 2008, Macneil 1974. 


\section{HYPOTHESES}

As explained in the Introduction, the literature on inter-firm contracting and contract design has not yet led to one or even a few coherent unifying theoretical approaches from which I can deduct a unified theory-driven set of hypotheses on the complexity of inter-firm contracts. Given this variety of theoretical approaches, inspired by a range of literatures, I will take a pragmatic and eclectic perspective to my exploratory research. However, despite this disjointed nature of the current literature on this topic this literature does suggest a number of analytical levels at which the conditions that impact contractual complexity can be analyzed. Following a range of contributions that will be discussed in more detail below, I will position my hypotheses at three levels:

- the level of the company characteristics of the partners involved in a contract,

- the level of the transactions to which a contract refers, and

- the level of the experience-based organizational routines, which refers to the preference that partners might have for certain contract designs.

At the level of company characteristics that impact the complexity of inter-firm contracts, the literature suggests three different aspects of inter-firm asymmetry, that refer to the difference between partners in terms of their size, their R\&D capability, and their information asymmetry. At the level of the transactions to which an interfirm contract refers, I will distinguish between the strategic importance and the asset specificity of the alliance. Finally, the level of organizational routines differentiates between the general experience of firms with alliances and their partner-specific experience. In other words, the following hypotheses are formulated in the context of the attributes of the parties involved in an R\&D alliance contract, the nature of the actual transaction governed by a contract, and the experience that parties have with these R\&D alliance contracts.

\section{Level of company characteristics}

\section{Size asymmetry}

Traditionally, the empirical industrial organization literature has paid extensive attention to the size of firms as an important aspect of their market power. In that context size differentials between firms are expected to create inter-firm asymmetries through which larger firms can reap benefits of their market power in terms of both thei economies of scale and scope and their bargaining power vis-à-vis smaller firms. ${ }^{16}$ This heterogeneity of firms engaging in commercial transactions is also recognized in the legal literature, where large parties are often found to possess substantial bargaining power, relevant organizational skills, information advantages, and greater legal expertise relative to their smaller counterparts. ${ }^{17}$

${ }^{16}$ Barla 2000, Bresnahan 1989, Cohen and Levin 1989, Freeman and Soete 1997, Schmalensee and Willig

1989.

Tjittes 1994, Garvin 2005, Barnhizer 2005, Van Bijnen 2005 
Contributions to the alliance literature point out that the size of companies participating in alliances and in particular the size difference between partners can play a role in the risk perception of companies during the partnership formation process. This literature suggests that the size asymmetry of partners generates a higher appropriability hazard to the smaller firm due to the potentially opportunistic behavior of its larger partner. For instance, the literature on inter-firm cooperation through licensing indicates that when firms of different size engage in technology collaboration, larger firms attempt to dominate the agreement based on bargaining asymmetries that affect the terms of the agreement. ${ }^{18}$ In more general terms, Barnhizer (2005) illustrates the negative effect that bargaining power disparities have on the ability of the weaker and smaller party to obtain preferred terms in inter-firm contracts.

Following these suggestions, $\mid$ assume that when companies of different sizes collaborate in R\&D, smaller firms run a greater risk of losing control over the input to and output from their R\&D cooperation than larger firms that have more resources and organizational capabilities to control and monitor their R\&D cooperation. This implies that smaller partners have an incentive to engage in a more complex contract to curb their appropriability hazard and to compensate for their more limited organizational resources and capabilities to control and monitor the alliance. Due to their control and monitoring capabilities and their bargaining power, larger firms have fewer incentives to engage in more complex contractual arrangements. ${ }^{19}$ Given these different incentives, the larger the difference in the size of companies and the more the market power lies with the larger firm, the more incentives the smaller partner has to increase the complexity of its contract. It is important to note that I do assume that the larger partner might prefer to economize on the transaction costs of more complex contracts and hence favors a less complex contract but, given its control and monitoring resources, its inclination to opt for a less complex contract is less critical than the incentive for its smaller partner to draft a more complex contract. It is in particular the smaller partner that is expected to favour a contract that facilitates the monitoring of the alliance through a number of safeguards, control rights, enforcement mechanisms, and other clauses that refer to specific responsibilities. Hence:

H1: The larger the asymmetry between partners, in terms of their size, the higher the likelihood that the contract of their R\&D alliance will be more complex.

$R \& D$ capability asymmetry

I expect the R\&D capabilities of partnering companies to have an impact on the degree to which they prefer more or less complex contracts. From the perspective of one partner, collaborating with other companies that have well developed R\&D capabilities, that increase the probability of the success of the alliance, might be preferred to

${ }^{18}$ Bessy and Brousseau 1998, Caves et al. 1983.

${ }^{19}$ See also Van Bijnen 2005. 
working with companies with less developed R\&D capabilities that 'bring little to the table' that can be used in the actual R\&D cooperation. This suggests that the benefits of a company's R\&D alliance partly depend on the R\&D capabilities of its alliance partner. As stated by Baum et al. (2000), cooperating with skilled innovators increases the most promising opportunities for a company to improve its technological know-how and to learn new routines.

However, the R\&D capabilities of a company's partner are not only a source of input into the alliance. These R\&D capabilities of a partner can also be seen as this partner's 'absorptive capacity' ${ }^{20}$ that enables this partner to benefit from the alliance. As there are at least two parties to an alliance (company $A$ and $B$ ), the R\&D capabilities of the partner (company B), which company $A$ needs in order to learn from the alliance, are also the capabilities that might enable its partner (company $B$ ) to learn from the alliance and from company $A$.

There is some empirical research that points at the role of R\&D capabilities that support companies in their attempt to benefit from alliances. Stuart (2000) finds that companies that create alliances with partners rich in well-established technological capabilities turn out to become more innovative than other companies that collaborate with technologically unsophisticated partners. Baum et al. (2000) indicate that linking up to technologically advanced partners has a positive effect on the innovative performance of firms that participate in alliances. Silverman and Baum (2002) establish that the survival rates of new biotech firms increased the more they collaborated with companies with higher technological capabilities. Gomes-Casseres et al. (2006) report that companies with higher R\&D expenditures receive higher knowledge flows from their alliance partner. This suggests that R\&D capabilities create an absorptive capacity that helps firms to absorb external technology.

The above implies that companies need their own current R\&D capabilities to be able to benefit from the R\&D capabilities that their partner brings to the alliance, whereas the same applies to their partner. This implies that the more both partners have somewhat similar R\&D capabilities the more a company can learn form its alliance but so can its partner. Given the appropriability hazards that both partners then face, I expect that the more equal the R\&D capabilities that both partners bring to the alliance, the more one or both partners are inclined to increase the complexity of the alliance contract through additional safeguards, monitoring clauses, control rights, and intellectual property rights. Alliances with partners that have limited R\&D capabilities are, given the expected lower returns of the alliance, less attractive to companies. Hence, I expect that:

H2: The smaller the asymmetry between partners, in terms of their R\&D capabilities, the higher the likelihood that the contract of their $R \& D$ alliance will be more complex.

${ }^{20}$ Cohen and Levinthal 1989,1990 
Information asymmetry

I already introduced an element of general information asymmetry between partners in an R\&D alliance through the first hypothesis where the size difference between partners indicates a market power differential which in its turn suggests that information asymmetries can for example affect bargaining asymmetries between parties. I now turn to the possible effect of more specific information asymmetries where one party to the alliance has more or better information, relevant to the alliance, than the other party. This information asymmetry can potentially create hold up problems when one party lacks the necessary information to monitor the tasks that are to be undertaken in a particular alliance. See for instance, Barnhizer (2005) who discusses a party's access to information as an important source of bargaining power.

When companies that engage in an R\&D alliance differ in the extent to which they possess information on the specific R\&D tasks that have to be performed, the party that faces the potential risk of moral hazard has an incentive to put a range of clauses, control rights, safeguards and enforcement mechanism in a contract turning this contract more complex. Lerner and Malmendier (2005) find that in R\&D alliances where one party is largely responsible for the R\&D financed by its partner, both parties have, depending on their position, an incentive to add a variety of different clauses such as termination rights, intellectual property rights, and elements of option contracts. This implies that when the partners in an R\&D alliance have very different roles, e.g. where one company is largely responsible for the actual R\&D and the other company is responsible for financing this R\&D, possibly in combination with complementary assets such as testing, production, etc., there is a built-in element of information asymmetry in the alliance. When companies engage in these information asymmetry-based R\&D alliances, I expect that one or both partners have an incentive to increase the complexity of the alliance contract. Hence:

H3: The higher the degree of information asymmetry between partners, the higher the likelihood that the contract of the R\&D alliance will be more complex.

\section{Level of transactions}

Strategic importance of $R \& D$ alliance

When an alliance is of strategic importance to one or both partners, e.g. because the alliance activities comes close to the core capabilities of one or both companies, economic and business theory indicates that there is greater risk of opportunistic behavior of partners and a range of safeguards from equity participation to contracts with monitoring clauses, control rights, and intellectual property rights are warranted. Vincent-Jones (1989) states that detailed contracts tend to be specifically negotiated wherever particularly complex and costly transactions are involved. These detailed and carefully written contracts specify the primary obligations, the effect of certain contingencies, defective performance, and the possibility of legal sanctions. As a conse- 
quence, the strategic importance of an alliance has an effect on the degree to which companies are expected to draft extensive, complex alliance contracts. ${ }^{21}$

Reuer et al. (2006) indeed find that contractual complexity is positively related to the strategic importance of an alliance. Related to the strategic importance of an alliance, Robinson and Stuart (2007) establish that the size of upfront payment, equity stake and the investments in the alliance are highly correlated with contract length: contracts are longer when the investments and the strategic importance of the alliance increase. Anderson and Dekker (2005) and Argyres et al. (2007) find a positive relationship between the value of the transaction organized through an alliance and the detail of task descriptions in the contract and contractual complexity and extensiveness of the alliance contract. Hence:

H4: The higher the strategic importance of the R\&D alliance to partners, the higher the likelihood that the contract of the $R \& D$ alliance will be more complex.

Asset specificity of $R \& D$ alliance

Prior research that focused in particular on buyer-seller relationships found that asse specificity is an important transactional attribute that affects contract design. ${ }^{22}$ This asset specificity refers to the degree to which investments create specialized transaction-specific assets that are not easily re-deployable and hence unique to a specific task. Higher asset specificity describes the extent to which a party, through these specific investments, is tied into an inter-firm relationship such as an R\&D alliance. Although originally placed within a unilateral setting, where one party faces the risk of hold-up created by its partner ${ }^{23}$, the consequences of asset specificity in terms of holdup can also be bi-lateral as both parties might have made specific investments and/or face exit and switching costs. ${ }^{24}$ For inter-firm alliances this implies that if asset specificity is high, there is a higher chance of holdup and thus parties are expected to negotiate more complex contracts which cover consequences of breach and termination as well as the legal processes through which such threats are handled. ${ }^{25}$

Ariño and Reuer (2004) suggest that when the investment in the specific assets for an alliance is high, it pays off to incur the costs of drafting complex contracts. ${ }^{26}$ Reuer and Ariño (2007) find support for this hypothesis as their research indicates that contractual complexity is positively related to asset specificity. More specifically, they notice that the greater the transaction specific investment, the greater the number of contractual provisions and the more extensive the stringency of provisions built into an alliance contract. Poppo and Zenger (2002) and Anderson and Dekker (2005) find

\footnotetext{
${ }^{21}$ Arĩ̃o and Reuer 2004, Reuer et al. 2006.

${ }^{22}$ Joskow 1988.

${ }^{23}$ Williamson 1983

${ }^{24}$ Joskow 1988, Klein 1988.

${ }^{25}$ Dyer 1997, Poppo and Zenger 2002, Reuer and Ariño 2007.

${ }^{26}$ See also Argyres and Mayer 2007.
} 
that increases in exchange hazards characterized by higher asset specificity, encourage more complex contracts. I expect that this role of asset specificity is also relevant in the context of R\&D alliances, where the asset specificity of certain R\&D investments has specific consequences for the complexity of contracts. Hence:

H5: The higher the asset specificity of the R\&D alliance activity for partners, the higher the likelihood that the contract of the R\&D alliance will be more complex.

\section{Level of organizational routines}

General experience with $R \& D$ alliances

There is a well-established body of alliance literature which indicates that the experience of companies with setting up alliances through a variety of partners has a positive impact on their capabilities to organize and manage future alliances. ${ }^{27}$ This experience with both previous alliances and a variety of partners is expected to increase the organizational learning of companies which not only affects the actual management of newly established alliances but, as a major element in the institutionalization of setting up alliances, it can also affect the design of alliance contracts. I expect that companies that have little or no experience in setting up alliances will be inclined 'to play it safe' and to increase the complexity of their initial alliance contracts through a wide range of clauses that create safeguards, monitoring options, control rights, and intellectual property rights. From an organizational learning perspective, contracts of companies with little alliance experience that are still at an early phase of the learning-tocontract-curve are expected to be more complex than the contracts of more experienced companies that have gradually learned to set up less complex contracts that focus on an efficient contract design. From a legal perspective, Collins (1996) mentions that that market conventions may supplement the contractual discrete communication system between contract parties. Contractual relations are understood to be embedded in existing market conventions and the familiarity of contract parties with these conventions increases with the transaction frequency. This implies that for experienced contract parties the conventions of the market may be sufficiently replete to dispense with the discussion of all but most central themes of contracts. ${ }^{28}$

The efficiency of contract design is also relevant from a transaction cost economics perspective which stresses that, although companies are due to their bounded rationality not able to design complete contracts, through their experience they can learn to customize their contractual relationships and improve on the efficiency of their otherwise incomplete contracts. ${ }^{29}$ Given the transaction costs of designing, monitoring and controlling complex contracts and the competitive pressures to minimize these costs, there is an incentive for companies to minimize the transaction costs of contract de-

${ }^{27}$ Anand and Khanna 2000, Lyles 1988, Ring and Van de Ven 1992, Sampson 2005.

${ }^{28}$ See also Beale and Dugdale 1975 .

${ }^{29}$ Williamson, 1996. 
sign and contract control. As expressed by Mayer and Argyres (2004) from a transaction cost economics perspective, experience with previous alliances might help firms to design more efficient and, ceteris paribus, less complex contracts. From the perspective of companies with little or no experience, this implies that due their inexperience there is a higher likelihood that their alliance contracts will be more complex that those of experienced companies. Hence:

H6: The smaller the alliance experience of parties, the higher the likelihood that the contract of their R\&D alliance will be more complex.

Partner-specific experience with $R \& D$ alliances

Apart from the effect of the general experience that companies have with setting up alliances, I also expect that the specific experience that companies have with one particular partner, through their prior ties, will affect the complexity of their alliance contract with that partner. Contributions by amongst others Gulati (1995), Nooteboom et al. (1997) and Saxton (1997) indicate that previous collaboration between partners will have an effect on their relational trust. As this relational trust between partners develops further, there is a declining need for elaborate contracts with a range of monitoring and control options. Gulati (1995) establishes that there is a decreasing likelihood that companies with prior ties set up elaborate equity-based alliances with extensive contracting, whereas repeated ties increase the likelihood that these companies engage in less complex contractual arrangements. In other words, as relational trust between companies develops through repeated interaction, there is less need for extensive contracting as this relational trust creates a certain degree of social control amongst partners that replaces contract-based monitoring and control. ${ }^{30}$

These findings are also supported by legal scholars such as Collins (1996) who state that the inference of trustworthiness (expectations of trustworthy behavior) may be drawn from past dealings and previous transactions with a particular partner that proved satisfactory. One of the effects of this trustworthiness is that it reduces the need to specify in detail the precise content of the deal or to engage in close monitoring of the performance. Somewhat similarly, Parkhe (1993) demonstrates that prior alliances between companies will lower their expectations regarding the potentially opportunistic behavior of these partners in future alliances and as partners are inclined to look for fewer contractual safeguards their future alliances will be characterized by less complex contracts. See also Ciccotello and Hornyak (2000) and Hansen and Higgins (2007) who find that prior ties lead to fewer contractual safeguards and less complex contracts.

A slightly different line of argument was introduced by Zollo, Reuer, and Singh (2002) who state that that prior ties facilitate the development of inter-firm administrative routines shared by alliance partners through which both companies develop a

${ }^{30}$ See also Larsson, 1992. 
mutual understanding of their decision making style, their administrative routines, and their management systems. Given this knowledge about their partner, there is less need for detailed, complex contracts that attempt to provide for a range of monitoring and control mechanisms. On the other hand, if companies have no or very few prior ties and less knowledge about their partners or if relational trust has not yet developed, I expect that companies will favor more extensive contracts with their unfamiliar alliance partners. Hence:

H7: The fewer prior ties between alliance partners, the higher the likelihood that the contract of their $R \& D$ alliance will be more complex

\section{DATA AND SAMPLE DESCRIPTION}

Contractual alliances occur frequently across a broad range of industries however they tend to cluster in risky, high-tech R\&D settings. ${ }^{31}$ Drug development is a highly uncertain and expensive endeavor and it is not surprising that alliances are frequently used to organize R\&D. ${ }^{32}$ Since the inception of the biotechnology industry in the mid 1970s, pharmaceuticals and biotechnology research firms have partnered to form alliances. These collaborations allow pharmaceutical companies to gain access to the latest technological and scientific advances in biotechnology and to combine complementary resources in order to cope with the dynamics of innovation in drug discovery research. ${ }^{33}$ Hagedoorn (1996) illustrates that especially in the biotechnology industry, collaborative activity has continued to grow steadily. Newly initiated R\&D and technology alliances involving pharmaceutical and biotechnology firms grew from a couple of dozens during the mid 1980 s to several hundreds in $2000 .^{34}$

The pharmaceutical development process often begins with the identification and validation of 'drug targets', enzymes or receptors that trigger or block biochemical processes within a cell. These targets are screened against thousands of molecules with the aim of finding compounds which trigger or block disease processes. When such 'lead' compounds are identified, they pass through several stages of testing and approval. The discovery/pre-clinical stage concerns laboratory/animal tests to contro for toxicity and precedes the clearance request with for instance the US Food and Drug Administration (FDA) for human testing. ${ }^{35}$ The pre-clinical stage is followed by three phases in which humans are used as test subjects. Phase I involves testing the compound on a small number of volunteers for dosage and toxicity. Phase II concerns larger number of patients on which the drug is tested for efficacy/side effects. Finally,

${ }^{31}$ Robinson 2008.

${ }^{32}$ Robinson and Stuart 2007

${ }^{33}$ Hansen 2001, Powell et al. 1996

${ }^{34}$ Hansen 2001.

${ }^{35}$ See also Hausler 2007. 
Phase III trials entail a controlled experimental design which tests for long-term adverse effects using a large group of human subjects. Phase III is followed by FDA review and possibly approval. Once approval is granted, additional tests may follow. The time path from the discovery stage to the marketing of a drug generally spans 10-15 years. Data suggest that for every 5,000 to 10,000 identified compounds, only 250 reach the pre-clinical testing stage. ${ }^{36}$ DiMasi et al. (2003) find that only about $20 \%$ of the drugs that begin Phase I trials will finally be granted approval by the FDA. Even then, securing FDA approval does not guarantee success. ${ }^{37}$

The organizational and contractual structure of the collaborations between pharmaceutical and biotechnology companies ranges from licensing agreements to more complex research agreements, including technology transfers, joint research and codevelopment agreements and minority equity investments. ${ }^{38}$ As of 1995 , Pharmaventures, a UK-based information and consulting firm, has identified approximately 28.726 alliances in the healthcare and biotech sector in their PharmaDeals database. The collected deals are grouped into 10 categories: licensing, technology access, collaborative R\&D, rights, distribution/marketing, manufacturing/supply, business acquisition, funding, co-development and marketing. For each agreement, the PharmaDeals database provides information on the names of the partners, type of contractual relationship, summary deal terms, upfront payment, product types, total deal value, territories, date deal signed, effective and expired, equity investment, milestone value and royalty value, relevant product areas and the technology field, press releases and where available actual contracts. These actual contracts are obtained from the U.S Securities and Exchange Commission (SEC) filings and Pharmaventures' clients. Publicly traded biotechnology firms are required by the SEC to file material documents. Biotechnology firms tend to interpret this requirement conservatively and often file contracts specifying alliances as amendments to $10-K, 10-0, S-1$ or $8-K$ statements. ${ }^{39}$ in addition, a number of state governments in the USA require privately held companies with employee stock options to file material documents, which are then made available to the public.

My dataset covers R\&D alliance contracts and additional information for the years 1996 to 2005 inclusive. I collected information on alliances where the main focus is on research and development and for which PharmaDeals includes an actual legal document (contract). The sample of contracts falls within one of either two categories iden-

\footnotetext{
${ }^{36}$ DiMasi et al. 1991.

${ }^{37}$ See also Robinson and Stuart 2007.

${ }^{38}$ Hansen 2001.

${ }^{39}$ See Overdahl (1991) for more information on the specific requirements and issues concerning contract filings with the SEC. Under the SEC requirements, companies file for their most substantial deals. Thus there is a tendency of overrepresentation of larger and publicly owned companies. Small firms are present in these filings but only when they partner with public companies who file with the SEC. The choice of contracts may not be a random phenomenon. However, other authors using a similar type of dataset (Hansen and Higgins 2007, Higgins 2007, Sampson 2005) conclude that a systematic bias in contract type and activity is not present in the recorded agreements.
} 
tified by the PharmaDeals database: (1) Co-development and (2) Collaborative R\&D. Co-development is defined as '(...) two (or more) companies working together with the aim of developing a clinical-stage compound (...). Collaborative R\&D is as codevelopment but used for preclinical or earlier stage research (...)' (PharmaDeals). Using this sample $\mathrm{l}$ am able to generate a set of contracts in a homogeneous contracting space, which facilitates the comparison of key contract features across alliances. In this manner, $I$ can be assured that variation in contracting terms comes not from variation in the underlying contracting environment, but instead from different solutions to a common contracting problem, which in turn may reflect underlying differences in firm characteristics. The preliminary sample comprised 587 deals for the period 19962005. I excluded all the agreements where:

- one of the parties is a government agency or university

- the alliance is a renegotiation or restatement of a previous alliance between the two firms

there is no research and development component to the alliance

one firm has a controlling interest in the other firm (greater than $50 \%$ )

contracts involve more than two parties.

- The final contract database contains a set of 309 contracts. These contracts represent the first interaction between the companies as filed with the SEC within the time period 1996-2005.

The agreements include both US (domestic) contracts, i.e. the contracting parties are both US-based firms (179 alliances), and international contracts, i.e. a US-based firm collaborates with a non-US based firm (130 alliances). A total of 285 firms were involved in the 309 contracts and roughly two thirds of the agreements are concluded between an established pharmaceutical company and a start-up or emerging firm.

I collected additional information on for instance size, R\&D, alliance experience, and prior ties between partners for the firms participating in these 309 deals. My complete dataset combines information from PharmaDeals with data retrieved from company annual reports, the MERIT Cooperative Agreements and Technology Indicators (CATI) Database, Datastream, Compustat, and Corptech.

\section{Dependent variable}

Contractual complexity. In prior studies, contractual complexity has been measured using objective constructs such as the number of pages, words or kilobytes of the contractual document. In this chapter, I use the construct of contractual complexity as suggested by Eggleston et al. (2000) and Chapter 4, which includes both an objective and a subjective dimension of contractual complexity. The subjective dimension of contractual complexity refers to the degree to which a contract imposes a cognitive load upon contract parties. More specifically, cognitive load refers to the effort and mental activity imposed on a person's ability to process information. This cognitive load can therefore be seen as an important aspect of bounded rationality. As discussed by Eggleston et al. (2000), an understanding of the role of cognitive load as the infor- 
mation processing capacity and information processing efforts of contract parties informs our perception of contractual complexity. In chapter 4 I find that the quantitative, objective measures of complexity, such as the length of a contract, and objective as well as subjective elements of cognitive load do indeed measure different aspects of contractual complexity and suggest that contractual complexity is a multidimensional phenomenon.

Using the construct of complexity as developed in chapter 4, the complexity of contracts consists of two dimensions. Dimension 1, the objective dimension of the complexity of a contract, consists of the time needed to read a contract (time-on-task) and the length of the contract in terms of the number of words. Given the different measurement scales these elements have been converted into a standard factor score ranging from -2 to 2 in order to compose Dimension 1. Dimension 2 contains three elements: (1) the invested mental effort that people have to make to read and understand a contract; (2) the perceived complexity of a contract; and (3) the stress level that respondents experience while reading a contract. Each of these elements was measured using a 7-point Likert Scale based on previous research (the scale ranged from 'very low' to 'very high'). The Likert scores serve as the dependent variable and compose Dimension 2. See Appendix I for a further description of the measurement of the complexity of contracts.

\section{Independent variables}

Size asymmetry. Size asymmetry is based on the total asset turnover ratio of both parties. For each company I collected data on total asset turnover in millions of dollars. Average total asset turnover is calculated based on the total asset turnover of the year of deal conclusion and the previous year. A ratio of total asset turnover is obtained for each deal (company with largest average total asset turnover divided by company with smallest average total asset turnover). ${ }^{40}$

$R \& D$ capabilities asymmetry. For each company I collected data on $R \& D$ expenses in millions of dollars. Average R\&D expenses are calculated based on the R\&D expenditures during the year of deal conclusion and the previous year. A ratio of R\&D expenses is obtained for each deal (company with largest average R\&D expenses divided by company with smallest average $R \& D$ expenses).

Information asymmetry. The PharmaDeals dataset categorizes each company as either 'Established', 'Global' or 'Start-up/Emerging'. Established companies are defined as ' $($...) companies with a history of profitability that generally operate on a limited territorial basis. Includes companies that have a global presence through distribution and marketing affiliates and partners.' Global companies are defined as ' (...) multinational companies with a true global presence, which are also included in the top 30 healthcare companies as ranked annually by MedAdNews.' Start-up and emerging corporations are defined as '(...) new and emerging companies, including biotechnol-

${ }^{40}$ Gillian et al. 2007, Ryall and Sampson 2007 
ogy, drug delivery and enabling technology companies. These are companies that have no record of sustained profitability.' Following Lerner and Malmendier (2005), information asymmetry is indicated by the collaboration between established and global pharmaceutical companies, that have more general pharmaceutical research capabilities and production and marketing skills, and the start-ups and emerging firms that have specialized bio-pharmaceutical R\&D skills. I use a dummy variable which equals 1 if the deal is concluded between an established or global and start-up or emerging company and 0 if otherwise.

Strategic importance. As a proxy for the strategic importance of an R\&D alliance I measure the extent to which intellectual property rights that results from an alliance are, according to the contract, shared equally between partners. Given the importance of intellectual property rights as a strategic tool in the pharmaceutical industry ${ }^{41}$, I understand the sharing of intellectual property rights between partners to indicate that both partners see the intellectual property rights that result from their R\&D alliance as of such importance that they demand an equal share in the intellectual property rights. Using a text analysis program, I obtained data on whether a contract provides for joint intellectual property ownership. I use a dummy variable which equals 1 if the contract provides for joint ownership of intellectual property and 0 if otherwise.

Asset specificity. As a proxy for asset specificity I measure the extent to which a contract provides for exclusive licensing rights. Exclusive licensing rights specify the limited use of a technology to a specific user, a geographic region, a specific length of time, and/or a specific field of use. In other words, exclusive licensing rights limit the degree to which a transaction-specific asset, i.e. the technology developed through an R\&D alliance, can be re-deployed and as such they indicate the asset specificity of this technology. I use a dummy variable which equals 1 if the contract contains any exclusive licensing rights for either party and 0 if otherwise.

Experience. I calculate the average alliance experience for each company per deal. Using the MERIT-CATI database ${ }^{42}$, I was able to obtain data on the prior R\&D alliance experience of each company, counting back five years from the year of deal conclusion. A five year window is widely accepted in the literature as an adequate period to measure the alliance experience of companies. ${ }^{43}$ For each deal I calculate the average $R \& D$ alliance experience based on the alliance experience of each partner.

Prior ties. Using the MERIT-CATI database, I was also able to search for prior ties between alliance partners; counting back five years from the start of the R\&D alliance. ${ }^{44}$ As prior ties are usually limited to one previous tie, with very few partners having multiple prior ties, I use a dummy variable to indicate the existence of a prior relationship between the contracting parties. The dummy equals 1 if there are any earlier R\&D alliances between partners, 0 if otherwise.

\footnotetext{
Cohen et al. 2000.

${ }^{42}$ Hagedoorn 2002.

${ }^{44}$ See also Gulati 1995
} 


\section{Control variables}

Year. As the propensity to engage in R\&D alliance contracts may vary during the period 1996-2005 I included year dummies. This year dummy equals 1 if the deal is concluded within the specific year and zero otherwise.

Research stage. The PharmaDeals database provides information on the phase of the R\&D underlying the deal. As mentioned in the above, PharmaDeals identifies two categories: collaborative R\&D and co-development. Early stage collaborative R\&D is characterized by high failure rates and the exact outcome of this kind of research is difficult to anticipate. Co-development of pharmaceutical products can be more readily specified. Hence, 1 expect the research stage of an R\&D alliance to impact the complexity of contracts. 1 use a dummy variable which equals 1 if the deal concerns collaborative R\&D and 0 if the deal concerns co-development.

Foreign partner. To control for the possibility of greater divergence in expectations in contractual disputes spanning national boundaries, 1 include a dummy variable which takes on a value of 1 if the firms are headquartered in the same country (the US) and a value of 0 if otherwise (international deal). Firms are expected to have less information about foreign firms than about domestic firms and trust tends to emerge more readily between firms that share a similar social background, e.g. those that are domestic partners. ${ }^{45}$ This also suggests that behavioral uncertainty and opportunistic behavior may be more likely to arise in cross-border alliances, which affect the governance of alliances. ${ }^{46}$

Equity investment. For every alliance contract I noted if any type of equity investment was present. Equity participation generates some control in the alliance. This control might affect the degree to which partners draft more or less complex contracts. ${ }^{47}$ Data was obtained by scanning each contract with a special text analysis program. A dummy variable was created which equals 1 if the contract provides for some type of equity stake and 0 if otherwise.

Same industry. Using the PharmaDeal data and the SIC categorization I assigned each company to a primary industry. The more companies are competitors in their main industry, the more they operate in similar product-markets and as direct competitors I expect them to write more complex contracts because of a higher need to control R\&D alliances with competitors. A dummy variable is included which equals 1 if both partners are active in either the pharmaceutical or biotechnological industry. If at least one partner's primary activity is in another industry (not pharmaceutical or biotechnological) the dummy variable takes on a value of 0

${ }^{45}$ Zucker 1986 .

${ }^{46}$ See also Hagedoorn et al. 2005.

${ }^{47}$ Robinson and Stuart 2007, Reuer and Ariño 2007, Hansen and Higgins 2007, Ryall and Sampson 2007. 


\section{ANALYSIS}

In the following I will present models where complexity is defined as an objective dimension (dimension 1) and, alternatively as a subjective dimension (dimension 2). The dependent variable 'contractual complexity' with these two dimensions is measured by the average factor scores for dimension 1 and by the average Likert-scale scores for dimension 2. For dimension 1 the Shapiro-Wilk test $(p<0.000)$ and residual plots do, however, reveal a somewhat skewed distribution of residuals. $I$ also find that dimension 1 and 2 are characterized by slight heteroscedasticity. Failure of these assumptions underlying multiple regression analysis can lead to biased estimates of coefficients and standard errors. I therefore use Ordinary Least Squares (OLS) regression with a Huber-White Sandwich estimator in my analysis.

The basic structure of the different models, which test the factors associated with the degree of contractual complexity in R\&D alliances, is as follows:

Complexity $=\beta_{0}+\beta_{1}$ Size asymmetry $+\beta_{2} R \& D$ capabilities asymmetry $+\beta_{3}$ Experience + $\beta_{4}$ Prior ties $+\beta_{5}$ Strategic importance $+\beta_{6}$ Asset specificity $+\beta_{7}$ information asymmetry + $\beta_{8}$ Research stage $+\beta_{9}$ Equity investment $+\beta_{10}$ Foreign partner $+\beta_{11}$ Same industry + $\beta_{12}$ Year $+\varepsilon$

The contracts represent 'first interactions' between companies and a small number of firms appear in the dataset more than once. This occurs when company $A$ contracts with company $B$ and company $A$ separately contracts with company $C$; both the $A B$ and $A C$ contracts are in the sample. Since company $A$ 's behavior in contract $A B$ is likely not independent of company $A^{\prime} s$ behavior in contract $A C$, error terms may not be independently distributed. However, the independent distribution of the error terms is confirmed by the Durbin-Watson statistic and the Breusch-Godfrey test.

A concern with estimating the effect of asset specificity and strategic importance on contractual complexity in an OLS regression is the potential endogeneity that may bias OLS estimates. Endogeneity arises when a regressor is correlated with the error term, thereby violating the exogeneity assumption. ${ }^{48}$ Asset specificity and strategic importance are measured through terms included in the alliance agreement and thus determined by contracting parties.

A common technique to tackle endogeneity is the use of instrumental variables. ${ }^{49}$ Instrumental variables are variables which are both uncorrelated with the error term and highly correlated with the endogenous regressor. I use a two-stage least squares (2SLS) instrumental variable analysis (ivreg2 in Stata) to handle the potential endogeneity in the decision of firms regarding the level of complexity of their R\&D alliance contracts. The 2 SLS estimation consists of a first stage ('reduced form equation') re-

\footnotetext{
${ }^{48}$ Wooldridge 2002, Maddala 2006
}

${ }^{49}$ Bascle 2008, Wooldridge 2006. 
gression of the endogenous variable on the instruments and covariates. The resulting fitted value of the endogenous regressor replaces the value of the original endogenous regressor in a second stage ('structural equation') regression. In my models I use 'Size difference' as an instrumental variable for strategic importance and 'Breadth deal' for asset specificity. ${ }^{50}$ These variables have been selected through instrumental variable inference. 1 run a robust 2 SLS for each endogenous regressor independently. ${ }^{51}$

I conduct a Durbin-Wu-Hausman (DWH) test to examine potential endogeneity. This test is achieved in Stata by first specifying the 2SLS regression and then using the 'ivendog' command which performs the test automatically. ${ }^{52}$ The DWH test examines whether the residuals of the regression of all exogenous variables on the suspected endogenous regressor are significant when included in the original model. The DWH test for dimension 1 and 2 is not significant for both asset specificity and strategic importance, with the exception of dimension 1 where instrumenting for asset specificity yields a marginally significant DWH test. Because $25 L 5$ can yield insignificant estimates when endogeneity is not a concern, 1 report OLS estimates for my regression models of dimension 1 and 2 . For the convenience of the reader I also report my 2SLS models for dimension 1 and 2 .

\section{RESULTS}

Table 1 provides the descriptive statistics. Table 2 and 3 present the results of the multivariate analyses. Table 2 (models $1-4$ ) presents the results for the objective dimension of contractual complexity (dimension 1), table 3 (models 5-8) presents the results for the subjective dimension of contractual complexity (dimension 2 ). ${ }^{53}$ The first models reported in tables 2 and 3 are the basic models with the control variables. The other models include the independent variables. Tables 2 and 6 give the results for the standard OLS regression. Models 3, 4, 7, and 8 present the results with the instrumental variables. The size of most samples used in the regressions is smaller than 309

${ }^{50}$ Breadth deal refers to the number of pre-identified interest areas which may be covered by the alliance. The alliances in the database may cover up to eight different areas of interest as defined by PharmaDeals database. Size difference is based on the total number of employees of both parties. For each company collected data on total number of employees. Average employee number is calculated based on the total number of employees of the year of deal conclusion and the previous year. A ratio of total number of emnumber of employees of the year of deal conclusion and the previous year. A ratio of total number of em-
ployees is obtained for each deal (company with largest average total number of employees divided by company with smallest average total number of employees).

${ }^{51} 25 L S$ estimation is very sensitive to finite-sample blas caused by e.g. weak instruments. As suggested by Bascle (2008) I therefore also run the instrumental variable regression with limited maximum Ilkelihood (LIML), Fuller's modified LIML (Fuller) and Moreira's conditional likelihood ratio (CLR). These regressions provide similar results to the 2 SLS estimations. Note that the equation is exactly identified (one instrument for each endogenous regressor) and the LIML estimation is in fact the 2SLS estimation (Bascle 2008)

${ }^{52}$ Argyres et al. 2007.
(1)

${ }^{53}$ I treated my average Likert-scale scores of dimension 2 as a continuous variable (Johnson and Creech 1983, Zumbo and Zimberman 1993). Ordered logit regression leads to similar results. 
due to missing values. In the following I first discuss the results for the objective dimension of contractual complexity (dimension 1 ) before I turn to the results for the subjective dimension of contractual complexity (dimension 2).

Hypothesis 1 predicts that contractual complexity will be greater for R\&D alliances with increasing size asymmetry between the partners. The results in table 2 (models 2 4) provide support for this prediction. Hypothesis 2 argues that the smaller the asymmetry between partners in terms of their R\&D capabilities, the higher the likelihood of the agreement to be more complex. This hypothesis is rejected, see models 2-4. Apparently, the larger the R\&D capabilities asymmetry between partners, the more they are inclined to design complex contracts. Hypothesis 3 concerns the degree of information asymmetry and predicts that the degree of information asymmetry between partners is positively related to contractual complexity. This hypothesis is supported in the models 2-4. The hypothesis related to the strategic importance of the alliance (hypothesis 4) predicts that the higher the strategic importance of the alliance for one or both partners, the greater the likelihood that parties will construct a complex contract. This hypothesis is supported in models 2 and 4 but not in model 3 . Asset specificity has, as predicted by hypothesis 5 , a positive impact on contractual complexity, i.e. asset specific investments increase the likelihood that a contract will be more complex (see models 2-4). Hypothesis 6 concerns the general alliance experience of parties and predicts that the smaller the experience, the higher the likelihood that parties will design a complex contract. However, models 2-4 show a reverse effect: the greater the experience of parties, the more likely that they will design a complex contract. Hypothesis 7 argues that prior ties can substitute for formal safeguards in alliance contracts leading to lower levels of contractual complexity. This hypothesis also does not receive support as my findings suggest a reverse effect (see models 2-4).

Interestingly, i find rather different results for the subjective dimension of contractual complexity, see table 3 . Only two key variables seem to impact the subjective dimension of contractual complexity: size asymmetry and asset specificity. Following hypothesis 1 the perceived contractual complexity will be greater for R\&D alliances with increasing size asymmetry between the partners. The results in table 3 (models 6 8) provide support for this prediction as the effect of size asymmetry is positive and marginally significant. As predicted by hypothesis 5 , asset specific investments increase the likelihood that a contract will be more complex. There is partial support for this hypothesis as asset specificity has a positive impact on contractual complexity in two out of three models (see models 6-8). The other independent variables appear to have no impact on the subjective dimension of contractual complexity.

Turning to the control variables, it appears that, with the exception of the research stage, these controls have only limited impact. ${ }^{54}$ For the objective dimension of con-

${ }^{54}$ The international scope of the alliance for example has no effect. Experts in the fleld conflirm this finding and indicate that in this sector, the fact that one partner is foreign does not significantly affect the complexity of the contract, with some exceptions. For example, one of the partners of a US law firm, specialized in negotiating and drafting these types of agreements, revealed that he was once involved in negotiations with 
tractual complexity, the results for the research stage illustrate that earlier stage agreements (collaborative R\&D) referring to preclinical research are generally less complex than later stage agreements (co-development) referring to clinical trials phase 1 or above. It appears that when the research outcome is still uncertain, parties do not know yet what to expect, and the contractual agreement is not yet complex. However, when parties have more certainty that some output may result from their collaboration and they have to invest more resources (larger trials etc), parties will draft more complex contracts. Interviews with experts in the field reveal that parties indeed experience the research stages in this manner and will invest in contractual complexity accordingly.

In addition, I considered a number of (unreported) moderating effects of equity investments, expecting that the governance of R\&D alliances through partial ownership would decrease the need for more complex contracts. As such I expected that equity investments in combination with larger size asymmetry, smaller R\&D capabilities asymmetry, larger information asymmetry, higher strategic importance of alliance, and higher asset specificity of alliance would lead to less complex contracts. I also considered a number of other possible interaction effects, mainly related to size asymmetry, alliance experience, and prior ties. However, none of the tested interaction effects were significant.

\section{DISCUSSION AND CONCLUSIONS}

As explained in the Introduction to my chapter, my study is of an exploratory nature and applies the theoretical input from a diverse body of literatures that include legal studies, applied industrial organization, finance, strategic management, and law and economics. In addition, my understanding of the role of the cognitive load of contractual complexity is largely influenced by the applied psychology literature. Against this diverse theoretical background, it is interesting to note that I found such basic differences between the impact that company characteristics, transaction level attributes, and the organization routines of contract parties have on the objective and subjective dimensions the complexity of inter-firm R\&D alliances.

For the objective dimension of contractual complexity, I specified the length of contracts and the time-on-task to measure this complexity. My findings suggest that asymmetries between contracting parties in terms of their size, their R\&D capabilities, and their information asymmetry affect the complexity of their R\&D alliance contracts. Size asymmetries between companies indicate higher appropriability hazards due to

a European pharmaceutical. Just prior to the negotiations this party had been exposed to a huge US product liability case. The company was thus very worried about liability issues and it had become fearful of the US legal system in general. This fear was strongly expressed by the executive board, which pressured the lawyers involved to really focus on drafting lengthy provisions concerning (product) liability, representations, 
the potentially opportunistic behavior of the larger partner and lower ex post bargaining power for smaller partners. ${ }^{55}$ The appropriability hazards for smaller firms imply that they face a higher risk of losing control over their R\&D input and output than their larger partners that are better equipped to control and monitor their R\&D cooperation. Given this market power asymmetry, smaller partners have an incentive to favour a contract that facilitates the monitoring of the alliance through clauses that refer to specific responsibilities, control rights, enforcement mechanisms, and a number of other contractual safeguards. The larger partner in an R\&D alliance probably prefers a less complex contract as this economizes on the transaction cost of a more complex contract but, given its control and monitoring resources, this preference is less critical than the incentive for its smaller partner to favour a more complex contract. My field research indicates that the smaller party often thinks its larger counterpart will behave opportunistically. Legal counsels indicate that a smaller party thus has a strong urge to write out what happens in every scenario.

In case of information asymmetries, when one contract party has a relevant in formation advantage, this can create potential hold up problems for the other partner that might lack the necessary information to monitor certain tasks that are to be undertaken through the alliance. This implies that when the partners in an R\&D alliance have very different roles, e.g. where one company is largely responsible for the actual $R \& D$ and the other company is responsible for financing this $R \& D$, possibly in combination with complementary assets such as testing, production, etc., there is a built-in element of information asymmetry in the alliance. ${ }^{56}$ Practitioners in the field of biotechnology alliances argue that this is the case in particular where a biotechnology firm has an important patent/compound and seeks a partner to develop and market this patent/compound. In a competitive bidding process, the biotech firm will send out a contract to several pharmaceutical firms. This position of specialized R\&D knowledge provides the biotech with a superior bargaining position. My findings suggest that when companies that engage in an R\&D alliance face information asymmetry, contracts are indeed found to be more complex.

Interestingly, contrary to what I suggested in the hypotheses development, the third element of inter-firm asymmetry that refers to R\&D capabilities has a similar effect as the other two asymmetry characteristics. It was expected that the more companies collaborate with companies with similar quantities of R\&D capabilities, the higher the appropriability risks to both partners and the more they are inclined to add a range of monitoring clauses and intellectual property rights clauses to a contract, increasing its complexity. My current findings suggest the opposite, as with the other inter-firm asymmetry characteristics, the larger the difference of companies, i.e. the larger the asymmetry in terms of their R\&D capabilities, the more complex their R\&D contracts. This suggests that companies with more R\&D capabilities than their alliance partners

\footnotetext{
${ }_{55}$ Barnhizer 2005, Bessy and Brousseau 1998.
}

${ }^{56}$ See also Lerner and Malmendier 2005 
might fear unintended knowledge leakage to partners with fewer R\&D capabilities. More complex contracts with additional safeguards, monitoring clauses, control rights, and intellectual property rights clauses offer a monitoring option to companies in an attempt to avoid unintended knowledge leakage through an R\&D alliance.

My findings at the transaction level of R\&D contracts that refer to the strategic importance and the asset specificity of an R\&D alliance support the understanding of the complexity of inter-firm contracts that is largely influenced by transaction cos economics. The higher the strategic importance of an R\&D alliance to partners and the higher the asset specificity of $R \& D$ investments made through an R\&D alliance, the more complex these R\&D alliances become. The higher the strategic importance of an $R \& D$ alliance, e.g. when both partners share the intellectual property rights signaling their interest in the alliance, the more effort is made to draft extensive alliance contracts. To a similar degree, the higher the asset specificity of the alliance activity, i.e. the more limited the use of the technology developed through the alliance, the more specific the investments made and the fewer the alternative options for use of the technology, the more partners specify the stringency of provisions and the more complex a contract becomes.

When it comes to the organizational routines of contracting firms, be it in terms of the experience that have with R\&D alliances in general or in terms of the more specific experience with particular partners, it turns out that these routines have an opposite effect to what l expected. Contrary to my expectations, learning to contract through history of previous alliances or repeated ties, shared experience with these partners and perhaps even the emergence of joint inter-firm administrative routines lead to more complex contracts. Although my initial understanding of the effect of experience and prior ties is founded in a number of legal, economic and management literatures, there is a recent stream of publications that point at similar findings to mine. Argyres et al. (2007) indicate that both more general experience with contracting and prior ties with particular companies have learning effects in the opposite direction: through this experience and repeated interaction firms get a better understanding of the task descriptions for both partners in the alliance. These task descriptions become more detailed and lead to contingency planning that is incorporated in subsequent contracts that are then gradually becoming more complex. In a somewhat similar contribution Mayer and Weber (2005) find that prior alliance contracts between partners invite firms to add useful provisions based on what they learned from their previous contracts. Ryall and Sampson (2006) also find that repeated alliances between partners and the more general experience of firms with alliance contracts leads to more detailed and complex contracts. These contributions and the current findings suggest that the organizational routines that companies have through inter-firm R\&D alliances may improve their contracting capabilities through which they learn which contractua safeguards, monitoring clauses, control rights, intellectual property rights clauses, etc. to add to their contracts. In the end, the inclusion of many of these clauses will lead to more extensive and more complex contracts. Contracts are organic documents and 
each event/crisis adds 'scar tissue'-not only concerning contracts between parties, but in general. ${ }^{57}$ As practitioners indicate, a party with more experience will know exactly which issues are important and should be addressed. As parties gain more general and specific partner experience, they will 'add on' to the agreement thereby increasing complexity.

The second dimension of the complexity of these inter-firm R\&D alliance contracts, the subjective dimension of contractual complexity refers to the degree to which a contract imposes a cognitive load upon boundedly rational contract parties. More specifically, this cognitive load refers to the effort and mental activity imposed on a person's or a contract party's ability to process the information in a contract. In other words, the higher the effort and mental activity to process the information found in a contract, the higher the complexity of this contract. Interestingly, my findings suggest that this subjective dimension of contractual complexity is mainly affected by two factors: the size asymmetries of firms and, to a larger extent, the asset specificity of the technology to which the contract refers. The other factors that do play a role in explaining differences in the objective dimension of contractual complexity seem to play no role in explaining the perception, the subjective dimension of the complexity of R\&D alliance contracts. The higher the asset specificity of the alliance activity, i.e. the more a contract refers to the limited the use of the jointly developed technology in terms of specific users, geographic region, a specific length of time, and/or a specific field of use, the more specific the investments made and the fewer the alternative options for use of the technology, the more these contracts are seen as complex contracts. The fact that asset specificity affects the subjective dimension of complexity may be due to the types and number of clauses which are added to the agreement. These types of clauses usually relate to royalty payments, price adjustment, usage rights etc.; clauses which may be difficult to understand due to complicated payment structures. ${ }^{58}$ These 'payment' clauses are also often dependent on factors incorporated in other clauses, which means that the interrelatedness between contract terms increases. This in turn affects the comprehensiveness and thus subjective dimension of the complexity of contracts. This last argument of interrelatedness may also apply to the affect of size asymmetry. An argument to the contrary may be made for the remaining factors, which did not show a significant effect. These factors increase contract length and parties' time on task (objective dimension) but do not appear to increase the cognitive load (subjective dimension) of the contract. In measuring both objective and subjective dimensions of contractual complexity, I may conclude that increasing contract length does not always imply that the contract becomes more complex in the sense of the cognitive ability to understand the document. Adding contract clauses or increasing the length of a particular clause might even make a contract more comprehensible (see e.g. the effect of information asymmetry on dimen.

\footnotetext{
${ }^{57}$ Buchheit, unpublished note.
}

${ }^{58}$ See also Eggleston et al. 2000. 
sion 2, which was negative but insignificant). Further research would be necessary to substantiate these expectations.

Although my contribution has, as discussed below, its limitations, my findings do demonstrate that, as suggested by Eggleston et al. (2000), the objective and subjective dimensions of complexity point at very different aspects of the complexity of contracts. The company characteristics of partners, the transaction features and the ex perience of partners that explain to quite some extent the more objective dimension of the complexity of these R\&D alliance contracts, have only limited impact on the more subjective cognitive load of these contracts.

This chapter has a number of limitations that I translate into suggestions for future research. It would be interesting to see whether measuring the cognitive load of contracts could be extended to a sample of legal professionals (corporate lawyers, legal counsel). Given the limitations that were discussed in the above, this would most probably imply that respondents are to evaluate a smaller sample of contracts, but even a small sample of inter-firm contracts could provide a 'real life' look into the professional perception of the complexity of contracts. In addition, the current chapter is based on an overall measurement of complexity along two dimensions. Future research could benefit from a more in-depth analysis of elements of contractual complexity in terms of the different contract clauses and their interactions that are expected to increase the level of contractual complexity. Also, the current chapter is based on a set of about three hundred contracts, limited to one particular industry, one group of alliances, i.e. R\&D alliances, and the sample is very US focused. A larger sample with a multi-industry and international perspective and a range of inter-firm contracts that go beyond R\&D can most probably provide a more thorough understanding of the contracting process between firms. 
Table 1 Descriptive statistics and correlation matrix

\begin{tabular}{|c|c|c|c|c|c|c|c|c|c|c|c|c|c|c|c|c|c|c|c|}
\hline & Variable & Mean & SD & (1) & (2) & (3) & (4) & (5) & (6) & (7) & {$[8]$} & (9) & (10) & (11) & (12) & (13) & (14) & (15) & (16) \\
\hline 1. & Dimension 1 & -0.007 & 0.986 & 1.000 & & & & & & & & & & & & & & & \\
\hline 2. & Dimension 2 & 4.244 & 1.319 & 0.193 & 1.000 & & & & & & & & & & & & & & \\
\hline 3. & Size asymmetry & 10.542 & 22.363 & 0.163 & 0.078 & 1.000 & & & & & & & & & & & & & \\
\hline 4. & $\begin{array}{l}\text { R\&D capabilities } \\
\text { asymmetry }\end{array}$ & 6.657 & 2.026 & 0.023 & 0.000 & 0.093 & 1.000 & & & & & & & & & & & & \\
\hline 5. & Experience & 9.238 & 8.683 & 0.251 & 0.019 & -0.056 & -0.271 & 1.000 & & & & & & & & & & & \\
\hline 6. & Prior ties & 0.472 & 0.500 & 0.187 & 0.025 & -0.041 & -0.035 & 0.272 & 1.000 & & & & & & & & & & \\
\hline 7. & Asset specificity & 0.631 & 0.483 & 0.229 & 0.168 & -0.013 & 0.008 & -0.032 & 0.064 & 1.000 & & & & & & & & & \\
\hline 8. & Strategic importance & 0.608 & 0.489 & 0.168 & 0.111 & -0.079 & 0.054 & -0.045 & 0.054 & 0.055 & 1.000 & & & & & & & & \\
\hline 9. & $\begin{array}{l}\text { Information } \\
\text { symmetry }\end{array}$ & 1.926 & 0.538 & 0.046 & 0.009 & -0.012 & -0.393 & 0.150 & -0.073 & 0.036 & -0.050 & 1.000 & & & & & & & \\
\hline 10. & Year & 2000 & 2.000 & 0.269 & 0.115 & 0.060 & 0.101 & 0.169 & 0.059 & -0.086 & 0.056 & -0.035 & 1.000 & & & & & & \\
\hline 11. & Research stage & 0.663 & 0.473 & -0.098 & -0.044 & -0.095 & -0.018 & 0.141 & 0.196 & -0.055 & 0.032 & -0.103 & 0.051 & 1.000 & & & & & \\
\hline & Equity investment & 0.181 & 0.386 & 0.107 & 0.058 & 0.051 & 0.056 & -0.075 & 0.063 & 0.195 & 0.021 & 0.063 & -0.045 & -0.089 & 1.000 & & & & \\
\hline & Foreign partner & 0.421 & 0.494 & 0.143 & -0.005 & 0.067 & -0.273 & 0.139 & 0.015 & 0.008 & -0.099 & 0.173 & 0.092 & -0.080 & -0.088 & 1.000 & & & \\
\hline & Same industry & 0.828 & 0.378 & 0.108 & 0.002 & -0.156 & 0.024 & 0.186 & 0.136 & 0.058 & 0.099 & -0.095 & 0.151 & 0.009 & 0.053 & -0.030 & 1.000 & & \\
\hline 15. & Breadth deal & 2.194 & 1.280 & 0.130 & 0.011 & -0.102 & -0.036 & 0.073 & 0.184 & 0.184 & 0.063 & 0.046 & 0.022 & 0.180 & 0.024 & -0.032 & -0.080 & 1.000 & \\
\hline & Size difference & -0.206 & 0.491 & 0.073 & 0.026 & 0.082 & -0.415 & 0.150 & -0.065 & 0.002 & -0.125 & 0.312 & 0.030 & -0.057 & 0.051 & 0.108 & -0.027 & -0.058 & 1.00 \\
\hline
\end{tabular}




\begin{tabular}{|c|c|c|c|c|}
\hline & Model 1 & Model 2 & Model 3 & Model 4 \\
\hline \multirow[t]{2}{*}{ Size asymmetry } & & $0.007^{*}$ & $0.007^{*}$ & $0.007^{*}$ \\
\hline & & $(0.003)$ & $(0.003)$ & $(0.003)$ \\
\hline \multirow[t]{2}{*}{ R\&D asymmetry } & & $0.080^{* * *}$ & $0.080^{* * *}$ & $0.061+$ \\
\hline & & $(0.030)$ & $(0.031)$ & $(0.032)$ \\
\hline \multirow[t]{2}{*}{ Information asymmetry } & & $0.595 * * * *$ & $0.599 * * *$ & $0.493^{* *}$ \\
\hline & & $(0.152\rangle$ & $(0.157)$ & $(0.183)$ \\
\hline \multirow[t]{2}{*}{ Strategic importance } & & $0.260^{*}$ & 0.225 & $0.253^{*}$ \\
\hline & & $(0.106)$ & $(0.794)$ & $(0.113)$ \\
\hline \multirow[t]{2}{*}{ Asset specificity } & & $0.396 * * *$ & $0.396^{* * *}$ & $1.296 *$ \\
\hline & & $(0.107)$ & $(0.103)$ & $(0.562)$ \\
\hline \multirow[t]{2}{*}{ Experience } & & $0.021^{*}$ & $0.021 *$ & $0.023^{* *}$ \\
\hline & & $(0.008)$ & $(0.009)$ & $(0.008)$ \\
\hline \multirow[t]{2}{*}{ Prior ties } & & $0.367 * * *$ & $0.370^{* *}$ & $0.291 *$ \\
\hline & & $(0.105)$ & $(0.127)$ & $\langle 0.128\rangle$ \\
\hline \multirow[t]{2}{*}{ Year (1997) } & 0.008 & 0.078 & 0.076 & 0.131 \\
\hline & $\langle 0.153\rangle$ & $(0.169)$ & (0.165) & $(0.177)$ \\
\hline \multirow[t]{2}{*}{ Year (1998) } & 0.080 & 0.160 & 0.163 & 0.259 \\
\hline & $(0.174)$ & $(0.178)$ & $(0.186)$ & $(0.215)$ \\
\hline \multirow[t]{2}{*}{ Year (1999) } & 0.138 & 0.238 & 0.232 & $0.407+$ \\
\hline & $(0.184)$ & $(0.196)$ & $(0.243)$ & $(0.227)$ \\
\hline \multirow[t]{2}{*}{ Year $(2000)$} & 0.133 & 0.150 & 0.146 & $0.384 \dagger^{\dagger}$ \\
\hline & $(0.157)$ & (0.159) & $\langle 0.186\rangle$ & $(0.233)$ \\
\hline \multirow[t]{2}{*}{ Year (2001) } & $0.393^{*}$ & $0.454^{*}$ & $0.449^{*}$ & $0.738^{* *}$ \\
\hline & $(0.193)$ & $(0.196)$ & $(0.215)$ & $\langle 0.259)$ \\
\hline \multirow[t]{2}{*}{ Year (2002) } & $0.835 * *$ & $0.674^{*}$ & $0.670^{*}$ & $0.910^{* *}$ \\
\hline & $(0.266)$ & $(0.261)$ & $(0,260)$ & $(0.316)$ \\
\hline \multirow[t]{2}{*}{ Year (2003) } & $0.850 * *$ & $0.584^{*}$ & $0.588^{*}$ & $0.691^{*}$ \\
\hline & $(0.292)$ & $(0.267)$ & $(0.268)$ & $(0.303)$ \\
\hline \multirow[t]{2}{*}{ Year (2004) } & 0.202 & 0.059 & 0.060 & 0.161 \\
\hline & $(0.224)$ & $(0.223)$ & $\langle 0.216\rangle$ & $(0.316)$ \\
\hline \multirow[t]{2}{*}{ Year (2005) } & $1.539 * * *$ & $1.791^{* * *}$ & $1.808^{* *}$ & $1.877^{* *}$ \\
\hline & $(0.395)$ & $(0.496)$ & $\langle 0.600\rangle$ & (0.608) \\
\hline \multirow[t]{2}{*}{ Research stage- } & $0.206 \dagger$ & $-0.380^{* * *}$ & $-0.379 * * *$ & $-0.338^{* *}$ \\
\hline & $(0.118)$ & (0.114) & $(0.110)$ & $(0.127)$ \\
\hline \multirow[t]{2}{*}{ Equity investment } & $0.294^{*}$ & 0.130 & 0.130 & -0.063 \\
\hline & $(0.146)$ & $(0.131)$ & $(0.125)$ & (0.191) \\
\hline \multirow[t]{2}{*}{ Foreign partner } & $0.263^{*}$ & 0.128 & 0.124 & 0.104 \\
\hline & $(0.117)$ & $(0.114)$ & $(0,141)$ & $(0.123)$ \\
\hline \multirow[t]{2}{*}{ Same industry } & $0.224 \uparrow$ & $0.196 \dagger$ & 0.202 & 0.107 \\
\hline & $(0.117)$ & $(0.110)$ & $(0.173)$ & $(0.143)$ \\
\hline \multirow[t]{2}{*}{ Constant } & $-0.491 * *$ & $-2.074^{* * *}$ & $-2.061 * * *$ & $-2.488^{* * *}$ \\
\hline & $(0.161)$ & $(0.356)$ & $(0.484)$ & $(0.458)$ \\
\hline R-squared & 0.162 & 0.369 & 0.369 & 0.197 \\
\hline F-value & $4.26 * * *$ & $7.68 * * *$ & $7.14^{* * *}$ & $5.21 * * *$ \\
\hline $\mathrm{N}$ & 296 & 277 & 277 & 277 \\
\hline Durbin-Wu-Hausman test & & 0.002 & $2.978^{+}$ & \\
\hline Endogenous & & Strategic & & Asset specificity \\
\hline regressor & & importance & & \\
\hline Instruments & & Size difference & & Breadth deal \\
\hline
\end{tabular}




\begin{tabular}{|c|c|c|c|c|}
\hline & Model 5 & Model 6 & Model 7 & Model 7 \\
\hline \multirow[t]{2}{*}{ Size asymmetry } & & $0.004 \mathrm{t}$ & $0.004^{\dagger}$ & $0.004 t$ \\
\hline & & $(0.002)$ & $(0.002)$ & $(0.002)$ \\
\hline \multirow{2}{*}{ R\&D asymmetry } & & 0.004 & 0.003 & 0.004 \\
\hline & & $(0.045)$ & $(0.044)$ & $(0.046)$ \\
\hline \multirow[t]{2}{*}{ Information asymmetry } & & -0.132 & -0.133 & -0.130 \\
\hline & & $(0.248)$ & (0.242) & $(0.271)$ \\
\hline \multirow[t]{2}{*}{ Strategic importance } & & 0.230 & 0.268 & 0.230 \\
\hline & & $(0.167)$ & (1.157) & $(0.161)$ \\
\hline \multirow[t]{2}{*}{ Asset specificity } & & $0.398^{*}$ & $0.398^{* *}$ & 0.382 \\
\hline & & $(0.160)$ & $(0.154)$ & $(0.980)$ \\
\hline \multirow[t]{2}{*}{ Experience } & & 0.003 & 0.003 & 0.003 \\
\hline & & $(0.011)$ & $(0.012)$ & $(0.010)$ \\
\hline \multirow[t]{2}{*}{ Prior ties } & & 0.065 & 0.062 & 0.066 \\
\hline & & $(0.168)$ & $(0.177)$ & $(0.172)$ \\
\hline \multirow[t]{2}{*}{ Year (1997) } & 0.377 & 0.362 & 0.365 & 0.361 \\
\hline & $(0.333)$ & $(0.371)$ & $(0.364)$ & $(0.357)$ \\
\hline \multirow[t]{2}{*}{ Year (1998) } & 0.412 & 0.364 & 0.359 & 0.363 \\
\hline & $(0.368)$ & $(0.404)$ & $(0.413)$ & $(0.392)$ \\
\hline \multirow[t]{2}{*}{ Year (1999) } & 0.466 & 0.490 & 0.496 & 0.487 \\
\hline & $(0.331)$ & $(0.356)$ & $(0.385)$ & $(0.381)$ \\
\hline \multirow[t]{2}{*}{ Year $(2000)$} & $-0,134$ & -0.083 & -0.079 & -0.087 \\
\hline & $(0.331)$ & $(0.372)$ & $(0.368)$ & $(0.418)$ \\
\hline \multirow[t]{2}{*}{ Year (2001) } & 0.016 & 0.114 & 0.118 & 0.109 \\
\hline & $(0.344)$ & $(0.394)$ & $(0.402)$ & $(0.466)$ \\
\hline \multirow[t]{2}{*}{ Year (2002) } & $0.877^{*}$ & $0.871^{*}$ & $0.873^{*}$ & $0.866^{*}$ \\
\hline & $(0.345)$ & $(0.383)$ & $(0.372)$ & $(0.434)$ \\
\hline \multirow[t]{2}{*}{ Year (2003) } & $0.711+$ & $0.760 \dagger$ & $0.756 \dagger$ & $0.759 *$ \\
\hline & $\{0.383\rangle$ & $(0.393)$ & $(0.401)$ & $\{0.379\}$ \\
\hline \multirow[t]{2}{*}{ Year (2004) } & 0.678 & 0.672 & 0.668 & 0.670 \\
\hline & $(0.418)$ & $(0.450)$ & $\langle 0.452\rangle$ & $\langle 0.434\rangle$ \\
\hline \multirow[t]{2}{*}{ Year (2005) } & $1.539^{* * *}$ & $1.363^{*}$ & $1.344 t$ & $1.362 * *$ \\
\hline & $(0.423)$ & $(0.539)$ & $(0.765)$ & $\langle 0.520\rangle$ \\
\hline \multirow{2}{*}{ Research stage- } & -0.135 & -0.161 & $-0,162$ & -0.162 \\
\hline & $(0.156)$ & $(0.176)$ & $(0.170)$ & $\{0.175\}$ \\
\hline \multirow[t]{2}{*}{ Equity investment } & 0.191 & 0,051 & 0.050 & 0.055 \\
\hline & $(0.198)$ & $(0.210)$ & $(0.203)$ & $(0.286)$ \\
\hline \multirow[t]{2}{*}{ Foreign partner } & -0.073 & -0.038 & -0.034 & $-0,038$ \\
\hline & $(0.153)$ & $(0.174)$ & $(0.207)$ & $(0.167)$ \\
\hline \multirow[t]{2}{*}{ Same industry } & -0.036 & -0.117 & -0.122 & -0.115 \\
\hline & $(0.189)$ & $(0.199)$ & $(0.254)$ & $(0.218)$ \\
\hline \multirow[t]{2}{*}{ Constant } & $4.035 * * *$ & $3.704^{* * *}$ & $3.686^{* * *}$ & $3.712 * * *$ \\
\hline & $(0.306)$ & $(0.584)$ & $(0.786)$ & $(0.708)$ \\
\hline R-squared & 0.084 & 0.111 & 0.111 & 0.111 \\
\hline F-value & $2.85 * * *$ & $2,03^{* *}$ & $1.86^{* *}$ & $1.77^{*}$ \\
\hline $\mathrm{N}$ & 309 & 288 & 288 & 288 \\
\hline Durbin-Wu-Hausman test & & & 0.001 & 0.000 \\
\hline Endogenous & & Strategic & & Asset specificity \\
\hline regressor & & importance & & \\
\hline instruments & & Size difference & & Breadth deal \\
\hline
\end{tabular}


APPENDIX I

THE MEASUREMENT OF CONTRACTUAL COMPLEXITY

In order to measure the contractual complexity for these 309 contracts I used the method applied in chapter 4 which suggests a multi-dimensional and multi-item measurement of contractual complexity with both objective and subjective characteristics. This measurement includes the cognitive load of contracts as an important element of contractual complexity as suggested by Eggleston et al. (2000).

The length of contracts as an objective measure of contractual complexity is measured through the number of words in a contract. The electronic copies of the contracts provided by PharmaDeals are presented in a comparable layout in pdfformat. The document conversion feature of a text miner was used to convert all the documents into a readable ASCII file. The text miner provides me with information on the number of words in each contract. ${ }^{59}$

To measure the cognitive load of these contracts, sixty graduate students of the Faculty of Law of Maastricht University in The Netherlands were asked to read the contracts and fill out a short questionnaire with various items related to the cognitive load of each contract. This choice for students might raise some concern as, compared to professionals, students lack professional experience and are generally younger, which may lead to a different attitude than one would expect for managers and corporate lawyers who would otherwise deal with these contracts. Although the option of having these contracts read by managers, corporate lawyers, and legal counsel to assess the cognitive load of the sample of contracts was considered, both the reading of the relevant literature and the consultation of a number of experts made it clear that in practice it would be impossible to have a survey of hundreds of contracts, with an average of fifty pages per contract, read by practitioners. Korobkin (2002) indicates that using actual contracting parties as experimental subjects, however, raises other validity concerns. Moreover, research on this topic provides significant evidence that students are indeed valid surrogates for professionals. Comparing professional and student behavior, many studies do not find a substantial difference in behavior. ${ }^{60}$

The actual measurement of the cognitive load of contracts is based on a questionnaire with three validated and widely used items found in the cognitive load literature. ${ }^{61}$ Scale-based reporting was used to investigate the degree of cognitive load in relation to the contracts. As a direct subjective measure of cognitive load, participants were asked to rate the perceived level of complexity of the contracts (question 1). The cognitive load of information is amongst others defined by the extent to which various elements in e.g. a contract interact. High element interactivity imposes a heavy load on working memory, which translates into a high level of perceived complexity. As an

${ }^{59}$ The number of words, number of pages, and the kilobytes of information in these contracts are highly correlated (between 0.95 and 0.99 ).

${ }^{60}$ See chapter 4 for a review of the literature.

${ }^{61}$ See the discussion of this literature in chapter 4 . 
indirect subjective measure, participants were asked to report the invested mental effort necessary to understand the contracts (question 2). This mental effort relates to the effort made to process and comprehend information in the contracts. The meas urement of experienced stress levels while reading these contracts (question 3), was adopted from the Subjective Workload Assessment Technique (SWAT) ${ }^{62}$ and the $\mathrm{Na}$ tional Aeronautics and Space Administration-Task Load Index (NASA-TLX) ${ }^{63}$. Stress is a direct subjective measure of cognitive load and as such complements mental effort Experienced stress levels measure the perceived workload of assessing the information in a contract. Finally, the respondents were also asked to report the time spent reading each contract and as such an objective indirect measure was obtained: time-on-task. Time-on-task provides a meaningful measurement as this reflects the difficulty or ease of a task. Time-on-task typically increases with complexity and a high time-on-task points towards a high cognitive load.

A representative 'dummy' contract was first administered to all respondents to measure the within-group homogeneity of the respondents. The results for this test indicated that each respondent could be taken as representative for the group of respondents as a whole and each respondent received a randomly distributed small number of contracts. Principal component analysis was used to investigate the degree to which perceived complexity, mental effort, stress level, time-on-task, and the length in words represent different dimensions of contractual complexity. The results of this analysis indicated that time-on-task and the number of words load on one dimension of contractual complexity, which I label as the objective dimension of contractual complexity (dimension 1). Perceived complexity, mental effort and stress level load on the other dimension, labeled as the subjective dimension of contractual complexity (dimension 2).

Reid and Nygren 1988.

${ }^{63}$ Hart and Staveland 1988. 
CHAPTER 6

CONCLUSION 


\section{INTRODUCTION}

This dissertation started out with the observation that diverse theories of contract exist across a range of disciplines, but empirical proof of these theories is scarce. The main purpose of this thesis is to integrate different perspectives on contract in order to look beyond the face value of the legal document at the intricacy of contract design. What insights have we gained? This final chapter provides an overview of the most important conclusions of this dissertation. I will seek to answer the research questions and reflect on the results of the analyses, thereby elaborating on the methodological, theoretical and empirical implications of this study.

In the introduction to this dissertation I presented the following general research question:

How do we define contract design and what differences do we find within a particular industry and between countries?

In order to answer this question, I made use of three sub-questions, which can be traced to the different chapters of this dissertation.

Chapter 2 investigated to what degree commercial agreements are governed by either a classical or more relational contracting perspective. This chapter is based on six case studies concerning inter-firm collaborations: two non-equity contractual collaborations, two licensing contracts, and two equity joint venture agreements between companies in the bioscience, fine chemicals, biotechnological and pharmaceutical industries. The case studies encompass an analysis of the actual legal documents underlying the collaborations, and interviews with legal counsel and corporate lawyers involved in drafting these documents.

In chapters 3 to 5 I sought to answer what method(s) may be used to measure contract design and subsequently what factors create discrepancies in contract design. As a measure of contract design, I presented the concept of contractual complexity, which I verified empirically (chapter 4 ). In chapters 3 and 5,1 evaluated to what extent different factors, controlling for their environmental embeddedness, affect contractual complexity. The empirical validation in these chapters is based on a dataset of over 400 R\&D alliance contracts in the biotechnological and pharmaceutical sector, on surveys with graduate students in law and economics, and on interviews with professionals involved in drafting commercial (R\&D) contracts. 


\section{SYNOPSIS OF SOME MAJOR FINDINGS}

Strangers and friends - from classical to relational perspectives on contract Several authors contend that transactional styles and their specific mode of governance necessitate a diversified set of contract law systems. ${ }^{1}$ Modes of governance, ranging from discrete via hybrid to hierarchy are expected to follow classical (market) and more relational (hybrid and hierarchy) doctrines of contract. Considering interfirm agreements, other contributions indicate that equity joint ventures are quasihierarchical in nature, non-equity collaborations represent contractual hybrids, and licensing agreements largely reflect market exchange. Accordingly, equity joint ventures and non-equity contractual collaborations are expected to be governed by a more relational contracting perspective, while licensing contracts should almost exclusively reflect a classical contracting perspective. In chapter 2 of this dissertation, I examined to what extent contract clauses referring to revision, adaptation (hardship/force majeure), damages, warranties and dispute resolution reflect a more classical or relational contracting perspective in each of the aforementioned agreements. Scholars consider these clauses, in addition to property rights allocation, as important contractual safeguards in inter-firm contracts, especially in high-technology settings where exchange hazards are high. In general, l expected the relational perspective to correspond with the incorporation of revision clauses, damages based on the reliance and restitution interest, warranties, and alternative dispute resolution mechanisms. In contrast, agreements governed by a more classical contract doctrine were expected to lack revision clauses and consequential damage awards, but support warranties and adjudication in court.

The case studies generally confirm my expectations and my findings suggest that different types of inter-firm agreements are governed by either a more classical or relational contracting perspective (see also chapter 2, table 1). However, there are some surprises. Contrary to my expectations, I did not find explicit revision clauses in the equity joint venture and non-equity agreements. Instead, the opportunity for revision was often integrated in other clauses such as force majeure/hardship and severability. This indicates that although parties value flexibility, there must be an explicit reason to revise. In addition, licensing contracts were found not to always contain extensive warranties. My findings also indicate that non-equity partnerships provide for litigation where patent disputes are involved. This was not expected while nonequity partnerships are associated with 'softer' dispute resolution mechanisms such as arbitration and mediation. However, this choice may be related to the fact that many countries recognize special patent judges and a court's decision is open to appeal. In addition, the profits associated with a patent might outweigh the substantial costs associated with litigation in some jurisdictions. Furthermore, discovery procedures allow valuable information to be gained from the other party.

${ }^{1}$ Macneil 1978, Williamson 1979 
More in general, the non-equity collaborations are characterized by a clear division of property rights even though these collaborations do not involve a de facto common ownership structure ( $c f$. equity joint ventures). An analysis of the contracts for the equity joint venture and non-equity collaborations also revealed the inclusion of elaborate appendices with project plans, explicit task and responsibility descriptions, and other agreements. This finding emphasizes the relational perspective governing equity joint ventures and non-equity collaborations while such appendices place the actual collaboration and the inter-relationship of the partners in the realm of the contract itself. In addition, the set initial duration of the joint venture collaborations, shows how much companies place their long-term relationship at the centre of the agreement. $^{2}$

Defining relationships - contractual complexity

As the foregoing paragraphs show, existing theories of contract such as relational and classical perspectives on contracting entail a predefined framework in which we may place contractual provisions. This means we are pressed to qualify provisions and contracts either as relational or classical while it is not evident that every contractual element can be positioned within this spectrum. In addition, it is debatable how strictly classical and relational aspects should be defined. The theory of incomplete contracts, the extent to which contracts efficiently provide for every possible contingency, is a more general and less arduous theory, which has developed in both the legal and economics literature. It is apparent that most contracts are incomplete and subsist as such. The (degree of) incompleteness becomes evident or 'problematic' only in the event of a dispute. Ex ante, the theory of incomplete contracts cannot offer much insight in contract design. ${ }^{3}$ In chapters 3 to 5 I presented the concept of contractual complexity in order to study the intricacy of contract design. I use this concept to investigate the differences between countries (chapter 3 ) and within sectors (chapter 5).

In chapter 3 I define contractual complexity as a multidimensional concept relating to the number and types of terms incorporated in a contract, the specificity of these terms and the cognitive load necessary to understand a contract. The idea of contractual complexity initially developed in relation to the observation, that compared to the Netherlands and other Continental European jurisdictions, relatively complex legal documents dominate the contracting environment in the US and England. This complexity is often attributed to specific elements of the contract: the definition of terms, provisions for contingencies in performance, task descriptions, and boilerplate provisions. Business economic theory tells us that factors such as trust and reputation, nondisclosure, parties' limits of cognition and contracting costs positively affect contractual complexity, while monitoring difficulties, asset specificity, strategic importance,

${ }^{2}$ Eisenberg 2000, Speidel 2000

${ }^{3}$ Especially given the fact that only a fraction of all contractual relationships results in a dispute. This ex pos approach is also evident from the literature, as most scholarly work on incomplete contracting is concerned with rules on contract interpretation and gap-filling (see e.g. Ayres and Gertner 1989, Van Bijnen 2005). 
environmental uncertainty and enforcement costs negatively affect contractual complexity. However, to tease out differences between countries, we must evaluate these factors within their legal and socio-cultural context. ${ }^{4}$

A study of different aspects of the legal environment illustrates that the legal setting has a significant influence on contracting and enforcement costs, and the disclosure of information. Contracting costs are often used as an argument to substantiate the existence of relatively simple contracts. In principle, contracting costs are an impediment to complexity. One aspect of the legal system that may reduce contracting costs is the existence of an extensive codification. The willingness to rely on this codification allows parties to write either (1) simple contracts; or (2) complex contracts at a relatively low cost. Parties in the Netherlands, a civil code jurisdiction, write contracts which appear simple compared to contracts in the US and England, both common law jurisdictions. This seems to suggest that the ability to rely on an extensive codification, i.e. the default rules therein, allows parties to suffice with simple contracts. ${ }^{5}$

While the existence of a general codification may be said to negatively affect contracting costs, this argument is largely negated by the development of word processing programs. Such programs enable practitioners to store standard form contract (forms) on their computer from which the preferred template can be pulled and amended when necessary. ${ }^{6}$ The emergence of these programs is a global technological development, evident in the US, England, the Netherlands, Germany, etc., and thus not dependent on a particular type of legal system. Even if contracting costs are initially larger in a particular jurisdiction, the storage of forms creates economies of scale which cause contracting costs to decrease with each successive contract. Why then do forms in both the US and England exhibit greater contracting effort, i.e. complexity? Moving from the front to the back end of the contracting process, I seek an answer in the realm of enforcement costs.

Front end contracting costs and back end enforcement costs are to a large extent affected by their legal environment. Parties to a contract will exert contracting effort at the frond end of the contracting process as long as this creates benefits at the back end of the contracting process; a decrease thus in enforcement costs. Enforcement costs are predominantly influenced by the manner in which the judiciary is organized and functions. A system of case law and rules of parol evidence in conjunction with a primarily objective approach toward the interpretation of contracts as found in the US and England, may lead to higher enforcement costs. In addition, some authors argue that rules of civil procedure in these countries give rise to unreliable and inefficient proceedings, which may lead parties to experience greater enforcement costs. Such

${ }^{4}$ As mentioned in chapter 3 , several factors are not directly shaped by their legal and socio-cultural environment. These factors relate to limits of cognition, monitoring difficulties, asset specificity and the strategic importance of the contract.

Common law countries such as the US and England are not completely devold of codes and statutes, but in contrast to the Netherlands, case law remains the primary source of law.

${ }^{6}$ Tjittes and Hartlief 2005, Buchheit 2006, Schweitzer 2007. 
increased enforcement costs may induce parties in the US and England to incur greater contracting costs, in the sense that they add more terms to their contract, thereby eventually increasing contractual complexity. In contrast, the shorter duration of proceedings, the expertise of the judiciary and the lack of extensive discovery make for swiftness and reliability in the Netherlands ${ }^{7}$, which is also characterized by a more subjective approach toward contract interpretation My analysis suggests that the level of enforcement costs in the US and England render it beneficial for parties to exert a greater contracting effort at the front end of the contracting process, which leads to an increase in contractual complexity.

Without solid numerical evidence it, however, remains difficult to correctly quantify and evaluate both contracting and enforcement costs. 1 therefore propose that parties' perception of enforcement costs and their attitude towards contracting practices are elements which should not be disregarded. I believe that the socio-cultural environment and to a lesser extent the legal environment play a significant role in shaping these perceptions and attitudes. For example, a legal principle that permeates the contracting practice in the Netherlands is the principle of good faith. Good faith advances norms of fairness, trust and cooperation. ${ }^{8}$ Due to the general and sustained recognition of good faith, parties contracting in the Netherlands may traditionally place greater reliance on conventions of fairness to guide their transactions, which gives rise to the construction of relatively simple contracts.

Generally, the socio-cultural environment affects levels of trust and reputation, environmental uncertainty, and the manner in which parties perceive enforcement and contracting costs. Diverse literatures suggest that trust and reputation may substitute (in part) for complex contracts. ${ }^{9}$ The degree to which trust and reputation play a role as supporting governance mechanism is dependent upon their institutional endorsement. A homogeneous and repeat contracting community cultivates trust, produces behavioral norms and facilitates reputational sanctions. Network institutions such as trade associations for example, play a role in enforcing norms and reputation. Different studies have illustrated that the aforementioned institutional features are especially characteristic of civil law jurisdictions such as Germany and the Netherlands. ${ }^{10}$ In these countries, behavioral norms and standards are additionally reinforced by the ability to rely on a general codification. ${ }^{11}$ Turning to another facet of the socio-cultural environment, some authors point to the fact that Americans are prone to excessiveness and perfectionism; characteristics which transcend their contracting practice. In combination with an increased apprehension of opportunistic behaviour, American parties strive to reduce contracting risks to a minimum. As Hill and King (2004) indi-

\footnotetext{
${ }^{7}$ Note must be taken that the data underlying these civil procedure claims is not conclusive (see chapter 3 ). ${ }^{8}$ See also Eggleston et al. 2000.

${ }^{9}$ However, empirical studies illustrate that it is difficult to make concepts such as trust operational and thus determine whether one culture is more trusting than another (see chapter 3).

${ }^{10}$ Langbein 2001, Arreghetti et al. 1997, Collins 1999 (cf. Bernstein 1992).

${ }^{11}$ Burchell and Wilkinson 1997, Hill and King 2004, p. 916.
} 
cate, the failure to accept 'good enough' solutions to a diverse range of issues of conflict means that American contracting parties often become involved in a costly 'arms race'. The result is a highly complex contract. The risk averseness and litigious culture is reinforced (or created?) by the large lawyer to laymen ratio. ${ }^{12}$ Concluding, I believe that the legal and socio-cultural environments are not unimportant in evaluating contractual complexity.

Chapter 4 and 5 of this dissertation offered an empirical verification of some of the more theoretically embedded assertions of chapter 3 . Chapter 4 explored to what extent we can actually speak of a multidimensional concept of contractual complexity. My findings indicate that, as suggested by Eggleston et al. (2000), contractual complexity is indeed a multidimensional phenomenon. Quantitative, objective measures of complexity, such as length, and objective as well as subjective elements of cognitive load, such as mental effort, mental load and time on task, do indeed measure different aspects of contractual complexity. Based on an exploratory factor analysis, I define the objective dimension of complexity to comprise both the length of the contract in words and the time on task. ${ }^{13}$ In addition, I retrieve a subjective dimension of contractual complexity which is related to the cognitive load of contracts. This dimension of cognitive load can be broken down into two factors: (1) the mental load and (2) the mental effort individuals experience while reading the contract. Mental load refers to the task complexity. This perceived level of complexity suggests a more subjective perception of the task difficulty that people face when they 'digest' contracts. The element of mental effort can be broken down into two sub-elements: (a) the actual cognitive effort individuals make to understand contracts and (b) the degree of stress that they experience as they have to read through contracts. These different elements signal the intricacy of cognitive load as such and illustrate that it is worthwhile for scholars to not only determine the complexity of contracts through objective measures, even when these measures go beyond simple counts of pages or words.

Chapter 5 is a study of an exploratory nature using the concept of contractual complexity - as developed and verified in chapters 3 and 4 - as response variable in a model which tests assumptions from a varied theoretical background that includes legal studies, applied industrial organization, finance, strategic management, and law and economics. Interestingly, I find that basic differences exist between the impact that company characteristics (size, information and R\&D capabilities asymmetries), transaction level attributes (strategic importance and asset specificity), and the organizational routines (prior ties and contracting experience) of contract parties have on the objective and subjective dimensions of the complexity of inter-firm R\&D alliances. Chapter 5 confirms some of the theoretical assumptions made in chapter 3 , namely that asset specificity, strategic importance and monitoring difficulties - the latter

${ }^{12}$ See chapter 3. Data over 2006 renders the following ratios: Netherlands 1:1148, US 1:267 and England: 1:398.

${ }^{13}$ In this manner I can also account for the extensiveness of contractual terms. Data shows that the number of words, clauses and kilobytes are all highly correlated (see also chapter 4). 
founded in the existence of information asymmetries - positively affect contractual complexity, independent of the particular legal or socio-cultural environment.

My chapter 5 findings suggest that asymmetries between contracting parties in terms of their size, R\&D capabilities, and information asymmetry positively affect the objective dimension of the complexity of R\&D alliance contracts. First of all, size asymmetries between companies indicate higher appropriability hazards due to the potentially opportunistic behavior of the larger partner and lower ex post bargaining power for the smaller partner. ${ }^{14}$ Given this market power asymmetry, smaller partners have an incentive to favor a contract that facilitates the monitoring of the alliance through a diverse range of clauses. My marginal note that this incentive of the smaller partner is greater than the incentive of the larger partner to draft a less complex contract is confirmed. In the second place, information asymmetries create potential hold up problems for the partner that lacks the necessary information to monitor certain alliance tasks. This means that in the situation where partners to an R\&D alliance have very different roles, there is a built-in element of information asymmetry in the alliance. ${ }^{15}$ This may be the case in particular where a biotechnology firm has an important patent/compound and seeks a partner to develop and market this patent/compound. In line with $m y$ expectations, parties to an R\&D alliance that face information asymmetries draft relatively complex contracts. In chapter 3,1 assumed that the information asymmetry that contracting parties face potentially has two opposing effects on contractual complexity, namely a negative effect created by the non-disclosure of information and a positive effect by way of monitoring difficulties. My findings seem to illustrate that in the particular area of R\&D alliances, monitoring difficulties have a stronger impact on the complexity of the contract than the non-disclosure of information. This may be due to the fact that in these types of contracts, parties are very wary of any undisclosed information and the contracts are often characterized by extensive warranties, representations and indemnifications. ${ }^{16}$

Third and contrary to my hypothesis, my findings suggest that the R\&D capabilities asymmetry between parties is positively related to contractual complexity. It was expected that partners with similar quantities of R\&D capabilities would face higher appropriability risks and therefore be inclined to add a range of monitoring clauses and intellectual property rights clauses to a contract, increasing its complexity. However, companies with greater $R \& D$ capabilities than their alliance partners apparently fear unintended knowledge leakage to partners with fewer R\&D capabilities, causing the former to incorporate more contractual safeguards. My hypotheses on the transactional level relate to the strategic importance and the asset specificity of the R\&D alliance. 1 argue that when parties perceive the strategic importance of the $R \& D$ alliance

${ }^{14}$ Barnhizer 2005, Bessy and Brousseau 1998

${ }^{15}$ Lerner and Malmendier 2005.

${ }^{16}$ Hill 2001, and Hermalin and Craswell 2007 on the general effects of information asymmetry in relation to contracting. 
to be high and the asset specificity of their investments to be large, the complexity of the R\&D alliance contract will increase. In line with earlier studies, my findings confirm this expectation. The organizational routines of contracting firms - in terms of the experience that they have with $R \& D$ alliances in general or in terms of the more specific experience with particular partners, - appear to have an effect opposite effect to what I expected. Learning to contract through a history of previous alliances or repeated ties, shared experience with these partners, and perhaps even the emergence of joint inter-firm administrative routines, lead to more complex contracts. Although my initial understanding of the effect of experience and prior ties is founded in a number of legal, economic and management literatures, there is a recent stream of publications that point at similar findings. Several other authors indicate that both more general experiences with contracting in a particular sector and prior ties with partnering companies create learning effects which induce firms 'to add' to their agreement. ${ }^{17}$ Practitioners acknowledge this finding, and point to the fact that a party with more experience will know exactly which issues are important and should be addressed. This finding also endorses the view of contracts as 'organic documents', in the sense that each market crisis ads 'scar tissue' to the document. ${ }^{18}$ In addition, these results may have implications for the extent to which trust can be viewed as a complement or substitute to formal contracting. ${ }^{19}$ Prior ties and experience may engender trust and create reputational effects. In chapter 3 I posited an inverse relationship between trust and reputation on the one hand, and complexity on the other hand. The findings in chapter 5 seem to suggest that the role trust may play as a substitution to formal contracts is secondary to any learning effects.

In contrast to my findings concerning the objective dimension of R\&D alliance contracts, the subjective dimension of contractual complexity is mainly affected by two factors: size asymmetry between firms and, to a larger extent, the asset specificity of the technology to which the contract refers. The positive direction of these effects corresponds with my results related to the objective dimension. The fact that asset specificity positively affects the subjective dimension of complexity may be due to the types and number of clauses which are added to the agreement. These types of clauses usually relate to e.g. royalty payments, price adjustment and usage rights, clauses which may be difficult to understand due to complicated incentive structures. ${ }^{20}$ These clauses are often dependent on the content and scope of other clauses, which means that the interrelatedness between contract terms increases. Cross-references

${ }^{17}$ Argyres et al. 2007, Mayer and Weber 2005, Ryall and Sampson 2006.

${ }^{18}$ See Buchheit (unpublished note), Buchheit (2006), p. 16 on Eurocurrency agreements: '[s]ome people want to lend money, some other folks want to borrow it, and then the crowd of the first part would like to get the money back again. It should not, you might think, require 50 pages of single-spaced text to expres this business objective.' But '[a] Eurocurrency loan agreement carries its scars like an aging prize fighter (...) each bearing silent witness to some major or minor skirmish that has disturbed the Euromarket during its relatively short history.'

relatively short history.'
${ }_{19}$ Poppo and Zenger 2002 .

${ }^{19}$ Poppo and Zenger 2002 
and interrelatedness negatively affect the comprehensiveness and thus subjective dimension of the complexity of contracts. This last argument of interrelatedness may also hold for the results relating to size asymmetry. An argument to the contrary may be made for the other factors concerning organizational routines, transactional attributes and asymmetries which did not render a significant effect. My findings suggest that these factors increase contract length and parties' time on task (objective dimension) but do not appear to increase the cognitive load (subjective dimension) of the contract. In measuring both objective and subjective dimensions of contractual complexity, I may conclude that increasing contract length does not always imply that the contract becomes more complex in the sense of the cognitive ability to understand the document. Adding contract clauses or increasing the length of a particular clause might even make a contract more comprehensible. ${ }^{21} \mathrm{~A}$ simultaneous effect on both the objective and subjective dimension of complexity seems to appear especially with the addition of complicated clauses and/or clauses which increase the interrelatedness of the contractual terms overall.

My understanding of the complexity of contracts has some interesting implications for the broader perspective of bounded rationality and its impact on contracts. Bounded rationality, as mentioned earlier, generally refers to the fact that our ability to process information and solve problems is limited. ${ }^{22}$ This defective capability distorts the manner in which an actor searches for, processes and weighs information and scenarios. Bounded rationality is expected to affect the degree to which economic actors are limited in their cognitive capabilities to design and write contracts that would fit all current and future contingencies. ${ }^{23}$ In other words, bounded rationality has a front-end impact on the effectiveness of contract design due to the limitations and costs of information processing. However, the cognitive load of contracts has some post-design implications for the bounded rationality with which contract parties are able to implement and monitor their contracts. If the cognitive load of contracts affects the complexity of contracts, this implies that higher levels of the cognitive load of contracts increase the likelihood that economic actors do not fully comprehend contracts or are limited in their interpretation of the consequences of the content of their contract. ${ }^{24}$ As such, it appears that the cognitive load of contracts affects the bounded rationality with which contract parties have to govern their contractual agreements such as R\&D alliance contracts. Given this bounded rationality and the

${ }^{21}$ See also Smith 2006, who wonders why longer contracts should be costly to read: '[a] few extra pages can be read quickly and lawyers are experts at looking for provisions that do not suit their clients, especially if the problem is the addition or not of a given clause.' (p. 1123). Smith (2006) does acknowledge that complex

contracts may be difficult to process.
${ }^{22}$ Simon 1955 . See more recently in retat

${ }^{22}$ Simon 1955. See more recently in relation to contracts Eisenberg (1994).

${ }^{23}$ See for example the literature on transaction cost economics and incomplete contract theory.

${ }^{24}$ See also Elsenberg 1994, and some authors who write on the complexity of legal rules. Schuck (1992) relates complexity to constraints on an individual's capacities and indicates that complexity's demands are bound to outstrip the given capacitles to manage it. Likewise Kades (1997) indicates that technical (elaborative) rules represent cognitive difficulties for people. 
cognitive load of contracts, the there may very well be an upper limit to the actual level of complexity of contracts that not only contract parties, but also judges, juries and lawyers are able to absorb. This has implications for the assumption in the economics of law and managerial contract literature that increasing levels of economic risk necessitate greater levels of contractual complexity in order to safeguard the transaction.

Building relationships: what can we learn? Methodological, theoretical and empirical implications

Does complexity matter? Certainly! Parties at all levels of the contracting process should be concerned with contractual complexity. In the following paragraphs I will review some of the implications that complexity has for practitioners, such as lawyers and legal counsel. In addition, I will briefly touch upon some complexity-related issues that are relevant for third party enforcers and policymakers.

Practitioners - drafting

Parties involved in drafting contracts need to think about the complexity of their documents. ${ }^{25}$ Adding clauses may come at a cost and it is questionable whether more detail is always good. ${ }^{26}$ As my research illustrates, the relative complexity of contracts is driven by numerous factors. It appears that complexity evolves over time. This process is facilitated by the rapid technological advancement of computer systems and programs, allowing law firms and legal departments of multinational corporations to collect and store large datasets of contracts. ${ }^{27}$ Forms then appear to instigate complexity in the sense that with each successive draft contract, contract terms may be added and interrelatedness between contract terms may increase.

The use of forms, regardless complexity issues, also offers several advantages. First of all, forms achieve standardization of a contracting practice within a particular firm. But more importantly, the use of a form is less costly than producing a contract from scratch, due to economices of scale with each successive use. A form is thus able to increase drafting efficiency. A form provides a baseline document, which incorporates the benefits of experience. More specifically, the use of forms creates learning and network externalities. ${ }^{28}$ Learning externalities emerge when a firm adopts a term that has been commonly used in the past, independent of whether its peers will continue to use this term in the future. Network benefits arise when a firm incorporates a provision in it's contract which is at the same time incorporated by it's peers, independent

${ }^{25}$ See also Eggleston et al. 2000, p. 126: '[f]urther research should focus on how lawyers ought to evaluate complexity when drafting contracts.'

${ }^{26}$ Eggleston et al. 2000.

${ }^{27}$ Eijsbouts 2002, p. 50-51, who refers to the worldwide database of contracts at Akzo Nobel N.V.

${ }^{28}$ Learning externalities emerge when a firm adopts a term that has been commonly used in the past, independent of whether its peers will continue to use this term in the future. Network benefits arise when a firm incorporates a provision in it's contract which is at the same time incorporated by it's peers, independent of whether the term has been commonly used in the past (Kahan and Klausner 1997). 
of whether the term has been commonly used in the past. ${ }^{29}$ The path dependency of corporate contracting is evident: a term gains value with its use and this standardization is evidenced by the use of forms in general and boilerplate provisions in particular. ${ }^{30}$ Standardized provisions appear to reduce the possibility for any misunderstandings.

Parties drafting contracts must remain aware of the informational cascade: net work effects are capable of trumping the benefits of improved provisions and there is a risk that too much of the text is saved in each new incarnation of the contract. As mentioned, the pervasive use of forms may enhance contractual complexity - both in terms of length and comprehensiveness - an attribute often bemoaned in accounts with practitioners. How does this happen?

One malefactor of increased complexity is the path dependency. The reputation of the drafting party hinges on the success or failure of his/her drafting efforts and the reputational damage appears to be greater when it concerns 'the failure' of a customized contract than 'the failure' of a more standardized form contract. Departures from the form appear to be disfavored: deletions must usually meet high standards of justification while adding provisions that don't seem to help - but do not hurt - require a lower level of justification. The (inexperienced) associate often cannot discern the relevance of certain provisions, in particular whether the contract will benefit from the deletion of a particular contractual clause. ${ }^{31}$ Provisions which are regarded as standard are thus often adopted without taking into account previously established and possibly conflicting arrangements between parties. As a result, templates may cover the same issues several times, leading to the co-existence of multiple (conflicting) provisions. ${ }^{32}$ Sloppy drafting techniques only enhance the dense language and duplication of terms: ' $y$ Jou will find yourself staring for 10 minutes at a paragraph containing 38 singlespaced lines and, try as you might, the light of comprehension will be repeatedly snuffed out in the fourth line. (...) With an audible sigh, the recipient of such a text must pick up a pencil and start reconstructive surgery on contractual language that has the density of uranium $238 .^{, 33}$

Routinisation may increase tolerable levels of complexity - experience of a repeated complex pattern may reduce cognitive load. However, even lawyers cannot always oversee complexity in the sense of the number of added terms and their density. Grosheide (2000) correctly notes that professional support and advice with regard to contract drafting is not always a guarantee for clarity. It is common practice for corpo-

\footnotetext{
${ }^{29}$ Kahan and Klausner 1997.

${ }^{30}$ This path dependency is reinforced by limits of cognition such as the status quo bias (favouring the status quo rather than changing it), the anchoring bias (favouring the initial starting point) and the conformity bias (the form is also used by peers). See also Kahan and Klausner 1996, Kahan and Klausner 1997, HIII 2008.

${ }_{31}$ Buchheit (2006) and Hill (2001) on the inexperience of junior associates in relation to commercial contract ${ }^{31}$ Buchher

drafting.
${ }^{32}$ King and Segain 2007, Hermalin et al. 2007.

${ }^{33}$ Buchheit 2006, p. 169.
} 
rate lawyers to simply copy a lot and thus also each others' mistakes. ${ }^{34}$ In short, only counterparties and their counsel willing to acknowledge the limitations of their own reading comprehension will have something to say about the contract. ${ }^{35}$

It is clear that cognitive limitations stemming from bounded rationality have ex post design implications: individuals drafting contracts must acknowledge that the ability of lawyers and laymen to concentrate on the contract and understand its interdependencies is limited. The incidence of small and large mistakes increases with the length of contracts, and the interrelatedness of provisions and complex language of the latter. Unfortunately, mistakes are usually caught only when a party attempts to determine his/her rights under the contract, at which point things usually are not going well. ${ }^{36}$ In accordance with Visée (2002) and Buchheit (2006), I believe that drafting a high-quality contract is a true skill which 'calls for razor sharp clarity. ${ }^{37}$ A contract should not only be accurate in the legal-technical sense, but must also remain manageable for the client. ${ }^{38}$ The drafter of the contract should continuously consider whether the contract still comprises a comprehensible narrative. In the following section, I will review some recommendations which may serve to limit contractual complexity.

Given the above, I believe that one of the cardinal rules of drafting contracts is to be sparing with cross-references and the interrelatedness of terms in general. These features contribute to contractual complexity, especially in the subjective sense. Crossreferences often occur due to the careless addition of clauses and the fear of eliminating a clause which potentially creates ripple effects in the rest of the document. In this light, Smith (2006) propagates the concept of modularity, which refers to 'splitting a system into relatively autonomous components. ${ }^{39}$ According to Smith (2006) Modularity is a mechanism which can increase drafting quality while it enables the reduction of unnecessary interrelatedness between contract provisions. A modular provision can be

${ }^{34}$ Grosheide 2000. Likewise Buchheit 2008: 'considering the tasks performed by lawyers one might think that lawyers are perfectly able to suppress needless complexity and promote reading comprehension. Hower, lawers However, lawyers sufer the handicap of beng lawyer and (..) not occasion more expressions of outrage by bankers, analysts, rating agencies, investors and regulators (they do sometimes incur the wrath of the judiciary)? Is it because the legal profession has dazzled them all into believing that contract drafting is such an arcane science that no one other than a consecrated practitioner has standing to express a view about what is good and what is truly dreadful? Is it because they think that impenetrability in contract drafting is a sure sign of the drafter's capacious intellect? Complexity can obscure the risks of the transaction, and the danger lies therein that the market must be able to see the risks before it is possible to transaction, and the ding
sensibly price them.'

sensibly price them.'
${ }^{35}$ Buchheit 2006, p. 170.

${ }^{36}$ See also Grosheide 2000: 'overeenkomsten dlenen zo duidelijk mogelijk te worden opgesteld want er 'komt een dag dat lemand zal proberen het contract onderuit te halen'.

${ }^{37}$ Visée 2002, p. 56: 'Th]et schrijven van een goede overeenkomst is een echt ambacht. Het lukraak invullen van een "uit de kast gerukt" model leidt vaak niet tot een goed resultaat.'

${ }^{38}$ This is substantiated by accounts of partners at global law firms and the legal counsel at several multinational corporations. See also Visée 2002.

${ }^{39}$ Smith 2006, p. 1196, and Simon (1978) who refers to 'a patterned structure'. 
added to or subtracted from the contract without substantial disruption to the contract as a whole. Because such modular clauses interact only in a specific manner, a clause can be substituted for another as long as they perform similar roles. Allowing for modularity also sheds light on whether the same material is covered in more than one provision, a phenomenon which is not uncommon in the forms of large law firms.

I believe that two particular sections of contracts in which modularity may create added value are the Definitions and Boilerplate sections. The Definitions section of a contract is often lengthy, unnecessarily befuddled, and prone to non-modularity. ${ }^{40}$ The only terms that I believe should be included in the Definitions section, are terms that are used in the contract often and/or are subject to problems of holistic and complex interpretation. Closely related definitions of a given term which are 'hidden' in substantive provisions should also be factored out and defined in the Definitions section. Preferably, the Definitions section should be inserted at the beginning of the contract, directly visible to the reader. In this manner, no confusion can arise over term in the drafter's idiosyncratic language, with the corresponding terms highly discernible with each repetition in the contract.

The concept of modularity may also be applied to boilerplate provisions of the contract. Examples of boilerplate provisions which according to 5 mith (2006) are suitable for modularization are governing law and severability provisions. ${ }^{41}$ Smith (2006) indicates that most governing law provisions select the law of a single state to govern the agreement, with the exclusion of the state's conflict of laws rules. Other variations are less common. The selection of one state, combined with a bar on the choice of law rules, increases modularity and predictability: 'bby] selecting one state, these contracts are displacing off-the-rack law that might involve nonmodular and hard-to-foresee choice of law questions (...) By blocking a state's conflict of laws rules, the provision is even more modular: the choice of law of a certain state will not vary with changes in the business or contract context. ${ }^{42}$

Severability relates to the validity and enforceability of contractual provisions and can be taken as an expression for modularity and against re-modularization by the court. ${ }^{43}$ The modularity of severability clauses lies therein that they apply to the entire contract and are usually not parsed for separate provisions. This cross-referencing and interconnection of terms is also apparent in provisions governing the warranties and representations. Parties may make broad representations and warranties but bury catch-all exclusions in schedules, related agreements or other parts of the contract. ${ }^{A 4}$

${ }^{40}$ Buchheit 2006, p. 22; ' 'b]rowse through the Definitions section at the front of a complicated indenture or a debt restructuring agreement. You may easily find yourself at page 30 before the drafter offers you the first taste of an operative clause.

${ }^{11}$ Smith 2006.

${ }^{12}$ Smith 2006, p. 1194

${ }^{43}$ Smith 2006.

${ }^{14}$ See also on tricky drafting techniques E. Goldman, 'Ethical Issues in Contract Drafting, Seminar on Teaching Contract Skills to Young Lawyers', 4 August 2006 Annual Meeting of ABA Section of Business Law, $\mathrm{p}, 48$ 64 , cited in King and Segain 2008. 
However, parties drafting contracts must realize that cross-references cannot be fully eliminated; non-modularity will always continue to exist to some extent. Therefore, care must be taken to use symmetrical language: interrelated provisions must comply with each other. ${ }^{45}$

Apart from modularity concerns, there are some other issues concerning the structure of a contract which may mitigate the effects of or reduce (subjective) complexity. I believe headings for example, are fairly important to enhance reading comprehension. Parsing an agreement into sections and subsections improves clarity and promotes an orderly system. Contracting parties should also take care to keep the main document 'clean': detailed information on collateral documents and other arrangements should be included in schedules and exhibits to the main legal text. In addition, it is useful to spell out the intentions of parties in plain language at the beginning of the document. This section may be referred to as the Preamble. A preamble will help parties, especially those not involved with the drafting process itself, to quickly discern parties' intentions and the main goal of the agreement. Finally, drafter must question themselves whether a provision is really necessary taking into account the environment, i.e. which factors (including past market events) would justify the inclusion of such a term.

The aforementioned tools may be helpful in constraining complexity. But the study of the complexity of contracts also sheds light on another issue. The commercial contracting practice in Continental Europe, characterized by relatively simple contracts, is increasingly influenced by complex Anglo-Saxon contract models. ${ }^{46}$ Hill (2008) notes that the transcendence of American drafting techniques may be the product of agency costs within law firms and between law firms and their clients, as well as path dependency. ${ }^{47}$ The convergence relates to the complexity of the contract as a whole, but is explicitly visible with regard to certain provisions. I will refer to these provisions as 'legal transplants' which include US-style boilerplates such as entire agreement clauses, representations and warranties, provisions for contingencies such as material adverse change clauses and break-up fees, and sections relating to Definitions. As set out in chapter 3 of this dissertation, I believe that contract design and thereby complexity is very much influenced by the legal and socio-cultural environment. As illustrated, the legal and socio-cultural environments on both sides of the Atlantic are quite diverse. I believe it is important to note that while Continental Europe may assimilate its corporate practice with its Anglo-American counterpart, it has not necessarily adopted the Anglo-American system of doing deals. The integration of the AngloAmerican contract practice into Continental European legal systems is a continuous

${ }^{15}$ For example, representations and warranties will have counterparts in the covenants section and these will be repeated in certificates and legal opinions).

${ }^{46}$ Schuit 200, and Drion 2002, who primarily points to the process of the 'localization' of contracts. This implies that American law firms increasingly demand European firms to render American contracts compliable with mandatory rules of European law (see also Schweitzer 2007, Hofstede and Oostwouder 2006).

${ }^{47}$ Hill (2008) in reference to a similar trend in Latin America. 
and ongoing process. Parties should carefully consider randomly adopting foreign drafting techniques. They should take into account the governing law and forum provisions of the respective contract. In their 'local' context, provisions may have a particular meaning and legal effect which the foreign user of the term is not always familiar with. ${ }^{48}$ Already, it has become clear that certain concepts, even if identical in name, have significantly different functions and legal effects, which the user of the term may not be familiar with.

Schweitzer (2007) singles out three Anglo-Saxon concepts which are frequently used in merger agreements and copied to the European corporate practice: Letter of Intent (Lols), Material Adverse Change (MAC) clauses and break-up fees. ${ }^{49}$ Other legal transplants include entire agreement provisions ${ }^{50}$ and NOM clauses. Hofstede \& Oostwouder (2006) draw attention in particular to the risks of using Anglo-American concepts in Dutch contracts. The example they offer is of 'representations' and 'warranties'. The authors indicate that in English law these terms have distinct legal implications, a gradation which is not necessarily present in Dutch law. The use of foreign legal concepts may also create interpretation risks. This risk appears to increase due to the fact that contrary to the US and England, the Dutch court takes a predominantly subjective approach towards contract interpretation. Corporate parties, however would often prefer the court to take a more objective approach toward contract interpretation. An objective approach toward contract interpretation is believed to push the court to stick with the document as written and as such create greater certainty. ${ }^{51}$ Contracting parties may therefore strive to reduce potentially undesirable interpretation to a minimum and ironically attempt to use foreign legal concepts (legal transplants) to do so. ${ }^{52}$ For example, inserting an American style Definitions section may minimize the risk of a more subjective interpretation which goes against the intention of parties. In addition, parties may insert entire agreement and NOM clauses. ${ }^{53}$

\section{Adjudicators - enforcement}

I believe that complexity should also be of concern to courts and other adjudicators. In the Introduction to this dissertation, I wonder whether greater levels of contractual complexity will lead to more mistakes and subsequently litigation. In addition, I wonder whether varieties in contract design should give rise to a differentiated enforcement of contracts. The first issue concerning litigation levels does not have a simple

${ }^{18}$ Tjittes 2008.

${ }^{49}$ Lols generally contains procedural rules for further negotiations to which the parties have agreed, the MAC grants the buyer a termination right when the state of the target looses significant value between a particular date (usually signing) and the closure date of the agreement, and a breakup fee is a lump sum payment due by one of the parties in case the transaction is unsuccessful. On MAC clauses see HR 7 September 2007, RVDW 2007, 747.

${ }^{50}$ See chapter 3 and Schelhaas 2007, 2008.

${ }^{51}$ Tjittes 2005.

${ }^{52}$ De Vrey 2006, Drion 2002

${ }^{53}$ HR 29 June 2007, NJ 2007, 576, HR 19 January 2007, NJ 2007, 575. 
answer, while empirical data is not easy to obtain. I may observe that litigation rates appear to be higher in the US (where contracts are relatively complex) than for example the Netherlands (where contracts are relatively simple). It is, however, questionable whether this litigious culture is the driver of contractual complexity or vice versa. On the one hand, a culture where litigation is not uncommon may encourage parties to increase the complexity of the contract in order to ensure that nothing is left to chance. This would substantiate the vision that litigiousness increases complexity. On the other hand, as complexity raises the misunderstanding of contract (terms), complexity may increase the potential for the development of disputes. The latter point of view supports the claim of complexity as a cause of litigation. However, increased complexity in terms of length in conjunction with modularity may actually lead to simplified contracts that ease the interpretation, which in turn will reduce the potential for disagreements. The issue thus remains unclear and subject to speculation.

find the promulgation of a differentiated enforcement of contracts, a difficult issue. My research findings illustrate that the complexity of a contract may signal to the court information on the contracting process and environment. This may help the judge to understand and interpret the agreement, especially if we assume that the normative goal of the court is to maximize the ex ante value of contractual relationships. ${ }^{54}$ Dependent upon the causes of the simplicity or complexity of the contract, the court may apply different interpretation techniques. ${ }^{55,56}$ Eggleston et al. (2000) for example offer some suggestions on how the court should react to various causes of contractual simplicity. ${ }^{57}$ However, parties must beware that adjudicators also suffer from cognitive limitations. Complexity may thus create problems of interpretation increasing enforcement costs. Furthermore, the fact that Dutch contracts are increasingly influenced by the Anglo-Saxon corporate practice, does not only concern contracting parties, but also the adjudicator. I believe that courts should therefore take care to interpret legal transplants in a consistent and practical manner.

Policymakers - legislation

A greater understanding of the complexity of contracts may substantiate the debate on the proper content of and role for contract law. In the Introduction to my dissertation I wondered to what extent parties opt out of default law rules, and whether the

\footnotetext{
${ }^{54}$ The goal of the court may also be another one, such as achievement of efficiency or ex post optimization ${ }^{55}$ There is a large incomplete contracts literature which theorizes on how the court should fill contractua 'gaps' due to incompleteness (Ayres and Gertner 1989, 1992). I will not address this literature in this conclu'gaps'

The focus of this dissertation is on commercial agreements, but one could relate complexity to consume contracts as well, i.e. in the sense that consumers are confronted with complex language and lengthy contracts. Examples are mobile phone contracts, car rental agreements, insurance contracts and software licensing agreements. The contractual complexity given the contracting environment may be a reason for the courts to construe such contracts in favor of consumers. Another argument made for interpretation slanted in the favor of consumers is their relatively 'weak' position as layperson.

${ }^{57}$ Eggleston et al. 2000, p. 128.
} 
answer should lead us to reconsider the argument for more or less law. Contract law being largely non-mandatory; firms contract in the realm of the freedom of contract and often develop rules tailored to their particular relationship. Subsequently, contract terms vary depending on parties' characteristics and goals, their shared understandings, transaction costs, the characteristics of the transaction, and the background legal regime. When parties opt-out of default rules, this may point toward the suboptimality of these rules. However, the relatively simple contracts in the Netherlands seem to illustrate that firms are generally not wary to rely on default rules. This may in part be due to the fact that civil law jurisdictions define concepts very systematically in their legislation which means parties do not have to devote much effort to defining these concepts themselves: background civil law may substitute for the role boilerplate plays in American contracts. ${ }^{58}$ The extent to which firms actually contract around default rules in practice, necessitates further research.

The study of the complexity of contracts may be able to offer some insights into the harmonization of contract law rules, especially on a European level. ${ }^{59} \mathrm{~A}$ comparative study of contractual complexity sheds light on the internationalization and crosspollination of contract styles. As mentioned numerous times already, Anglo-Saxon style contracts appear to increasingly dominate the (international) corporate practice. Schuit (2001) indicates that the choice of law of a commercial agreement is not in the first place determined by the legal system which supplies the 'best' law, but especially by other factors such as power relations, common practice of the type of transaction, the issue of bankability, etc. He continues with an account on the openness of the Dutch economy which creates ample room for foreign influences welcoming developments which also bring with them also create the risk of the 'impoverishment' of Dutch law: contracts will be characterized increasingly by a convergence of to English type forms and language. Convergence takes place within the limits set by (immutable) rules of domestic law. ${ }^{60}$ De Ly (2006) states that international contract drafting has been developed by practitioners responding to practical problems and needs. ${ }^{61}$ In most jurisdictions commercial contract law is largely non-mandatory in nature, and contracting parties are limited only by rules of mandatory law, which - at least for large firms - emanate predominantly from corporate and securities law. The aforementioned developments might let us wonder what the European harmonization of contract law may still offer the (internationally oriented) corporate contracting practice. The idea behind the harmonization of contract law rules is that national laws create constraints to inter-state trade and hamper the creation of an internal market. The

${ }^{58}$ Smith 2006, Hill and King 2007, Kahan and Klausner 1997.

${ }^{59}$ Other scholars have already written extensively on this topic and I will merely point to some Issues which I encountered while studying the relative complexity of contracts between jurisdictions.

${ }^{60}$ See also De klulver 2001, p. 4-14: 'wat de ondernemingsrechtelijke praktijk onderscheid van de algemene contractspraktijk is dat ondernemingsrechtjuristen contracteren tegen de achtergrond van een in beginsel dwingendrechtelijk systeem.'

${ }^{61}$ See also Bercowitz et al. (2003) who emphasize that it is law in practice and not law in books that matters. 
goal of harmonization then should be the facilitation of the internal market and the creation of the 'best' law. But only the aforementioned immutable rules seem to carry the potential to hamper inter-state trade and thus the creation of an internal market. Collins (1999) argues that even the internal market argument does not provide a justification for the top-down implementation of a civil code. It appears to be predominantly the different socio-cultural environment that creates constraints to the func-

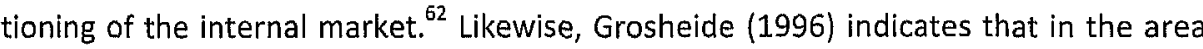
of international commercial contract law, of decisive significance are the legal culture of the international transactional practice and the familiarity with and involvement therein of parties such as legal counsel, lawyers, arbitrators, and commercial chambe judges. I believe that a European civil code will not take away these constraints; parties will have to solve these problems themselves. Smits (2002) also emphasizes that firms are skeptical about the benefits of harmonization. In the first place because the role of private law is overestimated: other constraints such as the manner in which parties cooperate and trade (the contracting practice) are more important. If rules of law would hamper the creation of the internal market, it is specifically rules of tax and corporate law which are more important than private law rules. Second, corporations profit from as little change as possible. ${ }^{63}$ Smits (2002) therefore proposes that competition between legal systems should create a practice of 'best' or 'most favorable' law. This competition will lead to the best possible rules, because otherwise a system of law will be 'pushed out' of the market.

There are some remarks I would like to make to this account. First of all, the current transplantation of Anglo-Saxon concepts and convergence of corporate style contracting seems indeed illustrative of the competitive and practical approach. But at the same time, the 'impoverishment' of Dutch law lurks - at least with regard to the corporate practice. Smits may thus be right in the sense that some legal systems 'loose' value in their application. But I would question whether competition between legal systems indeed generates the 'best' law. Why does the preference for American style contracts dominate when there is as a high cost associated with this style in sense of complexity costs and is the move to a more efficient style lacking? ${ }^{64}$ The transplantation of Anglo-Saxon terms and the associated contracting style is not a flawless process, which creates risks and does not always encompass the 'best' rules. Apparently, parties have a preference for this system, whose commonality is in part induced by path dependency and standardization. Actually the competitive process illustrates a market inefficiency or failure. Parties are caught in an informational trap: unless comparative law specialists either rely on outside lawyers or own law, they thus accept law with few constraints such as English law and live with verbose contracting and tricky drafting. Given these observations, the most interesting approach to harmonization of

\footnotetext{
${ }^{62}$ See also Smits 2000, 2002, 2003, and Van den Bergh 2002.

${ }^{63}$ Smits 2002
}

${ }^{64}$ King and Segain 2007. 
contract law seems the optional code as propagated by Smits. In this manner parties may choose whether or not they will 'switch' to the law embedded therein. Currently, the Common Frame of Reference seems to be the first step in this direction. However, given network effects and path dependency, I wonder whether the harmonization of contract law rules will indeed provide an advantage in the sense of a superior system to large corporations. ${ }^{65}$ This is confirmed by several authors who find that the Dutch corporate practice has until now shown little interest in the Common Frame of Reference project. ${ }^{66}$

\section{Contracts in genera}

Complexity in a multidimensional sense triggers us to think about contract design. In drafting contracts, parties must constantly be aware of the specific characteristics of the transaction and the environment in which the transaction takes place in order to justify the relative complexity of a contract. Complexity may show distrust and overwhelm the cognitive abilities of parties, absorb resources, and have other negative consequences $^{67}$ and parties should always be aware of the contextual embeddedness of complexity. In addition, depending on the type of relationship parties aspire they may give the contractual terms a more classical or relational content.

\section{LIMITATIONS AND SUGGESTIONS FOR FURTHER RESEARCH}

This dissertation offers a preliminary investigation into the design of contracts from a multidisciplinary perspective, but it is only a small step on the long road leading to a more detailed understanding of, what Ronald Coase described as the actual process of contracting between companies. This chapter has a number of limitations that I would like to translate into suggestions for future research.

My contribution is based on a dataset that comprises about four hundred contracts, but focuses on a limited number of modes of governance: inter-firm collaborations, and one particular contractual setting: the biopharmaceutical industry. While my research clearly invites further study of legal and managerial implications of inter-firm

${ }^{65}$ Basedow 1998, p. 7, who states that the harmonization of contract law is of less useful for smaller firms and (who trade mostly in a national context) and larger firms (who have the expertise and resources to impose their own terms).

${ }_{66}$ Bouwes 2005. Smits (2002) states that Dutch government has not received many complaints from SMEs on the diversity of contract law rules ( $c f$. Vogenauer en Weatherill 2006). This may be different for consumers who are often seen as weaker party and may be less able to exert influence on the terms of the contract (EIsenberg 1994, Smith 2006). Even if terms are written clearly, a consumer usually will be unable to fully understand their effects, because preprinted terms characteristically vary the form takers' baseline legal rights and most consumers do not know their baseline rights. This may call for harmonization primarily for protection of the consumer (as evidence by numerous Directives).

${ }^{67}$ See for example Buchheit (2008) who argues that the current financial crisis was triggered not only by the
6 ped complexity of financial products, but also by the corresponding complexity of the legal documents used to memorialize the transactions. 
technology collaborations based on larger samples of companies and contracts, my dissertation is also an encouragement for contract research with a larger sample across other industries. For example, a range of commercial contracts where technology is not of primary importance (e.g. marketing agreements, customer-supplier relationships, and outsourcing) can most probably provide a more thorough understanding of the contracting process between firms. Furthermore, my dataset is very much US oriented, datasets of a more international nature will surely provide relevant new insights. It would for example be interesting to investigate further whether either common law or civil law jurisdictions are predominantly classically or relationally oriented. This also brings me to the point of the contractual setting. Future research would benefit from a more in-depth understanding of the specific context in which the contracting and negotiation process takes place. I have highlighted only several elements of what I call the legal and socio-cultural environment. It would be interesting, also in light of business economics, to analyze for example why and how particular rules of contract law and (intellectual) property law, which will vary according to each jurisdiction, affect the terms of a contract. Do parties choose to make use of default rules or are they guided predominantly by the freedom of contract and create their own system of law (where possible) $?^{68}$ In light of the asymmetries between contracting partners, it would be interesting to asses whether terms are particularly slanted in favour of one of the parties. ${ }^{69}$

My research is based on a dataset of actual contracts. A limitation concerning this type of research is that these contracts represent the outcome of a particular contracting process. Data relating to actual contracting practice is scarce. Even for a small(er) dataset, it would be wonderful to shed light on the negotiation processes themselves and when and how parties to contracts consider using any alternative means for the governance of their relationship.

Finally, I would like to offer some suggestions for future research related to the measurement of contractual complexity. It would be interesting to see whether measuring the cognitive load of contracts could be extended to a sample of legal professionals (corporate lawyers, legal counsel). Given the limitations discussed earlier, this would most probably imply that respondents are to evaluate a smaller sample of contracts, but even a small sample of inter-firm contracts could provide a 'real life' look into the professional perception of the complexity of contracts. In addition, the dissertation is based on a concept of complexity along two dimensions. In addition to insights into the respective weights that each of these dimensions should be assigned, future research could benefit from a more in-depth analysis of elements of contractual complexity in terms of the different contract clauses and their interactions that are expected to increase the level of contractual complexity. The ultimate aim of a multidimensional perception of contractual complexity is the understanding of the implica-

${ }^{68}$ Marotta-Wurgler 2007

${ }^{69}$ Marotta-Wurgler 2009 
tions of different levels of contractual complexity for the costs of commercial contracts in terms of design, writing, implementation, control, and enforcement. 
SUMMARY

The real world is always more complex than we can attempt to capture in any model. This thesis is an endeavor to de-theorize and simplify at least a small corner of this complex world. In four distinct chapters, I integrate different perspectives on contract theory in order to look beyond the face value of the legal document at the intricacy of contract design. To this extent I introduced the following general research question:

How do we define contract design and what differences do we find within a particular industry and between countries?

Each of the chapters of this dissertation sheds light on different aspects of contract design. Chapter 2 investigates to what degree commercial contracts are governed by either a classical or more relational contracting perspective. In chapters 3 to 5 I seek to answer what method(s) may be used to measure contract design and subsequently what factors create discrepancies in contract design. The empirical validation in these chapters is based on a dataset of over $400 R \& D$ alliance contracts in the biotechnological and pharmaceutical sector, on surveys with graduate students in law and economics, and on interviews with professionals involved in drafting commercial (R\&D) agreements.

In chapter 2, I study some major legal implications of inter-firm technology partnering through equity joint ventures, non-equity partnerships, and licensing contracts. These different partnerships are placed within the classical and relational contracting perspectives, while also considering intellectual property rights issues. My findings suggest that different types of inter-firm agreements are governed by either a more classical or relational contracting perspective. Equity joint ventures and non-equity partnerships are found to largely follow a relational contracting perspective, while licensing contracts are governed by a classical contracting perspective.

I use both legal and business perspectives on contract theory to develop a multidimensional framework of contractual complexity in chapter 3. Complex contracts are defined as those contracts that contain many clauses with a relatively large number of interdependencies that also impose a significant cognitive load upon parties. My findings illustrate that factors generally invoked to explain the complexity of contracts, such as contract and enforcement costs, limits of cognition, asymmetric information, asset specificity and strategic importance, uncertainty of the environment, trust and reputation, are ultimately driven by their embeddedness in the particular legal and socio-cultural environment. A study of different aspects of the legal environment 
shows that the legal setting has a significant influence on contracting and enforcement costs, and the disclosure of information. The socio-cultural environment generally affects levels of trust and reputation, the parties' perception of enforcement and contracting costs, and environmental uncertainty.

The extent to which we can speak of a multidimensional concept of contractual complexity is evaluated in chapter 4.1 find that quantitative, objective measures of complexity, and objective as well as subjective elements of cognitive load, measure different aspects of contractual complexity. The objective dimension of complexity comprises both the length of the contract in words and the time on task, i.e. the time it takes an individual to read a contract. The subjective dimension of contractual complexity comprises the cognitive load of a contract. The cognitive load can be broken down into two components: (1) the mental load and (2) the mental effort individuals experience while reading the contract. The element of mental effort consists of two sub-elements: (a) the actual cognitive effort individuals make to understand contracts and (b) the degree of stress that they experience as they have to read through the contracts.

In chapter 5, I investigate to what extent firm characteristics, transactional characteristics and the organizational routines of firms affect contractual complexity. I find that basic differences exist between the impact that company characteristics (size, information and R\&D capabilities asymmetries), transaction level attributes (strategic importance and asset specificity), and the organizational routines (prior ties and contracting experience) of contract parties have on the objective and subjective dimensions of the complexity of inter-firm R\&D alliance contracts. Asymmetries between contracting parties in terms of their size, R\&D capabilities, and the availability of information, positively affect the objective dimension of the complexity of R\&D alliance contracts. With regard to the level of transactional attributes, I find that both the strategic importance of the R\&D alliance and the asset specificity of the investments involved are positively related to the objective dimension of contractual complexity. With regard to the organizational routines of contracting firms, I find that the history of previous alliances and repeated ties, shared experience, and perhaps even the emergence of joint inter-firm administrative routines, leads to more complex contracts. The subjective dimension of contractual complexity is mainly affected by two factors: the size asymmetry between firms and the asset specificity of the technology to which the contract refers.

Chapter 6 comprises my conclusions. Based on my research results, I believe that a multidimensional concept of contractual complexity is able to enhance our understanding of contract design. In particular, my findings illustrate that there may very well be an upper limit to the actual level of complexity of contracts that not only contract parties, but also judges, and other third parties are able to absorb. Parties at al levels of the contracting process should thus be concerned with contractual complexity. 
Parties drafting contracts must consider that the ability of individuals to understand the different elements of a contract is limited. Awareness of the relative complexity of contracts may is also important for a third party such as a judge. An awareness and understanding of contractual complexity may advance contract interpretation in case of a dispute. Finally, contractual complexity may be relevant for policymakers in light of the design of legal rules and policies.

To conclude, my research is a first endeavor into actual contract design. I acknowledge that my research is characterized by several limitations. In the end, however, I believe that a multidimensional construct of complexity enables our understanding of the implications of different levels of contractual complexity for the costs of commercial contracts in terms of design, writing, implementation, control, and enforcement. 
EEN EMPIRISCHE ANALYSE VAN OVEREENKOMSTEN

Empirische en theoretische beschouwingen over de vormgeving van overeenkomsten 


\section{SAMENVATTING}

De praktijk is vaak te gecompliceerd om in een model te bevatten. Deze dissertatie is een poging om een inzicht te verschaffen in een (klein) deel van de contracteringspraktijk. In de vier kernhoofdstukken van deze dissertatie behandel ik verschillende contractstheorieën waarbij het accent ligt op het doorgronden van de wijze waarop overeenkomsten worden vormgegeven. Hiertoe introduceer ik de volgende algemene onderzoeksvraag:

Wat kenmerkt de specifieke vorm van een overeenkomst en welke verschillen treffen we hierin aan binnen een bepaalde bedriffstak en tussen diverse landen?

De vier kernhoofdstukken van dit proefschrift behandelen elk verschillende aspecten van de vormgeving van overeenkomsten. In hoofdstuk 2 wordt onderzocht in hoeverre verschillende typen commerciële overeenkomsten gekenmerkt worden door de klassieke danwel relationele theorie van de overeenkomst. In de hoofstukken 3 tot en met 5 onderzoek ik op welke manier de specifieke vorm van een overeenkomst gekwantificeerd dan wel gekwalificeerd kan worden en welke factoren van invloed zijn op de vormgeving van overeenkomsten. Voor de empirische analyses in deze deze hoofdstukken maak ik gebruik van een dataset van meer dan 400 samenwerkingsovereenkomsten op het gebied van onderzoek en ontwikkeling (O\&O) in de biotechnologische en pharmaceutische industrie, enquêtes die zijn afgenomen bij rechten- en economiestudenten en interviews met professionele partijen die zich bezighouden met het opstellen van commerciële samenwerkingsovereenkomsten op het gebied van $0 \& 0$.

In hoofdstuk 2 bestudeer ik in het bijzonder de juridische implicaties van samenwerkingsovereenkomsten op technologisch gebied door een aantal overeenkomsten die betrekking hebben op equity joint ventures, non-equity samenwerkingsverbanden en intellectueel eigendomslicenties te analyseren. Deze verschillende overeenkomsten worden bestudeerd in het licht van de klassieke en relationele contractstheorieën. Ook onderzoek ik in hoofdstuk 2 een aantal interessante intellectueel eigendomsaspecten. Uit mijn bevindingen volgt dat de vormgeving van de bestudeerde overeenkomsten in overwegende mate wordt gekenmerkt door elementen uit de klassieke dan wel de relationele contractstheorie. De vormgeving van de overeenkomsten die betrekking hebben op de equity joint venture en non-equity samenwerkingsverbanden wordt voornamelijk gekenmerkt door de relationele contractstheorie, terwijl de licentieovereenkomsten vooral elementen van het klassieke contractsmodel vertonen. 
Om de vorm(geving) van een overeenkomst te kunnen kwalificeren, gebruik ik het begrip van de complexiteit van een overeenkomst. in hoofdstuk 3 bestudeer ik hiertoe enkele juridische en bedrijfseconomische theorieen die betrekking hebben op de vormgeving van commerciele overeenkomsten. Complexe overeenkomsten definieer ik als die overeenkomsten die zijn opgebouwd uit meerdere contractsbedingen met een grote onderlinge samenhang, waarbii de overeenkomst een aanzienlijke cognitieve belasting voor de contractspartijen met zich meebrengt. In zowel de bedrijfseconomische als juridische literatuur wordt een aantal factoren genoemd die van invloed zijn op de vorm(geving) van overeenkomsten. Voorbeelden hiervan zijn transactiekosten, cognitieve beperkingen, informatie asymmetrieen, bedrijfsspecifieke investeringen, strategische belangen, de veranderlijkheid van de transactie omgeving, het vertrouwen en de reputatie van contractspartijen. Mijns inziens spelen de juridische en sociaal-culturele context een aanzienlijke rol in de mate waarin deze factoren van invloed zijn op de vorm(geving) c.q. complexiteit van overeenkomsten. De juridische context beinvloed de transactiekosten en de informatie asymmetrieèn tussen partijen. De social-culturele context heeft voornamelijk een effect op het vertrouwen tussen contractspartijen, de reputatie van contractspartijen, de wijze warrop contractspartijen transactiekosten ervaren, alsmede de mate van verandering van de transactie omgeving.

De wijze waarop de complexiteit van overeenkomsten gemeten kan worden, onderzoek ik in hoofdstuk 4. Uit hoofdstuk 4 volgt dat de complexiteit van overeenkomsten bepaald kan worden aan de hand van een objectieve en subjectieve maatstaf. Deze maatstaven weerspiegelen verschillende dimensies van de complexiteit van een overeenkomst. De objectieve dimensie van complexiteit omvat zowel de lengte van de overeenkomst - gemeten aan de hand van het aantal woorden van een overeenkomst - als de tijd die een individu nodig heeft om een overeenkomst te lezen. De subjectieve dimensie van complexiteit bestaat uit een cognitieve maatstaf. Deze cognitieve maatstaf omvat twee elementen: (1) de mentale belasting; en (2) de mentale inspanning die een individu ervaart tijdens het lezen van een overeenkomst. De mentale inspanning omvat weer twee subonderdelen: (a) de daadwerkelijke mentale inspanning die een individu nodig heeft om de overeenkomst te begrijpen; en (b) de mate van stress die een individu ervaart wanneer hij of zij een overeenkomst leest.

In hoofdstuk 5 onderzoek ik de mate waarin specifieke eigenschappen van een onderneming, transactiegerelateerde eigenschappen en organisatorische routines bepalend zijn voor de complexiteit van een overeeenkomst. Uit mijn onderzoek volgt dat de specifieke eigenschappen van een onderneming (de asymmetrieën tussen de grootte van de contractspartijen, informatie-asymmetrieën en asymmetrieën in 0\&0capaciteiten), transactiegerelateerde eigenschappen (het strategisch belang van de overeenkomst en de bedrijfsspecifieke investeringen), en organisatorische routines (de specifieke en algemene transactie-ervaring van een onderneming) op verschillende wijze van invloed zijn op de objectieve en subjectieve dimensie van de complexiteit van een overeenkomst. Asymmetrieën tussen partijen in de zin van de grootte van de 
contractspartijen, informatie en O\&O-capaciteiten, hebben een positief effect op de complexiteit van een overeenkomst. Op het niveau van de transactiegerelateerde eigenschappen concludeer ik dat er een positieve relatie bestaat tussen zowel het strategisch belang van de samenwerking als de bedrijfsspecifieke investeringen enerzijds en de objectieve dimensie van de complexiteit van een overeenkomst anderzijds. Met betrekking tot de organisatorische routines, toont mijn onderzoek aan dat een grotere partijspecifieke en algemene ervaring met betrekking tot het aangaan van samenwerkingsovereenkomsten, leidt tot complexere contracten. De subjectieve dimensie van de complexiteit van een overeenkomst wordt vooral beïnvloed door twee factoren: de verschillen in de grootte van de contractspartijen en de bedrijfsspecifieke investeringen

Hoofdstuk 6 bevat een samenvatting van mijn bevindingen. Uit de onderzoeksresultaten van de hoofdstukken 2 tot en met 5 blijkt dat het concept van de complexiteit van overeenkomsten een verhelderend inzicht kan bieden in de wijze waarop commerciële overeenkomsten worden vormgegeven. Uit mijn onderzoek volgt mijns inziens meer specifiek dat alle partijen die op enigerlei wijze betrokken zijn bij het opstellen van overeenkomsten zich bewust dienen te zijn van de mate van de complexiteit daarvan.

Partijen die zich bezig houden met het opstellen van overeenkomsten dienen zich te realiseren dat de mogelijkheid van individuen om de verschillende onderdelen van een complexe overeenkomst te begrijpen, begrenst is. Een inzicht in de mate van de complexiteit van overeenkomsten kan ook een voordeel opleveren voor rechters en andere partijen die aangewezen zijn om een overeenkomst uit te leggen wanneer zich een conflict voordoet. Daarnaast is een inzicht in de mate van complexiteit van overeenkomsten ook van belang voor de wetgever.

Ten slotte merk ik op dat mijn onderzoek slechts een poging is om door middel van empirisch onderzoek een licht te werpen op de wijze waarop overeenkomsten worden vormgegeven. Het concept van de complexiteit van overeenkomsten kan daarbij inzicht bieden in de mate waarop de kosten van het ontwerp, opstellen, implementeren en de afdwingbaarheid van de overeenkomst van invloed zijn op de vormgeving van de overeenkomst. 
REFERENCES

Abbink and Rochenbach 2006

K. Abbink, B. Rockenbach, 'Option pricing by students and professional traders: a behavioral investigation', Managerial and Decision Economics 27(6) 2006, p. 497-510.

Adams and Brownsword 1999

J.N., Adams, R. Brownsword, Understanding Law, 2nd edition, London: Sweet \& Maxwell 1999, p. 285. Akerlof 1970

Akerlof, G., 'The market for "lemons": quality uncertainty and the market mechanism', Quarterly Journal of Economics 84(3), 1970, p. 488-500.

Alchian and Demsetz 1972

A.A. Alchian, H. Demsetz, 'Production, Information Costs, and Economic Organization', The American Economic Review 62(5), 1972, p. 777-795.

Alderfer and Bierman 1970

C.P. Alderfer, H. Bierman, 'Choices with risk: beyond the mean and variance', Journal of Business 43(3), 1970, p. 341.

Anand and Khanna 2002

B.N. Anand, T. Khanna, 'The Structure of Licensing Contracts', Journal of Industrial Economics 48(1), 2002, p. $103-135$.

\section{Anderlini and Felli 2004}

L. Anderlini, L. Felli, 'Bounded rationality and incomplete contracts', Research in Economics 58(1), 2004, p. 3-30.

Anderson and Dekker 2005

S.W. Anderson, H.C. Dekker, 'Management control for market transactions: the relation between transaction characteristics, incomplete contract design and subsequent performance', Management Science 51(12), 2005, p. 1734-1752.

Argyres and Mayer 2007

N. Argyres, K.J. Mayer, 'Contract design as a firm capability: an integration of learning and transaction cost perspectives', Academy of Management Review 32(4), 2007, p. 1060-1077.

Argyres et al. 2007

N. Argyres, J. Bercovitz, K. Mayer, 'Complementarity and evolution of contractual provisions: an empirical study of IT services contracts', Organization Science 18(1) 2007, p. 3-19.

Ariño and Reuer 2004

A. Ariño, R. Reuer, 'Designing and renegotiating strategic alliance contracts', Academy of Management Executive 18(3), 2004, p. 37-48.

Arora 1995

A. Arora, 'Licensing tacit knowledge: intellectual property rights and the market of know-how', Economics of Innovation and Technology 4, 2007, p. 41-59.

Arora and Fosfuri 2002

A. Arora, A. Fosfuri, 'Licensing in the chemical industry' in E. Brousseau, J. Glachant (eds.), The Economics of Contracts: Theories and Applications, Cambridge: Cambridge University Press 2002, p. 373-392.

Arreghetti et al. 1997

A. Arreghetti, R. Bachmann, S. Deakin, 'Contract law, social norms and inter-firm cooperation', Cambridge Journal of Economics 21, 1997, p. 171-195.

Arrow 1971

K. Arrow, 'The Value and Demand for Information', and 'Expositlons of the Theory of Choice under Uncertainty' in C. McGuire, R. Radner (eds.), Decision and Organization: a volume in honour of Jacob Marschak, 1971, p. 268-278, p. 172-208. 
Asser-Hartkamp 4-II

Mr. C. Asser's handleiding tot de beoefening van het Nederlands Burgerlijk Recht, Deel 4.ll, Verbintenissenrecht, Algemene leer der overeenkomsten, bewerkt door A.S. Hartkamp, Deventer: Tjeenk Willink 2005, p. 632

Atiyah 1989

P.S. Atiyah, The Law of Contract, 4th edition, Oxford: Oxford University Press 1989, p. 495

Atiyah 2005

P.S. Atiyah, An introduction into the law of contract, 4th edition, London: Clarendon Press 2005, p. 207 Ayres and Gertner 1989

1. Ayres, R. Gertner, 'Filling Gaps in Incomplete Contracts: An Economic Theory of Default Rules', Yale Law Journal 99(1), 1989, p. 87-130

Ayres and Gertner 1992

1. Ayres, R. Gertner, 'Strategic contractual inefficiency and the optimal choice of legal rules', Yale Law Journal 101, 1992, p. 729-773.

Banks et al. 1994

J. Banks, C. Camerer, D. Porter, 'An experimental analysis of Nash refinements in signaling games', Games and Economic Behavior 6(1), 1994, p. 1-31

Barla 2000

P. Barla, 'Firm size inequality and market power', International Journal of Industrial Organization 18(5) 2000, p. 693-722.

Barnhizer 2005

D.D. Barnhizer, 'Inequality of bargaining power', University of Colorado Law Review 76, 2005, p. 199 223.

Barthélemy and Quélin 2006

J. Barthélemy, B.V. Quélin, "Complexity of Outsourcing Contracts and "Ex Post" Transaction Costs: An

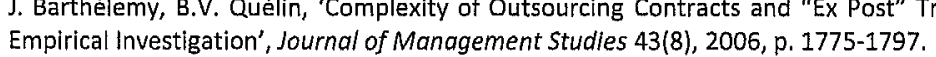
Bascle 2008

G. Bascle, 'Controlling for endogeneity with instrumental variables in strategic management research', Strategic Organization 5(3), 2008, p. 285-327.

Basedow 1998

J. Basedow, 'Un dralt commun des contrats pour le marché commun', Revue Internationale de Droit Compare, 1998, p. $7-28$

Baum et al. 2000

J.A.C. Baum, T. Calabrese, B.S. Silverman, 'Don't go at it alone: Alliance network composition and startups' performance in Canadian biotechnology', Strategic Management Journal 21(3), 2000, p. 267-294.

Beale 2004

H. Beale (ed.), Chitty on Contracts, Volume l: General Principles, 29th edition, London: Sweet \& Maxwell 2004, p. 758.

Beale and Dugdale 1975

H. Beale, T. Dugdale, 'Contracts between businessmen: planning and the use of contractual remedies', British Journal of Law and Society 2, 1975, p. 45-60.

Bedeian and Mossholder 2000

A.G. Bedelan, K.W. Mosshoider, 'On the use of the coefficient of variation as a measure of diversity', Organisational Research Methods 3, 2000, p. 285-297.

Bercowitz et al. 2003

D. Bercowitz, K. Pistor, J.F. Richard, 'The Transplant Effect', The American Journal of Comparative Law 51(1), 2003, p. 163-204.

Van den Bergh 2002

R. van den Bergh, 'Forced harmonization of contract law in Europe: not to be continued' in S. Grundmann, J. Stuyck (eds.), An academic green paper on European contract law, The Hague: Kluwer Law International 2002, p. 249-268.

Bernheim and Whinston 1998

B. Bernheim, W. Whinston, 'Incomplete contracts and strategic ambiguity', The American Economic Review (88)4, 1998, p. 902-932. 
Bernstein 1992

L. Bernstein, 'Opting out of the legal system: extralegal contractual relations in the diamond industry', Journal of Legal Studies 21, 1992, p. 115-157.

Bernstein 2001

L. Bernstein, 'Private commercial law in the cotton industry: creating cooperation through rules, norms, and institutions', Michigan Law Review 99, 2001, p. 1724-1790.

Bessy and Brousseau 1998

C. Bessy, E. Brousseau, 'Technology licensing contracts. Features and diversity', International Revlew of Law and Economics 18,1998 , p. 451-489.

Biard 1990

D. Baird, 'Self-interest and cooperation in long-term contracts', Journal of Legal Studies 19, 1990, p. $583-596$.

Van Bijnen 2005

R. Van Bijnen, Aanvullend Contractenrecht, Den Haag: Boom Juridische Uitgevers 2005, p. 414

Black 1990

C. Black, Black's Law Dictionary, $6^{\text {th }}$ edition, St. Paul: West Publishing Co. 1990, p. 1310.

Bonn 1972

R.L. Bonn, 'Arbitration: An alternative system for handling contract related disputes', Administrative Science Quarterly 17, 1972, p. 254-264.

Borg et al. 1971

G. Borg, O. Bratfish, O.S. Dorinc, 'On the problem of perceived difficulty', Scandinavian Journal of Psy" chology 12(1), 1971, p. 249-260

Bouwes 2005

M. Bouwes, 'Harmonisatie van het burgerlijk recht door de achterdeur, Een Common Frame of Reference', NJB 18, 2005, p. 944-948.

Bresnahan 1989

T.F. Bresnahan, 'Empirical Methods for Industries with Market Power' in: R. Schmalensee, R. WIIlig (eds.), Handbook of Industrial Organization II, Amsterdam: Elsevier Sclence Publishers 1998, p. 10111058.

Brousseau and Fares 2000

E. Brousseau, M. Fares, 'Incomplete Contracts and Governance Structures: Are Incomplete Contract E. Brousseau, M. Fares, Incomplete Contracts and Governance Structures: Are Incomplete Contract Theory and New Institutional Economics Substitutes or Complements? in: C. Ménard (ed.), Institutions, Contracts and Organization: Perspectives from New institutional Economics, Edward Elgar: Cheltenham
2000, p. 399-421. 2000, p. 399-421.

Brousseau and Glachant 2002

E. Brousseau, J-M. Glachant, 'Contract Economics and the renewal of economics', in E. Brousseau, J.-M. Glachant (eds.), The Economics of Contracts: Theories and Applications, Cambridge: Cambridge University Press 2002, p. 3-30.

Brunken et al. 2003

R. Brünken, J.L. Plass, D. Leutner, 'Direct measurement of cognitive load in multimedia learning', Educational Psychologist 38(1), 2003, p. 53-61.

Buchheit

L.C. Buchheit, 'A note on contract paleontology', unpublished note, p. 1-2.

Buchheit 2006

L.C. Buchheit, How to negotiate Eurocurrency loan agreements, 2nd edltion, London: International Financial Law Review 2006, p. 204

Buchheit 2008

L.C. Buchheit, 'Debt crises and transaction complexity', Speech University College London, February 2008

Burchell and Wilkinson 1997

B. Burchelt, F. Wilkinson, 'Trust, business relationships and the contractual environment', Cambridge Journal of Economics 21,1997, p. 217-237.

Burnett and Dunne 1986

J. J. Burnett, P.M. Dunne, 'An appraisal of the use of student subjects in marketing research', Journal of Business Research 4, 1986, p. 329-343. 
Carter and Furmston 1994

J.W. Carter, M.P. Furmston, 'Good faith and fairness in the negotiations of contracts, part 1', Journal of Contract Law 8, 1994, p. 1-15.

Caves et al. 1983

R.E. Caves, H. Crookell, J.P. Killing, 'The imperfect market for technology licenses', Oxford Bulletin of Economics and Statistics 1983, p. 249-267.

Ciccotello and Hornyak 2000

C.S. Ciccotello, M.J. Hornyak, 'Cooperation via contract: an analysis of research and development agreements', Journal of Corporate Finance 6, 2000, p. 1-24.

Chuah 2001

1. Chuah, 'The factual matrix in the construction of commercial contracts-the House of Lord clarifies', international Company and Commercial Law Review 12, 2001, p. 291-294.

Coase 1937

R. Coase, 'The Nature of the Firm', Economica 4(6), 1937 p. 386-405.

Coase 1960

R. Coase, 'The problem of social cost', Journal of Law and Economics 3, 1960, p. 1-44.

R. Coase, 'The institutional structure of production', American Econamic Review 82, 1992, p. 713-719,

Cohen and McKendrick 2005

N. Cohen, E. McKendrick (eds.), Comparative remedies for breach of contract, Oxford: Hart 2005, p. 372

Cohen and Levinthal 1989

W.M. Cohen, D.A. Levinthal, 'Innovation and Learning: The Two Faces of R\&D', Economic Journal, Royal Economic Society 99, 1989, p. 569-596.

Cohen et al. 2000

W.M. Cohen, R.R. Nelson, J.P. Walsh, 'Protecting their Intellectual Assets: Appropriability Conditions and Why U.S Manufacturing Firms Patent (or Not)', Working Paper 2000, p. 1-50.

Collins 1996

H. Collins, 'The length of contracts', Workshop proceedings of the E.U.-JAPAN Legal Dialogue (contracts) Workshop, Kyoto, Japan, November 1996, p. 1-16.

Collins 1999

H. Collins, Regulating contracts, Oxford: Oxford University Press 1999, p. 408

Contractor and Lorange 2002

F.J. Contractor, P. Lorange, Cooperative strategies and alliances, Amsterdam: Pergamon 2002, p. 790

Conway 2005

S. Conway, 'Contract interpretation in the USA: a practical overview', Nederlands Tijdschrift voor Handelsrecht 3, 2005, p. 119-122.

Cooter and Ulen 2003

R. Cooter, T. Ulen, Law \& Economics, Pearson Addison Wesley: Boston 2003, p. 545

Cooter and Ginsburg 2004

R.D. Cooter, T. Ginsburg, 'Leximetrics: why the same laws are longer in some countries than in others', American Law \& Economics Association Annual Meeting 2004, paper 64, p. 1-26.

Corbalan et al. 2006

G. Corbalan, L. Kester, J.J.G. Van Merriënboer, 'Towards a personalized task selection model with shared instructional control', Instructional Science 34(5), 2006, p. 399-422.

Corbin 1944

A. Corbin, 'The parol evidence rule', Yale Law Journal 53, 1944, p. 603-663.

Cotterrell 2006

R. Cotterrell, 'Comparative law and legal culture' in: M. Reimann, R. Zimmermann (eds.), The Oxford Handbook of Comparative Law, Oxford: Oxford University Press 2006, p. 709-737.

Courville and Hausman 1979

L. Courville, W.H. Hausman, 'Warranty scope and reliability under imperfect information and alternative market structures', Journal of Business 53(3), 1979, p. 361-378. 


\section{Cuevas et al. 2002}

M.H. Cuevas, S.M. Fiore, R.L. Oser, 'Scaffolding cognitive and metacognitive processes in low verbal ability learners: use of diagrams in computer-based training environments', Instructional Science 30(6), 2002 , p. 433-464.

Cunningham et al. 1974

W.H. Cunningham, W.T. Anderson, J.H. Murphy, 'Are students real people?', Journal of Business 47(3) 1974, p. 399 .

Craswell 2000

R. Craswell, 'Contract law; general theories' in B. Bouckaert, G. De Geest, G. (eds.), Encyclopaedia of law and economics, IV: general contract law, Cheltenham: Edward Elgar 2000, p. 1-24.

Davis 2006

$K$. Davis, 'The demand for immutable contracts: another look at the law and economics of contract modifications', New York University Law Review 81(2), 2006, p. 487-549.

Dess and Beard 1984

G. Dess, G., D. Beard, 'Dimensions of organizational task environments', Administrative Science Quarterly 29(1), 1984, p. 52-73.

DiMasi et al. 1991

J.A. DiMasi, R.W. Hansen, H.G. Grabowski, L. Lasagna, 'Cost of Innovation in the Pharmaceutical Industry', Journal of Health Economics 10, 1991, p. 107-142.

DiMasi et al. 2003

J. DiMasi, R. Hansen, H. Grabowskl, 'The Price of Innovation: New Estimates of Drug Development Costs', Journal of Health Economics 22, 2003, p. 151-185.

Djankov et al. 2003

S. Djankov, R. La Porta, F. Lopez-de-Silanes, A. Schlelfer, 'Courts', Quarterly Journal of Economics 118, 2003, p. 453-517.

DeJong et al. 1988

D.V. DeJong, R. Forsythe, W.C. Uecker, 'A note on the use of businessmen as subjects in sealed offer market', Journal of Economics, Behavior and Organisation 9(1), 1988, p. 87-100.

Doudko 2001

A.G. Doudko, 'Conference Report, Force Majeure and hardship-Paris (France)', March 8th, 2001, International Chamber of Commerce (ICC).

Drion 2002

C.E. Drion, 'Contracten maken: Amerikaanse standaardcontracten in Europa: het proces van "lokalisatie"', Contracteren 2, 2002, p. 30-35,

Dyer 1997

J.H. Dyer, 'Effective Interfirm Collaboration: How Firms Minimize Transactlon Costs and maximize transaction value', Strategic Management Journal 18(7), 1997, p. 535-556.

\section{Eggleston et al. 2000}

K. Eggleston, E. Posner, R. Zeckhauser, 'The design and Interpretation of contracts: why complexity matters', Northwestern University Law Review 95(1), 2000, p. 91-132.

Eijsbouts 2002

A.J. Eijsbouts, 'De betrekkelijke waarde der overeenkomst', Contracteren 3, 2002, p. 50-5

Eisenberg 1995

M.A. Elsenberg, 'The Limits of Cognition and the Limits of Contract', Stanford Law Review 47(2), 1995, p. 211-259.

Eisenberg 2000a

M.A. Eisenberg, 'Relational contract theory: unanswered questions a symposium in honor of lan. $R$. Macnell: Why there is no law of relational contracts', Northwestern University Low Review 94, 2000, $\mathrm{p}$ Macneil: M.A. Eisenberg, 'The emergence of dynamic contract law', California Law Review 88(6), 2000, p. 1743 1814

Eisenberg 2001

M.A. Eisenberg, 'The emergence of dynamic contract law', Theoretical Inquiries in Law 2(1), 2001, p. 1743-1814 
Elfenbein and Lerner 2003

D.W. Elfenbein, J. Lerner, 'Ownership and control rights in Internet portal alliances 1995-1999', RAND Journal of Economics 32, 2003, p. 356-369.

Grosheide 199

F.W. Grosheide, "Evenwicht in internationale commerciele contractsverhoudingen. Opmerkingen geinspireerd door de regeling van hardship in de PICC' in F.W. Grosheide, K. Boele-Woelki (eds.), Europees Privaatrecht 1996, p. 45-97.

Grosheide 2000

F.W. Grosheide, 'Lees maar, er staat wat er staat', Contracteren 4, 2000, p. 100-107.

Faems et al. 2008

D. Faems, M. Janssens, A. Madhok, B. Van Looy, 'Towards an integrative perspective on alliance governance: Connecting contract design, trust dynamics and contract application', Academy of Management Journal 51, 2008, p. 1053-1078.

Farnsworth 1969

E.A. Farnsworth, 'Unification of Sales law at the regional and international level: why they behave like Americans' in J.S. Ziegel, W.F. Foster (eds.), Aspects of Comparative Commercial Low: sales, Consumer Credit, and Secured Transactions, 1969, p. 110-123.

Farnsworth 1996

E.A. Farnsworth, 'A Common Lawyer's view of his civilian colleagues', Louisiana Law Review 57, 1996, p 227-238.

Farnsworth 1999

E.A. Farnsworth, Contracts, 3rd edition, New York: Aspen Law \& Business 1999, p. 2,192.

Feinman 1990

J.M. Feinman, 'The significance of contract theory', University of Cincinnati Law Review 58, 1990, $\mathrm{p}$ $1283-1318$.

Feinman 2000 J.M. Feinman, 'Relational Contract Theory in Context', Northwestern University Law Review 94, 2000, p.

Ferrarese 1997

M.R. Ferrarese, 'An entrepreneurial conception of the law? The American model through Italian eyes' in: D. Nelken (ed.), Comparing legal cultures, Aldershot: Dartmouth Publishing Company Limited 1997 p. 157-181.

Fischhoff 1982

B. Fischhoff, 'For Those Condemned to Study the Past: Heuristics and Biases in Hindsight', in D. Kahneman, P. Slovic, A. Tversky (eds.) Judgement under uncertainty: Heuristics and Biases, Cambridge: Cambridge University Press 1982, p. 332-351.

Fontaine and De Ly 2006

M. Fontaine, F. de Ly, Drafting International Contracts: an Analysis of Contract Clauses, Ardsley, New York: Transnational 2006, p. 653 .

Freeman and Soete 1997

C. Freeman, L. Soete, The Economics of Industrial Innovation, Cambridge, Massachusetts: The MIT Press 1997, p. 450.

Friedman 1973

L.M. Friedman, A history of American law, New York: Simon \& Schuster 1973, p. 655.

Foss et al. 2000

J.N. Foss, H. Lando, S. Thomsen, 'The theory of the firm' in B. Bouckaert, G. de Geest (eds.), Encyclopedia of law and economics, Volume III, The regulation of contracts, Great Britain: MPG Books Itd. 2000, p. 631-658.

Fox 1992

W.F. Fox (Jr.), International commercial agreements: A primer on drafting, negatiating and resolving disputes, The Hague: Kluwer Law International 1992, p. 394.

Fukuyama 1995

F. Fukuyama, 'Social capital and the global economy', Foreign Affairs 74(5), 1995, p. 89-103.

Fuller and Eisenberg 2006

L.L. Fuller, M.E. Eisenberg, Basic Contract Law, 8th edition, St. Paul: Thomson/West 2006, p. 1102. 


\section{Furlotti 2007}

M. Furlotti, 'There is more to contracts than incompleteness: a review and assessment of empirical research on inter-firm contract design', Journal of Management and Governance 11, 2007, p. 63-99.

Furmston 2003

M. Furmston, Powell-Smith and Furmston's Building Contract Casebook, Blackwell Publishing 2003, p. 576.

Gillian et al. 2007

S.L. Gillian, J.C. Hartzell, R. Parrino, 'Explicit vs. Implicit contracts: evidence from CEO employment agreements', working paper 2007, p. 1-38,

Gilmore 1999

G. Gilmore, The death of contract, 1st edition, Ohio: Ohio State University Press 1974, p. 182

Goetz and Scott 1985

C. Goetz, R. Scott, 'The limits of the expanded chaice: an analysis of the interaction between express and implied contract terms', Callfornia Law Review 73, 1985, p. 261-322.

an Gog and Paas 2008

T. Van Gog, F.G.W.C. Paas, 'Instructional efficiency: revisiting the original construct in educational research', Educational Psychologist 43(1), 2008, p. 16-26.

Gomes-Casseres et al. 2006

B. Gomes-Casseres, J. Hagedoorn, A.B. Jaffe, 'Do alliances promote knowledge flows', Journal of Financial Economics 80, 2006, p. 5-33,

Gopher and Braune 1984

D. Gopher, R. Braune, 'On the psychophysics of workload: why bother with subjective measures?', Human Factors 26(5), 1984, p. 519-532.

Gordley 1991

J. Gordley, The philosophical origins of modern contract doctrine, Oxford: Clarendon Press 1991, p. 263. Greif 1993

A. Greif, 'Contract Enforceability and Economic Institutions in Early Trade: The Maghribl Traders' Coalltion', American Economic Review 83(3), 1993, p. 525-548.

Greif 1989

A. Greif, 'Reputation and Coalitions in Medleval Trade: Evidence on the Maghrlbi Traders', Journal of Economic History 49(4), 1989, p. 857-882.

Greif et al. 1994

A. Greif, P. Milgrom, P.R. Weingast, 'Coordination, commitment and enforcement: the case of the merchant guild', Journal of Political Economy 102(4), 1994, p. 745-776.

Grossman and Hart 1983

S.J. Grossman, O.D. Hart, 'Implicit Contracts under Asymmetric Information', The Quarterly Journal of Econamics $98(3), 1983$, p. 123-56.

Grossman and Hart 1986

S. Grossman, O. Hart, 'The Costs and Benefits of Ownership: A Theory of Vertical and Lateral Integratlon', Journal of Political Economy (94)4, 1986, p. 691-71.9.

Gulati 1995

R. Gulati, 'Does Familiarity Breed Trust? The Implications of Repeated Ties on Contractual Choice in Alliances', Academy of Management Journal 38(1), 1995, p. 85-1.12.

Gulati 1998

R. Gulati, 'Alliances and networks', Strategic Management Journal, 19(4), 1998, p. 293-318.

Gulati 1999

R. Gulati, 'Network Location and Learning: The Influence of Network Resources and Firm Capabilities on Alliance Formation', Strategic Management Journal 20(5), 1999, p. 397-420. Hadfield 1994

G. Hadfield, 'Judicial competence and the interpretation of incomplete contracts', Journal of Legal Studies 23,1994, p. $159-184$.

Hagedoorn 1990

J. Hagedoorn, 'Organisational modes of inter-firm cooperation and technology transfer', Technovation $10(1), 1990$, p. 17-31. 
Hagedoorn 1996

. Hagedoorn, 'Trends and patterns in strategic technology partnering since the early seventies', Review of Industrial Organization 11, 1996, p. 601-616.

Hagedoorn 2002

J. Hagedoorn, 'Inter-firm R\&D partnerships: an overview of major trends and patterns since 1960', Research Policy, 31, 2002, p. 477-492.

Hagedoorn 2003

J. Hagedoorn, 'Sharing intellectual property rights - an exploratory study of joint patenting amongst companies', Industrial and Corporate Change 12(5), 2003, p. 1035-1050. Hagedoorn et al. 2005

J. Hagedoorn, D. Cloodt, H. Van Kranenburg, Intellectual property rights and the governance of international R\&D partnerships', Journal of International Business Studies 36, 2005, p. 175-186.

Hagedoorn and Duysters 2002

J. Hagedoorn, G. Duysters, 'Learning in dynamic inter-firm networks - the efficacy of multiple contacts', Organization Studies 23,2002 , p. 525-548

Hagedoorn and Kranenburg 2003

1. Hagedoorn, H. Kranenburg, 'Growth patterns in R\&D partnerships: an exploratory statistical study', International Journal of Industrial Organization 21(4), 2003, p. 517-531.

Hansen 2001

Z.K. Hansen, 'Effect of technological progress on contractual agreements: empirical analysis of pharmaceutical and biotechnology collaborations', working paper, 2001, p. 1-34.

Hansen and Higgins 2007

Z. Hansen, M. Higgins, 'The effect of contractual complexity on technology sourcing agreements', working paper, 2007, p. 1-45

Harrison 2004

D. Harrison, 'Is a long-term business relationship an implied contract? Two views of relationship disengagement', Journal of Management Studies 41, 2004, p. 107-125.

Hart 1988

. Hart, 'Incomplete contracts and the theory of the firm', Journal of Law, Economics \& Organization $4(1), 1988$, p. 119-140.

Hart 1995

O. Hart, Firms, Contracts and Financial Structure (Clarendon Lectures in Economics), Oxford: Clarendon Press 1995, p. 240.

Hart and Grossman 1986

O. Hart, S.J. Grossman, 'The Costs and Benefits of Ownership: A Theory of Vertical and Lateral Integration', The Journal of Political Economy 94(4), 1986, p. 691-719.

Hart and Moore 1990

O. Hart, J. Moore, 'Property rights and the nature of the firm', Journal of Political Economy $98(6), 1990$ p. 1119-1158.

Hart and Moore 1998

O. Hart, J. Moore, 'Incomplete contracts and renegotiation', Econometrica 56(4), 1998, p. 755-785.

Hart and Moore 1999

O. Hart. J. Moore, 'Foundations of incomplete contracts', Review of Economic Studies $66(1), 1999$, p. 115-138.

Hart and Staveland 1988

S.G. Hart, L.E. Staveland, 'Development of NASA-TLX (Task Load Index): Results of empirical and theoretical research', in P.A. Hancock, N. Meshkati (eds.), Human Mental Workload, Amsterdam: Elsevier 1988, p. 139-183,

Hartkamp and Tillema 2005

A. Hartkamp, M. Tillema, Contract law in the Netherlands, Deventer: Kiuwer 2005, p. 50.

Hausler 2007

C. Hausler, 'Can't buy me rights! The contractual structure of asymmetrical inter-firm collaborations', working paper 2007, p. 1-28. 


\section{Van Hecke 1962}

G. van Hecke, 'A civilian Looks at the common-law lawyer' in W. Reese (ed.), International contract: choice of law and language 5(10), Parker School of Foreign and Comparative Law, Columbia University, 1962, p. 5-11

ermalin et al. 2007

B.E. Hermalin, A.W. Katz, R. Craswell, 'The law and economics of contracts' in A.M. Polinsky and S. Shavell (eds.), Handbook of Law and Economics, Amsterdam: Elsevier 2007, p

Hesen and Hardy 2007

G.G. Hesen, R.R. Hardy, "Is the system of contract remedies in the Netherlands efficient from a law and economics perspective?' in J. Smits, G. Hesen, D. Haas (eds.), Specific performance: national and other perspectives, Antwerp: Intersentia 2008, p. 287-326.

Hesselink 1998

M. Hesselink 'Good faith' in A. Hartkamp, M. Hesselink, E. Hondius, A. Joustra, E. Du Perron (eds.), Towards a European Civil Code, Nijmegen: Ars Aequi Libri 1998, p. 287-310.

Hill 2001

C.A. Hill, 'A comment on language and norms in complex business contracting', Chicago-Kent Law Review 77(1), 2001 , 29-57.

Hill 2008

C.A. Hill, 'Commentary: the trajectory of complex business contracting in Latin America', Chicago-Kent Law Review 83(1), 2008, p. 179-183.

Hill and King 2004

C. Hill, C. King, 'How do German contracts do as much with fewer words?', Chicago-Kent Law Review 79, 2004, p. 889-926.

Hofstede 1980

G. Hofstede, Culture's consequences: international differences in work reloted values, Beverly Hills: Sage Publications 1980, p. 328 .

Hofstede 1997

G. Hofstede, Cultures and Organizations: software of the mind, 2nd revised edition, New York: McGraw Hill 1997, p. 300.

Hofstede and Oostwouder 2006

R. Hofstede, W. Oostwouder, 'To cultivate command of language. Over het gebruik en de uitleg van Engelstalige termen in Nederlandse (overname-)contracten' in Contracteren Internationaal (opstellen aangeboden aan prof. mr. F. Willem Grosheide), Den Haag: Boom 2006, p. 19-33.

Holmes 1897

O.W. Holmes, 'The path of the law', Harvard Law Review 10, 1897, p. 457-464.

Hondius 1986

E. Hondius, 'De "entire agreement" clausule: Amerikaanse contractsbedingen in het Nederlandse recht' in $\downarrow$ ten Berge (ed) Recht als norm en aspiratie: opstellen over recht en samenleving ter gelegenheid van het 350-jarig bestaan van de Utrechtse Juridische Faculteit, Nijmegen; Ars Aequi 1986, p. 24-34.

Horwitz 1977

M.J. Horwitz, The transformation of American law 1780-1860, Cambridge, Massachusetts: Harvard University Press 1977, p. 1-356

Hughes and Gibson 1991

C.T. Hughes, M.L. Gibson, 'Students are surrogates for managers in a decision-making environment: an experimental study', Journal of Management information Systems 8(2), 1991, p. 153-166.

Johnson and Creech 1983

D.R. Johnson, J.C. Creech, 'Ordinal measures in multiple indicator models: A simulation study of categorization error', American Sociological Review 48, 1983, p. 398-40.

Jolowicz 2003

J. Jolowlcz, 'Adversarial and inquisitorial models of civil procedure', International and Comparative Law Quarterly 52, 2003, p. 281-295.

Joskow 1988

P. Joskow, 'Asset specificity and the structure of vertical relationships: empirical test of transaction cost analysis', Journal of Law, Economics and Organization 4, 1988, p. 121-139. 
Kades 1997

E. Kades, 'The laws of complexity and the complexity of laws: the implications of computational complexity theory for the law', Rutgers Law Review 43, 1997, p. 403-476.

Kahan and Klausner 199

M. Kahan, M. Klausner, 'Path dependence in corporate contracting: increasing returns, herd behavior and cognitive biases', Washington University Law Quarterly 74, 1996, p. 347-366.

Kahan and Klausner 1997

M. Kahan, M. Klausner, 'Standardization and innovation in corporate contracting (or "the economics of boilerplate"), Virginia Law Review 83(4), 1997, p. 713-770.

Kalnins and Mayer 2004

A. Kalnins, K.J. Mayer, 'Relationships in hybrid contracts: an analysis of contract choice in information technology', Journal of Law, Economics, \& Organization 20, 2004, p. 207-229.

Kalyuga et al. 1998 Kalyuga et al. 1998
S. Kalyuga, P. Ayres, P. Chandler, J. Sweller, 'Levels of expertise and instructional design', Human Factors
40, 1998, p. 1-17. Kalyuga et al. 1999

S. Kalyuga, P. Chandler, J. Sweller, 'Managing split-attention and redundancy in multimedia instruction', Applied Cognitive Psychology 13(4), 1999, p. 351-371.

Kalyuga et al. 2000

S. Kalyuga, P. Chandler, J. Sweller, 'Incorporating learner experience into the design of multimedia instruction', Journal of Educational Psychology 92(1), 2000, p. 126-136.

Kalyuga et al. 2001

S. Kalyuga, P. Chandler, J. Sweller, 'Learner experience and efficiency of instructional guidance', Educational Psychology 21(1), 2001, p. 5-23.

Kalyuga et al. 2004

S. Kalyuga, P. Chandler, J. Sweller, 'When redundant on-screen text in multimedia technical Instruction can interfere with learning', Human Factors 46(3), 2004, p. 567-581.

Kaplan and Stromberg 2003

S.N. Kaplan, P. Stromberg, 'Financial contracting theory meets the real world: an empirical analysls of venture capital contracts', Review of Economic Studies 70, 2003, p. 281-315

Katz 2004

A. Katz, 'The Economics of form and substance in contract interpretation', Columbia Law Review 104, 2004 , p. 496-538.

Khera and Benson 1970

I.P. Khera, J.D. Benson, 'Are students really poor substitutes for businessmen in behavioral research?', Journal of Marketing Research 7, 1970, p. 529-532.

Killing 1988

J.P. Killing, 'Understanding Alliances: the role of task and organizational complexity' in F.L. Contractor, P. Lorange, P. (eds.), Cooperative Strategies in International Business, USA: Lexington Books 1988, p. 55 67.

King and Segain 2007

C. King, H. Segain, 'Cross Border Negotiated Deals: Why Culture Matters?', European Company and Financial Review 1, 2007, p. 126-166.

King et al, 1992

R.R. King, V.L. Smith, M. van Boening, 'The robustness of bubbles and crashes in experimental stock markets' in I. Prigogine, R.H. Day, P. Chen (eds.), Evolutionary Dynamics and Nonlinear Economics, A transdisciplinary Dialogue, 1992, p. 183-200.

Klein 1988

B. Klein, 'Vertical Integration as Organizational Ownership: The Fisher Body-General Motors Relationship Revisited', Journal of Law, Economics and Organization 4, 1988, p. 199-213.

Klein 1996

B. Klein, 'Why hold-ups occur: the self-enforcing range of contractual relationships', Economic Inquiry 34,1996, p. 444-463.

Klein et al. 1978

B. Klein, R. Crawford, A. Alchian, 'Vertical integration, appropriable rents, and the competitive contracting process', Journal of Law \& Economics 21(2), 1978, p. 297-326. 
De Kluiver 2001

H.J. de Kluiver, 'De ondernemingsrechtelijke contractspraktijk: onderhandelen in de schaduw van de wet', Contracteren 1, 2001, p. 4-14.

Kornet 2006

N. Kornet, Contract interpretation and gap filling: comparative and theoretical perspectives, Antwerpen Intersentia 2006, p. 485.

Korobkin 1998

R. Korobkin, 'The status quo bias and contract default rules', Cornell Law Review 83, 1998, p. 608-687.

Korobkin 2002

R. Korobkin, 'Empirical scholarship in contract law: possibilities and pitfalls', University of Illinois Law Review 4, 2002, p. 1033-1066.

Korobkin and Guthrie 1994

R. Korobkin, C. Guthrie, 'Psychological barriers to litigation settlement: an experimental approach', Michigan Law Review 93(107), 1994, p. 107-192.

Korobkin and Ulen 2000

R. Korobkin, S. Ulen., 'Law and behavioral sclence: removing the rationality assumption from law and economics', California Law Review 88(4), 2000, p. 1051-1144.

Kötz 2003

H. Kötz, 'Clivil justice systems in Europe and the United States', Duke Journal of Comparative and Inter national Law 13, 2003, p. 61-77.

Kötz 1998

H. Kötz, 'Towards a European Civil Code: the duty of good faith' in: P. Cane, J. Stapleton (eds.), The Law of obligations (Essays in celebration of John Fleming), Oxford: Clarendon Press 1998, p. 243-259.

tafontaine 1992

F. Lafontaine, 'Agency Theory and Franchising: Some empirical results', Rand Journal of Economics 23 1992, p. 81-103

Langbein 1987

J. Langbein, 'Comparative civil procedure and the style of complex contracts', American Journal of Comparative Law 35, 1987, p. 381-394.

Lerner and Malmendier 2005

J. Lerner, U. Malmendier, 'Contractibility and design of research agreements', NBER working pape 11292,2005, p. 1.59

Lerner and Merges 1998

J. Lerner, R.P. Merges, 'The control of technology alliances: an empirical analysis of the biotechnology industry', Journal of Industrial Economics 46, 1998, p. 125-156.

Levitt 1965

T.A. Levitt, Industrial purchasing behavior: a study of communication effects, Cambridge, Massachusetts: Harvardy University Press 1965, p. 184

Lorenz 1999

E. Lorenz, 'Trust, contract and econamic cooperation', Cambridge Journal of Economics 23, 1.999, p. 301-305.

Lumineau and Oxley 2007

F. Lumineau, J. Oxley, 'The determinants of dispute resolution mode in inter-firm contracts, working paper, 2007, p. 1-45.

Lundmark 2001

T. Lundmark, 'Verbose contracts', American Journal of Comparative Law 129, 2001, p. 121-145.

De Ly 2006

F.J.M. De Ly, 'Non-compete clauses in international contracts/Les clauses de non-concurrence dans les contrats internationaux', Revue de Droit des Affaires Internationales (Paris) 54, 2006, p. 441-494.

Lyles 1988

M.A. Lyles, 'Learning among joint venture sophisticated firms', Management International Review 28(4), 1988, p. $85-98$.

Lyons 1996

B.R. Lyons, 'Empirlcal relevance of efficient contract theory: inter-firm contracts', Oxford Review of Economic Policy 12, 1996, p. 27-52. 
Macaulay 1963

S. Macaulay, 'Non-contractual relations in business: a preliminary study', American Sociological Review 28,1963, p. $55-67$

Macleod 2000

B. Macleod, 'Complexity and contract' in E. Brousseau \& J-M. Glachant (eds.), The economics of contracts - theories and applications 2000, p. 213-240.

Macneil 1978

I.R. Macneil, 'Contracts: adjustment of long-term economic relations under classical, neoclassical, and relational contract law', Northwestern University Law Review, 72(6), 1978, p. 854-905,

Macneil 2000

I.R. Macneil, 'Relational contract theory: unanswered questions a symposium in honor of lan R. Macneil: relational contract theory: challenges and queries', Northwestern University Law Review 94, 2000, p. $877-908$.

Maddala 2006

G.S. Maddala, Introduction to econometrics, $4^{\text {th }}$ edition, New York: Wiley 2006, p. 672

Marcus et al. 1996

N. Marcus, M. Cooper, J. Sweller, 'Understanding instructions', Journal of Educational Psychology, 1996, p. 49-63.

Marotta-Wurgler 2007

F. Marotta-Wurgler, 'What's in a Standard Form Contract? An Empirical Analysis of Software License Agreements', Journal of Empirical Legal Studies 4(4), 2007, p. 677-713.

Marotta-Wurgler 2009

F. Marotta-Wurgler, 'Are "Pay Now, Terms Later" Contracts Worse for Buyers? Evidence from Software License Agreements', The Journal of Legal Studies 38, 2009, p. 38-50.

Maskin 2002

E. Maskin, 'Incomplete contracts: on indescribable contingencies and incomplete contracts', European Economic Review 46, 2002, p. 725-733.

Maskin and Tirole 1999

E. Maskin, J. Tirole, 'Unforeseen Contingencies and incomplete contracts', Review of Economic Studies $66,1999, p, 83-114$

Mason 2006

C.M. Mason, 'Exploring the processes underlying within-group homogeneity', Smal/ Group Research 37 2006, p. 233-271.

Masten 1996

S.E. Masten, 'Contractual choice', in B. Bouckaert, G. de Geest (eds.), Encyclopedia of Law and Economics, Volume III, The Regulation of Contracts, Massachusetts: Edgar Elgar, 1996, p. 25-45.

Masten and Saussler 2002

S.E. Masten, S. Saussier, 'Econometrics of Contracts: An Assessment of Developments in the Empirical S.E. Masten, S. Saussier, 'Econometrics of Contracts; An Assessment of Developments in the Empirica
Literature of Contracting' in E. Brousseau, J-M. Glachant (eds.), Economics of Contracts: Theories and Literature of Contracting' in E. Brousseau, J-M. Glachant (eds.), Economications, Cambridge: Cambridge University Press 2002, p. 273-292

Applications, Cambridge:
Mayer and Argyres 2004

K. Mayer, N. Argyres, 'Learning to contract: evidence from the personal computer industry', Organization Science 15(4), 2004, p. 394-410.

Mayer and Teece 2008

K.J. Mayer, D.J. Teece, 'Unpacking strateglc alliances: The structure and purpose of alliance versus suppller relationships', Journal of Economic behavior and organization 66, 2008, p. 106-127.

McKendrick 2003

E. McKendrick, Contract Law. Text, cases and materials, Oxford: Oxford University Press 2003, p. 420

Von Mehren 2000

A.T. von Mehren, 'The U.S. Legal system: between the Common Law and Civil Law Legal Traditions', dis-

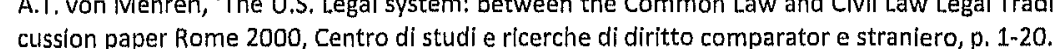

Von Mehren and Gordley 1977

A.T. von Mehren and J. Gordley, The Civil law system, 2nd edition, Boston: Little, Brown 1977, p. 1243.

T. Mellewigt, A. Madhok, A.A. Weibel, 'Trust and formal contracts in interorganizational relationshipssubstitutes and complements', Management and Decision Economics, 2007, p. 833-847. 
Merryman 1985

J.H. Merryman, The civil law tradition. An introduction to the legal systems of Western Europe and Latin America, 2nd edition, Stanford: Stanford University Press 1985, p. 184.

Milgrom et al. 1990

P.R. Milgrom, D.C. North, B.R. Weingast, 'The Role of Institutions in the Revival of Trade: The Law Mer* chant, Private Judges, and the Champagne Fairs', Economics \& Polltics 2, 1990, p. 1-23.

Milgrom and Roberts 1992

P. Milgrom, J. Roberts, Economics, Organization and Management, New Jersey: Prentice Hall 1992, p. 621.

Moreno 2004

R. Moreno, 'Decreasing cognitive load for novice students: effects of explanatory versus corrective feedback in discovery-based multimedia', Instructional Science 99, 2004, p. 99-113.

Narula 2001

R. Narula, 'Choosing between modes of non-internal technological activities by firms: some technological and economic factors', Technology Analysis and Strategic Management 13, 2001, p. 365-388.

Narula and Hagedoorn 1998

R. Narula, J. Hagedoorn, "Innovating through strategic alliances: moving towards international partnerships and contractual agreements', MERIT Research Memoranda 1998-030-284, p. 1-50

Nassar 1995

N. Nassar, Sanctity of Contracts Revisited: A Study in the Theory and Practice of Long-Term International Commercial Transactions, Dordrecht: Kluwer Academic Publishers 1995, p. 336

Nicholls of Birkenhead 2005

Lord Nicholls of Birkenhead, 'My kingdom for a horse: the meaning of words', Law Quarterly Review 121,2005 , p. 577-591.

B. Nooteboom, J. Berger, N.G. Noorderhaven, 'Effects of trust and governance on relational risk', Academy of Management Journal 40(2), 1997, p. 308-338.

Overdahl 1991

A.J. Overdahl, 'A researcher's guide to the contracts of firms filing with the SEC', Journal of Low and Economics 34, 1991, p. 695-701.

Paas 1992

F.G.W.C. Paas, 'Training strategies for attaining transfer of problem-solving skill in statistics: a cognitiveload approach', Journal of Educational Psychology 1992, p. 429-432.

Paas and Van Merriënboer 1994a

F.G.W.C. Paas, J.J.G. van Merriënboer, 'Instructional control of cognitive load in the training of complex cognitive tasks', Educational Psychology Review 6, 1994, p. 351-371.

Paas and Van Merriënboer 1994b

F.G.W.C. Paas, J.J.G. van Merriënboer, 'Variability of worked examples and transfer of geometrical problem-solving skills: a cognitive-load approach', Journal of Educational Psychology 86, 1994.

Paas et al. 1993

F.G.W.C. Paas, J.J.G. Van Merriënboer, 'Short note: the efficiency of instructional conditions: an approach to combine mental effort and performance measures', Human Factors 1993, p. 737-743.

Paas et al. 1994

F.G.W.C. Paas, J.J.G. Van Merriënboer, J.G.J.J. Adam, 'Measurement of cognitive load instructional research', Perceptual and Motor Skills 79, 1994, p. 419-430.

Paas et al. 2003a

F.G.W.C. Paas, J.E. Tuovinen, H. Tabbers, P.W.M. Van Gerven, 'Cognitive load measurement as a mean to advance cognitive load theory', Educational Psychology 38, 2003, p. 63-71.

Paas et al. 2003b

F.G.W.C. Paas, A. Renkl, J. Sweller, 'Cognitive load theory and instructional design: recent developments', Educational Psychology 38(1), 2003, p. 1-4.

Park and Lessig 1977

W.C. Park, P.V. Lessig, 'Students and housewives: differences in susceptibility to reference group influence', Journal of Consumer Research 2, 1977, p. 102-110. 
Parkhe 1993

A. Parkhe, 'Strategic alliance structuring: a game theoretic and transaction cost examination of interfirm cooperation', Academy of management Journal 36(4), 1993, p. 794-829.

Peden 1998

E. Peden, A rationalization of implied terms in contract law, Ph.D. thesis; University of Cambridge 1998.

Perillo 1998

J.M. Perillo, 'Force majeure and hardship under the UNIDROIT Principles of International Commercial Contracts', Universidad Autonoma de Mexico 1998, p. 1-10.

Pollock et al. 2002

E. Pollock, P. Chandler, J. Sweller, 'Assimilating complex information', Learning and Instruction 12, 2002, p. 61-86.

Poppo and Zenger 2002

L. Poppo, T. Zenger ' $D$ o formal contracts and relational governance function as substitutes or complements?', Strategic Management Journal 23, 2002, p. 707-725.

Posner 1986

R. Posner, Economic analysis of law, Boston, Massachusetts: Little, Brown \& Company 1986, p. 787

Posner 2000

E. Posner, 'A theory of contract law under conditions of radical judicial error', Northwestern University Law Review 94, 2000, p. 749-774.

Posner 2003

E. Posner, 'Economic analysis of contract law after three decades: success or failure?', Yale Law Journal 112,2003, p. $829-880$.

Powell et al. 1996

W. Powell, K. Koput, K., L. Smith-Doerr, "Interorganizational collaboration and the locus of innovation: Networks of learning in biotechnology', Administrative Science Quarterly 41, 1996, p. 116-145.

Przerackl 1989

D. Przeracki, '"Working it out": a Japanese alternative to fighting it out', Cleveland State Law Review 37, 1989, p. $149-178$

Rachlinski 2000

J. Rachlinski, 'Heuristics and biases in the courts: Ignorance or adaptation?', Oregon Law Review 79 , 2000, p. 61-102.

Rasmusen 2001

E.B. Rasmusen, 'Explaining incomplete contracts as the result of contract-reading cost', Advances in Economic Analysis and Policy 1, 2001, p. 1000-1010.

Reide and Nygren 1988

G.B. Reid, T.E. Nygren, 'The subjective workload assessment technique: a scaling procedure for measuring mental workload' in P.A. Hancock, N. Meshkati (eds.), Human Mental Workload 1988, p. 185-218.

Reuer and Ariño 2002

J.J. Reuer, A. Ariño, 'Contractual renegotiations in strategic alliances', Journal of Management 28, 2002, p. 51-74.

Reuer and Ariño 2007

J.J. Reuer, A. Ariño, 'Strategic alliance contracts: dimensions and determinants of contractual complexity', Strategic Management Journal 28, 2007, p. 313-330.

Reuer et al. 2002

J.J. Reuer, M. Zollo, H. Singh, 'Post-formation dynamics in strategic alliances', Strategic Management Journal 23(2), 2002, p. 135-151.

Reuer et al. 2006

J. J. Reuer, A. Ariño, T. Mellewigt, 'Entrepreneurial alliances as contractual forms', Journal of Business Venturing 21,2006, p. 306-325.

Richman 2004

B.D. Richman, 'Firms, courts, and reputation mechanisms: towards a positive theory of private ordering', Columbia Law Review 104, 2004, p. 2328-2368.

Ring 2002

P.S. Ring, 'The role of contract in strategic alliances' in F.J. Contractor, P. Lorange (eds.), Cooperative strategies and alliances, Amsterdam: Pergamon 2002, p. 145- 162. 
Ring 1997

P.S. Ring, 'Transacting In the State of Union: A Case Study of Exchange Governed by Convergent Interests', Journal of Management Studies 34(1), 1997, p. 1-25.

Ring and Van de Ven 1992

P.S. Ring, A. Van de Ven, 'Structuring cooperative relationships between organizations, Strategic Management Journal 13, 1992, p. 483-498.

Robinson 2002

D. Robinson, 'Strategic alliances and the boundaries of the firm', Review of Financial Studies 21(2), 2002, p. 649-681.

Robinson and Stuart 2007

D. Robinson, T.E. Stuart, 'Financial Contracting in Blotech Strategic Alliances', Journal of Law and Economics 50(3), 2007, p. 559-596.

Root 1988

F.R. Root, 'Some taxonomies of international cooperative agreements' in F.L. Contractor, P. Lorange (eds.), Cooperative strategies in international business, New York, New York: Lexington Books 1988, p. 69-80.

Rothaermel and Deeds 2004

F.T. Rothaermel, D.D. Deeds, 'Exploration and exploitation alliances: a system of new product develop. ment', Strategic Management Journal 24, 2004, p. 201-221.

ment', Strategle
Rousseau et al. 1998

D.M. Rousseau, S.B. Sitkin, R.S. Burt, C. Camerer, 'Not so different after all: a cross-discipline view of trust', Academy of Management Review 23(3), 1998, p. 393-404.

Ryall and Sampson 2003

M.D. Ryall, R.C. Sampson, 'Do prior alliances influence contract structure? Evidence from technology alliance contracts', working paper, 2003, p. 1-45.

Ryall and Sampson 2006

M.D. Ryall, R.C. Sampson, 'Do prior alliances influence alliance contract structure?' in: A. Ariño, A., J. J. Reuer (eds.), Strategic Alliances, Houndsmills: Palgrave MacMillan 2006, p. 206-216.

Ryall and Sampson 2007

M.D. Ryall, R.C. Sampson 'Formal contracts in the presence of relational enforcement mechanisms: evlM.D. Ryall, R.C. Sampson 'Formal contracts in the presence of relational ent
dence from technology development projects', working paper 2007, p. 1-44.

Sampson 2004

R.C. Sampson, 'The cost of misaligned governance in R\&D alliances', Journal of Law, Economics, \& Organization 20, 2004, p. 484-526

Sampson 2005

R.C. Sampson, 'Experience Effects and Collaborative Returns in R\&D Alliances', Strategic Management Journal 26(11), 2005, p. 1009-1031.

Saxton 1997

T. Saxton, 'The effects of partner and relationship characteristics on alliance outcomes', Academy of Management Journal 40, 1997, p. 443-461.

Schelhaas 2007

H.N. Schelhaas, 'Rechtsvergelijking in de praktijk: de entire agreement clause in het Europese contractenrecht' in D. Busch, H.N. Schelhaas (eds.), Vergelljkenderwils, Deventer: Kluwer 2007, p. 289-303.

Schelhaas 2008

H.N. Schelhaas, 'Pacta sunt servanda bij commerciële contractanten, Over redelijkheid \& billijkheid en objectieve uitleg bij handelscontracten', Nederlands Tijdschrift voor Burgerlijk Recht 4, 2008, p. 150-160. Schuck 1992

P.H. Schuck, 'Legal complexity: some causes, consequences, and cures', Duke Law Journal 42(1), 1992 , p. $1-52$.
.

S.R. Schuit, 'De onstultbare opmars van het Anglo-Amerikaanse recht', Contracteren 2, 2001, p. $42-44$.

Schweitzer 2007

H. Schweitzer, 'Private legal transplants in negotiated deals', European Company and Financial Low Review 1,2007, p. $79-125$. 
Schmalensee and Willig 1989

R. Schmalensee, R. Willig, Handbook of Industrial Organization II, Amsterdam: Elsevier Science Publishers 1989, p. 632 .

Schwartz 1992

A. Schwartz, 'Relational contracts in the courts: an analysis of incomplete agreements and judicial strategies', The Journal of Legal Studies 21(2), 1992, p. 271-318.

Schwartz 1998

A. Schwartz, 'Incomplete contracts' in: P. Newman (ed.), The New Palgrave Dictionary of Economics and the Law, Volume II, Macmillan Reference Limited: London 1998, p. 277-278.

Schwartz and Scott 2003

A. Schwartz, R.E. Scott, 'Contract theory and the limits of contract law', Yale Law Journal 113, 2003, p. 540-596.

Scott 2002

R.E. Scott, 'The rise and fall of Article 2', Louisiana Law Review 62, 2002, p. 1009-1064

Scott 2003

R.E. Scott, 'The theory of self-enforcing indefinite agreements', Columbia Law Review 103(7), 2003, p. $1641-1699$

Scott and Triantis 2006

R. Scott, G. Triantis, 'Anticipating Litigation in Contract Design', Yale Law Journal 115(4), 2006, p. 814 879 .

Segal 1999

1. Segal, 'Complexity and renegotiation: a foundation for incomplete contracts', Review of Economic Studies 66(1), 1999, p. 57-82.

Shane 1994

S. Shane, 'The effect of national culture on the choice between licensing and direct foreign investment' Strategic Management Journal 15(8), 1994, p. 627-642.

Siegel and Harnett 1964

S. Siegel, D.L. Harnett, 'Bargaining behavior: a comparison between mature industrial personnel and college students', Operation Research 12, 1964, p. 334-343.

Silverman and Baum 2002

B.S. Silverman, J.A.C. Baum, 'Alliance-based Competitive Dynamics', Academy of Management Journal $45(4), 2002$, p. 791-817.

Simon 1955

H. Simon, 'A behavioral model of rational choice', Quarterly Journal of Economics 69(1), 1955, p. 99-118. Simon 1981

H. Simon, The sciences of the artificial, Cambridge, Massachusetts: The MIT Press 1981, p. 215

Slapper and Kelly 2006

G. Slapper, D. Kelly, English Law, 2nd edition, New Vork: Routledge-Cavendish 2006, p. 1009

Smith 2006

H.E. Smith, 'Modularity in contracts: bollerplate and information flow', Michigan Law Review 104, 2006 p. $1175-1222$

Smits 1998

J.M. Smits, 'A European Private Law as a Mixed Legal System', Maastricht Journal of European and Comparative Law 5(4), 1998, p. 328-340.

Smits 2000

M. Smits, The Good Samaritan in European private law On the perils of Principles without a programme and a Pragramme for the future, Deventer: Kluwer 2000, p. 50.

Smits 2002a

J.M. Smits, 'De toekomst van het Europees contractenrecht, Het Weekblad voor Privaatrecht, Notariaat en Registratie 6513, 2002, p. 827-833.

\section{Smits 2002b}

J.M. Smits, 'How to predict the differences in uniformity between different areas of a future European private law? An evolutionary approach' in A. Marciano, J.-M. Josselin (eds.), The economics of harmonizing European contract law, Cheltenham/Northhampton, Massachusetts: Elgar 2002, p. 50-70. 
Smits 2003

J.M. Smits, 'De missing link in het debat over unificatie van privaatrecht: het evolutionair perspectief', Nederlands Tijdschrift voor Burgerlijk Recht 20, 2003, p. 241-246.

Sorenson 2002

J.B. Sorenson, 'The use and misuse of the coefficient of variation in organizational demography research', Sociological Methods and Research 30, 2002, p. 475-491. Suchman 2003

M.C. Suchman, 'The Contract as Social Artifact', Law and Society Review 37(1), 2003, p. 91-142.

Stiglitz 1974

J.E. Stiglitz, 'Incentives and Risk Sharing in Sharecropping', The Review of Economic Studies 41(2), 1974 p. $219-255$

Smits 1998

J. Smits, 'Eenheid en verscheidenheid in het contractenrecht', Nederlands Tijdschrift voor Rechtsfilosofie en Rechtstheorie 27, 1998, p. 10-38.

Smits 2002

J.M. Smits, The making of European private law. Toward a lus Commune Europaeum as a mixed legal system, Antwerp, Oxford and New York: Intersentia 2002, p. 306.

Smith 2006

H.E. Smith, 'Modularity in contracts: boilerplate and information flow', Michigan Law Review 94, 2006, p. $175-1223$

Solan 2000

L. Solan, 'The written contract as safe harbor for dishonest conduct', Chicago-Kent Law Review 77, 2000, p. $89-90$

Speidel 2000

R.E. Speidel, 'Relational contract theory: unanswered question a symposium in honour of lan R. Macneil: The characteristics and challenges of relational contracts', Northwestern University Law Re. view 94,2000 , p. 823-846

Steyn 2003

J. Steyn, 'The intractable problem of the interpretation of legal texts', Sydney Law Review 2003, p. 5-19.

Stuart 2000

T.E. Stuart, 'Interorganizational alliances and the performance of firms: a study of growth and innovation rates in a high-technology industry', Strategic Management Journal 21(8), 2000, p. 791-811. Stürner 2001

R. Stürner, 'Transnational civil procedure: discovery and sanctions against non-compliance', Revue de Droit Uniforme/Uniform Law Revlew 4, 2001, p. 871-886

Summer 1982

R.S. Summer, 'The general duty of good faith-its recognition and conceptualization', Cornell Law Review 67,1982, p. $810-840$

Teece 1992

D.J. Teece, 'Competition, cooperation, and innovation; organizational arrangements for regimes of rapid technological progress', Journal of Economic Behavior and Organization 18, 1992, p. 1-25.

Tirole 1999

J. Tirole, 'Incomplete contracts: where do we stand?', Econometrica 67(4), 1999, p. 741-781.

Tjittes and Hartlief 2005

R.P.J.L. Tjittes, T. Hartlief, 'Kroniek van het vermogensrecht', Nederlands Juristenblad 31, 2005, p. 1605 1623

Tindall-Ford et al. 1997

S. Tindall-Ford, P. Chandler, J. Sweller, 'When two sensory modes are better than one', Journal of Experimental Psychology Applied 3, 1997, p. 257-287.

Tjittes 1994

R.P.J.L. Tjittes, De hoedanigheld van contractspartljen. Een rechtsvergelijkend onderzoek naar de betekenis van de (onderlinge) hoedanigheid van partijen voor de totstandkoming en de vaststelling van de inhoud van rechtshandelingen, diss. Groningen, Serle recht en praktijk deel 77, Deventer: Kluwer 1994 284. 
Tjittes 2000

R.P.J.L. Tjittes, 'De betekenis van de parol evidence rule in het Amerikaanse contractenrecht', Contracteren 1,2000, p. $4-12$

Tjittes 2005

R.P.J.L. Tjittes, 'Uitleg van schriftelijke contracten', Rechtsgeleerd Magazijn Themis 1, 2005, p. 2-29.

Tjittes 2008

R.P.J.L. Tjittes, 'Contracten maken: Veelvoorkomende misverstanden bij het gebruik van AngloAmerikaanse termen in internationale contracten', Contracteren 2, 2008, p. 41-43

Treitel 1988

G. Treitel, Remedies for breach of contract: a comparative account, Oxford: Clarendon 1988, p. 422.

Treitel 2003

G. Treitel, The Law of Contract, 11th edition, London: Sweet \& Maxwell 2003, p. 192.

Triantis 2000

G.G. Triantis, 'Unforeseen contigencies: risk allocation in contracts' in B. Bouckaert, G. de Geest (eds.), Encyclopedia of Law and Economics, Volume III, The Regulation of Contracts, Great Britain: MPG Books 2000, p. 100-115

Triantis 2002

G. Triantis, 'The efficiency of vague contract terms: a response to the Schwartz-Scott theory of U.C.C. Article 2', Louisiana Law Review 62, 2002, p. 1071-1072.

Ulen 1989

T. Ulen, 'Cognitive imperfections and the economic analysis of law', Hamline Law Review 12, 1989, p. $385-410$

Vincent-Jones 1989

P. Vincent-Jones, 'Contract and business transactions: a socio-Legal analysis', Journal of Law and Society 16, 1989, p. 166-186.

Visee 2002

S.W.A.M. Visée, 'Contracteren in de transactiepraktijk', Contracteren 3, 2002, p. 56-57.

Vogenauer and Weatherill 2006

S. Vogenauer, S. Weatherill, (eds), The Harmonisation of European Contract Law implications for European Private Laws, Business and Legal Practice, Oxford/Portland/Oregon: Hart Publishing 2006, p. 259.

De Vrev 2006

R.W. de Vrey, 'Vermogensrechtelijke gevolgen van oneerlijke handelspraktijken', Vermogensrechtelijke Analyses 1, 2006, p. 51-71

Watkin 1999

T.G. Watkin, An historical introduction to modern civil law, Dartmouth: Ashgate 1999, p. 498.

Watson 1981

A. Watson, The making of the civil law, Cambridge: Harvard University Press 1981, p. 224.

Weber and Mayer 2005

L. Weber, K.J. Mayer, 'Building contract capabilitles with standard form contracts: Selecting the content, usage, and negotiating party', working paper 2005, University of Southern Californla, p. 1-36.

Wehrt 2000

K. Wehrt, 'Warranties' in B. Bouckaert, G. de Geest (eds.), Encyclopedia of Law and Economics, Volume III, The Regulation of Contracts, Great Britain: MPG Books Itd. 2000, p. 179-199.

Whelan 2007

R. Whelan, 'Measuring cognitive load: a comparative study of self-report and direct measurement techniques', Working paper, 2007, p. 1-35.

Wholey and Brittain 1989

D. Wholey, J. Brlttain, 'Characterizing environmental variation', Academy of Management Journal 32(4), 1989, p. $867-882$

J. Wightman, Contract: a critical commentary, London: Pluto Press 1996, p. 224

Williamson 1979

O.E. Williamson, 'Transaction cost economics: the governance of contractual relationships', Journal of Law and Economics 22(2), 1979, p. 233-261. 
Williamson 1983

O.E. Williamson, 'Credible Commitments: Using Hostages to Support Exchange', American Economic Review 73, 1983, p. 519-540.

Williamson 1985

O.E. Williamson, The Economic Institutions of Capitalism: firms markets, relational contracting, New York: Free Press, 1985, p. 450

Williamson 1991

O.E. Williamson, 'Comparative economic organization: the analysis of discrete structural alternatives', Administrative Science Quarterly 36, 1991, p. 269-296.

Williamson 1996

O.E. Williamson, The mechanisms of governance, Oxford: Oxford University Press, 1996, p. 429

Wissink 2002

M. Wissink, 'Chapter 5: Interpretation. Art. 5:101-5:107' in D. Busch, E. Hondius, H. van Kooten, H. Schelhaas, W. Schrama (eds.), The Principles of European Contract Law and Dutch Law. A Commentary Nijmegen: Ars Aequi Libri 2002, p. 241-257.

Wissink 2004

M. Wissink, 'Uitleg volgens Havilex of de CAO-norm? Over een vloeiende overgang en de noodzaak om toch te kiezen', Weekblad voor Privaatrecht, Notariaat en Registratie, 6579, 2004, p. 407-415.

Wolf 1995

$$
\begin{aligned}
& \text { R.C. Wolf, A } \\
& 1995, \text { p. } 288 .
\end{aligned}
$$

Wooldridge 2000 and 2006

J.M. Wooldridge, Introductory econometrics: a modern approach, Cincinnati, Ohio: South-Western ColJ.M. Wooldridge, Introductory

Wooldridge 2002

J.M. Wooldridge, Econometric Analysis of Cross Section and Panel Data, Cambridge, Massachusetts: The MIT Press 2002, p. 22

Wrigth and Lockett 2003

M. Wright, A. Lockett, 'The structure and management of alliances: syndication in the venture capita industry', Journal of Management Studies 40, 2003, p. 2073-2102.

Zaheer et al. 1998

A. Zaheer, B. McEvily, V. Perrone, 'Does trust matter? Exploring effects of interorganizational and interpersonal trust on performacne', Organization Science 9(2), 1998, p. 141-159.

Zucker 1986

L.G. Zucker, 'Production of trust: institutional sources of economic structure', Research in Organizational Behavior 8, 1986, p. 53-111. Zweigert and Kötz

K. Zweigert, H. Kötz, An introduction to comparative law, Oxford: Oxford University Press 1998, p. 744 Zumbo and Zimmerman 1993

D. Zimmerman, B.D. Zumbo, 'Relative power of the Wilcoxon test, the Friedman test, and the repeated measures ANOVA on ranks', Journal of Experimental Education 62, 1993, p. 75-86. 


\section{CURRICULUM VITAE}

Geerte Hesen (Salalah, Oman, 1981) received her secondary education at the American Nicaraguan School (Managua, Nicaragua) and Marnix College (Ede, the Netherlands). Geerte holds a degree in Economics (doctoraal Economie 2004) and Law (doctoraal Nederlands Recht 2005) from Maastricht University, the Netherlands. She also studied at the Université de Paris I Panthéon-Sorbonne and the London School of Economics and Political Science. During her studies she was a Summer Associate at Allen \& Overy LLP and at the Netherlands Competition Authority. She was a Research Assistant in the Department of Economics of Maastricht University and President of the European Law Students' Association. From January 2005 to September 2008, Geerte worked as a (Ph.D.) Researcher at Maastricht University. During this period she was also a Visiting Scholar at the University of California, Berkeley School of Law (Boalt Hall), Stanford University (SCANCOR), and Columbia University (Columbia Law School/Center for Contract and Economic Organization). Geerte was Co-editor (redactiesecretaris) of the Nederlands Tijdschrift voor Burgerlijk Recht and Law Clerk the Court of Appeal (Gerechtshof Arnhem). Geerte has published several articles in journals and books. As of September 2008, Geerte works as an Associate at De Brauw Blackstone Westbroek N.V. and as a Lecturer/Researcher in Law at Maastricht University, Faculty of Law. 